\author{
UNIVERSIDADE DE SÃO PAULO \\ INSTITUTO DE RELAÇÕES INTERNACIONAIS \\ PROGRAMA DE PÓs GRADUAÇÃo EM RELAÇÕES INTERNACIONAIS
}

JOSE LUIZ PIMENTA JUNIOR

\title{
O BRASIL NAS CADEIAS GLOBAIS DE VALOR (CGV) - O CASO DO SETOR Avícola
}

São Paulo

2020 


\section{JOSÉ LUIZ PIMENTA JUNIOR}

\section{O BRASIL NAS CADEIAS GLOBAIS DE VALOR (CGV) - \\ O CASO do SETOR Avícola}

Tese de doutoramento apresentada ao Programa de Pós-Graduação em Relações Internacionais do Instituto de Relações Internacionais da Universidade de São Paulo, para obtenção do título de Doutor em Ciências - Programa de Pós-Graduação em Relações Internacionais

Orientador: Prof. Dr. João Paulo Candia Veiga

São Paulo

2020 
Autorizo a reprodução e divulgação total ou parcial deste trabalho, por qualquer meio convencional ou eletrônico, para fins de estudo e pesquisa, desde que citada a fonte.

Catalogação na publicação

Serviço de Biblioteca e Documentação

Instituto de Relações Internacionais da Universidade de São Paulo

Pimenta Junior, José Luiz

O Brasil nas Cadeias Globais de Valor (CGV): o caso do setor avícola

I José Luiz Pimenta Junior ; orientador: João Paulo Cândia Veiga. -- São

Paulo, 2020.

$178 \mathrm{p}$.

Tese (Doutorado) - Instituto de Relações Internacionais. Universidade de São Paulo, São Paulo, 2020.

1. Cadeias globais de valor (CGV) 2. Avicultura 3. Internacionalização 4. Upgrading 5. Valor agregado I. Veiga, João Paulo Cândia, orient. II. Título.

$\mathrm{CDD}-382.0981$

Responsável: Giseli Adornato de Aguiar - CRB-8/6813 


\section{AGRADECIMENTOS}

Agradeço, em primeiro lugar, a Deus, pela saúde, paciência, resiliência e sabedoria necessárias para a realização deste projeto.

À Marília Souza Pimenta, minha esposa, amiga, mãe do nosso Antônio e eterna companheira em momentos, sobretudo, desafiadores como esses últimos cinco anos de doutorado. Sem seu apoio, eu jamais sequer teria começado tudo isso. Obrigado, principalmente, pelo apoio irrestrito nos últimos meses de realização deste trabalho.

Ao meu pai e à minha mãe, que tanto me apoiaram por todos esses anos, sobretudo, nos momentos finais da tese. Meu muito obrigado!

Ao amigo e irmão, Luiz Jácomo, pela parceria nas leituras, correções e recomendações essenciais para a realização desta tese.

À Bruna Kassama, pela amizade e parceria ao longo deste trabalho. Obrigado, principalmente, por compartilhar seu vasto conhecimento setorial comigo. Ele foi fundamental para que este trabalho tivesse começo, meio e fim.

Aos amigos Diego Coelho, Marcelo Zorovich, Fábio Andrade e Abrão Neto pelas conversas, conselhos, orientações e parceria ao longo do trabalho. Da mesma forma, a Ângelo Gurgel, pelas orientações e acolhida ao longo da pesquisa.

À minha mentora acadêmica Janina Onuki, pelas conversas, orientações, conselhos e direcionamentos, tão fundamentais desde à época da graduação. Ao meu orientador João Paulo Cândia Veiga, pelas conversas e direcionamentos cruciais para a realização deste trabalho. Sem eles, o processo seria indubitavelmente mais difícil. Meu muito obrigado a vocês dois!

Aos amigos e colegas do setor e, principalmente, da Associação Brasileira de Proteína Animal, lugar em que pude aperfeiçoar meus conhecimentos, graças aos excelentes profissionais que fizeram parte do meu cotidiano.

Ao Instituto de Relações Internacionais da USP, lugar de excelência e que me possibilitou fazer este trabalho com todo apoio necessário. À UNESP, sempre, lugar em que me formei e que me deu a base para que pudesse alçar voos cada vez maiores. 


\section{RESUMO}

Este trabalho tem como objetivo analisar os principais fatores que explicam a inserção do Brasil na cadeia global de valor (CGV) da avicultura. Para tanto, buscar-se-á aplicar uma metodologia com dois eixos de análise. No primeiro, o mapeamento da atividade produtiva e da dinâmica de comercialização inerente ao setor avícola por meio da aplicação do modelo teórico de cadeias globais de valor, com foco nos trabalhos recentes de Gereffi e Fernandez-Stark $(2012,2016)$. No segundo momento, apresentar-se-á uma avaliação detalhada dos principais fatores de influência direta sobre a inserção do Brasil na CGV em questão, obtida por meio da realização de entrevistas com questionário fechado, em profundidade, com 15 especialistas do setor que atuam no Brasil e internacionalmente. Por meio dessa análise combinada, buscar-se-á compreender quais variáveis efetivamente influenciam a forma como Brasil se insere na cadeia global de valor da avicultura.

Palavras-chave: Cadeias Globais de Valor (CGV). Avicultura. Competitividade. Upgrading. Governança. Exportação. Valor agregado. 


\begin{abstract}
This study aims to analyze the main factors that explain the insertion of Brazil in the Poultry Global Value Chain (GVC). To this purpose, we will seek to apply a methodology with two axes of analysis. In the first, the mapping of the productive activity and of the trade dynamics inherent to the poultry sector through the application of the theoretical model of Global Value Chains, focusing on the recent works of Gereffi; Fernandez-Stark, 2012 and Gereffi, FernandezStark, 2016. After that, a detailed assessment of the main factors with direct influence on the insertion of Brazil in the CGV in question will be presented, obtained through interviews with in-depth closed questionnaire with 15 industry experts working in Brazil and abroad. Through this combined analysis, we seek to understand which variables effectively influence the insertion of Brazil into the Poultry Global Value Chain.
\end{abstract}

Keywords: Global Value Chains. Poultry Sector. Competitiveness. Upgrading. Governance. Exports. Value-Added. 


\title{
LISTA DE ABREVIATURAS E SIGLAS
}

\author{
ABIs - Acordos Bilaterais de Investimento \\ ABPA - Associação Brasileira de Proteína Animal \\ BPC - British Poultry Council \\ BPP - Boas Práticas de Produção \\ CFNA - China Chamber of Commerce of Foodstuffs and Native Produce \\ CGV - Cadeias Globais de Valor \\ CPEPC- Candian Poultry \& Egg Processors Council \\ EMNs - Empresas Multinacionais \\ FAO - Food and Agriculture Organization of the United Nations \\ GATT - General Agreement on Tariffs and Trade \\ GCC - Global Commodity Chains \\ GVC - Global Value Chains \\ IED - Investimento Estrangeiro Direto \\ IPC - International Poultry Council \\ JPM - Japanese Productive Model \\ LMR - Limites Máximos de Resíduos \\ MAPA - Ministério da Agricultura Pecuária e Abastecimento \\ MGA - Material Genético Avícola \\ MRE - Ministério das Relações Exteriores \\ NI - Negócios Internacionais \\ OCDE - Organização para Cooperação e Desenvolvimento Econômico \\ OECD - Organisation for Economic Cooperation and Development \\ OIE - Organização Mundial de Saúde Animal \\ OMC - Organização Mundial do Comércio \\ OMS - Organização Mundial da Saúde \\ ONU - Organização das Nações Unidas \\ P\&D - Pesquisa e Desenvolvimento \\ P\&D I - Pesquisa, Desenvolvimento e Inovação \\ PD - Países Desenvolvidos \\ PEDs - Países em Desenvolvimento \\ PNCRC - Programa Nacional de Controle de Resíduos e Contaminantes \\ PNSA - Programa Nacional de Sanidade Avícola \\ TICs - Tecnologias da Informação e Comunicação \\ TRIMs - Trade Related Investment Measures \\ USAPEEC - USA Poultry \& Egg Export Council \\ USDA - United States Department of Agriculture \\ WHO - World Health Organization
}




\section{LISTA DE ENTREVISTAS REALIZADAS (DATA E LOCAL) \\ Instituição, data e local}

AgroIcone - 20/12/2019 - São Paulo, SP

Asia-Brazil Agro Alliance - 06/01/2020 - São Paulo, SP

Associação Brasileira de Proteína Animal - 18/12/2019 - São Paulo, SP

Associação Brasileira de Proteína Animal - 19/12/2019 - São Paulo, SP

Associação Brasileira de Proteína Animal - 20/12/2019 - São Paulo, SP

Associação Brasileira de Proteína Animal - 20/12/2019 - São Paulo, SP

BRF - 17/12/2019 - São Paulo, SP

Consultoria em Avicultura - 18/12/2019 - São Paulo, SP

Cooperativa Aurora - 20/12/2019 - São Paulo, SP

Elanco - 08/01/2020 - São Paulo, SP

International Poultry Council - 17/12/2019 - São Paulo, SP

JBS - 17/12/2019 - São Paulo, SP

Ministério da Agricultura, Pecuária e Abastecimento - 08/01/2020 - São Paulo, SP

Ministério da Agricultura, Pecuária e Abastecimento - 27/12/2019 - Brasília, DF.

WQS Group - 07/01/2020 - São Paulo, SP 


\section{SUMÁRIO}

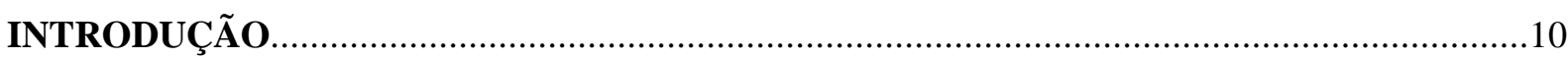

1 A Evolução Teórica das Cadeias Globais de Valor (CGV) ….................................................17

1.1 Comércio, investimentos e fragmentação produtiva global ..............................................17

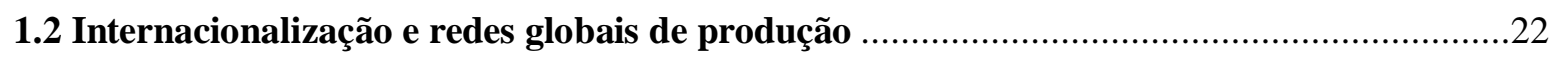

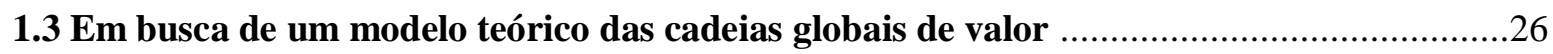

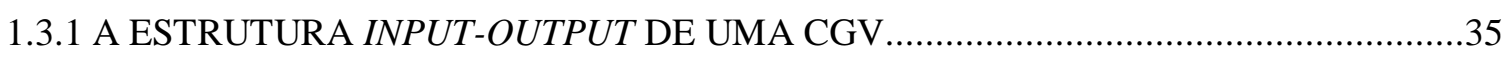

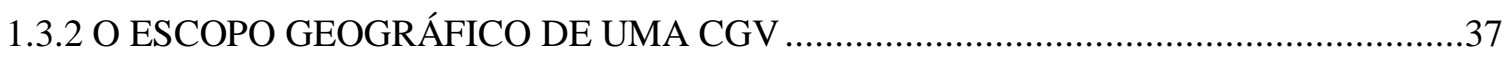

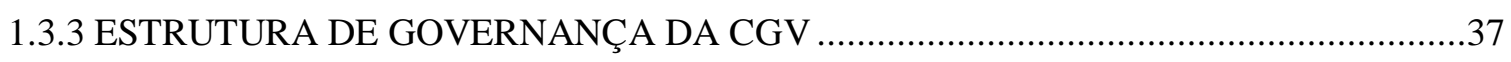

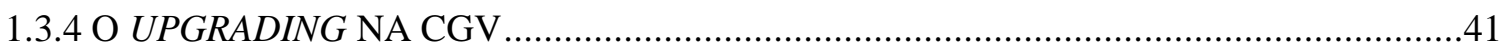

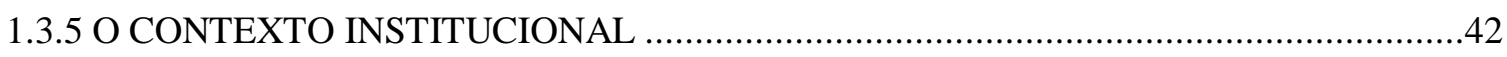

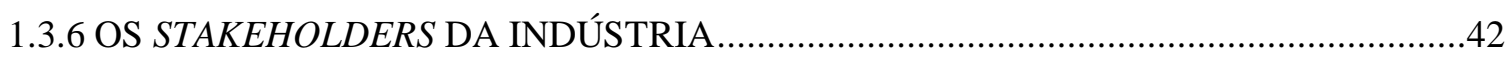

1.4 A nova agenda das CGV: estratégias de upgrading e a análise do valor adicionado...........43

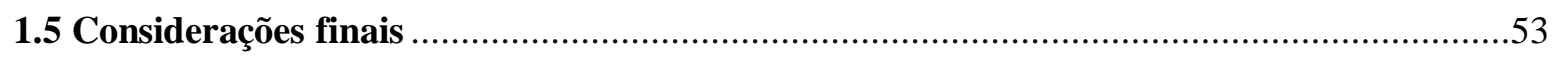

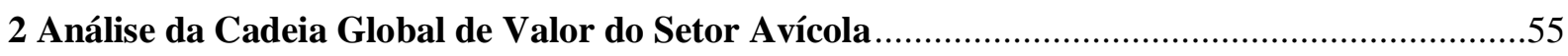

2.1 Evolução da cadeia global de valor do setor avícola: principais aspectos ...........................55

2.2 A abordagem do modelo de CGV para o setor avícola ................................................. 70

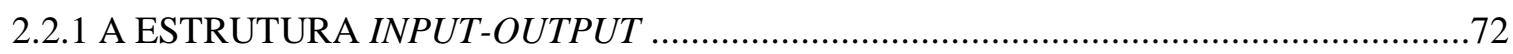

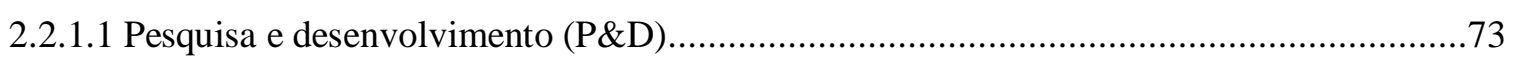

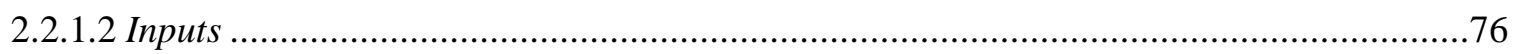

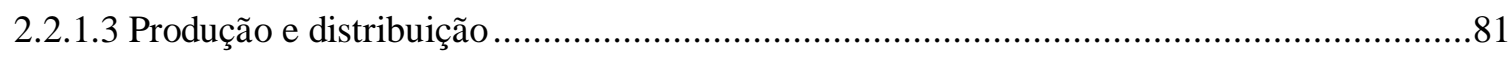

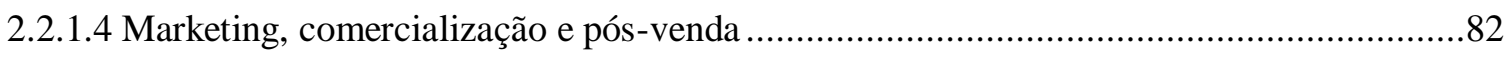

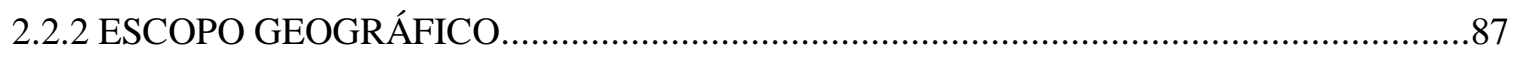

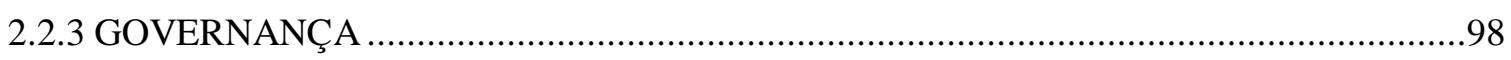

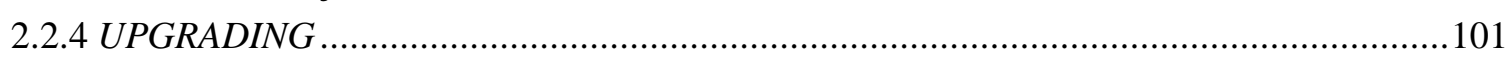

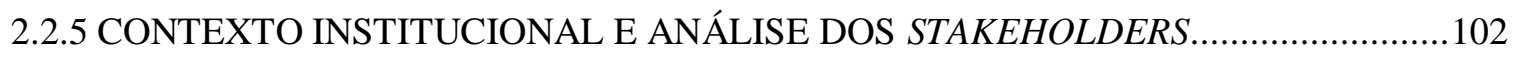

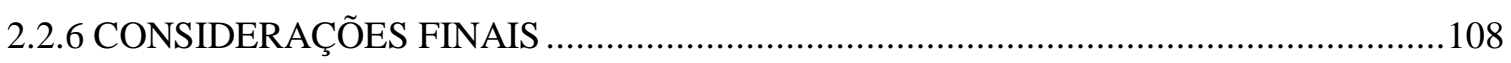

3 A Inserção do Brasil na Cadeia Global de Valor Avícola ........................................................110

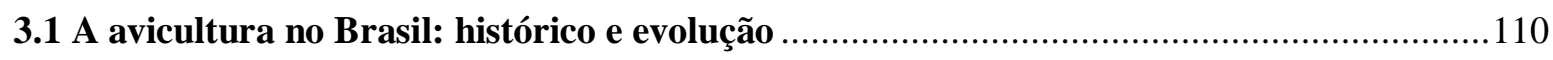

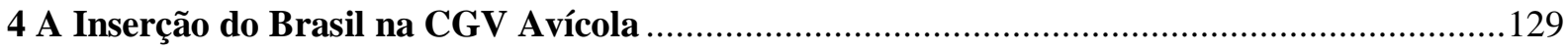

4.1 A produção e comercialização da proteína avícola em nível global .................................129

4.2 Fatores que influenciam diretamente a inserção do Brasil na CGV avícola .....................131

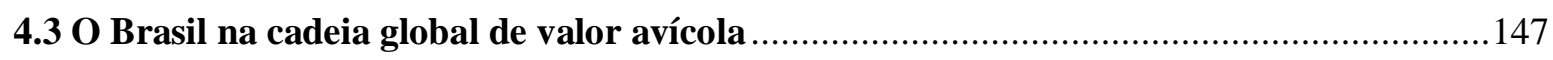

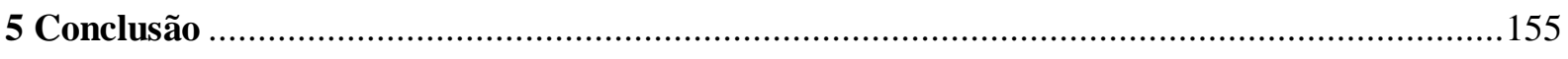

ANEXO I - Questionário aplicado aos especialistas para fins de subsídio técnico à presente pesquisa

REFERÊNCIAS... 


\section{INTRODUÇÃO}

O presente trabalho tem como objetivo analisar os principais fatores que explicam a inserção do Brasil na cadeia global de valor (CGV) da Avicultura. Para tanto, busca-se aplicar uma metodologia com dois eixos de análise. No primeiro, traça-se o mapeamento da atividade produtiva e da dinâmica de comercialização inerente ao setor avícola por meio da aplicação do modelo teórico de cadeias globais de valor, com foco nos trabalhos recentes de Gereffi e Fernandez-Stark (GEREFFI e FERNANDEZ-STARK, 2012; GEREFFI, FERNANDEZSTARK, 2016).

A importância desse modelo reside na compreensão integrada dos padrões globais de produção e comercialização de diferentes setores, bem como de seus efeitos econômicos e sociais para os países e regiões direta e indiretamente relacionados à cadeia em tela. Tal leitura permite uma percepção ampla dos direcionadores de competitividade setorial em nível global, contribuindo diretamente para a manutenção e/ou reposicionamento das empresas e dos países que dele fazem parte (GEREFFI; HUMPHFREY; KAPLINSKY; STURGEON, 2001; GEREFFI; HUMPHFREY; STURGEON, 2005; GEREFFI; FERNANDEZ-STARK, 2012). Em suma, o modelo de cadeias globais de valor tem como pressupostos fundamentais a combinação dos níveis micro (firma) e meso (setor), da dinâmica regional e global da atividade econômica estudada. Dessa forma, fica clara a relevância da rede organizacional do setor como sua unidade de análise principal, com destaque, sobretudo, para o conjunto de interações entre os diversos atores da cadeia, assim como as estratégias de upgrading por eles implementadas, a contribuição específica, e o diferencial a ser destacado ao longo da presente tese de doutoramento (GEREFFI; HUMPHREY; KAPLINSKY; STURGEON, 2001; WOOD, 2005).

O estudo mostra que, apesar de ser uma cadeia extremamente verticalizada nacionalmente em termos de estratégia produtiva - uma aparente contradição com o conceito de CGV que parte da ideia de distribuição produtiva global, os ganhos de competitividade no setor avícola dependem de uma série de interações multisetoriais em diversos níveis, geralmente coordenadas pelos grandes frigoríficos multinacionais. Poder-se observar que, a despeito da evolução global dos fatores intrínsecos ao negócio, como genética, nutrição, manejo e sanidade, cabe tanto às empresas-líderes como aos grandes países produtores, como o Brasil, o papel de efetivo gerenciamento dos fatores de produção e comercialização do setor avícola, como forma de potencializar esses avanços técnicos e traduzi-los em ganhos de escala e 
incremento da qualidade do produto, tendo como base um sistema sanitário altamente eficaz. Em outras palavras, é exatamente a singularidade da organização da cadeia produtiva no Brasil que torna o país competitivo na cadeia global de valor do setor avícola (VALDES; HALLAHAN; HARVEY, 2015).

Nesse sentido, a aplicação do modelo de CGV aqui proposto (GEREFFI; FERNANDEZ-STARK, 2016) tem como objetivo uma compreensão integrada das relações econômicas, produtivas, comerciais, ambientais e concorrenciais presentes na atividade avícola no Brasil vis-à-vis à cadeia avícola global, com vistas ao mapeamento de suas particularidades produtivas, comerciais e mercadológicas. Para tanto, a análise setorial ocorre à luz das seis dimensões analíticas propostas por Gereffi e Fernandez-Stark (2016), quais sejam: (i) Estrutura Input-Output; (ii) Escopo Geográfico; (iii) Governança: (iv) Upgranding; (v) Contexto Institucional e (vi) Stakeholders. No texto, destacam-se quais são as dimensões que explicam o diferencial competitivo do Brasil.

No segundo eixo de análise, apresenta-se uma avaliação detalhada dos principais fatores de influência direta sobre a inserção do Brasil na CGV em questão, com destaque para aqueles que diferenciam a organização da cadeia produtiva no país, obtida por meio da realização de entrevistas com questionário fechado, em profundidade (ANEXO I), com 15 especialistas do setor que atuam no Brasil e internacionalmente (MARCONI; LAKATOS, 2010; DUARTE, 2010). A análise parcimoniosa das entrevistas permite identificar 15 fatores de natureza econômica, produtiva e social com relação direta sobre a competitividade e o desempenho global do Brasil na área avícola. São eles: (i) consumo global; (ii) eventos sanitários; (iii) qualidade percebida; (iv) responsividade local; (v) capacidade de atendimento em larga escala e fator preço; (vi) fator campo — recursos naturais, genética, nutrição, manejo, sustentabilidade e ambiência; (vii) viés de complementaridade; (viii) desenvolvimento de parcerias; (ix) protecionismo em nível global; (x) cadeia regulatória; (xi) acordos comerciais e ações de promoção comercial; (xii) ameaças de competidores externos; (xiii) certificações privadas, sobretudo com foco em bem-estar animal; (xiv) fatores internos - infra-estrutura, logística e o custo-Brasil; e (xv) fatores externos - representação institucional no plano internacional, capacitação em inteligência comercial e ações de melhoria de imagem em nível internacional.

Por meio dessa análise combinada, que traz a esfera analítica do modelo de CGV e o mapeamento dos fatores acima elucidados, busca-se compreender quais variáveis efetivamente influenciam a forma como Brasil se insere na cadeia global de valor da avicultura. Ademais, é 
possível identificar os diferenciais e as principais estratégias que fizeram do país um ator relevante nessa atividade em nível global. A pesquisa, nesse sentido, parte da hipótese de que o Brasil, maior exportador de produtos avícolas nos últimos anos, está inserido na CGV do setor como um global player na condição de fornecedor de produtos in natura e/ou matéria-prima a ser processada, com viés de adição de valor e futuro desenvolvimento de marca em terceiros mercados. O conceito de global player ora utilizado refere-se a países com elevada competitividade setorial, cujas empresas multinacionais se configuram como grandes exportadoras, com presença global de seus produtos e marcas, além de elevada participação na governança de todos os elos da cadeia global de valor do setor (STURGEON, 2005; OECD, 2008; OECD 2013; GEREFFI; FERNANDEZ-STARK, 2016).

Dessa forma, a variável dependente é a inserção do Brasil na CGV avícola, com destaque para sua principal estratégia de acesso a mercados, baseada no chamado upgrading estratégico-seletivo, a contribuição original da presente tese de doutoramento à teoria da CGV (HUMPHREY; SCHMITZ, 2002; UNCTAD, 2013; GEREFFI; FERNANDEZ-STARK, 2016). As variáveis independentes, por sua vez, são a fragmentação produtiva global e as dinâmicas internacionais dos fluxos de comércio e investimentos produtivos - em ambos casos, ligados ao setor, sintetizados no conceito de globalização econômica (KEOHANE, 1984; NYE JR. et al., 1998; GILPIN, 2002; FRIEDEN, 2008).

Tal hipótese se justifica, sobretudo, pela crescente participação do Brasil no comércio global de carne de aves ao longo dos últimos vinte anos, quando o país se tornou o maior exportador mundial desse tipo de proteína, à frente de grandes produtores e exportadores, como Estados Unidos e China. Desde 2005, o Brasil mantém, em média, 15\% de participação na produção mundial de carne de aves. Em 2018, esse número chegou a 14\% produção mundial avícola, com 13,4 milhões de toneladas, atrás somente de Estados Unidos, com 19,3 milhões de toneladas produzidas no mesmo ano. Em termos de exportação, em 2005 o Brasil exportou 2,8 milhões de toneladas, enquanto em 2018 esse número saltou para 4,0 milhões, um crescimento da ordem de $43 \%$ em produtos que alcançaram mais de 150 mercados (USDA, 2019; COMEXSTAT, 2019; TRADEMAP, 2019).

Ao longo dos últimos 60 anos, a avicultura brasileira, assim como diversas outras cadeias do agronegócio, passou por profundas transformações em termos produtivos, o que fez com que a produção agrícola nacional passasse a desenvolver sistemas adaptados às condições tropicais. Em suma, as principais condições capacitadoras ao longo desse período, como fatores 
naturais, tecnologia de agricultura tropical e iniciativas em termos de política agrícola, somadas a investimentos públicos e privados, promoveram diversos ganhos de produtividade que fizeram do país um dos maiores produtores mundiais de alimentos em diversas frentes, como milho, soja, açúcar, suco de laranja, proteína animal, café, variedades de frutas, entre outros (CHADDAD, 2017).

$\mathrm{Na}$ área de proteína animal, esse processo ocorreu com o mesmo dinamismo de outros setores, porém com particularidades que fizeram do país o maior exportador mundial de carne bovina e de aves, além de figurar como o quarto maior exportador de carne suína (USDA, 2019). Especificamente no caso da proteína avícola, esta tese mostra que tal realidade é fruto de um intenso trabalho conjunto, desenvolvido a partir da segunda metade do século XX, de produtores, técnicos, agroindústrias, indústrias de suporte, setor público, associações setoriais, entre outros. Em suma, pode-se constatar que o trabalho conjunto e coordenado inerente à cadeia da avicultura, sobretudo no que se refere aos setores de genética, nutrição, manejo e sanidade, foi essencial para os elevados ganhos de produtividade do país durante as últimas décadas (MARTINELLI; ROHENKOHL; MURAKAMI; 2014; VOILA; TRICHES; 2015; WAKER; NÄ̈̈S, 2018).

$\mathrm{Na}$ área de genética, destaca-se todo o maciço investimento em Pesquisa \& Desenvolvimento e Inovação (P\&D I) desde o início dos anos 1950, bem como a presença gradual de multinacionais que passaram a operar no país ao longo desse período. Pode-se perceber que, por meio de novas técnicas produtivas e aplicação de tecnologias específicas, essas empresas trabalharam constantemente em busca do aperfeiçoamento das linhagens e, consequentemente, em melhor desempenho e eficiência das aves.

Em termos de nutrição, o setor conviveu com uma transformação que beneficiou sobremaneira os ganhos em termos de conversão alimentar dos plantéis. A utilização de uma composição balanceada e a utilização de uma série de micronutrientes (minerais, aminoácidos e vitaminas) fundamentais para complementar os ingredientes básicos da ração animal (milho e farelo de soja) foram essenciais para o aumento da produtividade do setor.

Em relação às ações voltadas ao manejo mais eficiente, os ganhos ocorreram principalmente por meio do aperfeiçoamento dos aviários, com a introdução de novas instalações e equipamentos e o foco em bem-estar animal. No que se refere à sanidade, a adoção de práticas de biosseguridade em diversos níveis e o constante monitoramento e 
vigilância fizeram com que o Brasil nunca registrasse um caso de influenza aviária em sua história.

Apesar de esse conjunto de fatores ter sido extremamente relevante para o desenvolvimento da atividade avícola no Brasil, sua evolução combinada trouxe benefícios à produção de carne de aves em praticamente em todo o mundo. Isso, pois as empresas dos setores citados acima são, geralmente, multinacionais que operam in loco ou por meio de operações comerciais em diversos países com produção avícola em nível industrial. Diante do estudo minucioso da cadeia e das reflexões geradas por meio das entrevistas realizadas, este trabalho procura mostrar que o diferencial do Brasil vis-à-vis outros mercados está ligado a quatro fatores fundamentais, quais sejam: (i) a presença de importantes elementos internos, chamados aqui de fator-campo, que criaram as bases para os ganhos de produtividade avícola ao longo do período analisado; (ii) a coordenação das ações entre diversos stakeholders da cadeia direta e indiretamente relacionados ao setor; (iii) o elevado nível de sanidade e o controle de doenças na cadeia avícola e (iv) as estratégias produtiva e comercial implementadas pelas empresaslíderes do setor que operam em nível global.

O trabalho mostra, mais especificamente, que essas variáveis estão diretamente relacionadas a dois importantes elementos analíticos do modelo de CGV, os quais têm impacto direto sobre o incremento da produtividade avícola e expansão comercial do Brasil nas últimas décadas. São eles: (i) governança e (ii) Upgrading. Os dois eixos em tela configuramse na contribuição específica da presente tese de doutoramento à teoria da CGV.

Em relação ao primeiro elemento, destaca-se como cerne do modelo de governança da cadeia avícola o sistema de integração, que compreende $95 \%$ de toda produção avícola nacional. Nesse sistema, a formalização dos direitos e obrigações de integrados (produtores) e integradoras (agroindústrias) ocorrem por meio de contratos que visam garantir à operação o máximo de eficiência e produtividade. Em linhas gerais, os grandes frigoríficos e agroindústrias fornecem ao produtor todo o aparato necessário para a produção do frango de corte. O produtor, por sua vez, é responsável pelas instalações, equipamentos e as despesas operacionais do aviário. Dessa forma, as integradoras coordenam e monitoram as ações dos integrados, em uma sinergia da operação responsável pelo elevado nível de eficiência produtiva do setor. Essa coordenação direta junto ao produtor e a outros atores da cadeia, por parte da empresa líder, é que faz com que os fatores locais sejam os elementos centrais da competitividade brasileira. Os ganhos em termos de eficiência produtiva em uma cadeia extremamente verticalizada são, 
dessa forma, fundamentais para que o Brasil seja competitivo globalmente (LAZZARI, 2004; ARAÚJO et al., 2008; CHADDAD, 2017).

Quanto ao segundo elemento, esta tese mostra que as atividades ligadas a diferentes tipos de upgrading por parte de empresas e países em um determinado setor é um dos mais relevantes itens da agenda de pesquisa de CGV atualmente. Percebe-se, assim, que o nível de competitividade das nações e das empresas que operam em redes de produção e comercialização em nível global varia mais em função das atividades exercidas do que somente das mercadorias produzidas em um território específico (STURGEON; GEREFFI; GUINN; ZYLBERBERG, 2013; UNCTAD; 2013). Diante dos quatro principais tipos de upgrading que a literatura especializada traz à baila (processo, produto, funcional e intersetorial) (HUMPHREY; SCHMITZ, 2002; PINTO; FIANI; CORRÊA, 2017), a cadeia avícola brasileira tem como vetor principal de agregação de valor aos seus produtos a constante interação com parceiros locais em diferentes países, a qual possibilita a produção de proteína de qualidade e passível de atender às especificidades desses operadores. Por meio dos resultados encontrados nesta tese, foi possível comprovar a hipótese de que o Brasil se configura realmente como um global player fornecedor de produtos in natura e/ou matéria-prima a ser processada, com viés de adição de valor e futuro desenvolvimento de marca em terceiros mercados. Entretanto, fazse mister perceber que, a despeito de ser o maior exportador mundial de carne avícola, o país permanece num elo intermediário da cadeia de valor do setor, ocupando a oportunidade existente entre o custo de produção e o preço de importação praticado pelo importador local nos vários países que consomem a carne brasileira. Em suma, é possível compreender que o país consegue, sim, produzir com o volume e com o custo mais baixo que os seus concorrentes, e com um portfólio de produtos geralmente mais amplo do que a grande maioria deles, mas não tem a pretensão de avançar em níveis de maior agregação de valor, como o lançamento de marcas, produtos específicos para o varejo e ações de distribuição local nos mercados de destino. Esse tipo de upgrading estratégico-seletivo mostra como o país é capaz de operar em escala global, porém tendo parceiros locais como elementos-chave para sua atuação, em uma cadeia verticalizada nacionalmente, uma vez que esses serão os responsáveis pela maior parte do processamento da carne brasileira e de sua distribuição junto ao varejo local.

Essa maneira de conduzir as operações em nível global por grande parte das empresas brasileiras refuta a ideia de busca constante por atividades de maior valor agregado, dentro de uma determinada cadeia, sugerida pelo modelo teórico da CGV (UNCTAD, 2013; 
NONNENBERG, 2014; REIS; ALMEIDA, 2014; GEREFFI; FERNANDEZ-STARK, 2016). Trata-se de um importante resultado da presente tese de doutoramento que agrega valor substantivo à uma abordagem teórica de grande reconhecimento acadêmico e científico internacional. No caso da avicultura brasileira, a procura por ações que agregam valor ao produto final está, na maioria das vezes, atrelada à interação com parceiros que atuam junto ao mercado local. Exceções ocorrem, como no caso do Oriente Médio, onde algumas empresas brasileiras conseguiram expandir solidamente suas marcas ao longo de mais de quatro décadas de operação, porém vê-se que esse não é o padrão de atuação do setor em nível global. Em suma, esta tese mostra que grande parte do setor agrega valor ao produto com base nas orientações e padrões observados por importadores e distribuidores locais. A adição de valor à marca junto ao varejo, em nível internacional, apesar de ser um trabalho em curso, ainda é uma realidade distante das empresas brasileiras, já que exige uma grande quantidade de aporte de capital, investimentos, monitoramento constante e atuação in loco que o setor, atualmente, parece não estar disposto a implementar como eixo central de sua atuação.

A tese está estruturada, ao longo do trabalho, em quatro capítulos que procuram explorar os principais aspectos até aqui sugeridos. Dessa forma, o primeiro capítulo busca apresentar a evolução do conceito de CGV, por meio de uma análise dos principais elementos relativos à fragmentação produtiva global ao longo do século XX e do processo de estruturação do modelo de CGV apresentado por Gereffi et al. (2016). Em seguida, o segundo capítulo procura demonstrar como o modelo teórico de CGV pode ser aplicado à cadeia avícola, de modo a tornar a análise de suas dinâmicas produtivas e comerciais mais integradas. O terceiro capítulo tem como objetivo analisar a inserção do Brasil na CGV avícola, por meio da análise da evolução da atividade no país ao longo das últimas décadas e do mapeamento das principais variáveis que fizeram do país um ator fundamental no abastecimento mundial desse tipo de proteína. Por fim, o quarto capítulo busca analisar as variáveis acima identificadas em conjunto com a hipótese sugerida, observando quais fatores são determinantes para impulsionar ou restringir a atuação do Brasil na CGV avícola. 


\section{A Evolução Teórica das Cadeias Globais de Valor (CGV)}

O presente capítulo tem como objetivo expor os principais autores que contribuíram com a construção conceitual do modelo teórico das CGV. Para tanto, busca-se, num primeiro momento, analisar as principais dinâmicas globais de comércio, investimento e fragmentação produtiva. Em seguida, serão apresentadas as principais correntes teóricas que fomentaram a discussão em torno do surgimento das CGV ao longo do século $\mathrm{XX}$, bem como o processo de elaboração do conceito e, posteriormente, do modelo ora apresentado.

\subsection{Comércio, investimentos e fragmentação produtiva global}

A segunda metade do século XX foi um período caracterizado, sobretudo, pelo aumento da complexidade nas relações interestatais, derivada, principalmente, do crescente fluxo do comércio e investimento internacional. Tal complexidade, resultado do aumento da fragmentação produtiva em escala global, elevou o nível de interdependência econômica entre as nações e possibilitou a diversas empresas transnacionais um papel preponderante na produção e comercialização de bens e serviços (ESTERVADEORDAL; BLYDE; SUOMINEN, 2013).

A literatura especializada aponta inúmeros fatores que viabilizaram o incremento gradual da globalização econômica ao longo do século XX, entre os quais se destacam:

a) Inovações tecnológicas relativas às áreas de comunicação, logística, manufatura e computação, que transformaram profundamente a operacionalização do comércio internacional em um curto espaço de tempo;

b) O processo de liberalização comercial e de investimentos estrangeiros diretos em escala mundial, caracterizado pela diminuição das barreiras tarifárias e, em certa medida, não tarifárias, e a adoção de mecanismos voltados à facilitação de investimentos em nível internacional.

Em linhas gerais, os avanços tecnológicos possibilitaram considerável redução dos custos de transação em escala global, tornando as operações internacionais viáveis para empresas de pequeno, médio e grande porte. Além disso, impulsionaram a criação de novos produtos e serviços, permitindo que economias emergentes os incorporassem em sua esfera econômica, seja em termos de consumo ou voltados para o setor produtivo (leapfrogging 
tecnológico). Associadas diretamente a esse processo de impulso tecnológico estão as iniciativas voltadas à inovação, pesquisa e desenvolvimento, as quais viabilizaram a transformação, ao longo do século XX, do sistema produtivo como conhecido até então, tornando-o mais dinâmico, descentralizado e globalmente integrado (CAVUSGIL; KNIGHT; RIESENBERGER, 2010):

Between 1920 and 1990, average ocean freight and port charges for US import and export cargo fell by almost 70 per cent. Between 1930 and 1990, average air-transport fares per passenger mile fell by 84 per cent. The cost of a threeminute telephone call between New York and London has fallen from US $\$ 300$ in 1930 to US\$ 1 in 1997; the cost of computer processing power has been falling by an average of 30 per cent per year in real terms over recent decades. (VAN DEN BOSSCH; ZDOUC, 2013, p. 7).

O uso intensivo de tecnologias, sobretudo no campo da informação e comunicação (TICs), influenciou diretamente as estratégias de outsourcing e offshoring, que culminaram com a especialização vertical das firmas. A desagregação do processo produtivo, com a diversificação do seu escopo geográfico, passou a ser central para o aumento da competitividade das empresas, sem prejuízo, contudo, à eficiência do processo como um todo e à qualidade do produto final. Essa dinâmica está associada ao segundo globalization's unbundling, em que a revolução das TICs, sobretudo a partir da década de 1980, permitiu a coordenação de tarefas complexas à distância e garantiu o controle da operação à empresa-líder, que, mesmo ao atuar globalmente, consegue controlar os riscos inerentes ao processo por meio da transferência de tecnologia (sede-subsidiária) e, concomitantemente, ampliar sua esfera de influência, gerando emprego, renda e auxiliando no processo de desenvolvimento econômico em diversas regiões do mundo (BALDWIN, 2012; CARNEIRO, 2017).

Quanto ao segundo fator, é importante elucidar que o século XX, sobretudo a partir da década de 1950, foi caracterizado econômica e juridicamente pelo incremento de arranjos normativos de natureza multilateral e bilateral que tinham como principal objetivo proporcionar maior previsibilidade às trocas comerciais e aos fluxos de investimento em nível internacional. $\mathrm{Na}$ esfera multilateral, as oito rodadas de negociações comerciais do sistema General Agreement on Tariffs and Trade (GATT-OMC) entre 1947 e 1994 foram responsáveis pela diminuição da tarifa ad valorem de importação de uma gama de países que, gradualmente, incrementaram suas participações ao longo das rodadas ${ }^{1}$. Em suma, as oito rodadas foram

1 O sistema GATT-OMC contou com oito rodadas de negociação tarifária entre 1947 e 1994. São elas: Geneva (1947), Annecy (1949), Torquay (1950-51), Geneva (1956), Geneva (1960-61) — also known as 
marcadas, além das negociações tarifárias, pelo incremento do número de países participantes (23 países na Geneva Round em 1947 e 123 países na Uruguay Round, em 1984), bem como inclusão de novos temas a serem negociados ao longo dos diálogos — direitos antidumping (Kennedy Round), Medidas não-tarifárias e subsídios (Tokyo Round) e agricultura, serviços, propriedade intelectual, entre outros (Uruguay Round) (OMC, 2019).

Em contrapartida, a regulação internacional de investimentos ganhou amplitude e complexidade sobretudo em nível bilateral, por meio da conclusão do chamados Acordos Bilaterais de Investimentos (BITs, em inglês), entre países desenvolvidos e, principalmente, entre aqueles em processo de desenvolvimento. Ao contrário da esfera comercial, os investimentos internacionais dispõem de uma série de fóruns de regulação como a Organização para Cooperação e Desenvolvimento Econômico (OCDE), Organização das Nações Unidas (ONU) e até mesmo a Organização Mundial do Comércio (OMC), por meio do acordo sobre Trade Related Investment Measures (TRIMS). No entanto, foi na esfera bilateral que os países consolidaram importantes linguagens voltadas à regulação de temas que conferem maior previsibilidade e segurança jurídica quando da ocorrência do investimento estrangeiro direto, tais como expropriação, transferência de fundos, solução de controvérsias, entre outros (PIMENTA JUNIOR, 2012).

Figura 1 - Negociações comerciais e regulação de investimentos ao longo do século XX.

Diminuição Tarifária (\%) no sistema GATT-OMC (1947-1994)

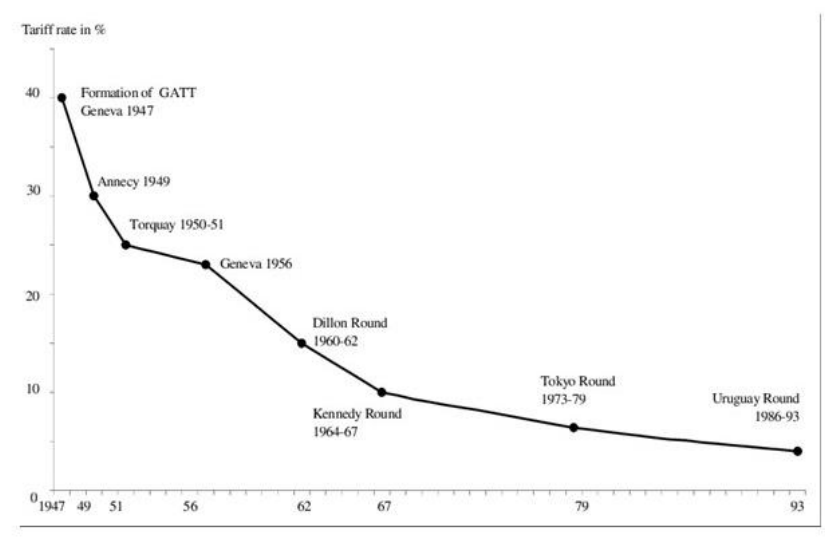

Crescimento de Acordos Bilaterais de Investimentos (1950-1990)

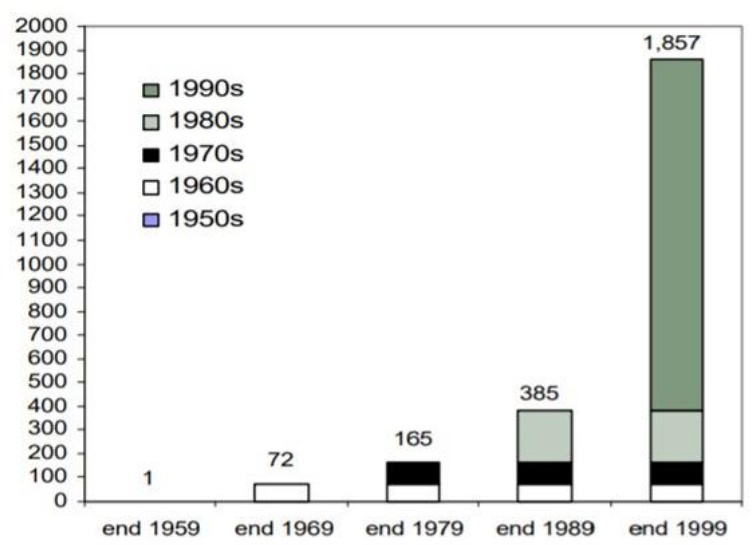

Fonte: Extraído de Busse (2002) e UNCTAD (2000).

the Dillon Round, the Kennedy Round (1964-67), the Tokyo Round (1973-79) e a Uruguay Round (198694) (OMC, 2019). 
Como já salientado, a partir da utilização combinada desses fatores (tecnologia e liberalização comercial e de investimentos), as empresas multinacionais (EMNs) passaram a alocar seus recursos de forma estratégica, buscando incrementar sua produtividade e diminuir seus custos de transação, atuando, recorrentemente ao lado de Estados, como indutores do processo de formação e consolidação das redes internacionais de produção (WEF, 2012; OECD, 2013; FGI; NTU; WTO, 2013).

De forma geral, as EMNs maximizaram sua capacidade de coordenar atividades produtivas em diferentes regiões, controlando vários processos e transações em redes de produções transnacionais, beneficiando-se das diferenças geográficas na distribuição dos fatores de produção e de políticas nacionais setoriais. Consequentemente, por meio de sua flexibilidade geográfica potencial, essas empresas assumiram um papel preponderante na alocação de investimentos em regiões distintas, influenciando o crescimento do emprego, renda, incrementando os fluxos comerciais (de interfirmas para intrafirmas), o Produto Interno Bruto (PIB), entre outros indicadores econômicos, em escala nacional, regional e, consequentemente, global (DICKEN, 2007):

A dimensão internacional se tornou cada vez mais presente no âmbito empresarial. $\mathrm{O}$ avanço e a inserção das empresas no exterior tornaram-se a opção estratégica predominante do novo século, inclusive à própria manutenção e sobrevivência no mercado doméstico. (COELHO; OLIVEIRA JUNIOR, 2016).

Tal alocação estratégica de recursos, no entanto, não aconteceu de maneira linear e harmonizada ao longo do tempo. As EMNs passaram, sobretudo no decorrer do século XX, por diversos processos de adaptação e evolução em termos de recursos, competências e habilidades na medida em que buscavam novas formas de expansão internacional. Fleury e Fleury (2012) destacam três grandes ondas de internacionalização das empresas multinacionais:

a) $1^{\mathrm{a}}$ onda (século XIX até a segunda metade do século $\mathrm{XX}$ ): período dominado pela expansão das atividades de empresas originárias da Europa Ocidental, Inglaterra e, posteriormente, Estados Unidos. Os países emergentes, essencialmente, se comportavam como receptores de Investimento Estrangeiro Direto (IED) e hospedeiros de multinacionais de países industrialmente avançados, por conta sobretudo do avanço de tecnologias de transporte marítimo. Apesar dos reveses causados por dois grandes conflitos mundiais, o período pós-guerra (entre 1950 e 1970) contou com uma forte 
retomada da globalização econômica, impulsionada, sobretudo, pelo crescente papel das multinacionais americanas e do American System of Manufacturing (Ex:Taylorismo/Fordismo) nas atividades de reconstrução da economia mundial;

b) 2a onda (ocorrida entre os anos 1970 e 1980): período de profundas alterações nos regimes de mercados, em que empresas de diferentes países passam a operar internacionalmente e pressionar substancialmente a oferta de produtos. Com a oferta maior do que a demanda, os mercados passam a operar sob a chamada "lei do comprador", na qual os consumidores passam a ter poder de escolha e a qualidade tornase o atributo mais importante de produtos e serviços. Ganha destaque a atuação de multinacionais japonesas e, posteriormente, de outros países asiáticos, as quais passaram a operar sob essa nova lógica de competitividade empresarial, na qual as empresas orientam-se às necessidades dos clientes. O Japanese Productive Model (JPM), alicerçado em um novo sistema interorganizacional de gestão, coordenação de negócios e relações industriais, revelou-se uma alternativa ao modelo fordista, promovendo o desenvolvimento e consolidação das atividades de multinacionais japonesas na arena internacional;

c) $3^{\text {a }}$ onda (início da década de 1990): período em que as EMNs de países desenvolvidos passaram por processos de revisão de seus posicionamentos estratégicos e arquiteturas organizacionais com foco nas atividades de maior valor agregado e controle de redes globais de produção. Para tanto, diversas transformações em termos de gestão e processo produtivo foram colocadas em curso tanto nas matrizes quanto em suas subsidiárias. Em suma, as multinacionais tradicionais, então focadas em atividades de alto valor agregado, passaram a subcontratar mundo afora competências organizacionais geralmente focadas em atividades de rotina ou produtos e componentes de baixo valor agregado. Essa dinâmica gerou diversas oportunidades para as empresas dos países emergentes, já que, paralelamente a esse processo, os governos das nações em desenvolvimento passaram a incentivar a criação de políticas industriais que tinham como propósito a intensificação do processo de internacionalização. Como consequência, a $3^{a}$ onda de internacionalização ilustra a criação e expansão da atuação global das multinacionais de países emergentes em nível global, ocupando nichos de mercado, desenvolvendo novas competências e, em alguns casos, tornando-se líderes globais em alguns segmentos econômicos. 


\subsection{Internacionalização e redes globais de produção}

Principal período de expansão da atividade empresarial em nível global, o século XX também foi marcado pela evolução do campo teórico dos negócios internacionais (NI). Em suma, percebe-se gradualmente a necessidade da elaboração de novos modelos teóricos que tenham como objetivo explicar as particularidades do processo de expansão da atividade da firma em nível internacional nos diferentes momentos e lugares em que ele ocorre. Modelos capazes de capturar as motivações, estratégias e determinantes quando do estabelecimento de novas operações da firma no exterior ganharam espaço:

O fato de as empresas responderem pelos grandes volumes de investimento, levando a cabo estratégias de expansão internacional era novo, com as suas determinantes ainda não exploradas tampouco entendidas. E, de imediato, percebeu-se que os modelos teóricos neoclássicos do comércio internacional e das finanças, tidos como principais instrumentos de análise dos fluxos econômicos internacionais, não eram capazes de fornecer interpretações robustas para os movimentos ora observados. Isso devido as suas restrições teóricas, sendo os seus motivos mais destacados a existência, nessa nova realidade, de maior intensidade na mobilidade de fatores (capital e trabalho) entre os países, bem como a constatação de que as diferenças entre taxas de juros não explicavam satisfatoriamente a movimentação de capitais, nem as diferenças entre as indústrias. (BUCLEY, 2002 apud COELHO, 2016, p. 47).

A predominância de empresas norte-americanas na expansão de suas atividades no exterior ao longo do século XX impulsionou a agenda de pesquisa no país. Além dos EUA, países desenvolvidos do continente europeu também tiveram participação relevante na construção de importantes modelos teóricos que visavam explicar a dinâmica de internacionalização de empresas europeias. Na busca por ampliar os horizontes das teorias neoclássicas, autores/as como Edith Penrose, Stephen Hymer, Raymond Vernon, Peter Buckley, Mark Casson, Oliver Williamson, John Dunning, Jan Johanson, Jan-Erik Vahlne, entre outros, criaram frameworks capazes de abordar sob variados aspectos as particularidades do processo de internacionalização em diferentes países (GUEDES, 2010).

É importante salientar que o presente trabalho não tem como foco detalhar a discussão sobre as diferentes abordagens teóricas e conceituais relativas à área de negócios internacionais ${ }^{2}$. Em contrapartida, busca-se apresentar aspectos relevantes da evolução dessa agenda teórica, com o intuito de favorecer a compreensão de importantes conceitos, processos

Para um estudo detalhado da evolução teórica e conceitual da área de negócios internacionais e gestão internacional, sugere-se a leitura de Coelho (2016). 
e dinâmicas relativas à fragmentação produtiva e, consequentemente, à formação das CGV. Nesse sentido, é importante destacar que a literatura especializada identifica diferentes perspectivas relacionadas ao processo de internacionalização das redes de produção, as quais podem ser agrupadas em torno de três correntes: econômica, comportamental e estratégica (ROCHA; ALMEIDA, 2006; CARNEIRO; DIB, 2007).

As teorias da corrente econômica partem, em geral, do pressuposto de que o processo de expansão das operações internacionais decorre de uma decisão racional-utilitária, em que a escolha para a alocação de recursos produtivos obedeceria a critérios estritamente econômicos. São teorias elaboradas entre os anos de 1950 e 1970 e, por conta disso, dão ênfase ao investimento direto como o mais estratégico meio para as firmas ampliarem suas operações no exterior - sobretudo por conta da preocupação inerente do investidor no controle dos ativos no país de destino. A transferência de vantagens específicas entre matrizes e filiais, internalizando atividades-chave para sua operação, seria um meio de a firma expandir suas operações já consolidadas internamente, mitigar riscos inerentes ao negócio e buscar, quando possível, a estruturação de novos monopólios e/ou oligopólios (ROCHA; ALMEIDA, 2006; COELHO, 2016).

Um importante autor que procurou ampliar a agenda de pesquisa dessa corrente foi John Dunning, Professor da Universidade de Warwick, que buscou elucidar não somente a dinâmica, mas, principalmente, os motivos que levaram uma empresa a atuar no exterior, analisando conjuntamente os motivadores privados e públicos que interferem diretamente na atração de investimentos e incremento produtivo. Por meio do Paradigma Eclético da Produção, Dunning identifica quatro grandes motivos para que as empresas invistam no exterior, quais sejam: a busca por recursos, mercados, eficiência (racionalização da produção) e ativos (competências e ativos estratégicos voltados à inovação e à distribuição da empresa multinacional (FLEURY; FLEURY, 2012; DUNNING, 2014;). Ademais, o autor destaca, essencialmente, três grupos de vantagens com influência direta no processo de deslocamento e fragmentação do processo produtivo da empresa: (i) vantagens de propriedade, tais como patentes ou marcas, monopólios comerciais, produção em escala, desenvolvidos pela própria empresa ou adquiridos de outras; (ii) vantagens de internalização, em que se torna mais conveniente para a empresa transferir ativos por intermédio das fronteiras nacionais, utilizando sua própria estrutura, do que contratar agentes econômicos em mercados externos; e (iii) vantagens de localização, relativas ao mercado que recebe o investimento. Nesse tipo de 
vantagem, o papel do governo na atração do investimento tem extrema relevância, lançando mão de subsídios de diversas naturezas a fim de gozar de benefícios diretos e indiretos do incremento do parque produtivo nacional. De maneira geral, o Paradigma Eclético de Produção (DUNNING, 2001) considera que as empresas multinacionais possuem vantagens competitivas ou de propriedade vis-à-vis seus principais rivais, que elas utilizam para estabelecer produção em locais que são atrativos devido às suas vantagens de localização (DUNNING, 1980; ROCHA; ALMEIDA, 2006):

Enterprises will engage in foreign production whenever they perceive it is in their best interests to combine spatially transferable intermediate products produced in the home country, with at least some immobile factor endowments or other intermediate products in another country. [...] the decision on where to site a mine, factory or office, is not independent of the ownership of these assets nor of the route by which they or their rights are transacted. [...] At the same time a reduction in transport costs and the formation of customs unions or regional trading blocs (e.g., EEC and LAFTA) have prompted greater regional specialization of production by MNEs. (DUNNING, 1988, p. 4).

A corrente comportamental, por sua vez, tem em seu arcabouço teorias que observam o processo de internacionalização da firma como um fenômeno derivado de uma série de eventos, atitudes e percepções que, gradualmente, reduziriam o risco percebido de atuação transfronteiriça do investidor e aumentaria o comprometimento de recursos na arena internacional.

Essa corrente está associada ao surgimento da escola nórdica de internacionalização, originada nos anos 1960, especificamente, na Universidade de Uppsala. Em suma, o programa de pesquisa sobre negócios internacionais buscava compreender a forte dependência da indústria sueca dos mercados internacionais para seu crescimento; a proposta de integração econômica europeia dos anos 1950; e a entrada agressiva das empresas americanas no mercado europeu. Ao longo das pesquisas, percebe-se que um dos elementos principais relativos ao processo de internacionalização é o modo de entrada.

A maneira como uma empresa irá operar no exterior estaria diretamente relacionada ao conhecimento dos gestores em relação ao país de destino. Conceitos importantes como distância psíquica, comprometimento de recursos, cadeia de estabelecimento, entre outros, são criados a partir do avanço dos trabalhos (FLEURY; FLEURY, 2012). Importante salientar que, por estar diretamente ligada à incerteza oriunda da realização de negócios em mercados externos, as 
pesquisas identificam um certo gradualismo em termos de alocação de recursos em outros mercados:

\begin{abstract}
Another feature of the pattern was that internationalization frequently started in foreign markets that were close to the domestic market in terms of psychic distance, defined as factors that make it difficult to understand foreign environments. The companies would then gradually enter other markets that were further away in psyquic distance terms. [...] We also assumed that learning and commitment building take time. This explains why moves into more risky, but potentially rewarding, modes and moves into markets that are more distant in terms of psychic distance are made incrementally. (JOHANSON; VAHLNE, 2009).
\end{abstract}

A teoria da Escola de Uppsala, dessa forma, sugere que a incerteza da firma em entrar em novos mercados deveria ser mitigada por uma sequência incremental de ações, que variaria desde a simples exportação até o investimento produtivo no país de destino. Vale destacar que, por conta da distância psíquica "as empresas tendem a buscar, inicialmente, mercados considerados mais similares ao doméstico e mais tarde se voltariam aqueles cujas condições culturais, econômicas etc., são menos semelhantes às de seu país de origem (ROCHA; ALMEIDA, 2006, p. 26).

Por fim, existe ainda a corrente estratégica, em que o principal componente do processo de internacionalização estaria na estratégia adotada pela empresa, sobretudo em relação a uma concorrência já estabelecida. Essa estratégia, no entanto, estaria ligada diretamente aos recursos exclusivos da firma e sua competência organizacional, de modo que a firma tenderia a privilegiar os modos de entrada que mais favorecessem o uso desses recursos e competências (ROCHA; ALMEIDA, 2006). A internacionalização de empresas, analisada sob à luz da teoria do comportamento estratégico, deveria ser encarada como um processo dotado de componentes estratégicos (decisões, operações, estrutura organizacional, gestão, etc.) e direcionadores externos (pull factors, push factors e policy factors) (COELHO, 2016).

Como se pode notar, a evolução da agenda de pesquisa na área de negócios internacionais ao longo do século XX permitiu ganhos notórios em termos de complexidade, sobretudo, por conta da interação com outras áreas de conhecimento (ciências sociais, jurídicas, relações internacionais, etc.). Se as pesquisas iniciais tinham como objeto central o comportamento da firma e sua internacionalização por meio, principalmente, de IED, a ampliação do escopo analítico permitiu que outros elementos, estratégias e atores ganhassem extrema relevância quando do momento da internacionalização: 
Foi no contexto acadêmico anglo-americano que as abordagens predominantes na área de NI [Negócios internacionais] e GI [Gestão internacional] se originaram. Essa concentração regional dos desenvolvimentos de ambas as áreas reflete o fenômeno de expansão dos/as IDEs e EMNs dos países industrializados no pós-guerra, mas sugere a doção de uma abordagem mais crítica, especialmente em países menos desenvolvidos. (...) A análise da evolução da agenda de pesquisa das referidas áreas sugere que as decisões estratégicas e práticas de empresas multinacionais contemplam múltiplos níveis de análise (global, internacional, nacional, interorganizacional e intraorganizacional) que refletem as complexidades e interdependências referentes aos negócios internacionais. Consequentemente, essa análise também evidencia que o entendimento das estratégias e práticas de empresas multinacionais requer a adoção de abordagens interdisciplinares com as demais áreas das ciências sociais. (GUEDES, 2010, p. 36-37, grifos do autor).

A evolução da agenda nos próximos anos, nesse sentido, apresenta desafios, principalmente, em termos de escopo de análise, uma vez que novos temas e novos atores passaram a influenciar sobremaneira a arena dos negócios internacionais. Se até aqui a agenda pode ser dividida em três grandes momentos ou ondas, cada uma com suas particularidades de pesquisa, os autores certamente terão como desafio incorporar, sistematicamente, à área de NI, temas como: o papel das instituições internacionais; o papel dos governos e das políticas públicas como indutores de IED; as relações governamentais contemporâneas; os impactos sociais e ambientais do comércio internacional e do IED; o recrudescimento gradual do protecionismo em nível global; o upgrading produtivo e as cadeias globais de valor; entre outros.

\subsection{Em busca de um modelo teórico das cadeias globais de valor}

Especificamente no que se refere à área temática da pesquisa aqui apresentada, qual seja, as CGV, tal agenda começa a ganhar densidade a partir das décadas de 1970 e 1980, período economicamente caracterizado pelo incremento da liberalização econômica em escala global e do aumento do fluxo de investimentos entre países desenvolvidos e em desenvolvimento. De maneira geral, podemos identificar quatro diferentes enfoques referentes à evolução conceitual da área de pesquisa sobre $\mathrm{CGV}$, quais sejam:

a) A corrente de pesquisa da Sociologia Econômica voltada para o Sistema-Mundo (década de 1970), em que autores analisam a perspectiva macroeconômica e histórica das Commodity Chains; 
b) O modelo de cadeia de valor, introduzido por Michael Porter, ao longo da década de 1980, que tinha como objetivo precípuo a compreensão minuciosa da construção da vantagem competitiva por parte das empresas;

c) O framework analítico de Global Commodity Chains, desenvolvido por Gary Gereffi e outros pesquisadores (década de 1990), como uma fusão de elementos oriundos da Sociologia Organizacional e estudos comparados sobre desenvolvimento econômico;

d) O modelo teórico das cadeias globais de valor, que aperfeiçoa o modelo anterior criado por Gereffi, adicionando elementos relativos à tradição econômica voltada para a análise de custos de transação (BAIR, 2009).

O conceito de commodity chain foi elaborado ao longo de artigos e capítulos de livros escritos ao longo das décadas de 1970 e 1980, principalmente por autores como Terence Hopkins e Immanuel Wallerstein, oriundos de uma agenda de pesquisa orientada pela Teoria do Sistema-Mundo, a qual tinha, entre outros objetivos, estudar as relações de subordinação entre centro e periferia, bem como os padrões de dependência e distribuição assimétrica dos ganhos provindos do sistema capitalista de produção. Em suma, autores dessa corrente, ao analisarem as commodity chains, estavam preocupados em comprovar a existência da fragmentação produtiva em nível global como algo inerente ao sistema capitalista de produção, originário do século XVI, refutando a ideia de que a globalização produtiva é um fenômeno recente (BAIR, 2009):

Our basic query is whether and to what extent a capitalist world-economy was na organizing force and structural reality during the sixteenth, seventeenth, and eighteenth centuries. This requires examining two issues. First, to what degree were production processes in different political jurisdictions and geographical areas integrated parts os a complex 'world scale' division of labor marked by phases of of expansion and contraction? From our knowledge of changes in the locations and types of commodity production between (and indeed event within) the seventeenth and eighteenth centuries as opposed to the nineteenth and twentiteth centuries, comes a second quesiton: Exactly what major changes in commodity production occurred as part of the hypothetical periodic restructuring of the world-scale division of labor? Pursuing these two inquiries requires constructing and tracking relations among production operations across time and space. Toward this end, we shall utilize the concept of 'commodity chains'. The concept 'commodity chain' refers to a network of labor and production processes whose end result is a finished commodity. In building this chain we start with the final production operation and move sequentiallu backward [...] until one reaches primarily raw material inputs. (HOPKINS; WALLERSTEIN, 1986, p. 159). 
Com o intuito de responderem a essas perguntas, os autores passaram a dissecar as atividades de algumas cadeias produtivas que perpassavam os séculos XVI a XVIII, notadamente as cadeias de trigo e de transporte (navios). O objetivo era encontrar evidências empíricas da existência de uma economia mundial (world-economy) durante os séculos XVI, XVII e XVIII, por meio da análise minuciosa da distribuição geográfica das operações dessas duas cadeias, das formas de trabalho e tecnologias envolvidas ao longo do processo produtivo, além do nível de dispersão/concentração geográfica das operações em cada etapa produtiva. Em suma, os autores conseguiram encontrar respostas satisfatórias às suas hipóteses relativas à existência e evolução gradual de uma divisão do trabalho em escala global que influenciava o processo produtivo em escala mundial e, ao mesmo tempo, era influenciado pela incipiente conjuntura de globalização econômica ao longo dos XVII e XVIII (HOPKINS; WALLERSTEIN, 1986):

We think it is quite clear that for these fundamental processes of the capitalist
world-economy in the seventeenth and eighteenth centuries, the commodity
chains were geographically extensive, complex, and in constant
recomposition. We think it would be imprudent to assume that production
decisions were made by anyone without some awareness of the existence of
such chains, at least to the degree of appreciating that there were alternative
possible sources of inputs and alternative possible outlets of outputs
(HOPKINS; WALLERSTEIN, 1994, p. 48)

Apesar de o conceito de commodity chains ter ganhado força por conta da agenda liderada pelos teóricos do Sistema-Mundo, foi a partir da publicação do livro Commodity Chains and Global Capitalism, organizado por Gary GereffIi e Miguel Korzeniewicz, em 1994, que um conjunto de autores amplia e redireciona o conceito de commodity chains para Global Commodity Chains (GCC), consolidando uma agenda de pesquisa voltada à análise das particularidades das relações (networks) intrafirmas em indústrias globais. De acordo com alguns autores dessa corrente, era necessário encontrar, naquele momento, um approach teórico analiticamente sensível a alterações históricas que pudesse distinguir padrões cíclicos de comportamento de novas tendências. Ademais, o framework precisava capturar elementos espaciais das transformações na economia global, bem como os relacionamentos que influenciam essas transformações. Era preciso encontrar uma forma de analisar novos padrões de organização e mudanças globais (GEREFFI; KORZENIEWICZ, 1994):

A GCC consists of sets of interorganizational networks clustered around one commodity or product, linking households, enterprises, and states to one another within the world economy. These networks are situationally specific, 
socially constructed, and locally integrated, underscoring the social embeddedness of economic organization. [...] The GCCs approach promotes a nuanced analysis of world-economy spatial inequalities in terms of differential access to market and resources (GEREFFI; KORZENIEWICZ, 1994, p. 2)

Se os autores da Teoria do Sistema-Mundo introduziram o conceito de commodity chain para, entre outros objetivos, compreender como a divisão global do trabalho se reproduz ao longo do tempo e espaço, tornando as relações de produção vetores de sustentação e reprodução da dinâmica de dominação centro-periferia, os autores da vertente de global commodity chain estavam preocupados em incorporar o conceito em uma agenda de pesquisa mais ampla e contemporânea. Em suma, eles buscavam entender algumas importantes alterações nos padrões produtivos dos anos 1990 e como eles influenciavam e tornavam mais dinâmica a relação entre produção e consumo em nível global (KORZENIEWICZ; MARTIN, 1994).

Havia a necessidade de entender como os produtores passariam a responder de maneira rápida às demandas mercadológicas, adaptando-se a um mundo extremamente competitivo. As GCCs eram vistas, dessa forma, como um agente propagador dessa necessidade de estabelecer networks produtivos que tivessem efeito direto na competitividade da firma, por meio da capacidade que esta teria de mitigar os efeitos da distância, incrementando sua habilidade em comprimir o tempo e o espaço (SCHOENBERGER, 1994):

The development and application of the GCC framework is a methodological advance because it provides a way for researchers interested in global industries to map and analyze the spatially dispersed and organizationally complex production networks that are an important part of economic globalization. (BAIR, 2005).

Nesse sentido, mais do que o processo produtivo em si, era fundamental entender as relações que permeavam e davam sustentação à capacidade da firma de produzir em escala e acessar mercados em nível regional e global. Para tanto, era fundamental ter uma clara diferenciação dos elementos que compunham esse sistema produtivo, os quais eram diretamente responsáveis pela capacidade de a firma desenvolver, produzir e distribuir commodities específicas. Em suma, Gereffi (1994) destaca que as GCCs têm três dimensões principais:

a) Estrutura input-output: conjunto de produtos e serviços relacionados conjuntamente em uma sequência de atividades econômicas; 
b) Territorialidade: dispersão espacial ou concentração da produção e redes de distribuição, compostas por empresas de diferentes tamanhos e tipos;

c) Estrutura de governança: relacionamentos de poder e autoridade que determinam como recursos materiais, financeiros e humanos são alocados e movidos ao longo da cadeia.

$\mathrm{O}$ autor ilustrou à época dois tipos diferentes de governança: buyer driven e producer driven commodity chains:

Producer-driven commodity chains refer to those industries in which transnational corporations (TNCs) or other large integrated industrial enterprise play the central role in controlling the production system (including its backward and forward linkages). This is most characteristic of capital-andtechnology-intensive industries like automobiles, computers, aircraft, and electrical machinery. [...] Buyer driven commodity chains refer to those industries in which large retailers, brand-named merchandisers, and trading companies play the pivotal role in setting up decentralized production networks in a variety of exporting countries, typically located in the Third World. This pattern of trade-led industrialization has become common in labor-intensive, consumer goods industries such as garments, footwear, toys, consumer electronics, housewares, and a wide range of hand-crafted items (e.g., furniture, ornaments). (GEREFFI, 1994).

O framework analítico de GCC lançou as bases para uma compreensão mais ampla e integrada da dinâmica produtiva global, bem como seus efeitos econômicos e sociais nos diferentes setores produtivos em nível mundial. Todavia, o incremento do fluxo de comércio e investimento, nas últimas décadas, tornou necessário o aperfeiçoamento da análise da relação entre fragmentação da produção, trocas comerciais e estratégias de investimento em escala global. Dessa forma, diversos esforços passaram a ser realizados no intuito de mapear os padrões, variáveis e dinâmicas inerentes a esses três processos. A necessidade de analisar o fenômeno das GCC de maneira coordenada tornou ainda mais tênue a fronteira entre processo produtivo, regulação comercial e fluxo de investimentos em nível internacional.

Concomitantemente a esse processo, a literatura voltada ao estudo específico dos negócios internacionais, relacionada principalmente à área de administração, passou a perceber com mais ênfase, e de maneira sistemática, a importância do conceito de agregação de valor às operações produtivas fragmentadas globalmente. Dessa forma, o sistema de valor estaria diretamente atrelado às diversas variáveis da conjuntura política econômica internacional, o que dava não somente às empresas, mas também às nações, um papel preponderante na edificação e no impulso da competitividade setorial independentemente da região a ser analisada: 
In a world of increasingly global competition, nations have become more, not less, important. As the basis of competition has shifted more and more to the creation and assimilation of knowledge, the role of the nation has grown. Competitive advantage is created and sustained through a highly localized process. Differences in national values, culture, economic structures, institutions, and histories all contribute to competitive success. There are striking differences in the patterns of competitiveness in every country; no nation can or will be competitive in every or even most industries. Ultimately, nations succeed in particular industries because their home environment is the most forward-looking, dynamic, and challenging. (PORTER, 1990).

Ao introduzir conceito de cadeia de valor, Michael Porter procurou entender como as relações entre atividades intrafirma e intercadeia, bem como instituições a elas relacionadas, são essenciais para a construção das fontes de vantagem competitiva. Em suma, a abordagem proposta desagrega a firma em suas atividades estrategicamente relevantes com o intuito de compreender o comportamento de custos, bem como as potenciais e existentes formas de diferenciação. De acordo com o autor, o ganho e a manutenção da vantagem competitiva dependeriam do entendimento não somente da cadeia de valor da firma, mas como a firma se integra ao sistema de valor como um todo (PORTER, 1985).

Figura 2 - Representação de uma cadeia de valor genérica.

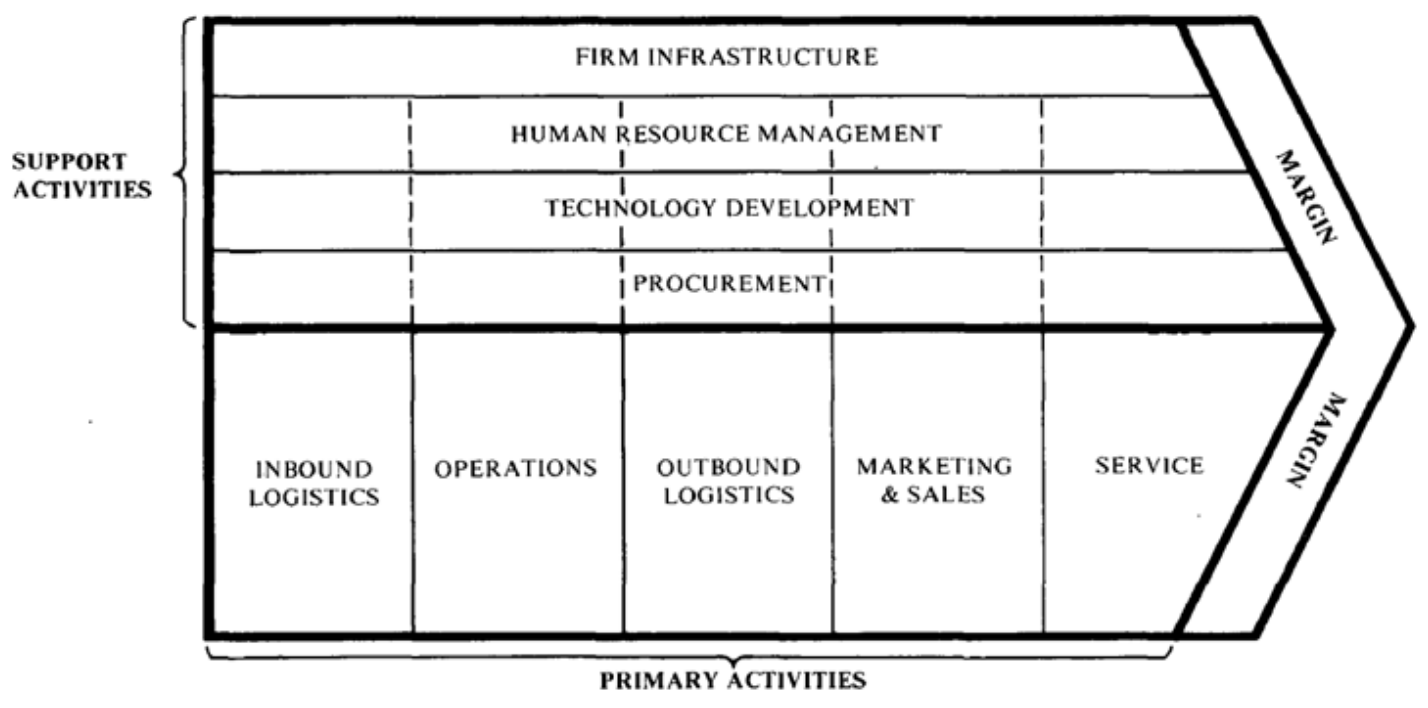

The Generic Value Chain

Fonte: Extraído de Porter (1985). 
Por meio de um modelo que visava desagregar as atividades da firma, de forma a analisá-las profunda, objetiva e sistematicamente, Porter procurou mostrar como a comparação entre diferenças nas diversas cadeias de valor entre competidores são a chave para compreender como a construção da vantagem competitiva acontece. Nesse sentido, embora as atividades fossem a base (building blocks) da vantagem competitiva, o modelo enfatizava que a cadeia de valor não deveria ser vista como uma coleção de atividades independentes, mas um sistema de atividades interdependentes. Dessa forma, a coordenação e otimização das relações (linkages) entre as atividades funcionavam efetivamente como vetores da geração de valor à firma e, consequentemente, à vantagem competitiva (PORTER, 1985).

Ao longo da década de 1990, a agenda de pesquisa que relacionava temas como Global Commodity Chains, cadeias de valor, sistemas de valor, fragmentação produtiva, redes internacionais de produção, entre outros, começa a chamar a atenção para a necessidade de criação de um framework que possibilitasse a análise dos padrões globais de produção, bem como seus efeitos econômicos e sociais, de maneira mais integrada (GEREFFI; HUMPHFREY; KAPLINSKY; STURGEON, 2001). Ou seja, um modelo que tornasse viável, a empresas e estados nacionais, a análise interconectada da disposição global de recursos naturais atrelados a um ou vários setores, a dinâmica mercadológica expressa sobretudo em termos de governança e os interesses nacionais inerentes ao processo de internacionalização de médio e longo prazos. O framework de cadeias globais de valor (CGV), como ficou conhecido, tinha justamente esse objetivo: analisar a integração entre diferentes sistemas globais de produção e distribuição, como forma de entender quais direcionadores de competitividade setorial atuariam diretamente para a melhoria do posicionamento global das empresas de países em desenvolvimento (GEREFFI; FERNANDEZ-STARK, 2012):

The evolution of global-scale industrial organization affects not only the fortunes of firms and the structure of industries, but also how and why countries advance - or fail to advance - in the global economy. Global value chain research and policy work examine the different ways in which global production and distribution systems are integrated, and the possibilities for firms in developing countries to enhance their position in global markets. (GEREFFI; HUMPHFREY; STURGEON, 2005, p. 79).

A agenda de CGV ganhou magnitude ao longo das décadas de 1990 e 2000, sobretudo quando o comércio internacional passou a ser percebido como um componente essencial ao crescimento econômico dos países em desenvolvimento. Gradualmente, diversas nações do Sul passaram a abandonar definitivamente o modelo de industrialização pautada pelo Estado, 
implementando estratégias de desenvolvimento export-oriented. Paralelamente a esse processo, diversos autores passaram a promover agendas de pesquisas ligadas ao funcionamento das indústrias globais em geral, sendo que, em julho de 2001, alguns deles participaram de uma edição especial do jornal IDS Bulletin, publicando papers que tinham sido apresentados no ano anterior em um workshop sobre o tema na cidade de Bellagio, na Província de Como, Itália. A edição especial recebeu o nome de The Value of Value Chains e foi, definitivamente, um marco na consolidação da agenda de pesquisa acerca do tema (BAIR, 2005).

A partir de então, os estudos sobre cadeia produtiva em nível mundial passaram a um último estágio, mais complexo, amplo e capaz de capturar as variáveis intrafirma, interfirma e setoriais relacionadas às redes globais de produção. O próprio conceito de cadeia de valor, nesse sentido, promovia, segundo alguns autores, um eixo de análise integrado para disciplinas da economia, administração e sociologia industrial, voltado para o estudo de dois importantes aspectos da globalização, quais sejam, a integração econômica e a desintegração do processo produtivo (WOOD, 2001):

The two latter chains variants - the GCC and GVC approaches - are analytically oriented towards the micro (individual firm) or meso (sector) level as opposed to the macro and holistic perspective characteristic of the worldsystem conceptualization of commodity chains. [...] Specifically, the central question that appears to motivate many GCC and value chain researchers is how (especially developing-country) firms can improve their position within these chains so as to generate and retain more value. (BAIR, 2005, p. 164)

O quadro 1, a seguir, ilustra as principais diferenças entre as três vertentes relacionadas ao estudo de commodity chains. Como se pode perceber, os ganhos da abordagem de CGV, proposta por Gereffi e outros pesquisadores, estariam justamente na possibilidade de entender a relação mútua entre a organização industrial transnacional e o fluxo comercial e de investimentos em escala global, sobretudo pela ótica da agregação de valor ao produto a ser exportado. Ficava cada vez mais claro que, ao focar na cadeia ou na rede organizacional como unidade de análise, em vez da firma, emergiam as possibilidades de aprofundar as pesquisas em torno de temas como poder, governança e dinâmicas produtivas em geral. Dessa forma, seria possível compreender como uma participação efetiva nas cadeias globais de valor e redes internacionais de produção poderia ser um fator-chave para o crescimento econômico, à luz da rápida transformação tecnológica, do incremento da concorrência internacional e da crescente dispersão da atividade produtiva em nível global (GEREFFI; HUMPHREY; KAPLINSKY; STURGEON, 2001). 
Quadro 1- Evolução conceitual da agenda de pesquisa sobre cadeias globais de valor.

\begin{tabular}{|c|c|c|c|}
\hline Critérios Analíticos & Commodity Chains & $\begin{array}{l}\text { Global Commodity } \\
\text { Chains }\end{array}$ & Global Value Chains \\
\hline $\begin{array}{l}\text { Fundações } \\
\text { Teóricas }\end{array}$ & Teoria Sistema-Mundo & $\begin{array}{c}\text { Teoria Sistema-Mundo } \\
\text { Sociologia Organizacional }\end{array}$ & $\begin{array}{l}\text { Negócios Internacionais } \\
\text { Global Commidity Chains }\end{array}$ \\
\hline Objetos de pesquisa & $\begin{array}{l}\text { Economia Mundial } \\
\text { Capitalista }\end{array}$ & $\begin{array}{l}\text { Networks Inter-firma em } \\
\text { indústrias globais }\end{array}$ & $\begin{array}{c}\text { Lógicas setoriais de indústrias } \\
\text { globais }\end{array}$ \\
\hline Conceitos norteadores & $\begin{array}{l}\text { 1.Divisão Internacional } \\
\text { do Trabalho } \\
\text { 2. Centro-Periferia- } \\
\text { Semi-Perferia } \\
\text { 3.Desigualdade } \\
\text { 4. Ciclos de } \\
\text { Kondratieff } \\
\end{array}$ & $\begin{array}{l}\text { 1. Estrutura Industrial } \\
\text { 2. Governança (Producer } \\
\text { Driven/Buyer Driven } \\
\text { 3. Aprendizado } \\
\text { Organizacional/Upgrading } \\
\text { Industrial }\end{array}$ & $\begin{array}{c}\text { 1. Cadeias de Valor } \\
\text { Adicionado } \\
\text { 2. Modelos de Governança } \\
\text { (modular, relacional, cativa) } \\
\text { 3. Custos de Transação } \\
\text { 4. Upgrading Industrial }\end{array}$ \\
\hline Influência intelectual & $\begin{array}{c}\text { 1. Teoria da } \\
\text { Dependência } \\
\text { 2. Teoria Estruturalista- } \\
\text { Desenvolvimentista }\end{array}$ & $\begin{array}{c}\text { 1. Literatura sobre } \\
\text { Empresas Multinacionais } \\
\text { 2. Desenvolvimento } \\
\text { Comparado }\end{array}$ & $\begin{array}{l}\text { 1. Negócios Internacionais / } \\
\text { Organização Industrial } \\
\text { 2. Comércio Internacional } \\
\text { 3. Sistemas } \\
\text { Globais/Internacionais de } \\
\text { Redes de Produção }\end{array}$ \\
\hline Textos-chave & $\begin{array}{c}\text { Hopkins \& Wallerstein } \\
\text { (1977; 1986), Arrighi } \\
\text { \& Drangel (1986); } \\
\text { Arrighi (1990), } \\
\text { Review, } 23 \text { (1), 2000 }\end{array}$ & $\begin{array}{l}\text { Gereffi \& Korzeniewcz } \\
\text { (1994), Appelbaum \& } \\
\text { Gereffi (1994) Gereffi } \\
\text { (1999), Bair \& Gereffi } \\
\text { (2001) }\end{array}$ & $\begin{array}{c}\text { Humphrey \& Schmitz } \\
\text { (2000), IDS Bulletin, } 29 \text { (1), } \\
\text { Gereffi et al (2005) }\end{array}$ \\
\hline
\end{tabular}

Fonte: Elaboração própria, a partir dos dados de Bair (2005).

Em linhas gerais, os autores dessa agenda de pesquisa procuraram valorizar a perspectiva qualitativa da fragmentação produtiva global, como se pode ver a seguir. Os autores acreditavam que, embora as estatísticas sobre comércio e investimento apresentassem uma ideia geral da atividade econômica global, as relações interfirma e intraindústria seriam melhor capturadas por meio de uma análise mais robusta da interação dos diversos eixos (econômicos, políticos, sociais, institucionais, etc.) que as compõem, dispostos em dois espectros básicos organizacional e espacial:

I believe that the division of labor within value chains and the natures of the network linkage itself - its information capacity, or 'bandwidth', connection mechanism, governance style, power dynamics and geographic reach - are extremely important research subjects. What is clear is that macro-level statistics, while they can help us to gain a rough idea about the volume and location of economic activity, provide little insight into the actual shape and 
texture of global value chains and almost nothing about the nature of interfirm linkages. We must rely on the painstaking collection of qualitative field data, which, when used in combination with macro-level statistics on trade and investment, can lead us to a more fine-grained understanding of globalscale economic patterns and trends. (STURGEON, 2001, p. 10).

Nesse sentido, Gereffi define a cadeia de valor como "uma ferramenta que descreve toda a gama de atividades que empresas e trabalhadores desempenham para produção de um bem, desde sua concepção até para além de seu uso final" (GEREFFI; FERNANDEZ-STARK, 2016, p. 7). Em suma, essas atividades correspondem às áreas de Pesquisa \& Desenvolvimento, Design, Produção, Marketing, Distribuição e Suporte ao Consumidor Final. Ademais, Gereffi destaca que as atividades contidas em uma cadeia de valor podem referir-se a uma empresa individualmente ou dividida entre diferentes empresas. Todavia, em um mundo economicamente globalizado, é importante ter presente que as atividades relativas a uma cadeia de valor são geralmente desenvolvidas em uma escala global, por redes de produção interfirma (GEREFFI; FERNANDEZ-STARK, 2016).

Nesse sentido, o framework de CGV busca, por meio da análise de seis dimensões analíticas, divididas entre elementos globais e locais, mapear as particularidades de diversas redes de negócios fragmentadas em termos organizacionais e globalmente distribuídas, tendo como foco a localização do valor agregado em sistemas de produção globais, tanto no que tange às atividades upstream quanto downstream de uma determinada cadeia produtiva:

By focusing on the sequences of tangible and intangible value-adding activities, from conception and production to end use, GVC analysis provides a holistic view of global industries - both from the top-down (for example, examining how lead firms 'govern' their global-scale affiliate and supplier networks) and from the bottom-up (for example, asking how these business decisions affect the trajectory of economic and social 'upgrading' or 'downgrading' in specific countries and regions). (GEREFFI; FERNANDEZSTARK, 2012, 2016).

\subsubsection{A ESTRUTURA INPUT-OUTPUT DE UMA CGV}

De caráter global, a dimensão analítica da estrutura input-output tem como objetivo principal descrever o processo de transformação de matéria-prima no produto final. Basicamente, busca-se identificar as principais atividades e segmentos em uma cadeia de valor, sendo que, geralmente, as etapas de mapeamento dividem-se em: Pesquisa \& Desenvolvimento, Insumos, Produção, Armazenamento, Processamento, Distribuição, Marketing e, em alguns casos, Reciclagem (ver na Figura 3, a seguir, de maneira mais precisa, tais etapas presentes na 
CGV de Frutas e Vegetais). Em suma, a estrutura input-output envolve bens, serviços e uma série de atividades-suporte, as quais estão graficamente representadas em uma série de caixas conectadas que mostram os fluxos de bens tangíveis, intangíveis e serviços, cruciais para o mapeamento do valor adicionado em diferentes estágios da cadeia. O objetivo principal, ao elaborar o mapeamento da estrutura input-output é, justamente, segmentar essas informações e criar uma cadeia autoexplicativa que inclua as principais atividades da indústria. Dessa segmentação, decorre a identificação da dinâmica e da estrutura das empresas em cada eixo da cadeia de valor. Cada eixo identificado dispõe de características particulares que irão influenciar na operacionalização do negócio de maneira direta, sobretudo no que se refere à governança da cadeia.

Figura 3 - Representação de uma estrutura input-output da CGV de frutas e vegetais.

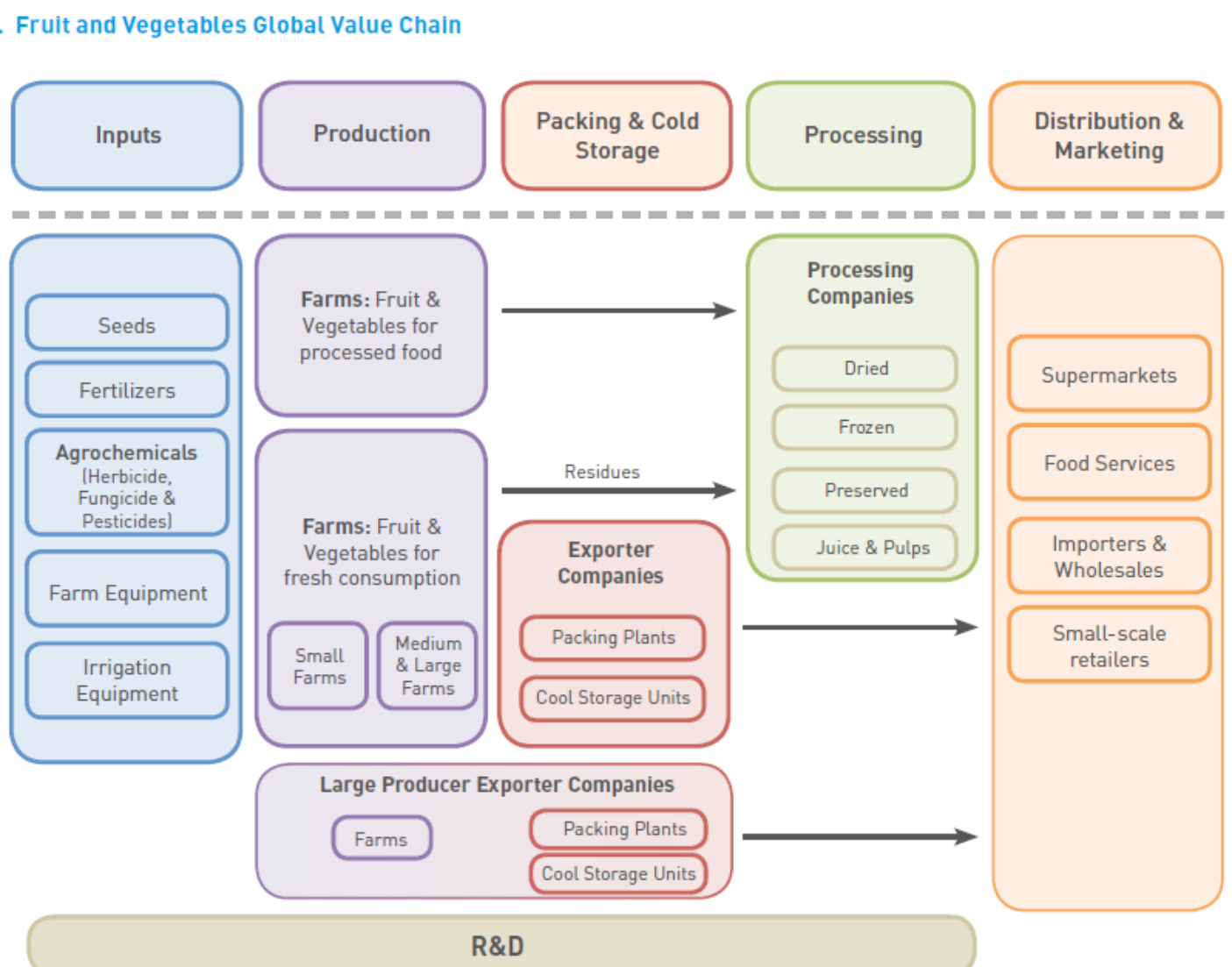

Fonte: Extraído de Gereffi e Fernandez-Stark (2012, 2016). 


\subsubsection{O ESCOPO GEOGRÁFICO DE UMA CGV}

Assim como no caso da estrutura input-output, o escopo geográfico de uma CGV também apresenta caráter global, uma vez que seu principal objetivo é a identificação de como o setor e, consequentemente, suas empresas-líderes, operam globalmente em cada segmento da cadeia de valor. De acordo com o modelo, a presença de um número de empresas-líderes em diferentes países tende a indicar o nível de posição do país na cadeia. Em linhas gerais, a análise do escopo geográfico é baseada, sobretudo, na leitura da oferta e demanda global relativa à CGV a ser estudada. Para tanto, usa-se o fluxo de comércio em cada estágio dessa cadeia, por meio de sua coleta em base de dados oficiais (UN Comtrade, por exemplo), além de informações secundárias obtidas em relatórios setoriais e entrevistas com experts. Gereffi e Fernandez-Stark (2016) destacam a importância da contribuição dessa dimensão analítica para o modelo teórico das CGV, uma vez que ele auxilia no mapeamento da dispersão global de industrias internacionalizadas. No entanto, os autores destacam que as empresas geralmente operam, de maneira contínua e crescente, em diferentes escalas geográficas (local, nacional, regional e global), o que torna o processo produtivo, em sua totalidade, mais complexo. Por fim, ambos aludem a evidências que sugerem que as CGV têm se tonado cada vez mais regionais, dinâmica que estaria sendo influenciada por uma gama de fatores, que vão desde o crescimento de economias emergentes até a ampliação da assinatura de acordos preferencias/regionais de comércio - APCs (atualmente, o mundo conta com 294 APCs, sendo 142 relativos ao comércio somente de bens e outros 152 que envolvem o comércio de bens e/ou serviços) (OMC, 2019).

\subsubsection{ESTRUTURA DE GOVERNANÇA DA CGV}

De caráter global, a análise da estrutura de governança permite entender como uma cadeia é controlada e coordenada em um ambiente de assimetria e complexidade econômica (GEREFFI, 1994 apud GEREFFI; FERNANDEZ-STARK, 2012). Em suma, é na compreensão da governança de uma cadeia que se pode depreender como os diversos fatores relativos ao modelo de negócio estão direta e indiretamente relacionados. Passa-se a perceber a maneira como algumas empresas influenciam e são influenciadas pela cadeia, e, da mesma forma, como os países buscam se relacionar à dispersão global da produção, tentando capturar elementos e dinâmicas que lhes tragam algum tipo de benefício: 
Governance is a central concept to value-chain analysis. Governance can be defined as non-market coordination of economic activity. The starting point for interest in Global Value Chains is the fact that some firms directly or indirectly influence the organization of global production, logistic and marketing systems. Through the governance structure they create, they take decisions that have important consequences for the access of developing firms to international markets and the range of activities these firms can undertake. (GEREFFI; HUMPHREY; KAPLINSKY; STURGEON, 2001, p. 4).

Como já visto anteriormente, nos anos de 1990, Gereffi identificou dois tipos básicos de governanças em cadeias produtivas transfronteiriças: producer driven e buyer driven. A partir daí, pode-se afirmar que essa dimensão analítica certamente foi a que mais evoluiu em termos no âmbito do modelo teórico de CGV, sobretudo pela necessidade de capturar, em nível global, as particularidades na interação produtiva e comercial entre empresas-líderes e fornecedores. Nesse sentido, o trabalho de Gereffi, Humphrey e Sturgeon (2005) procurou complementar os tipos de governança explorados na década anterior e propôs um modelo teórico específico sobre o objeto de pesquisa (operational theory of global value chain governance), com base em tipificações e critérios analíticos novos. Os autores, então, identificaram cinco tipos de governança nas CGV (Mercado, Modular, Relacional, Cativa e Hierárquica), os quais estariam diretamente relacionados a três fatores distintos: complexidade das informações e da transferência de conhecimento intrínseca a uma transação específica, sobretudo relativa a especificações de produtos e processos; nível de dificuldade da codificação das informações e posterior transmissão às partes envolvidas no processo produtivo; e capacidade dos atuais e potenciais fornecedores em relação aos requerimentos específicos das transações. A Figura 4, a seguir, ilustra os modelos sugeridos pelos autores. 
Figura 4 - Modelos de governança em CGV

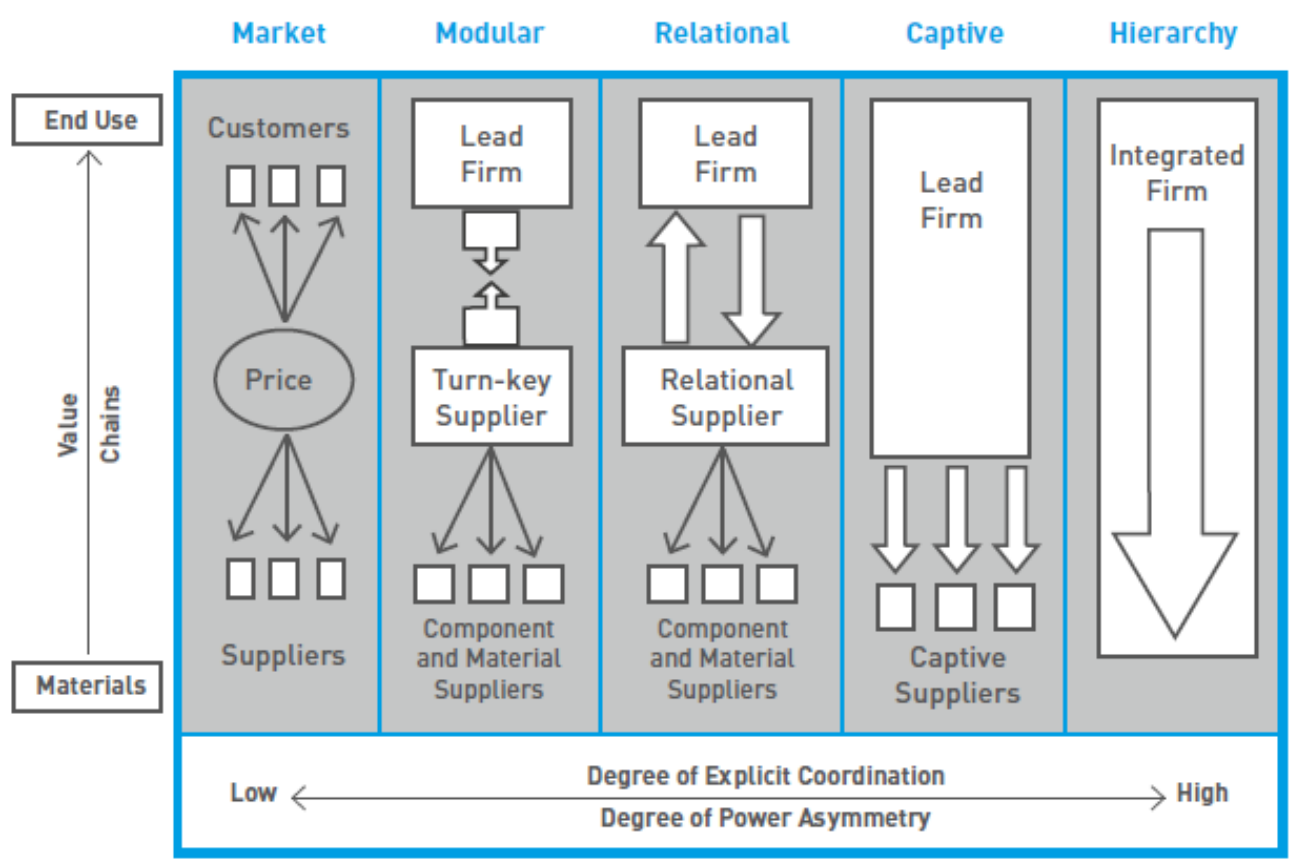

Fonte: Extraído de Gereffi e Fernandez-Stark $(2012,2016)$

De acordo com os autores ${ }^{3}$, a governança de mercado é aquela em que as informações são facilmente codificadas, as especificações dos produtos são relativamente simples e, por fim, os fornecedores têm a capacidade de atender a uma determinada de maneira simples, com poucos inputs advindos dos compradores. O preço do produto nesse modelo de governança é um elemento central à cadeia em análise, e, por conta do baixo nível de complexidade das informações intercambiadas entre fornecedores e compradores, as transações podem ser implementadas com pouca coordenação explícita entre eles.

O tipo de governança modular dispõe de uma diferenciação fundamental em relação ao modelo anterior, qual seja, a necessidade de codificação das especificações em produtos que são mais complexos. Nesse sentido, os padrões técnicos são um componente central desse modelo de governança, já que eles têm o objetivo de diminuir a complexidade das transações entre fornecedores e clientes. Por conta da codificação existente, as informações são trocadas 
com pouca coordenação explícita, e o custo para troca de parceiros é relativamente baixo, assim como na governança de mercado.

A governança relacional das CGV ocorre quando as especificações de um produto não podem ser codificadas, as transações são complexas, porém as capacidades dos fornecedores são elevadas. O que torna a transação viável é, justamente, a troca de conhecimento e constante interação entre compradores e fornecedores de alto nível. Dessa relação surge uma espécie de dependência mútua e a troca de complexas informações passa a ser governada por uma elevada coordenação explícita, que faz com que custo de trocar de parceiros seja elevado.

Já a governança cativa decorre de dinâmicas produtivas em que a habilidade de codificar informações e a complexidade de especificações produtivas são elevadas, porém as capacidades dos fornecedores são baixas. Essa situação leva a elevados níveis de intervenção da empresa-líder no processo produtivo e um alto nível de dependência dos fornecedores às dinâmicas impostas pelos compradores. De acordo com os autores, esse modelo tende a limitar as atividades realizadas pelos fornecedores, geralmente relacionadas à montagem ou atividades complementares àquelas realizadas pelas empresas-líderes.

Por fim, a governança hierárquica é aquela em que as especificações não podem codificadas, os produtos são complexos e há uma falta de fornecedores competentes. Isso leva as empresas-líderes a internalizar praticamente todo o processo produtivo. O quadro abaixo resume as principais características dos modelos explicitados pelos autores, de acordo com os três fatores relacionados a cada uma delas.

Quadro 2 - Modelos de Governança a partir de suas variáveis

\begin{tabular}{|c|c|c|c|c|}
\hline Tipos de Governança & $\begin{array}{c}\text { Complexidade } \\
\text { das Transações }\end{array}$ & $\begin{array}{c}\text { Habilidade em } \\
\text { Codificar } \\
\text { Transações }\end{array}$ & $\begin{array}{c}\text { Competência dos } \\
\text { Fornecedores }\end{array}$ & $\begin{array}{c}\text { Grau de Coordenação } \\
\text { Explícita e Assimetria } \\
\text { de Poder }\end{array}$ \\
\hline Mercado & Baixa & Alta & Alta & Baixa \\
Modular & Alta & Alta & Alta \\
\cline { 1 - 3 } Relacional & Alta & Baixa & Alta & \\
\hline Cativa & Alta & Alta & Baixa & High \\
\hline Hierárquica & Alta & Baixa & Baixa & \\
\hline
\end{tabular}

Fonte: Elaboração própria, a partir dos dados de Gereffi, Humphrey e Sturgeon, (2005). 


\subsubsection{O UPGRADING NA CGV}

De caráter local, a análise do upgrading econômico implica correlação de duas dinâmicas, Bottom Up (estratégia país) e Top Down (estratégia empresa) vis-à-vis uma determinada cadeia produtiva. Em suma, tal análise visa identificar como empresas, países e regiões buscam incorporar atividades de maior valor agregado, no âmbito das CGV, no intuito de aumentar os benefícios (segurança, lucro, valor adicionado, capacidades, etc.) advindos da maior participação da produção global (GEREFFI; FERNANDEZ-STARK, 2012, 2016). Isso decorre do fato de que, a despeito dos diversos fatores diretamente relacionados à integração dos países às CGV, tais como grau de abertura comercial e IED, dotação de recursos naturais, humanos e tecnológicos, relações geopolíticas com parceiros selecionados, entre outros, o nível de competitividade das nações e das empresas que operam nessas redes de produção globais passou a variar mais em função das atividades exercidas do que somente das mercadorias produzidas em uma território específico (STURGEON; GEREFFI; GUINN; ZYLBERBERG, 2013). A literatura identifica quatro tipos básicos de upgrading econômicos, quais sejam (HUMPHREY; SCHMITZ, 2002; PINTO; FIANI; CORRÊA, 2017):

a) Upgrading de processo: ocorre quando uma empresa transforma inputs em outputs de maneira mais eficiente por meio da reorganização do sistema produtivo ou pela introdução de uma tecnologia superior (absorção tecnológica e internalização de partes e componentes);

b) Upgrading de produto: ao migrar para linhas de produtos mais sofisticadas, uma empresa realiza o upgrading de produto. Esse tipo de movimento está associado ao aumento do valor adicionado em segmentos já existentes da CGV. Geralmente, é definido em termos de incremento de unidades produzidas pela empresa;

c) Upgrading funcional: aquisição de novas funções ou abandono de funções já executadas, com vistas ao incremento do conteúdo das competências em atividade. Esse tipo de upgrading ocorre geralmente quando uma empresa passa a atuar em um segmento de mais alto valor agregado e maior sofisticação tecnológica em uma CGV;

d) Upgrading intersetorial (ou de cadeia): empresas ou clusters passam a atuar em diferentes atividades produtivas e, consequentemente, $\mathrm{CGV}$, com base no conhecimento adquirido anteriormente. As empresas, dessa forma, passam a internalizar tecnologia e inovação para a atuação em outra CGV. 


\subsubsection{O CONTEXTO INSTITUCIONAL}

De caráter local, o contexto institucional identifica como as condições políticas locais, nacionais e internacionais moldam a participação do país em cada estágio da cadeia de valor (GEREFFI, 1995). A compreensão apurada dessa dimensão fornece uma ampla perspectiva de como as operações globais são influenciadas e influenciam determinadas localidades e suas instituições e, a partir daí, passam a se relacionar diretamente com a implementação de estratégias nacionais e/ou regionais de desenvolvimento econômico e industrial (STURGEON, 2001).

Isso ocorre pelo fato de as $\mathrm{CGV}$ sofrerem diretamente os efeitos das dinâmicas econômicas, sociais e institucionais em nível local, dependendo diretamente de diversas condições para sua existência e expansão. Dessa forma, diferentes fatores, como mão de obra, infraestrutura, regulamentação, atuação governamental, influência de sindicatos, associações, subsídios, nível educacional, políticas de inovação, entre outros, impactam diretamente o nível de crescimento e desenvolvimento industrial esperado por uma nação. Isso faz com que essa dimensão analítica requeira o exame de vários stakeholders públicos e privados envolvidos na cadeia de valor. Por fim, o estudo aprofundado do contexto institucional se torna também uma importante ferramenta analítica de política industrial, como sugerem os autores:

Because global value chains touch down in many different parts of the world, the use of this framework allows one to carry out more systematic comparative (cross-national and cross-regional) analysis to identify the impact of different features of the institutional context on relevant economic and social outcomes. (GEREFFI; FERNANDEZ-STARK, 2016).

\subsubsection{OS STAKEHOLDERS DA INDÚSTRIA}

Última dimensão a ser analisada, o mapeamento dos stakeholders da indústria em questão foi incorporado recentemente ao framework teórico das $\mathrm{CGV}$, na última revisão do modelo em 2016 (GEREFFI; FERNANDEZ-STARK, 2016). Em suma, essa dimensão consiste na exposição dos principais stakeholders na cadeia a ser analisada, bem como nas relações existentes entre eles. Geralmente, os principais participantes diretos e indiretos da cadeia são: associações, empresas, trabalhadores, instituições educacionais, agências governamentais, ministérios, entre outros. 
Esse tipo de análise tem ganhado relevância por conta da necessidade crescente de upgrading industrial tanto por parte das empresas quanto dos países. Dessa forma, instituições e mecanismos fortes e relevantes tendem a atuar em prol do desenvolvimento de uma política industrial que beneficie diferentes cadeias produtivas e atue permanentemente a favor da melhoria do ambiente de negócios.

\subsection{A nova agenda das CGV: estratégias de upgrading e a análise do valor adicionado}

A despeito do avanço teórico até aqui analisado, é importante salientar que o tema das CGV passou a ganhar relevância nas últimas décadas para diversos países que buscavam implementar melhorias em seus ambientes de negócios com vistas a criar condições estruturais que possibilitassem o aumento do fluxo de comércio, investimentos e, consequentemente, o upgrading econômico das empresas em seus respectivos territórios. Nesse sentido, ao longo das últimas décadas, ganha importância não somente o mapeamento das atividades produtivas por parte das empresas que as realizam, mas também a maneira como tais ações estão relacionadas com os países nos quais elas são desenvolvidas. Essa leitura mais específica e correlacionada da teoria das CGV permitiu a identificação da posição do país, em termos de agregação de valor, em redes de negócio globais e, consequentemente, a proposição de eventuais políticas públicas que lhe permitam galgar posições de maior valor adicionado dentro de uma cadeia produtiva:

For most of the subsequent two centuries, the high cost of moving instructions and goods dictated agglomeration in production. But revolutionary advances in transportation and (especially) communications technology have weakened the link between specialization and geographic concentration, making it increasingly viable to separate tasks in time and space. When instructions can be delivered instantaneously, components and unfinished goods can be moved quickly and cheaply, and the output of many tasks can be conveyed electronically, firms can take advantage of factor cost disparities in different countries without sacrificing the gains from specialization. The result has been a boom in 'offshoring' of both manufacturing tasks and other business functions. (GROSSMAN; ROSSI-HANSBERG, 2006).

Por ter um caráter específico de policy making, o tipo de análise que envolve releitura de dados de produção e comércio, posição atual/potencial do país no cenário econômico global e eventuais estratégias de upgrading de empresas/países passou a ganhar relevância crescente entre diversas organizações internacionais contemporâneas, o que fez com que várias delas 
passassem a elaborar trabalhos voltados ao tema. O conceito de trade in tasks ${ }^{4}$, que se relaciona diretamente com o fenômeno das CGV, passou a ser o alvo de diversas entidades multilaterais e regionais que buscavam se posicionar frente ao tema nas últimas décadas, sobretudo em virtude do aumento do fluxo de investimentos e do número de bens intermediários comercializados no mundo ter representado, em média, $43 \%$ do fluxo global de mercadorias, conforme mostra o Gráfico 1, abaixo.

Gráfico 1 - Fluxo mundial de mercadorias (\%).

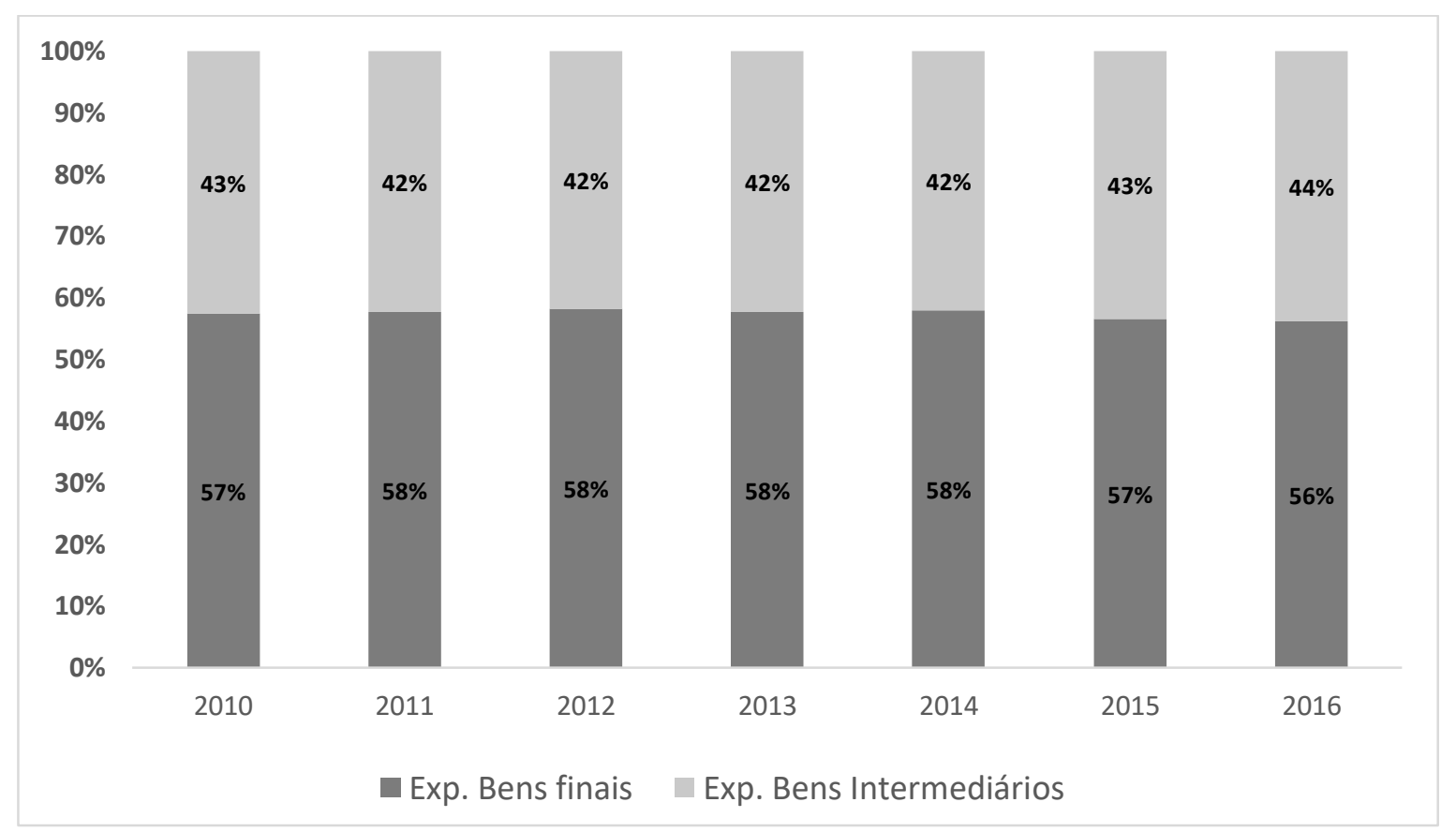

Fonte: elaboração própria, a partir do World Trade Statistical Review (WTO, 2018).

Saber o tipo de mercadoria a ser produzida e em qual atividade se inserir passaram a ser características fundamentais na definição da estratégia de atuação dos países e das empresas

$4 \quad$ Em paper produzido pela OCDE, em 2011, os pesquisadores Rainer Lanz, S. Miroudot e H. Nordas exploram o conceito de trade in tasks da seguinte forma: "[...] In the context of offshore outsourcing, tasks are traded more and more. What people generally mean when talking about trade in tasks is the fact that part of activities of firms that were previously provided in-house are now outsourced, i.e. supplied by an independent firm. [...] The paradigm of trade in tasks [...] goes beyond the increase in trade in services following new outsourcing strategies. Their basic idea is that instead of trade being an Exchange of goods, it "increasingly involves bits of value being added in many different locations. Trade in tasks is therefore a theory of offshoring - the consequence of the separation of tasks in time and space" (LANZ; MIRODOUT; NORDAS, 2011, p. 8). 
nas CGV. Por conta disso, uma melhor compreensão dos dados de comércio, por meio do mapeamento mais preciso do fluxo de bens finais e intermediários, possibilitaria uma leitura atualizada e complementar não somente do fluxo internacional de investimentos, mas também da divisão internacional do trabalho em curso. As tendências na comercialização de bens intermediários passaram, gradativamente, a ser encaradas como um elemento fundamental na formação de $\mathrm{CGV}$, sobretudo porque processos de produção fragmentada necessitam de partes, componentes e montadores que se movam de maneira transfronteiriça, às vezes mais de uma vez, antes da produção e embarque do bem final (UNIDO, 2011):

Trade in tasks not only allows firms to source an increasing portion of the tasks performed in the production of goods and services more cheaply from abroad, it also allows for deeper division of labour in the sense that the production process is divided into finer and more specialised slices. For instance if a ship building firm decides to replace a small in-house design and architecture division by a contract with a specialised outside supplier, it will obtain the inputs from, say 30 highly specialised engineers instead of three inhouse engineers that would have to cover a much broader field at the same cost. The opportunity to buy specialised tasks from outside suppliers is particularly important for tasks that are needed only occasionally such as testing of new products, recruitment, training and software development where in-house state-of-the-art expertise is way too costly, particularly for small and medium sized enterprises. (LANZ; MIRODOUT; NORDAS, 2011, p. 15).

Como já explorado neste trabalho, a fragmentação produtiva em escala global, aliada à reconfiguração mundial do fluxo de comércio e investimentos passou a impactar diretamente a estratégia de desenvolvimento e participação dos países nas redes globais de produção (THORSTENSEN, 2011). Nesse sentido, já que as estratégias de integração em CGV também dependem de uma leitura mais minuciosa e qualificada dos fluxos comerciais atuais, diversas organizações passaram a buscar alternativas para expor tais fluxos de maneira desagregada 5 .

Essa leitura desagregada dos dados se tornou o principal vetor de leitura da participação de um país nas CGV para diversas organizações. Nesse sentido, a UNCTAD, 2013 define que: "[...] GVC participation indicates the portion of a country's exports that is part of a multi-stage trade process, by adding to the foreign value added used in a country's own exports also the value added supplied to other countries' exports. Although the degree to which exports are used by other countries for further export generation may appear less relevant for policymakers as it does not change the domestic value added contribution of trade, the participation rate is a useful indicator for the extent to which a country's exports are integrated in international production networks and it is thus helpful in exploring the trade-investment nexus. This variable corrects the limitation of the previous indicators in which countries at the beginning of the value chain (e.g. exporters of raw materials) have a low foreign value added content of exports by definition. It gives a more complete picture of the involvement of countries in GVCs, both upstream and downstream. A country's GVC participation, measured as a share of exports, effectively assesses the reliance of exports on GVCs. In this sense, it is also an indicator of how much hypothetical 'damage' to GVCs (and global 
Em um desses esforços para mensurar o fenômeno das CGV, a Organização para a Cooperação e Desenvolvimento Econômico (OCDE), em conjunto com a OMC, lançou uma plataforma de dados que busca identificar a posição de cada país em termos de agregação de valor em diferentes cadeias globais de produção (Trade in Value Added-TiVA). Em linhas gerais, a base de dados estima as quantias de valor adicionado na produção de bens e serviços voltados à exportação e, com isso, busca mapear o fluxo intermediário de bens e serviços na composição final de uma mercadoria, indicando o nível de participação de um país nesse processo:

The emergence of GVCs has promoted a sharp increase of trade flows in intermediate inputs [...]Services are playing a key role in the operation of these GVCs and international production networks, especially transport, communications, and other business services, the fastest-growing component of world trade. Goods and services are now fully intertwined and inseparable in production, and investment decisions are pushing international trade flows and patterns [...] This new reality of international trade is starting to be reflected in international trade statistics, which until recently had attributed the full commercial value of a good (or service) to the last country of export, thus overstating the commercial importance of the final producer in the value chain. In recognizing the need to adapt to reflect the new trade relationships, the WTO and OECD have jointly undertaken an effort to produce international trade statistics on a value-added basis, so as to be able to disaggregate the value that is added at each stage of the production chain and measure the contribution made by each trading partner. (STEPHENSON, 2013, p. 1).

O Gráfico 2, a seguir, mostra o nível de insumos utilizados nas exportações de países selecionados, bem como o nível de exportações intermediárias desses países que foram incorporadas às exportações de terceiros países, durante o ano de $2009^{6}$. Como se pode perceber, o Brasil, por exemplo, possui um baixo percentual de insumos importados em suas exportações e, da mesma forma, contribui significativamente com a exportação de bens intermediários que receberão algum tipo de agregação de valor em terceiros países, de onde serão, finalmente, exportados.

GDP) would occur if a country's exports were blocked; alternatively, it represents the vulnerability of the GVC to shocks in the respective country" (UNCTAD, 2013, p. 5).

6 Para mais informações, consultar: Measuring Trade in Value Added: An OECD-WTO joint initiative. Disponível em: http://www.oecd.org/industry/ind/measuringtradeinvalue-addedanoecdwtojointinitiative.htm. Acesso em: 12/10/2017. 
Gráfico 2 - Participação nas CGV (1995 e 2009).

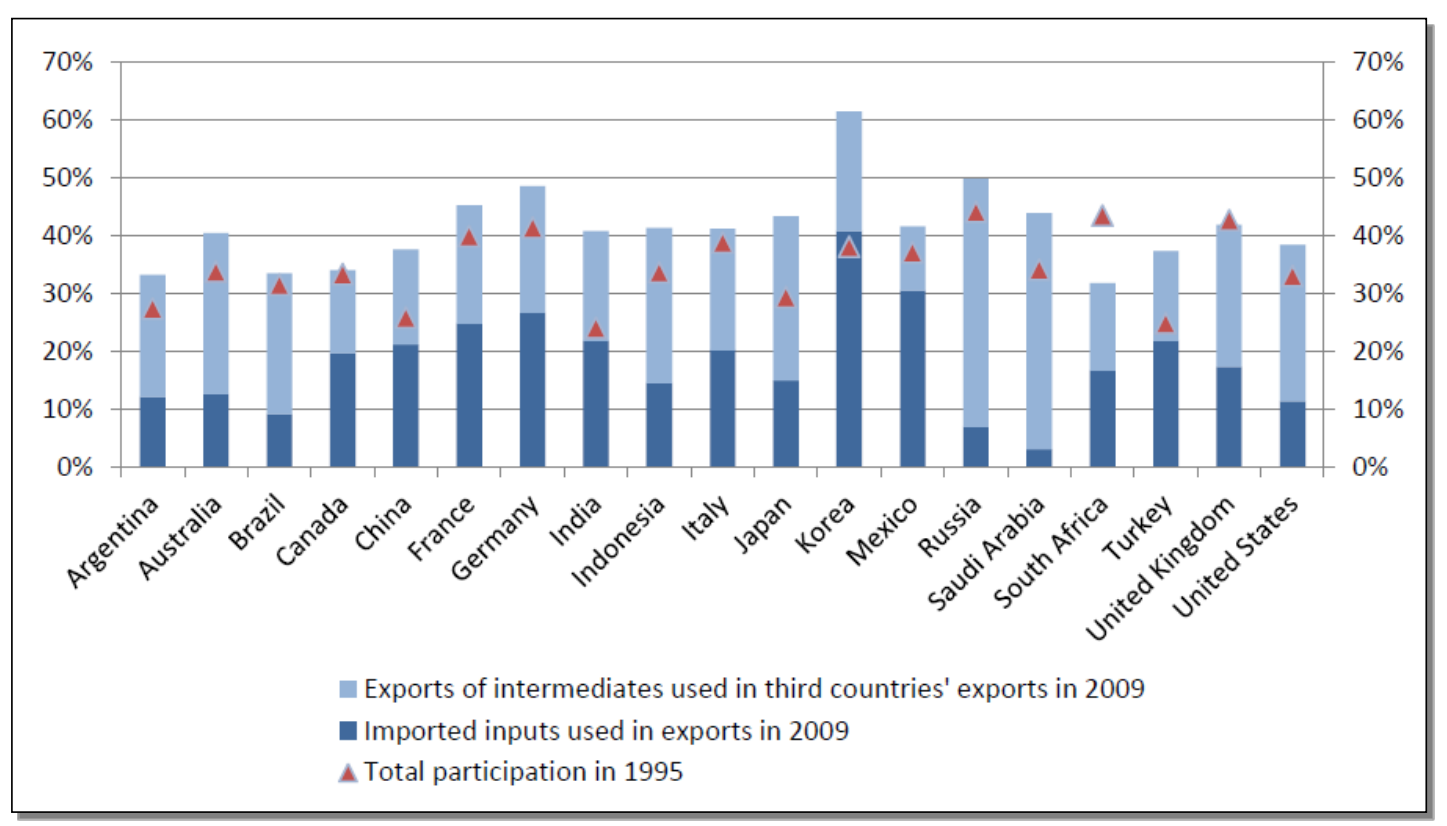

Fonte: extraído de OECD, WTO e UNCTAD (2013).

Concomitantemente, ao se analisar o perfil do comércio exterior brasileiro (ver Figura 5, abaixo) tem-se claramente um país que concentra suas importações em produtos de médiaalta tecnologia e suas exportações em produtos básicos, que receberão adição de valor em outros mercados. Somado a esse panorama, está o fato, já explorado acima, de o Brasil deter um dos maiores índices de valor adicionado doméstico nas suas exportações brutas, superando os 90\%, índice bem superior à média mundial (75\%) — dados de 2009 (OCDE, 2013; NAIDIN, 2014). 
Figura 5 - Perfil do comércio exterior brasileiro por intensidade tecnológica.

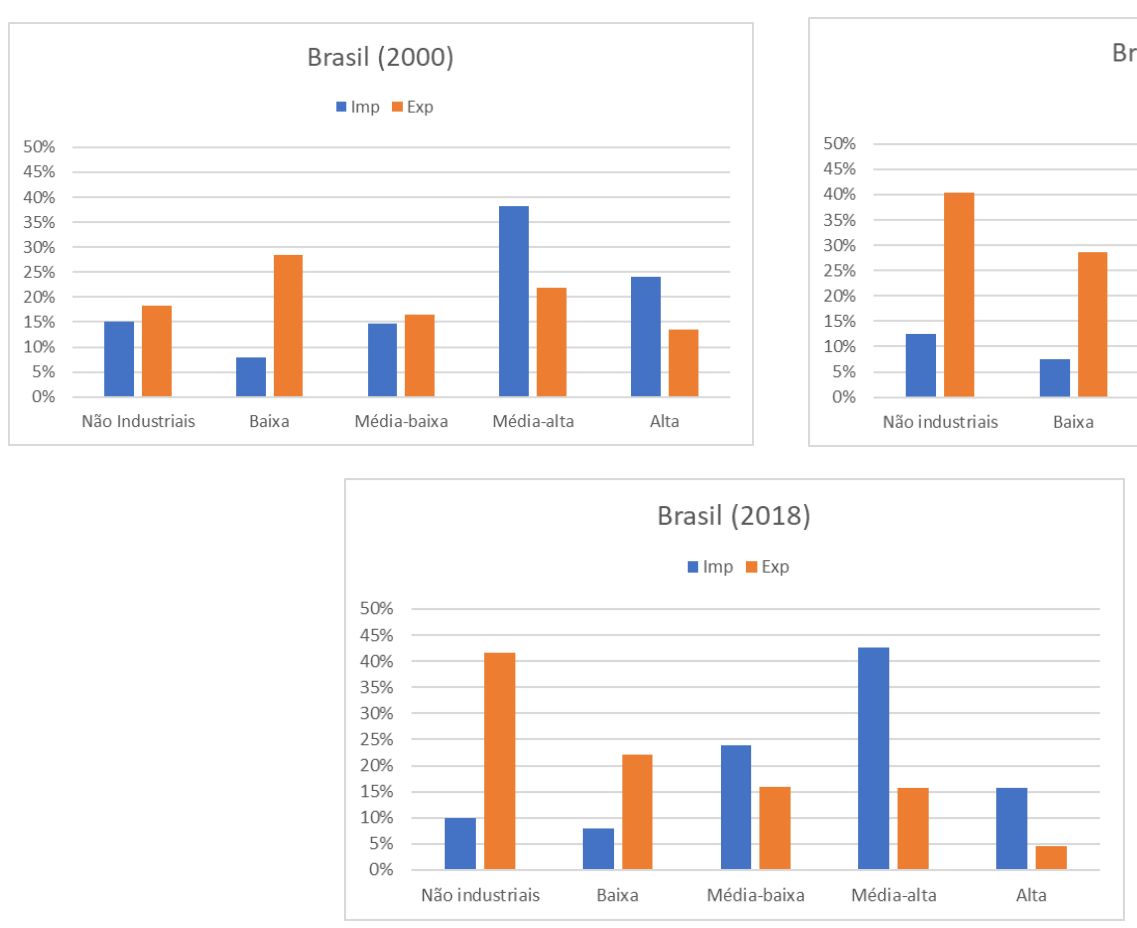

Fonte: elaboração própria, a partir dos dados de Comextat (2019).

Por conta da crescente necessidade de aperfeiçoamento em termos de dados do valor agregado comercializado globalmente, o Brasil passou a ser foco de análise não somente da OMC/OCDE, mas também de outras organizações e institutos internacionais. Na visão dessas entidades, atribuir o valor total comercializado ao último país de origem das exportações pode levar a distorções graves nas estatísticas, e "measuring trade in value-added terms seeks to address this distortion" (OMC, 2012). Em relatório sobre o tema, a UNCTAD fez uma lista, à época, dos principais esforços institucionais para mapear as $\mathrm{CGV}$ e o comércio de valor agregado em nível global, que segue esquematizado no Quadro 3, abaixo: 
Quadro 3 - Esforços internacionais para mapeamento das CGV e do comércio de valor adicionado.

\begin{tabular}{|c|c|c|c|c|}
\hline Projeto & Instituição & Dados & Países & Indústrias \\
\hline $\begin{array}{l}\text { UNCTAD-Eora } \\
\text { GVC Database }\end{array}$ & UNCTAD/Eora & $\begin{array}{l}\text { Matrizes Insumo- } \\
\text { Produto e Tabelas } \\
\text { Input-Output/ } \\
\text { Tabelas Input-Output } \\
\text { do Eurostat, IDE- } \\
\text { JETRO e OECD" }\end{array}$ & 187 & $\begin{array}{c}25-500 \\
\text { dependendo do } \\
\text { país }\end{array}$ \\
\hline $\begin{array}{l}\text { Inter-Country- } \\
\text { Input-Output } \\
\text { model (ICIO) }\end{array}$ & OECD/WTO & $\begin{array}{c}\text { Tabelas Input-Output } \\
\text { Nacionais }\end{array}$ & 40 & 18 \\
\hline $\begin{array}{c}\text { Asian } \\
\text { International } \\
\text { I-O tables }\end{array}$ & $\begin{array}{l}\text { Institute of } \\
\text { Developing } \\
\text { Economies } \\
\text { (IDE-JETRO) }\end{array}$ & $\begin{array}{l}\text { Contas Nacionais e } \\
\text { Pesquisas Industriais }\end{array}$ & 10 & 76 \\
\hline $\begin{array}{l}\text { Global Trade } \\
\text { Analysis } \\
\text { Project } \\
\text { (GTAP) }\end{array}$ & $\begin{array}{l}\text { Purdue } \\
\text { University }\end{array}$ & $\begin{array}{l}\text { Contribuições } \\
\text { Individuais de } \\
\text { pesquisadores e } \\
\text { organizações }\end{array}$ & 129 & 57 \\
\hline $\begin{array}{l}\text { World Input- } \\
\text { Output } \\
\text { Database } \\
\text { (WIOD) }\end{array}$ & $\begin{array}{c}\text { Consórcio de } \\
11 \text { instituições } \\
\text { patrocinadas } \\
\text { pela UE }\end{array}$ & $\begin{array}{c}\text { Matrizes } \\
\text { Insumo-Produto }\end{array}$ & 40 & 35 \\
\hline
\end{tabular}

Fonte: Elaboração própria, a partir dos dados de UNCTAD (2013).

A despeito do avanço em diversas frentes da agenda de pesquisa de GVCs nos últimos anos, ganha destaque o incremento das pesquisas e análises relativas às estratégias de upgrading econômico colocadas em prática tanto por empresas quanto por países em desenvolvimento. Isso ocorre, principalmente, pelo fato do aumento significativo da participação desses países no comércio global medido em termos de valor adicionado, que saltou de $20 \%$ em 1990 para $40 \%$ em 2013 (UNCTAD, 2013).

Por conta de uma inserção qualificada nas CGV estar diretamente atrelada às vantagens comparativas específicas das quais cada país dispõe, políticas industriais bem desenhadas podem, ao longo tempo, aumentar o nível de intensidade tecnológica empregado no parque industrial de um determinado país. O aumento da participação em processos de alto valor agregado em termos de comércio de bens e serviços tende, dessa forma, a aperfeiçoar a 
produtividade das empresas e melhorar os níveis de renda e emprego em âmbito nacional (NONNENBERG, 2014; REIS; ALMEIDA, 2014). Assim, políticas industriais e de comércio exterior passaram a atuar, sobretudo em países em processo de industrialização, como indutores de competitividade e desenvolvimento econômico em universo produtivo cada vez dinâmico:

Industrial policies play a positive role when they are designed on the basis of revealed comparative advantage, prioritize the removal of distortions, and are deployed within the ambit of the traditional government role, such as infrastructure or education investments that favor a sector or task of interest. More intrusive interventions, such as providing information and coordination services that promote a particular cluster, should be small and continuously evaluated. In considering industrial policies, it is vital that countries understand the full extent - downstream and upstream — of the GVCs that are critical to their economy. This knowledge is needed to identify what is most important so that they situate their operations on the GVC, and then design policies to foster innovation in order to move up the value chain. (STEPHENSON, 2013, p. 1).

Estudos preliminares já indicam os principais desafios encontrados por algumas indústrias no que se refere à adição de valor na produção e exportação. Por exemplo, em estudo específico para alguns setores produtivos brasileiros (aeronáutico, eletrônicos e dispositivos médicos), Sturgeon et al. (2014) elucidaram a complexidade e a instabilidade da política industrial do país, que resulta em falta de planejamento adequado à produção, sobretudo no longo prazo. Ademais, os autores destacaram que, de maneira geral, todos os setores devem buscar o aperfeiçoamento da mão de obra existente, incrementar a cadeia de abastecimento e logística e garantir altos níveis de investimento em pesquisa e desenvolvimento - todos problemas típicos de um país em desenvolvimento:

The challenge of economic upgrading in GVCs is to identify the conditions under which developing and developed countries and firms can 'climb the value chain' from basic assembly activities using low-cost and unskilled labor to more advanced forms of 'full package' supply and integrated manufacturing. However, increasingly many of the highest value activities are located in pre- and post-production manufacturing services, which challenge host countries to develop appropriate workforce development strategies to supply these services locally. (GEREFFI; FERNANDEZ-STARK, 2016, p. 13).

A despeito dos diferentes desafios enfrentados pelos PEDs em termos de agregação de valor em sua produção interna e, consequentemente, em suas exportações, a UNCTAD destaca que não há um padrão definido para a participação desses países nas CGV: "the different outcomes in each of the combination of GVC integration and domestic value added suggest that 
there may be a set of distinct 'GVC development paths' or evolutionary lines in countries' patterns of participation in GVCs" (UNCTAD, 2013, p. 21). Em que pese se tratar de uma simplificação da realidade, algo salientado pela própria organização, o modelo de linhas evolucionárias de participação destaca seis tipos diferentes de possibilidade de inserção dos PEDs em CGV, quais sejam (UNCTAD, 2013a):

a) Engajamento: neste modelo, há uma espécie de incremento, por parte dos PEDs, das importações de bens intermediários, componentes e serviços, bem como das exportações de bens processados. De acordo com a UNCTAD, esse padrão geralmente coincide com um aumento da presença de investimento estrangeiro direto e de empresas transnacionais nos PEDs;

b) Preparação para as CGV: alguns PEDs experimentam o fato de as exportações se tornarem predominante de setores e indústrias como capacidade produtiva doméstica (com limitada necessidade de conteúdo importado). O aumento de IED auxilia na produção de bens e serviços intermediários, provocando substituição das importações;

c) Upgrading nas CGV: alguns PEDs com um nível significativo de integração nas CGV tiveram sucesso no incremento das exportações de bens e serviços de alto valor agregado ou na captura de maior parcela das cadeias de valor. Esses padrões de upgrading geralmente estão relacionados ao aumento da entrada no IED no país, geralmente em setores de alta tecnologia;

d) Competindo nas CGV: alguns PEDs conseguem competir com sucesso em esferas de alto valor agregado por meio da capacidade produtiva doméstica em suas exportações. Pode-se perceber, geralmente, investimentos estrangeiros com o objetivo de integrar operadores domésticos em redes internacionais de produção, geralmente por meio de Fusões e Aquisições;

e) Convertendo CGV: alguns PEDs observam a composição de suas exportações sofrer alterações e suas indústrias passarem a requerer um aumento do conteúdo importado. Geralmente, esse processo coincide com um aumento do IED em indústrias de processamento.

Como já visto até aqui, o upgrading econômico é uma via de mão dupla. Enquanto os países buscam lançar mão de ações específicas que garantam à empresa um ambiente de 
negócio propício à sua atividade produtiva, estas se voltam para a contínua análise de suas funções em diferentes partes do mundo, obtendo, de cada lugar, as principais vantagens de localização que tenham impacto direto sobre suas operações. Essa dinâmica de captura de valor com base em distintas atividades nas CGV passou a apresentar determinados padrões ao longo do tempo, exemplificados pela figura 6 abaixo. De acordo com a Smile Curve, as atividades de maior valor agregado estariam justamente à montante ou à jusante da cadeia, sendo que a atividade produtiva atualmente agregaria menos valor à composição de um determinado bem quando comparada a outras atividades como P\&D e Marketing. Tal modelo explica de maneira satisfatória os fluxos de investimentos entre PDs e PEDs nas últimas décadas.

Figura 6 - Smile curve das atividades de valor agregado em CGV.

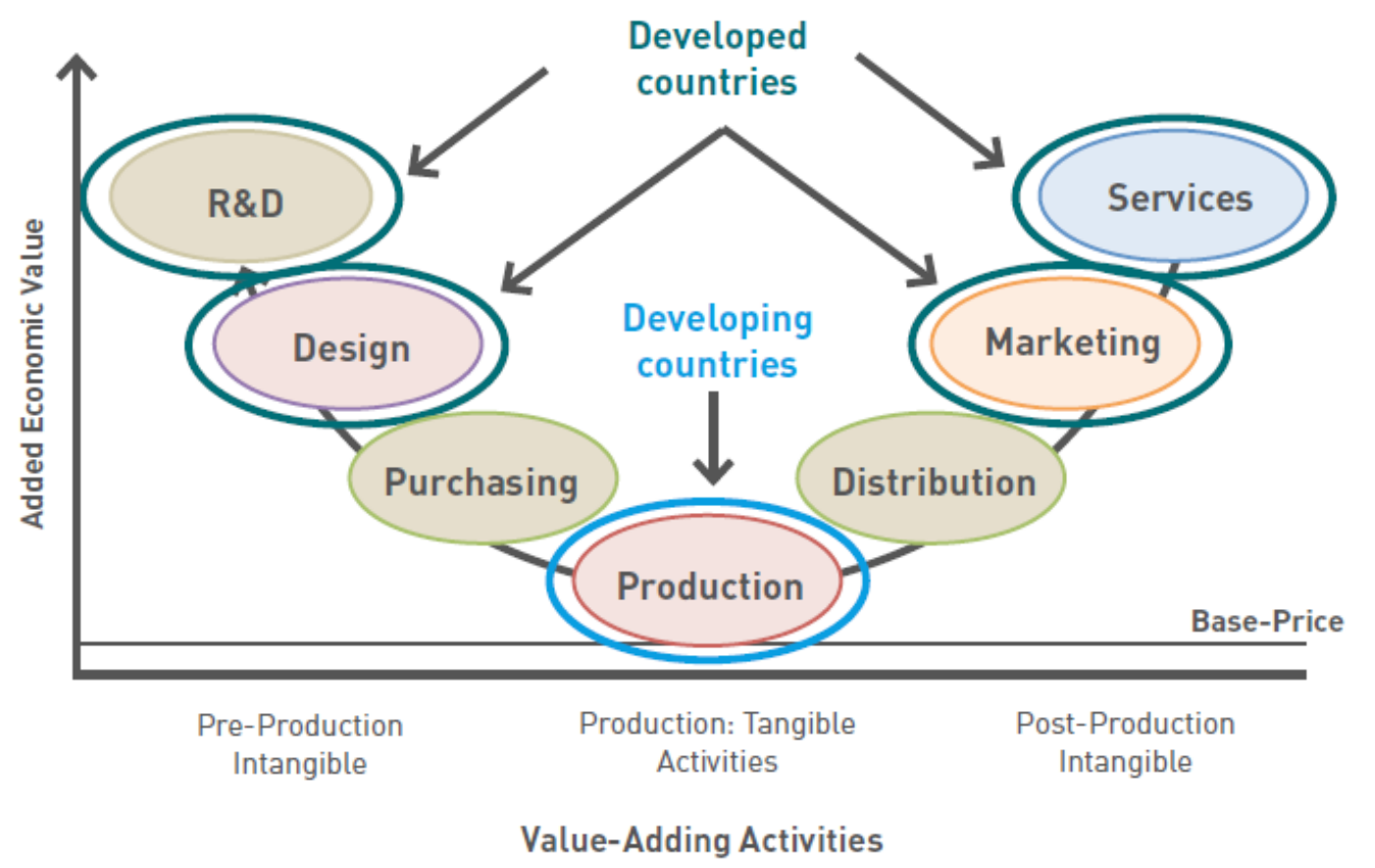

Fonte: BALDWIN et al., 2014; GEREFFI, FERNANDEZ-STARK, 2016, p. 14.

Diante dos pontos ora expostos, é importante ter presente que, mesmo que o upgrading seja um objetivo do PED, alcançá-lo dependente em grande parte das empresas ou clusters que operam em seu território, sendo que dois pontos são cruciais: a qualidade da conexão que os setores têm com as cadeias de valor; e as perspectivas das empresas em melhorar sua posição no âmbito de uma CGV (MOTTA VEIGA; RIOS, 2012). No entanto, essas dinâmicas somente encontram espaço para seu desenvolvimento quando o país em questão também busca 
implementar políticas que busquem viabilizar, em parte, a execução de estratégias de upgrading:

Os determinantes da posição - e, portanto, da capacidade de upgrade - de
uma firma - e de um país - nas CGVs são múltiplos e abrangem desde suas
vantagens comparativas - em sentido bastante amplo - até as políticas
públicas a que estão submetidos, além das características da própria cadeia,
como sua estrutura de governança. Diante disto, as políticas públicas têm
papel fundamental Fragmentação Internacional da Produção e Cadeias
Globais de Valor para que países em desenvolvimento possam beneficiar-se
da inserção em CGVs. Não se trata apenas de políticas comerciais e de
investimento estrangeiro, ainda que a liberalização e a abertura ao exterior
sejam condições necessárias para participar das redes de produção
fragmentada - embora não suficiente, visto que a participação não apenas
depende do interesse de um ou outro país, mas sobretudo da estratégia das
firmas-líderes e de outros agentes-chave na cadeia. (CARNEIRO, 2012).

Independentemente do modelo que obtenha ênfase, quando da análise do upgrading econômico dos PEDs, é importante notar que uma inserção qualificada em CGV decorre, necessariamente, de uma estratégia integrada de atuação que congregue, além de políticas industriais eficientes, avanços em infraestrutura, política comercial, desenvolvimento de mão de obra qualificada, inovação, parcerias público-privadas, incremento dos padrões produtivos (públicos e privados) entre outros fatores que garantam estabilidade aos atuais e potenciais investidores e dinamização do fluxo comercial com parceiros estratégicos selecionados.

\subsection{Considerações finais}

Como se pode perceber, o século XX foi marcado por profundas transformações econômicas impulsionadas pelo incremento dos fluxos comerciais de bens e serviços, bem como pelo pela expansão dos montantes de investimento direto, tanto por parte dos países desenvolvidos quanto aqueles em processo de desenvolvimento. Tais transformações viabilizaram o surgimento de distintos processos de internacionalização das empresas multinacionais, que passaram a operar, em escala, nas mais diversas localidades do globo.

Concomitantemente a esse processo, surgem modelos teóricos ligados à área de estudos de negócios internacionais com o objetivo precípuo de compreender as dinâmicas ligadas ao processo de internacionalização da economia global. Ao analisar-se mais especificamente o modelo de CGV, percebe-se que tal vertente dispõe de uma complexa evolução ao longo da segunda metade do século XX. 
Em suma, o modelo parte de uma perspectiva crítica do Sistema Internacional, ao longo da década de 1970, e chega aos dias atuais com um arcabouço renovado e dotado de uma leitura holística e integrada dos fatos relativos à dinâmica da fragmentação produtiva, por meio dos frameworks de GCCs e, em seguida, CGV. Ao se analisarem as opções de policy para os PEDs que desejam incrementar sua participação nas CGV, ganha espaço a necessidade de implementação de processos de upgrading, em suas diferentes vertentes, que tenham essa transformação para chegar.

Dessa forma, países que almejam incrementar sua participação nas CGV têm buscado criar políticas públicas que possibilitem ao seu conjunto de empresas operar em um ambiente previsível e dinâmico. Da mesma forma, as empresas têm buscado diversificar suas operações produtivas em diferentes países, com vistas a aproveitar-se das vantagens competitivas de diferentes nações, bem como mitigar riscos de operações importantes para o business. Nesse sentido, cabe aos PEDs implementar mecanismos propícios ao aumento da inserção de suas empresas nas mais diversas CGV, sobretudo por meio da melhoria do ambiente interno de negócios, bem como do incremento de ações em infraestrutura que permitam a ampliação e diversificação de suas operações.

As novas fronteiras analíticas de aplicação do modelo de CGV indicam uma agenda voltada, sobretudo, para a implementação de estratégias de upgrading, em seus mais diversos níveis, com foco na agregação de valor em produtos, processos, serviços, entre outros, por parte de empresas e de países que buscam uma inserção qualificada em um determinado setor. Especificamente no caso brasileiro, o modelo de análise de CGV se faz relevante, uma vez que possibilita uma análise integrada de como o setor empresarial opera nos diversos setores da economia nacional, permitindo o mapeamento atual do nível de inserção do país em determinadas cadeias, bem como eventuais estratégias para o incremento do valor adicionado em setores relevantes para o crescimento econômico em nível nacional.

No caso da CGV avícola, destacam-se as diversas estratégias implementadas pelas multinacionais do setor, bem como por alguns países, na incessante busca pelo aumento da produtividade, diferenciação e capilaridade no acesso a novos mercados, fatores que fizeram da proteína avícola uma das mais consumidas no mundo ao longo das últimas décadas. 


\section{Análise da Cadeia Global de Valor do Setor Avícola}

O presente capítulo tem como objetivo analisar os principais aspectos e dinâmicas da cadeia global de valor (CGV) do setor avícola. Para tanto, utiliza-se como base metodológica, o modelo teórico de CGV (GEREFFI; FERNANDEZ-STARK, 2012, 2016). Em suma, procura-se compreender as relações econômicas, produtivas, comerciais, ambientais, concorrenciais, entre outras, presentes nessa cadeia, de modo a mapear suas particularidades em termos produtivos e mercadológicos, bem como o grau de inserção dos principais países que nela operam. Antes do mapeamento em si, apresenta-se um panorama dos principais aspectos socioeconômicos da cadeia avícola em nível mundial, bem como as principais tendências relativas à produção e comercialização da carne de frango nos últimos anos.

\subsection{Evolução da cadeia global de valor do setor avícola: principais aspectos}

A avicultura de corte é o setor de proteína animal com maior dinamismo e integração, além de possuir rápido ciclo produtivo. Os avanços em Pesquisa, Desenvolvimento e Inovação (P\&D I), aliados às características naturais e de mão de obra de um determinado local, ao longo das últimas décadas, geraram grandes produtores de proteína avícola, responsáveis pela ampla escala de produção e abastecimento mundial, como nos casos dos Estados Unidos, Brasil, China e União Europeia.

De maneira geral, há uma série de recursos naturais fundamentais à produção avícola, dentre os quais se destacam a disponibilidade de água, terra, energia, clima favorável e produção e/ou disponibilidade de grãos, sobretudo milho, cerca de $70 \%$ da composição da ração e responsável por 70\% a 80\% do custo total do frango na granja (ABPA, 2018). A utilização de terra e água, bem como a produção de grãos e a composição de um estoque satisfatório de material genético para produção de proteína são tratadas com um dos principais desafios globais para alimentar a população de 9,7 bilhões de pessoas estimada pela ONU para o ano de 2050, das quais $86 \%$ serão de países em desenvolvimento ou de menor desenvolvimento relativo (UNDESA, 2019).

De acordo com as projeções da Organisation for Economic Co-operation and Development (OECD) e da Food and Agriculture Organization of the United Nations (FAO), publicadas em 2019 no relatório conjunto OECD - FAO Agricultural Outlook 2019-2028, até o final dessa década, próximo a 2030, a produção global de carne deverá crescer $13 \%$ na 
comparação com o período base (2016-2018), atingindo cerca de 340 milhões de toneladas, sendo que os países em desenvolvimento serão os grandes indutores dessa expansão produtiva.

Figura 7 - Crescimento da Produção Mundial de Carnes por região e tipo — 2028 vs 20162018.

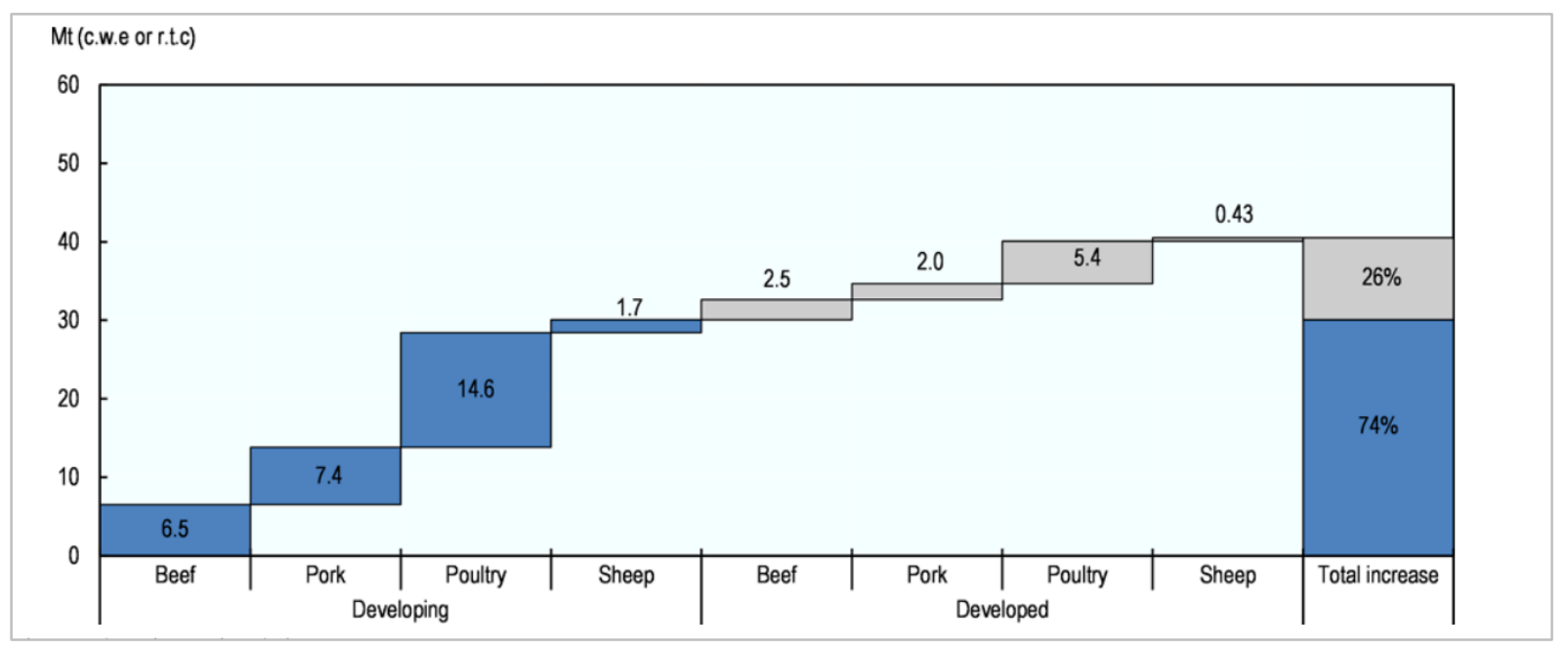

Fonte: FAO, 2019.

Em linhas gerais, o uso de processos de produção baseados em sistemas de alimentação intensiva em grãos será um fator determinante para o incremento do peso da carcaça do animal em um menor tempo de produção, o que favorece a expansão de carne de frango, devido à elevada composição de grãos na ração das aves. O relatório destaca que a carne de frango será o principal impulsionador do crescimento da produção de proteína animal ao longo do período, sobretudo por conta da combinação de três fatores: diminuição dos custos de produção, elevados níveis de conversão alimentar (Kg ração / Kg carne produzida) e preços relativamente menores do que outras proteínas animais, como a bovina e a suína. 
Figura 8 - Países com maior participação na quantidade adicional de carne a ser produzida Projeção OECD-FAO 2028 vs 2016-2018.

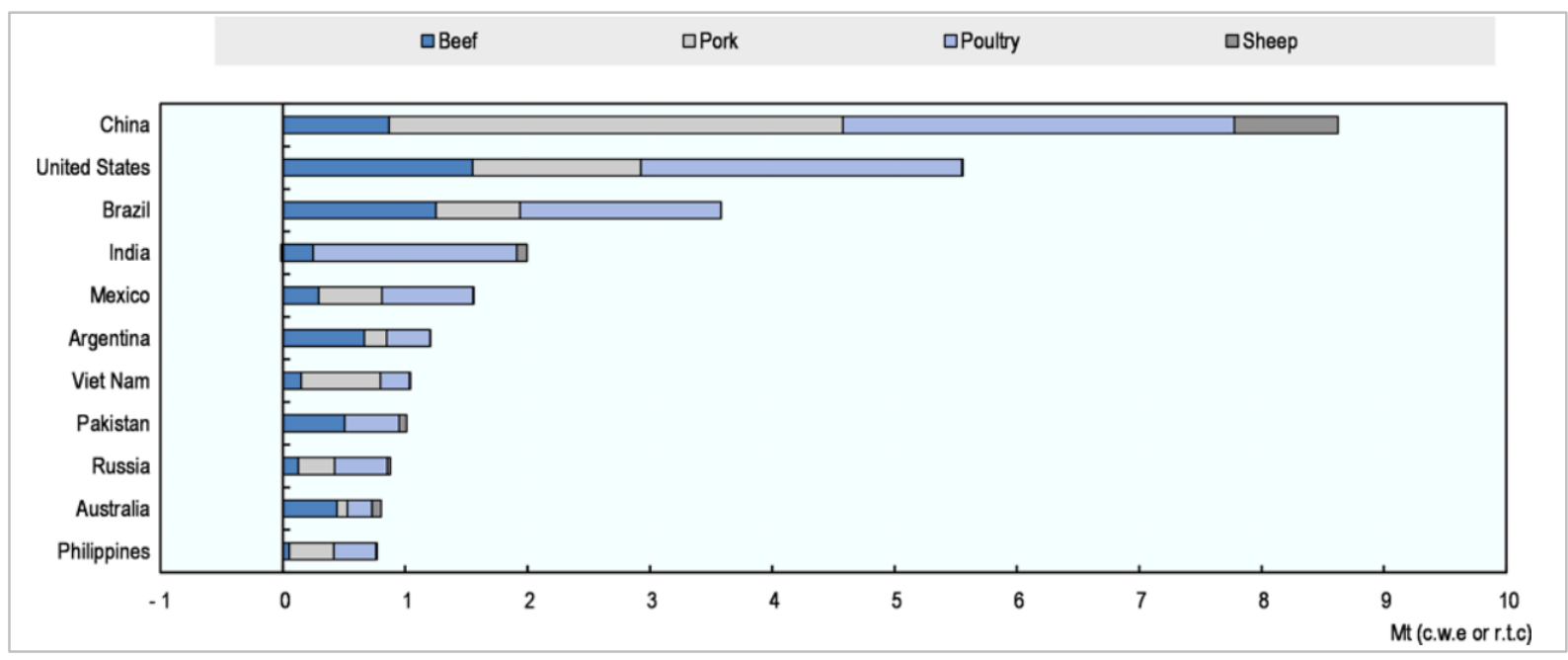

Fonte: OECD-FAO (2019).

Em suma, as projeções da OECD-FAO para a próxima década revelam todo potencial ainda a ser explorado de um setor que tem buscado aperfeiçoar-se constantemente através da implementação de um conjunto integrado e coordenado de soluções que vão do campo à mesa do consumidor. As etapas produtivas da cadeia avícola estão, em grande parte, relacionadas ao desenvolvimento de novas tecnologias que viabilizaram, ao longo dos anos, o incremento produtivo em escala global, com qualidade, eficiência e diversificação.

Entre os grandes produtores mundiais, Brasil e Estados Unidos, a criação de frangos voltados à produção de carne evoluiu para modelos intensivos, onde o potencial genético dos frangos é responsável por grande parte dos ganhos de produtividade — aumento de peso, conversão alimentar, rendimento de carcaça e redução da idade de abate. Esses ganhos ocorreram, especialmente, pelo constante melhoramento genético de aves, pela inserção de novas técnicas de manejo e também de produtos voltados à saúde animal e, por fim, pelo desenvolvimento e aprimoramento da nutrição animal. Esses fatores combinados possibilitaram ganhos expressivos em termos de produtividade, como mostra a Figura 8. 
Figura 8 - Evolução dos principais indicadores na criação de frango.

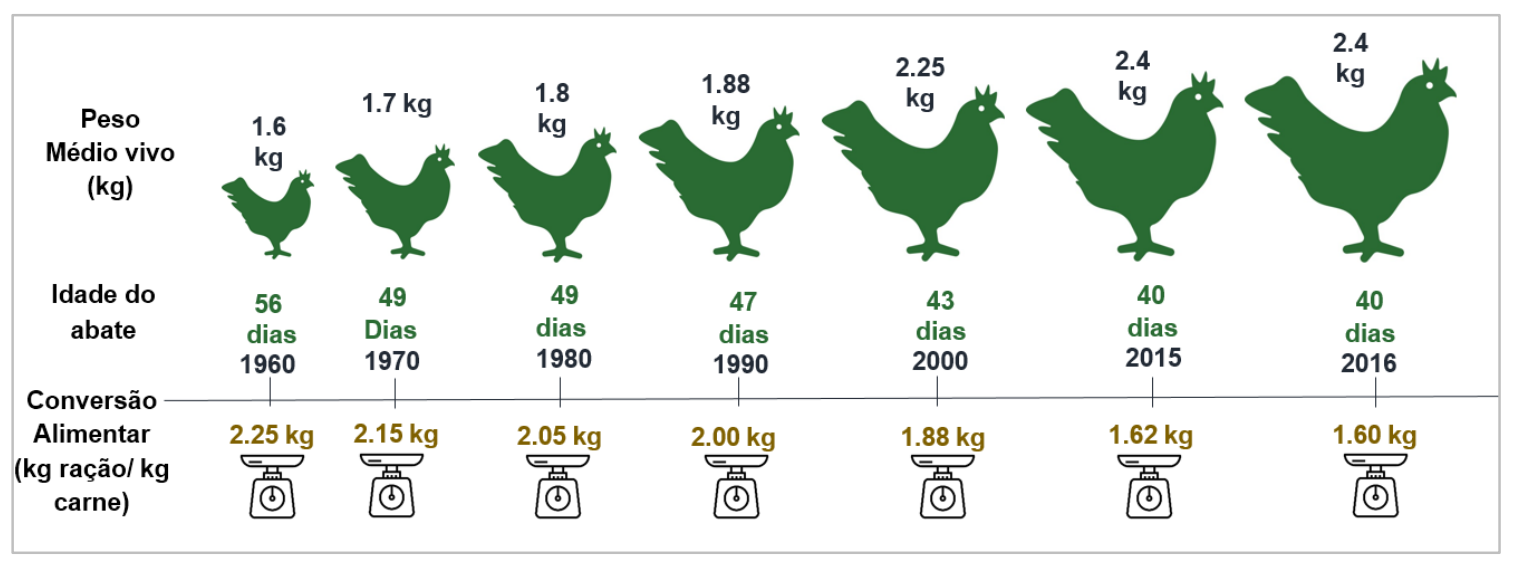

Fonte: JESUS JUNIOR, 2007; ABPA, 2018.

A análise integrada acerca da evolução do setor, bem como de sua complexidade, decorre da compreensão bem específica de cada fase do processo produtivo. Como se pode ver na Figura 9, o processo de produção de carne avícola tem início no alojamento de bisavós, seguida pela criação de avós e matrizes, passando pelo alojamento e abate de frangos e o processamento de produtos cárneos até chegar ao consumidor final. Em suma, trata-se de um modelo de negócio extremamente verticalizado e com crescente necessidade de investimento e aperfeiçoamento operacional em diversos eixos da cadeia.

Figura 9 - Ciclo produtivo da cadeia avícola.

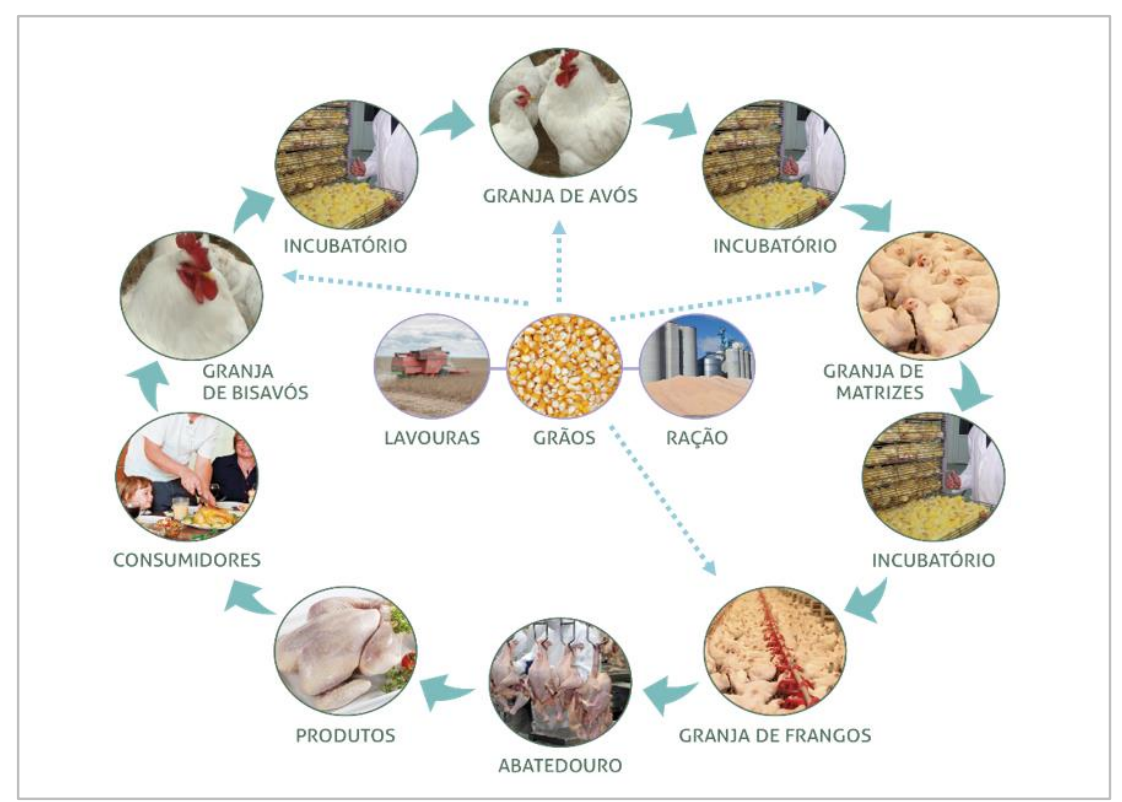

Fonte: ABPA, 2018. 
De maneira geral, a criação de bisavós, avós e do frango de corte é realizada por produtores rurais, que podem ser independentes ou vinculados ao sistema integrado de produção. O sistema integrado, originário dos Estados Unidos, consiste em uma parceria entre o produtor rural e a agroindústria, com intuito de otimizar a produção e o controle sanitário, compartilhar os riscos e custos produtivos, gerando maior controle e facilitando a rastreabilidade de produtos. Nesse sistema, as agroindústrias fornecem a ração, vacinas, controle veterinário e os animais, enquanto o produtor fornece a infraestrutura dos aviários e a mão de obra (WAKER; NÄÄS; 2018). O modelo é amplamente utilizado no Brasil, com representatividade de aproximadamente $90 \%$ da produção, e consiste em uma das vantagens competitivas do setor brasileiro de avicultura, por conta da ampla especialização dos produtores, que buscam, permanentemente, atuar em conjunto com as empresas do setor em busca de maior produtividade e excelência quanto aos padrões de qualidade exigidos nacional e internacionalmente (ABPA, 2018).

O ciclo de produção avícola tem sua continuidade nos abatedouros, onde a carne é processada e, posteriormente, distribuída aos atacadistas, varejistas, canais de food service, entre outros, antes de ser consumida pelo cliente final. O processo produtivo é, geralmente, dotado de várias etapas que vão desde o transporte da granja e a plataforma de recepção até o resfriamento e processamento final da carne. (FIGUEIREDO; SCHIMIDT; AVILA; JAENISCH; PAIVA, 2007; EMBRAPA, 2019).

As etapas relativas ao processamento da carne podem variar entre países, de acordo com o nível de automação, a utilização de diferentes métodos de insensibilização, e de fiscalização (autocertificação ou fiscalização in loco por um agente governamental, caso do Brasil). Tratase de uma etapa fundamental para o modelo de negócio das empresas do setor, uma vez que é onde se obtém o maior nível de produtividade, desempenho, diferenciação e qualidade do produto final (BITTENCOURT, 2017).

A despeito do desempenho produtivo e comercial extremamente satisfatório nas últimas décadas, as empresas do setor e os países produtores de proteína avícola dispõem de importantes desafios para a manutenção e o eventual incremento do volume de carne a ser disponibilizado nos próximos anos (COTTO, 2018). Entre os desafios, encontram-se as questões ambientais, ações de bem-estar animal e biosseguridade, que passaram a ganhar grande destaque, assim como novas técnicas de produção orgânica e slow growth (crescimento lento) (SHERRARD, 2019a). 
As questões ambientais sempre foram importantes para a produção de alimentos, uma vez que a atividade agrícola sustentável demanda uma série de ações que visam ao aumento da produtividade, porém com a utilização responsável de recursos naturais. Nesse sentido, um debate que tem crescido no setor de proteína animal diz respeito às emissões de gases de efeito estufa (GEEs) que a atividade gera, tanto por conta do crescente interesse por parte dos consumidores, quanto pelos compromissos assumidos por países produtores no Acordo de Paris, assinado em 2015, no âmbito da Convenção-Quadro das Nações Unidas sobre as Mudanças do Clima (UNFCCC). Por ser uma atividade que demanda uma série de ações relacionadas diretamente ao uso da água e do solo bem como ao tratamento de resíduos, a redução das emissões de gases de efeito estufa certamente é um ponto de atenção aos países produtores de proteína animal.

Figura 10 - Estimativas de emissões de GEEs por espécie.

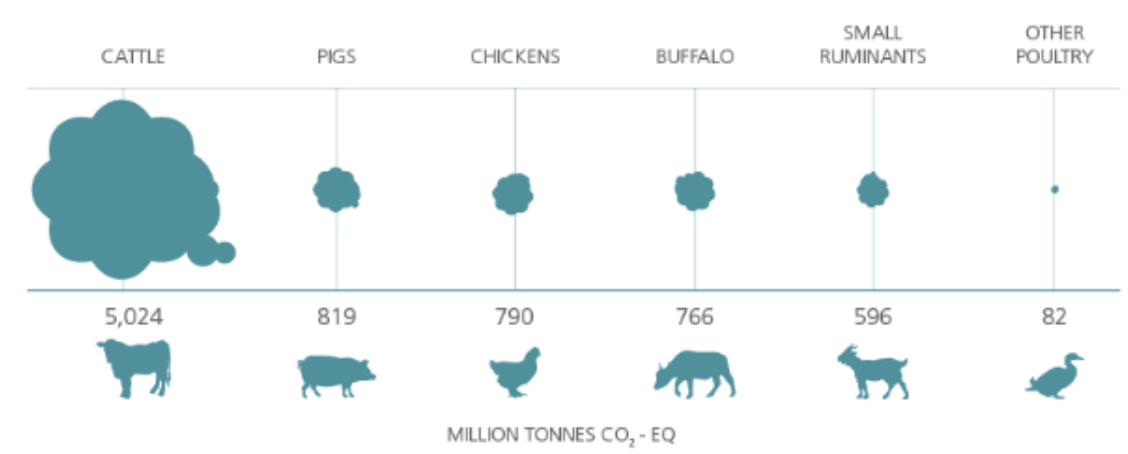

Fonte: GLOBAL LIVESTOCK ENVIRONMENTAL ASSESSMENT MODEL - FAO, 2019.

De acordo com o modelo Global Livestock Environmental Assessment Model (GLEAM), da FAO, a produção avícola é responsável cerca de $10 \%$ das emissões globais na pecuária, com 790 mil toneladas de CO2-EQ, como mostra a Figura 10. Grande parte das emissões de GEEs na pecuária corresponde à produção de carne bovina ou de leite, atividades que, juntas, emitem 5 milhões de toneladas de CO2-EQ, e que têm nos continentes americano, europeu e asiático seus principais vetores de emissão, conforme a Figura 11. 
Figura 11 - Estimativas de emissões regionais de GEEs e seu perfil por produto.

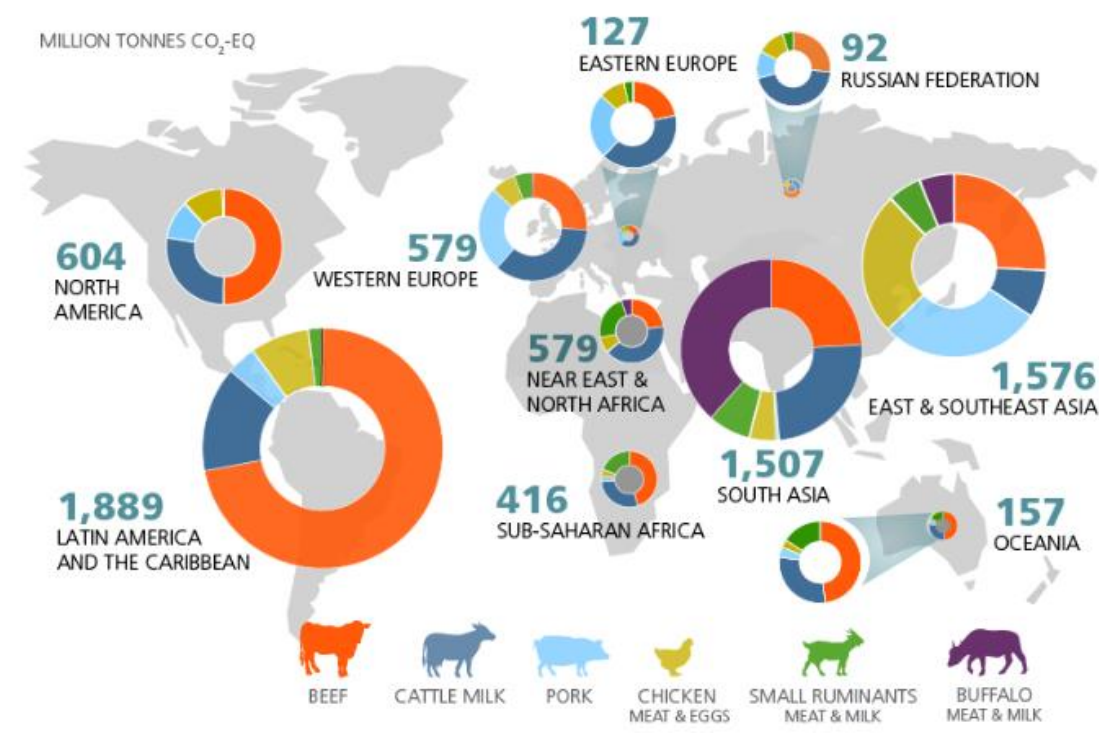

Fonte: GLOBAL LIVESTOCK ENVIRONMENTAL ASSESSMENT MODEL - FAO, 2019.

Segundo a FAO, três tipos de iniciativas são fundamentais para mitigar as emissões de GEEs provocadas pela pecuária: (i) o aumento da produtividade do setor por meio de ações ligadas à nutrição animal, reprodução e melhoria genética; (ii) o gerenciamento de pastagens com vistas ao incremento de sequestro de carbono; e (iii) a efetiva integração da pecuária à bioeconomia circular, com ações ligadas ao reaproveitamento de resíduos orgânicos, à produção de fertilizantes naturais, reciclagem e geração de energia (FAO, 2017).

A dispersão geográfica da produção e comercialização de animais, o crescimento e modernização da indústria avícola, além do incremento da população e, consequentemente, da demanda por alimentos do comércio, levou a questão de biosseguridade à lista de preocupações globais. Em suma, esse movimento teve um efeito direto na intensificação da produção de proteína animal avícola e suinícola, a qual passou a trabalhar com alojamentos mais densos e ciclos de menor duração, gerando a necessidade de um acompanhamento mais específico e permanente junto à saúde dos plantéis (PINHEIRO, 2014). De acordo com a Organização Mundial de Saúde Animal (OIE, em inglês), a biosseguridade corresponde a uma "série de medidas gerenciais e físicas com a finalidade de reduzir os riscos de introdução, estabelecimento ou ampliação de doenças, infecções e infestações de, para ou entre a população animal" (OIE, 2018a). 
No caso da indústria avícola, os casos graves de influenza aviária, que se espalharam pelo mundo em 2006, 2015 e 2017, exemplificam a importância da situação global de doenças animais, as quais têm um impacto direto sobre a produção e comercialização de carne de aves. Todos os grandes países produtores e/ou consumidores de carne de aves compartilham da preocupação com doenças que podem afetar a saúde pública e a produção de alimentos. Isso, pois, com a ocorrência da enfermidade, geralmente o país passa a ter seu produto suspenso à comercialização no mercado internacional, gerando prejuízos para a cadeia como um todo. Entre 2005 e 2012, 65 países registraram 6.345 surtos da doença. Entre 2013 e 2018, foram 68 países atingidos pela enfermidade, com 7.122 surtos (OIE, 2018b).

Segundo a OIE, os métodos existentes de prevenção e contenção de doenças, regulamentos, diretrizes e normas estão sendo disseminados nos níveis nacional e internacional para melhorar a capacidade dos países de prevenir, gerenciar e se recuperar da introdução natural, acidental ou deliberada de doenças animais. Em suma, os serviços veterinários dos países são orientados a desenvolver protocolos nos níveis: (i) local, em fazendas, integrados, etc.; (ii) regional, durante o transporte de animais, em abatedouros e lugares de comercialização; e (iii) nacional, sempre com o intuito de proteger os animais de uma eventual introdução ou ampliação de doenças a eles relacionados (BELLINI, 2018).

Figura 12 - Países e territórios afetados ao menos uma vez por surtos de influenza aviária em aves domésticas entre 2013 e 2018.

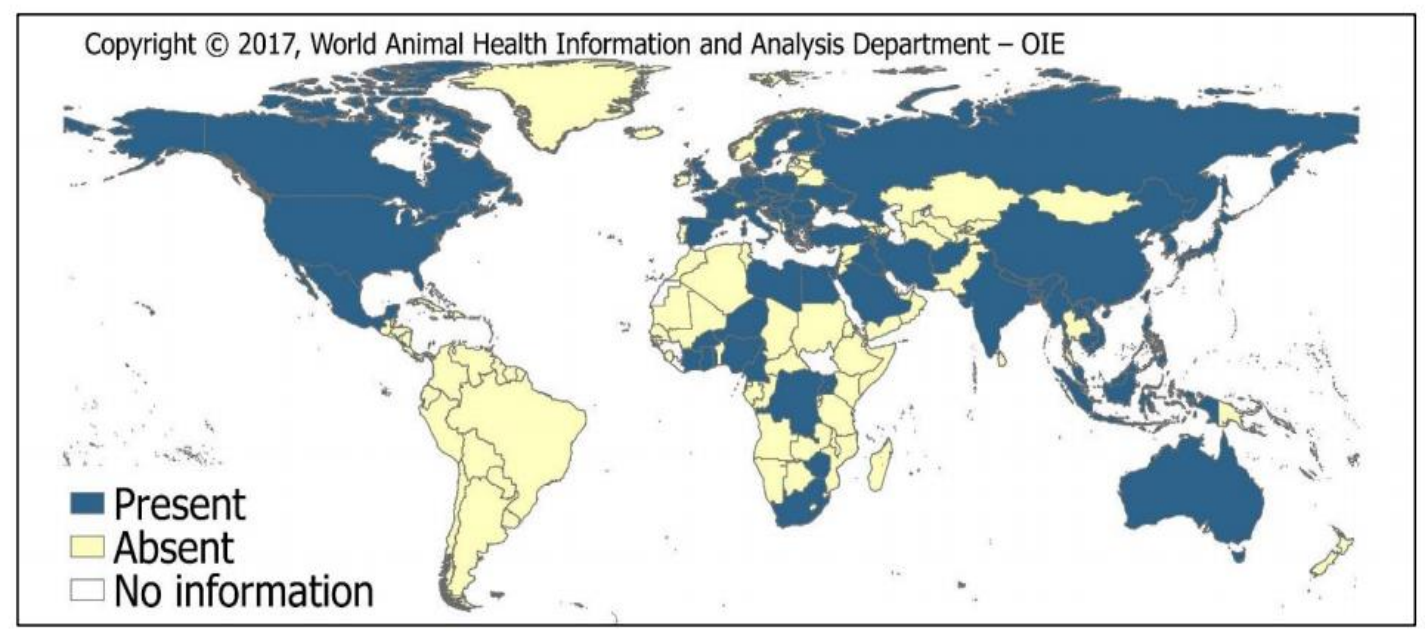

Fonte: OIE, 2018(b).

A Organização ainda dispõe de um importante programa de monitoramento e avaliação do desempenho e conformidade dos serviços veterinários com os padrões internacionais da 
organização, o Performance of Veterinary Services (PVS). De acordo com a última auditoria disponível do PVS realizada no Brasil, em 2014, por veterinários acreditados pela OIE, o país tem dois grandes destaques ligados à área de biosseguridade: o PNCRC (Programa Nacional de Controle de Resíduos e Contaminantes) destinado a produtos de origem animal e vegetal e o PNSA (Programa Nacional de Sanidade Avícola), destinado à vigilância epidemiológica e sanitária das enfermidades avícolas, que contempla a compartimentação (BITTENCOURT, 2017; OIE, 2017). Em suma, o país goza de um status sanitário diferenciado, fruto de anos de trabalho e constante aperfeiçoamento de todos os elos da cadeia produtiva, o que faz com que o país nunca tenha registrado um caso de influenza aviária.

Uma das principais tendências relativas à comercialização do consumo de proteína animal, em algumas regiões do mundo, diz respeito ao papel preponderante que o consumidor passou a exercer em relação ao volume de informação demandada junto ao produto a ser consumido. Mais do que uma simples informação, os consumidores com maior poder aquisitivo que, geralmente, estão distribuídos em cidades da Europa, EUA, Canadá, Austrália e em alguns centros urbanos da Ásia, Oriente Médio e América Latina passaram a demandar um produto não somente dotado de qualidade, mas que, de alguma forma, sua produção respeitasse diferentes padrões de sustentabilidade e ética (VERISSIMO, 2017; HARPER, 2019). Dentre os temas mais importantes relativos à produção de proteína animal avícola, destacam-se o bemestar animal e os métodos de produção diferenciados como orgânico e slow growth.

O tema bem-estar animal é de suma importância para a cadeia produtiva da avicultura porque o incremento das técnicas de produção e manejo relacionadas a uma melhor condição de vida das aves foi, ao longo dos anos, fundamental para o incremento da disponibilidade de carne de aves em todo o mundo (NASS; 2008; COTTO, 2018).

Cientificamente, a análise acerca do bem-estar animal ganhou força nos últimos 60 anos, com a realização de pesquisas e elaboração de manuais, protocolos e, em última instância, legislações, sobretudo pautadas por universidades presentes no continente europeu. Inicialmente, o bem-estar estava relacionado à identificação do atendimento às necessidades básicas do animal, como alimento, água, espaço, conforto térmico, entre outros. Gradualmente, abre-se espaço para uma maior valorização aos estados mentais e emoções decorrentes, principalmente, da falta de acesso a esses fatores básicos essenciais. As emoções e estados mentais passaram, dessa forma, a ser um elemento central para a avaliação do bem-estar animal (MELLOR, 2012; CEBALLOS; SANT'ANNA, 2018). 
De acordo com o Código Sanitário para Animais Terrestres da OIE, o termo bem-estar animal designa o "estado físico e mental de um animal em relação às condições em que ele vive e morre" (Cap. 7.1; Art. 7.1.1). O documento destaca que um animal experimenta bemestar se ele estiver são, cômodo, bem alimentado, em segurança e não ter sensações desagradáveis como dor, medo ou desassossego, e se for capaz de expressar comportamentos importantes para seu estado de bem-estar físico e mental (OIE, 2018a).

A partir da evolução científica do tema, o conceito de bem-estar foi associado às cinco liberdades definidas pela Farm Animal Welfare Council durante a década de 1980: i) livre de sede, fome e má nutrição; ii) livre de dor, ferimentos e doenças; iii) livre de desconforto; iv) livre de medo e estresse; iv) livre para expressar seus comportamentos naturais (FAWC, 2009). A continuidade das pesquisas passou a apontar para a necessidade de que o bem-estar fosse expresso a partir da qualidade de vida dos animais, com base em suas experiências positivas e negativas.

Esse prisma de análise contribuiu para o chamado Modelo dos Cinco Domínios, proposto pelo renomado pesquisador e professor da área, David Mellor (2004). A partir desse modelo, as experiências positivas e negativas vividas pelos animais poderiam ser expressas dentro dos seguintes domínios:

(i) nutrição - provisão de água, alimento e nutrientes essenciais aos mesmos; (ii) ambiente - desafios ambientais aos quais os animais estão submetidos; (iii) saúde - doenças, lesões e o comprometimento funcional que estas podem acarretar; (iv) comportamento - possibilidade de expressarem comportamentos importantes para os animais; e (v) estados mentais - emoções e sentimentos positivos e negativos que o animal possa experimentar. (MELLOR 2004 apud CEBALLOS; SANT'ANNA, 2018, p. 6).

Em linhas gerais, os critérios de bem-estar nos sistemas de produção de frangos de corte estão relacionados à localização, saúde animal, biossegurança, temperatura, nutrição, densidade, qualidade do ar, transporte, cama, planos de emergência, entre outros. Como se pode ver posteriormente, a partir desses critérios, são desenhados regulamentos públicos e certificações privadas que deverão ser cumpridas pelas empresas do setor, com o intuito de que seus processos produtivos obtenham a devida conformidade com os padrões de bem-estar exigidos atualmente em diversos mercados (SOUZA, 2017).

Nos últimos anos, várias redes de alimentação têm implementado programas voltados à maior sustentabilidade de sua cadeia produtiva. O McDonald's, por exemplo, tem promovido diversas ações relativas ao desenvolvimento de uma cadeia fornecedora que cumpra com os 
padrões de sustentabilidade aqui discutidos. Em suma, a rede mundial de fast food tem como foco três eixos em sua política de sustentabilidade relativa à cadeia avícola: (i) o uso responsável de antibióticos; (ii) o bem-estar animal; e (iii) uma estratégia sustentável de ração para animais. A figura 13, a seguir, relata brevemente as ações tomadas pela rede nos últimos anos com esse intuito.

Figura 13 - Estratégias relativas à política de sustentabilidade do McDonald's.

\section{Chicken Sustainability}

We're on a journey to build a better McDonald's.

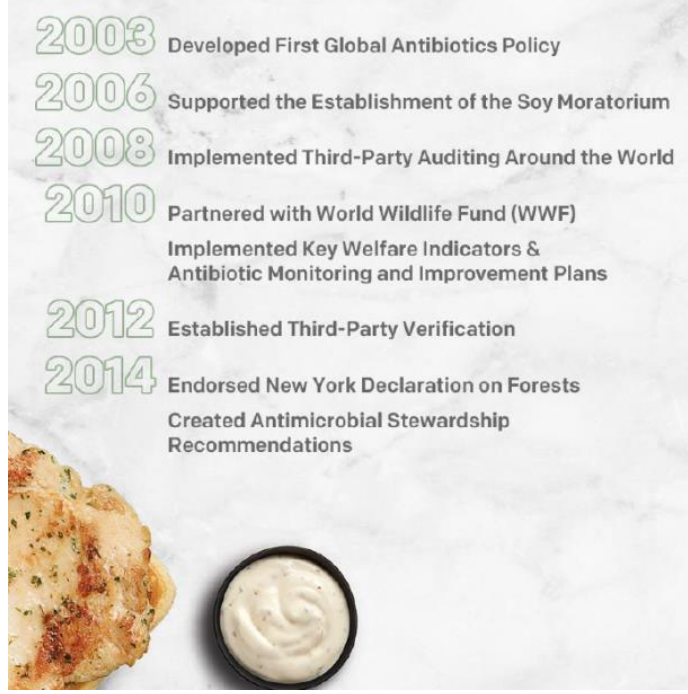

2010) Released the Global Vision for Antimicrobial Stewardship (VAS) in Food Animals

Formalized Cage-Free Sourcing Efforts

Committed to Eliminating Deforestation from our Global Supply Chains

Recognized for Collective Contribution to the Brazilian Soy Moratorium

Support Development of Alterative Protein Sources to Soy for Chicken Feed

Committed to Purchase Only Sustainably Certified Soy

Completed U.S. Antibiotics Chicken Commitment Supported Indefinite Extension of Brazilian Soy Moratorium

2)(0) 77 Refreshed VAS in Food Animals

Issued Antibiotics Use Policy for Broiler Chickens Outside the U.S.

Improving Key Welfare Outcomes Around the World

Fonte: HARPER, 2019.

Além do bem-estar, outros temas passaram a fazer parte da dinâmica de escolha e consumo da carne de aves por parte do cliente final, sobretudo nas regiões já citadas. Frango orgânico, biodinâmico, slow growth (crescimento lento), range free (criação sem o uso de galpões), antibiotic free (criados sem o uso de antibióticos), entre outros, são termos que passaram a estar presentes nas embalagens das mais diversas marcas mundo afora. $\mathrm{O}$ principal diferencial desses tipos de produto refere-se, sobretudo, aos métodos de produção implementados. As ações relativas à nutrição, manejo, mobilidade e densidade são, em grande parte, diferentes da chamada criação convencional.

As aves orgânicas, por exemplo, geralmente são criadas livres em todo o ciclo de vida (range free), em ambiente especialmente cuidado e a alimentação deve, necessariamente, ser de procedência orgânica — usualmente são utilizadas verduras, legumes, além de misturas balanceadas à base de milho, farelo de soja e complementos minerais. Não há o uso de 
antibióticos e outros promotores de crescimento. Em termos de sanidade, o manejo profilático dos sistemas orgânicos ocorre por meio de medicamentos fitoterápicos e/ou homeopáticos com vistas à prevenção de eventuais enfermidades que possam vir a ocorrer nos plantéis (AZEVEDO et al., 2016; TEIXEIRA, 2019).

Sobre este último tópico, é importante atentar para o fato de que uso de antimicrobianos como forma de prevenir e tratar enfermidades, bem como para a promoção de crescimento das aves, tem sido alvo de extensos debates pela comunidade internacional em nível público e privado nas últimas décadas. Isso decorre do fato de seu uso ter passado a estar constantemente associado ao fenômeno da resistência antimicrobiana em seres humanos, os quais, ao consumirem a proteína animal decorrente de sistemas convencionais de produção, também estariam, por consequência, ingerindo, em certa medida, uma variedade de compostos e moléculas utilizadas na criação do animal. Essa dinâmica estaria, por sua vez, relacionada ao crescimento das superbactérias, decorrente do uso indiscriminado de medicamentos antibacterianos (ANVISA, 2018). De acordo com Costa Leite (2013):

Independentemente do objetivo (terapêutico, profilático, metafilático ou intensificador) o uso de um antibiótico na produção pecuária estimula a seleção de anti biorresistências na população bacteriana, seja através da sobrevivência diferencial conferida por uma ou mais mutações espontâneas no cromossomo das bactérias, seja pela aquisição de material genético transferível, que codifica um determinado mecanismo funcional de anti biorresistência. (COSTA LEITE et al., 2013, p. 2355).

O uso de antimicrobianos na agropecuária foi fundamental para a manutenção da saúde dos plantéis e, consequentemente, para o incremento da produção e disponibilidade de carne ao longo do último século. A inserção de diversas moléculas de antimicrobianos na avicultura de corte promove a melhoria da eficiência alimentar, o bloqueio dos processos microbiológicos ligados à deterioração da ração, a prevenção de doenças infecciosas ou parasitárias, a diminuição da mortalidade, entre outros. Os antibióticos, um tipo de antimicrobiano, por serem compostos químicos que inibem o crescimento de outros micro-organismos, foram essenciais para combater as diversas infecções inerentes à atividade agropecuária (PEREIRA, 2009; BOECKEL et al., 2015).

Em linhas gerais, há quatro abordagens terapêuticas para o uso desses produtos: (i) promoção de crescimento: uso de antimicrobianos orais de baixa absorção intestinal, em baixas dosagens e por longos períodos, tendo como função modular a flora intestinal, resultando 
em ganhos de desempenho (conversão alimentar e ganho de peso diário); (ii) profilático: previne de forma individual ou grupal antes de a doença ocorrer; (iii) metafilático: tratamento dos animais em risco, prevenindo de forma grupal a disseminação do agente infeccioso assim que alguns animais adoecem; e (iv) terapêutico: é o tratamento individual ou grupal dos animais doentes sendo utilizados via injetável ou oral (ABCS; MAPA; EMBRAPA, 2011; WHO; 2017).

A regulamentação acerca do uso dessas moléculas ocorre por meio de legislações internacionais e nacionais, sendo a principal delas o estabelecimento dos Limites Máximos de Resíduos (LMRs) de medicamentos veterinários, processo coordenado pelo Codex Alimentarius, que consiste no estabelecimento de limites relativos à concentração máxima de resíduos permitida em um produto alimentício obtido de um animal em que se tenha ministrado um medicamento veterinário. Os países, dessa forma, devem elaborar programas que visem à efetiva fiscalização da aplicação desses medicamentos, tendo por base os limites estabelecidos pelo Codex (CODEX, 2018; ANVISA, 2018).

Figura 14 - Consumo global de antimicrobianos na agropecuária mundial (M1/10Km2 pixels) em 2010.

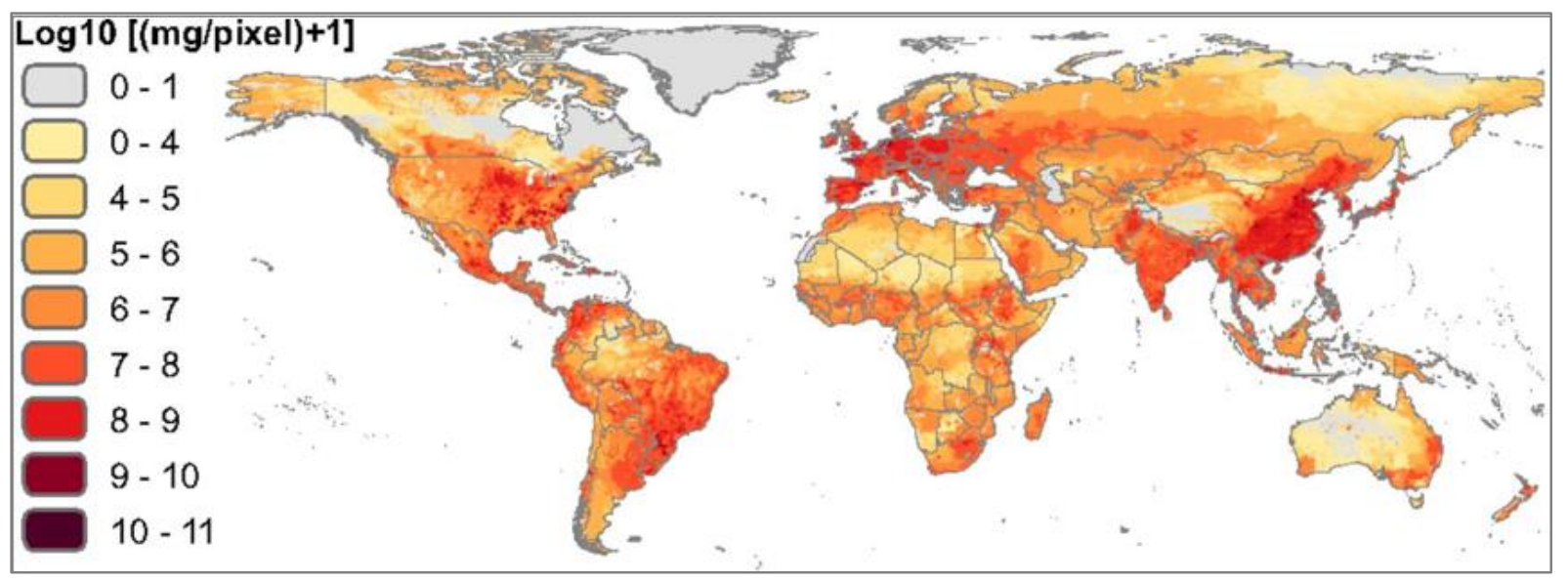

Fonte: (BOECKEL et al., 2015).

A despeito dos benefícios produtivos gerados pelo uso dos antimicrobianos, os crescentes estudos e análises realizadas ao longo das últimas décadas passaram a mostrar os efeitos nocivos associados ao uso indiscriminado de antimicrobianos na agropecuária (BOECKEL, 2015). O alerta contra a resistência antimicrobiana em animais e seres humanos passou a ecoar com mais intensidade, gerando manifestações públicas e privadas de diversos níveis e naturezas. Países começaram a tomar medidas relativas à proibição do uso de 
antimicrobianos como promotores de crescimento - A UE proibiu o uso desses produtos para essa finalidade em 2006, enquanto o Brasil proibiu o uso de alguns desses medicamentos em 2018. A OMS, por meio do relatório WHO - Guidelines on use of Medically Important Antimicrobials in Food-Producing Animals, publicado em 2017, indicou de maneira taxativa "the complete restriction of use of all classes of medically importantantimicrobials in foodproducing animals for growth promotion" (WHO, 2017, p. 15):

The large and expanding use of antimicrobials in livestock, a consequence of growing global demand for animal protein, is of considerable concern in light of the threat of antimicrobial resistance (AMR). Use of antimicrobials in animals has been linked to drug-resistant infections in animals and humans. In September 2016, the United Nations (UN) General Assembly recognized the inappropriate use of antimicrobials in animals as a leading cause of rising AMR. [...] In Europe, regulations have been the principal instrument to limit antimicrobial use in animal production. In the United States, consumer preferences have driven companies to reduce antimicrobial use in animals, although the impact on livestock rearing practices is still nascent. Some European countries maintain highly productive livestock sectors while using less than half the current global average amount of antimicrobial per kilogram of animal (50 mg/kg). (BOECKEL et al., 2017, p. 1350).

O debate acerca dos benefícios e possíveis malefícios dos antimicrobianos na produção agropecuária continuam a ter amplo espaço na atualidade. É fundamental, nesse sentido, a permanente busca pelo maior nível de informação possível. $\mathrm{O}$ atendimento às exigências dos LMRs dispostos no Codex Alimentarius é, certamente, o mais seguro caminho a seguir, e qualquer eventual alteração deve ser pautada por evidências científicas de risco à população animal e humana. Atualmente, governo e setor privado de diversos países têm buscado dialogar em diferentes níveis e instâncias, como congressos, seminários, organizações internacionais e fóruns nacionais e regionais, primando pela necessidade de encontrar soluções e iniciativas que visem preservar a efetividade dos antimicrobianos junto à produção de alimentos cárneos, ao mesmo tempo que busquem promover sua comercialização de maneira segura e com qualidade para a população do planeta (BOECKEL, 2017).

Como se pode perceber, a evolução de temas relativos à sanidade, origem, qualidade, entre outros aspectos do processo produtivo dos alimentos cárneos tem refletido uma constante preocupação do consumidor vis-à-vis o produto a ser consumido. Se a preocupação em torno do estabelecimento de critérios mínimos para a produção de alimentos orgânicos começou a ganhar força na década de 1970, com o estabelecimento do International Federation of Organic Agriculture Movements (IFOAM), atualmente os regulamentos públicos e uma míriade de 
padrões privados se encarregam de conferir ao alimento orgânico, range free, antiobitic free, slow growth, entre outros, o seu caráter diferenciado (KHATOUNIAN, 2001; IFOAM, 2019; MAPA, 2019). Essa proliferação de padrões, públicos e privados, pode gerar problemas quanto à percepção da qualidade do alimento avícola a ser consumido pela população, como mostra o amplo estudo, publicado em 2018, pelo Professor Jayson L. Lusk, chefe do Departamento de Economia Agrícola da Purdue University, Estado de Indiana, EUA. A pesquisa, intitulada Consumer Beliefs, Knowledge, and Willingness-to-Pay for Sustainability-Related Poultry Production Practices Broiler Survey Repor, teve como foco analisar o nível de conhecimento e disposição de mais de 2.000 consumidores em pagar por práticas de produção de aves relacionadas à sustentabilidade. Os principais resultados estão na Figura 15, a seguir:

Figura 15 - Principais resultados — pesquisa de percepção do consumidor sobre as melhores práticas do setor avícola, Prof. Jayson Lusk, Purdue University, Indiana, EUA.

- Willingness-to-pay for slow growth chicken, and importance of the attribute in consumer choice, is sensitive to the information provided and is generally lower in importance than other labels, except when consumers are provided pro slow growth information.

- Knowledge of slow-growth chicken is low. Only $1.2 \%$ of respondents report having previously purchased slow growth chicken, and only $12 \%$ and $17 \%$ agree with the statements "I am very knowledgeable of slow growth chickens" and "I have seen slow growth chicken for sale in my grocery store." Without pro slow growth information, consumers do not generally associate slow growth with high animal welfare. Only about $16 \%$ of respondents believe chicken breasts are currently too large.

- The presence of brands significantly lowered demand for label claims such as organic, non-GMO, and no antibiotics, suggesting brands partially serve as substitutes for these labels. Demand for slow growth labels was not much affected by presence of brands.

- If presented with a pair-wise choice between slow growth chicken priced at a $\$ 0.50 / 1 b$ premium and an unlabeled chicken breast, slow growth is projected to be chosen by $45 \%$, $54 \%$, and $41 \%$ of respondents in the no added information, pro slow growth, and anti slow growth information conditions, respectively when no brands are present. With brands, the respective slow growth choice probabilities are $49 \%, 54 \%$, and $39 \%$.

- The most important attributes, in terms of the ability to move market share, in the no added information, no brand condition are price and the presence/absence of organic, non-GMO, and no added hormone labels. The two least important labels in this condition were slow growth and no antibiotics ever. When brands were present, the only label to increase in importance was an antibiotic absence label.

- There are multiple market segments consisting of consumers with distinct preferences for chicken breast attributes; depending on the treatment in question, $30 \%$ to $40 \%$ of consumers are insensitive to price changes. Consumer demographics are not predictive of willingness to pay premiums for slow growth labels. Only when pro slow growth information is provided do consumer's relative preferences for novelty, animal welfare, and naturalness correlate with willingness-to-pay premiums for slow growth.

Fonte: LUSK, 2018.

Como se pode perceber, há uma baixa porcentagem de respostas em que a pessoa considera dispor de um bom nível de conhecimento sobre métodos alternativos da produção de frango. Ademais, a segurança alimentar foi citada pelos consumidores como um dos principais fatores para decisão de compra. De qualquer forma, pode-se constatar que os consumidores, 
pelo menos americanos, têm um baixo conhecimento acerca da produção de frango em geral e, em particular, da produção de aves slow growth.

Diante desse paradoxo relativo ao excesso de informação e, ao mesmo, a ausência de conhecimento, cabe às empresas buscar melhorar sua capacidade de informar ao cliente final as características do produto em questão, de maneira idônea, objetiva e correta. Quanto aos consumidores, uma melhor compreensão da cadeia produtiva e dos diferentes métodos de produção inerentes a ela é fator fundamental para uma escolha mais convergente com seus anseios e expectativas quando do consumo do produto final.

\subsection{A abordagem do modelo de CGV para o setor avícola}

Como observado ao longo do primeiro capítulo, o modelo teórico das CGV (GEREFFI; FERNANDEZ-STARK, 2016) tem como objetivo descrever o conjunto de atividades realizadas por empresas e trabalhadores com o intuito de gerar um determinado produto desde sua concepção até sua versão física final. Essa descrição apresenta as principais relações econômicas, produtivas e mercadológicas interfirma, em nível global, além de descrever o nível de participação de países e organizações privadas na dinâmica regulatória e econômica do setor (GEREFFI; FERNANDEZ-STARK, 2016).

Em suma, o modelo CGV está disposto em seis eixos de análise que buscam compreender tais dinâmicas: (i) estrutura input-output; (ii) escopo geográfico; (iii) governança (iv) upgrading; (v) contexto institucional e (vi) stakeholders. As principais fontes de pesquisa que embasam a análise são textos acadêmicos, bases de dados internacionais e entrevistas com especialistas no setor, conforme metodologia apresentada na introdução do presente trabalho.

Como já observado, a carne de frango se consolidou como uma das mais importantes fontes de proteína disponíveis atualmente. Seu consumo tem sido impulsionado por uma série de fatores, dentre os quais destacam-se: (i) o baixo preço relativo, quando comparado a outras carnes; (ii) a boa imagem e reputação junto ao consumidor, considerada uma fonte light de proteína; (iii) sua aceitação pela maioria das culturas e religiões; (iv) a substituição das carnes vermelhas por conta da crescente preocupação com saúde e meio ambiente; e (v) a disponibilidade de uma série de produtos (in natura e industrializados) que utilizam carne de 
frango em sua composição, entre outros (OLIVEIRA, 2012; COSTA et al., 2015; VOILA; TRICHES, 2015):

[...] This combination of growing demand in developing countries and stationary demand in industrialized countries presents a great opportunity for animal protein production in developing countries, where local production meets most of the demand, and this scenario is likely to remain stable in the predictable future. The world food economy is increasingly driven by the change in diets and food consumption patterns considering animal protein. Per capita consumption of animal protein has rapidly grown in several large countries, China and Brazil among them, which has increased the average of the developing countries and the world. The perception of the significant change in the meat industry reflects the increase performance of the global production and poultry meat consumption. It grew by more than $5 \%$ per year, and its share of world meat production increased from $15 \%$ three decades ago to $30 \%$ nowadays. Global production of animal protein has increased substantially since the 60 's. Meat production has more than doubled, and poultry meat production has increased by about ten times, consisting of an increase in both the number of animals and the productivity index. Carcass weights have increased by about $30 \%$ for both cattle and chicken from the early 1960 's to the mid-2000s, and by about $20 \%$ for pigs. (WAKER; NÄÄS; 2018, p. 517).

A cadeia produtiva avícola apresenta uma organização que pode ser definida em três grandes blocos: (i) a cadeia a montante, composta por elo produtivos fornecedores de insumos e serviços para a cadeia principal (produtos químicos e farmacêuticos, máquinas e equipamentos, embalagens e ração); (ii) a cadeia principal, formada por todo o processo relativo aos diversos elos de genética, avozeiros, matrizeiros, e incubatório até se chegar à produção efetiva do frango de corte, destinado ao abate; e (iii) a cadeia à jusante, composta pela indústria de alimentos, aproveitamento de resíduos, entre outros (SEBRAE, 2008; SANTOS FILHO, 2011). A literatura, no entanto, procura classificar de maneira objetiva a cadeia avícola como uma sequência de operações coordenadas que podem ser divididas também em três grandes eixos: (i) produção de insumos; (ii) industrialização e (iii) comercialização (VOILA; TRICHES, 2015).

Além disso, todo o processo de criação e abate de frangos de corte deve obedecer a boas práticas de produção (BPPs) com vistas a garantir a sustentabilidade da operação de forma sistêmica, levando em consideração a segurança alimentar e os aspectos sociais ligados à operação, além de fatores diretamente relacionados ao modelo de negócio, como manejo, nutrição, sanidade, ambiência e bem estar animal. Em suma, a implementação dessas BPPs, em 
todas as fases produtivas, consiste em atividade fundamental para a manutenção da qualidade e da competitividade global dos produtores (BELLAVER et al., 2003).

Como se pode ver no tópico seguinte, as atividades da CGV avícola estão diretamente ligadas a um contexto de intensificação de investimentos recentes em PD\&I em diversas etapas do negócio, fator que permitiu o incremento maciço da produção e disponibilidade de carne em nível mundial, tendo fatores como preço, qualidade e nutritividade como os propulsores dessa mudança. A verticalização da cadeia também é um fator relevante, sobretudo por conta da influência que as grandes empresas-líderes exercem sobre praticamente todas as etapas produtivas e, consequentemente, sobre fornecedores e outros stakeholders. Por fim, destaca-se o importante papel que os governos e organizações internacionais têm sobre o processo produtivo como um todo, com a criação de normas e regulamentos que são primordiais para a manutenção dos padrões de sanidade em nível global e com impacto direto sobre o volume produzido e comercializado atualmente.

\subsubsection{A ESTRUTURA INPUT-OUTPUT}

Como já elucidado no primeiro capítulo do presente trabalho, a estrutura input-output de um setor apresenta escopo global e tem como objetivo precípuo identificar as principais atividades e segmentos de uma determinada GCV. No caso da CGV avícola, foram identificados sete segmentos principais que a compõem:

a) As atividades de prospecção do produto, bem como de desenvolvimento de tecnologia necessária para sua elaboração, seja ela aplicada direta ou indiretamente sobre ele;

b) A complexa cadeia de inputs relacionada ao setor, que vão desde recursos naturais até outras indústrias cujas atividades têm efeito direto sobre a avicultura, como genética, saúde animal, nutrição e equipamentos;

c) As atividades de produção e distribuição, que atuam de maneira sequencial e apresentam elevada capacidade de gestão operacional conjunta, sempre com o intuito de disponibilizar o produto da melhor forma aos compradores intermediários e consumidores finais;

d) Os elos de marketing, comercialização e pós-venda, os quais fazem parte da jusante da cadeia avícola e são voltados para o atendimento às preferências e necessidades 
dos consumidores, no intuito de operar com vistas a garantir diversificação, rapidez, conveniência e qualidade.

Figura 16 - Estrutura input-output da cadeia global de valor da avicultura.

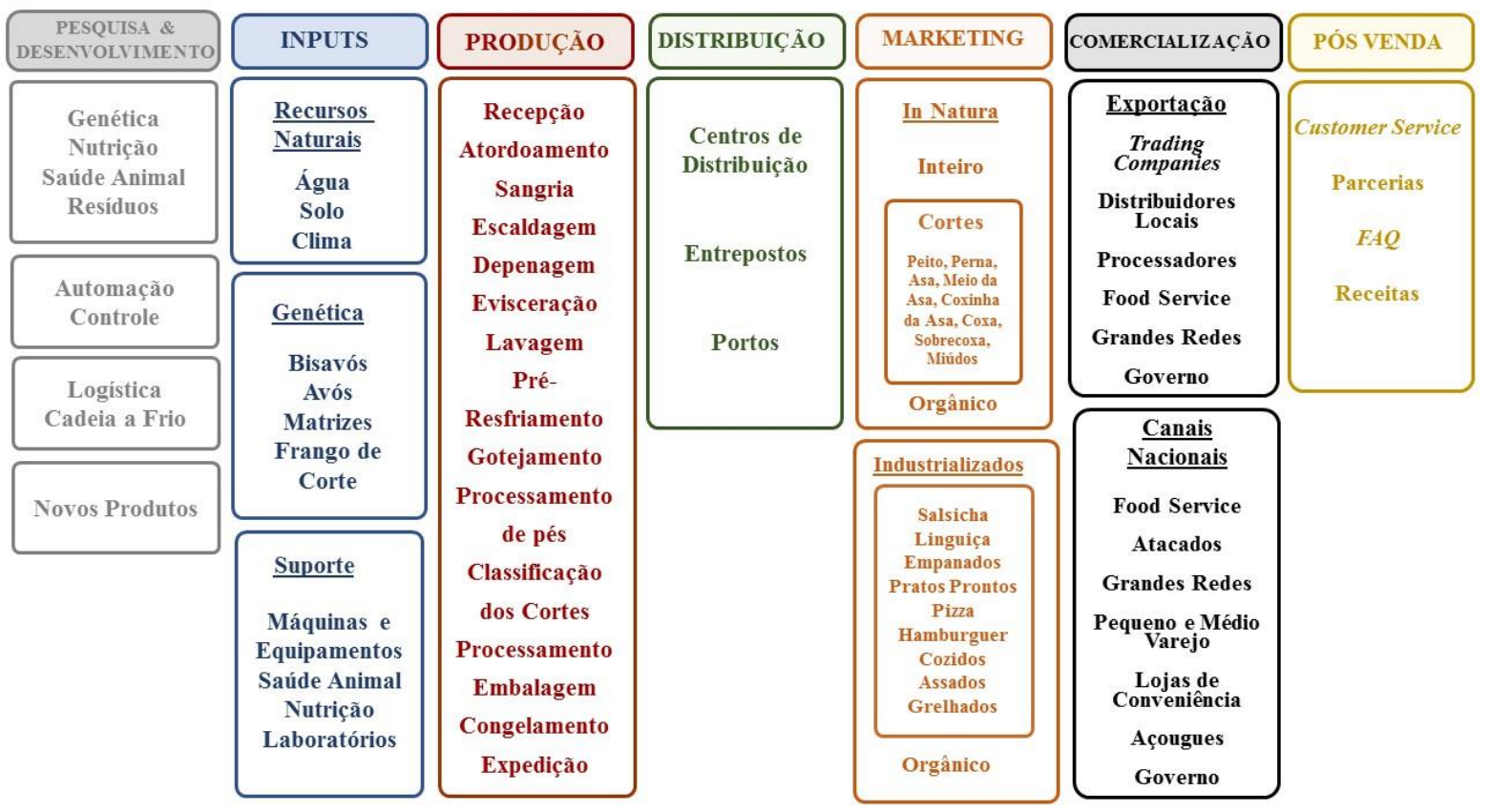

Fonte: VOILA; TRICHES; 2015; WAKER; NÄÄS, 2018; MARTINELLI; ROHENKOHL; MURAKAMI; 2014; BASSI, 2013; ARAÚJO et al., 2008; SEBRAE, 2008; JESUS JUNIOR, 2007; LAZZARI, 2004. Elaboração do Autor.

\subsubsection{Pesquisa e desenvolvimento (P\&D)}

As atividades relativas ao elo de $\mathrm{P} \& \mathrm{D}$ estão ligadas, sobretudo, à montante da cadeia avícola e ao processo de abate das aves. O dinamismo do setor está diretamente relacionado aos constantes ganhos produtivos, principalmente por conta do aumento das taxas de conversão, incremento dos ganhos nutricionais, pesquisas genéticas, expansão da automação em diversas etapas da cadeia e eficiência produtiva, com mais controle e gerenciamento de riscos. Todas essas ações, necessariamente, foram fruto de iniciativas que tiveram como cerne o eixo de P\&D (OLIVEIRA et al., 2012).

A contínua evolução e incorporação de tecnologias de automação e ambiência ao longo da produção, por exemplo, tornou viável o incremento de volume disponibilizado sem a necessidade de ampliar, necessariamente, a área física dos aviários. Dessa forma, grandes países produtores, dentre eles o Brasil, adquiriram elevados índices de eficiência produtiva decorrentes da melhor utilização do espaço físico dos galpões, em consonância com tecnologias das áreas 
de genética, sanidade e nutrição. Esses esforços coordenados influenciaram, gradativamente, a queda nos preços praticados pela cadeia, impulsionando o consumo da proteína avícola no mundo. No caso do Brasil, por exemplo, no ano de 1975, o quilo da carne de frango custava, em média, em valores atualizados pelo índice geral de preços, R\$14,75. Em 2010, o preço médio do quilo da carne de frango alcançou R \$ 2,57 e chegou a R \$ 4,70 em 2019 (SANTOS FILHO, 2011; COSTA et al., 2015; CEPEA-USP; 2020):

Há décadas a avicultura vem concentrando esforços em pesquisas nas áreas de genética, nutrição, sanidade e manejo. Os avanços obtidos tornaram a carne de aves uma das mais importantes fontes de proteína animal para o homem. Os altos volumes atingidos pela produção em larga escala colaboraram para a redução gradativa do preço do frango e para o acirramento da competitividade entre as empresas produtoras. (SEBRAE, 2008, p. 20).

Nos grandes países produtores, os centros de pesquisa frutos de parceria entre a academia e as empresas do setor privado passaram a ter um papel preponderante na evolução tecnológica da avicultura, sobretudo nas áreas de produção, sanidade, genética e meio ambiente. As empresas do setor destacam-se pela presença de granjas experimentais, laboratórios para testes de novos produtos e um corpo qualificado de pesquisadores. A literatura especializada identifica algumas ondas tecnológicas vividas pelo setor avícola ao longo dos últimos 70 anos, cujos marcos são (BASSI, 2013; SCHMIDT; SILVA, 2018):

a) Área da genética, 1950-1960: novos cruzamentos e o surgimento de raças híbridas (cruzamento entre raças ou linhagens diferentes que pertencem à mesma espécie.);

b) Área da sanidade, 1960-1970: higiene, profilaxia e novas vacinas;

c) Área da nutrição, 1970-1980: formulação de rações e compostos por meio do uso de programação linear;

d) Área do manejo, 1980-1990: introdução de novas instalações e equipamentos;

e) Área do meio ambiente, 1991-2000: introdução de controles como, por exemplo, climatização.

Nos últimos anos, impulsionado pelo crescimento da demanda, o setor buscou desenvolver tecnologias relacionadas ao incremento da eficiência produtiva, sobretudo por conta das características inerentes ao produto final, que tinha o preço como principal atrativo. 
Esse movimento aconteceu, principalmente, ao longo da década de 1990. A década seguinte, todavia, seria marcada, principalmente, pela necessidade de aperfeiçoamento e geração de novas tecnologia relacionadas a adequações ambientais, fruto das novas legislações e exigência sanitárias que passaram a vigorar nacional e internacionalmente desde então (BASSI, 2013).

É importante salientar que a dinâmica que impulsiona as diversas iniciativas ligadas ao eixo de P\&D no setor perpassa a natural e constante interação entre as agroindústrias e seus fornecedores, dentre os quais se destacam as empresas multinacionais de nutrição, saúde animal e equipamentos. Em relação à nutrição animal, os grandes produtores passaram a lançar mão de mecanismos que provessem alta precisão nas formulações e qualidade das rações. As principais evoluções tecnológicas em termos de sanidade estão relacionadas, principalmente, a utilização de prebióticos, probióticos, acidificantes e enzimas, com o objetivo de melhorar a absorção dos nutrientes contidos na alimentação bem como prevenir enfermidades no trato gastrointestinal das aves, como a coccidiose. O aperfeiçoamento e desenvolvimento de vacinas e outros medicamentos também são fundamentais para prover saúde ao animal, seja em nível profilático ou terapêutico. No caso das empresas de equipamentos, destacam-se, entre outros, as inovações em bem-estar animal, como, por exemplo, a melhoria das instalações dos aviários, utilizando-se de ventiladores, umidificadores, aquecedores, entre outros equipamentos e sistemas controlados por software (SANTINI, 2006; SCHMIDT; SILVA, 2018).

As empresas de genética também investem maciçamente em $\mathrm{P} \& \mathrm{D}$ para atender continuamente às necessidades impostas pelas agroindústrias e clientes finais. Por meio da aplicação e integração de novas técnicas e tecnologias, busca-se o constante aperfeiçoamento das linhagens e, consequentemente, melhor desempenho e eficiência das aves. Em suma, os laboratórios, granjas-teste e as diversas instalações das grandes empresas do setor de genética têm como foco a busca permanente em inovações relacionadas à: (i) conversão alimentar e produção de ovos; (ii) bem-estar animal — robustez, aptidão cardiovascular e força esquelética; (iii) rendimento de peito; (iv) investigação genômica; (v) uniformidade; (vi) sanidade, entre outros (AVIAGEN, 2019; COBB VANTRESS, 2019).

Por fim, destacam-se as inovações ocorridas durante o processo de industrialização (abate), que têm as agroindústrias como seus maiores impulsionadores. Visando diminuir custos de processamento, aumentar a produtividade, incrementar a diversificação de produtos e garantir a sustentabilidade, empresas-líderes do setor, como BRF, Seara, Tyson Foods, entre outras, investem em processos que têm como foco o uso de novas tecnologias, a construção de 
novas instalações e, não menos importante, a reestruturação organizacional. Um dos mais relevantes é a automação e robotização dos processos que vão do abate até a desossa do frango, por conta da gradual escassez de mão de obra que, de maneira geral, assola o setor, bem como aumento da produtividade. Destaca-se assim a utilização de automação em linhas de evisceração, ao longo da classificação de carcaça por visão eletrônica e também nas áreas de corte, pesagem e embalagem de frangos inteiros e partes. Além dos fatores já citados, o incremento da automação e digitalização das linhas de produção também têm como foco a parametrização da qualidade dos produtos, melhor aproveitamento das matérias-primas, maior consistência quanto aos processos produtivos utilizados e efetiva coleta de dados para melhoria da performance (NUNES, 2015; BRF; 2019). Outro importante eixo de P\&D no processo de industrialização decorre da crescente preocupação com a sustentabilidade. Nesse sentido, diversas tecnologias passaram a ser implementadas para a promoção do uso adequado de recursos naturais com consequências diretas para toda cadeia de valor, como as inovações referentes à gestão de efluentes, eficiência hídrica, controle de emissões de GEEs e resíduos sólidos (BRF, 2019; SEARA, 2019).

\subsubsection{Inputs}

Os inputs da cadeia produtiva avícola podem ser dispostos em três grandes blocos: (i) recursos naturais; (ii) genética e (iii) indústrias suporte. Cada eixo apresenta um conjunto de particularidades e dinâmicas que, conjuntamente, irão impactar diretamente a qualidade da principal matéria-prima para o setor: o frango de corte.

A disponibilidade de recursos naturais com potencial de transformação e/ou influência à produção agrícola é fundamental para manutenção da competividade de países e empresas do setor. Água corrente e abundante, disponibilidade de terra e um clima favorável são fatores diretamente ligados ao incremento da produção de proteína animal. O Brasil, por exemplo, ao congregar todas essas características, alterou seu perfil de produção nas últimas décadas, com vistas a incrementar sua produtividade e, consequentemente, o volume de carne disponibilizado. As empresas tem se beneficiado do fato de o país ser um importante produtor de grãos (milho e soja), recursos hídricos em larga escala, extensão de terra (sobretudo no Centro-Oeste do país, onde grandes empresas tem se instalado com mais frequência), além de uma média climática de $24,5^{\circ} \mathrm{C}$, extremamente favorável à produção agrícola e de proteína, quando comparada a outros países como Rússia $\left(-5,1^{\circ} \mathrm{C}\right)$, China $\left(7^{\circ} \mathrm{C}\right)$, Alemanha $\left(8,5^{\circ}\right)$ e EUA 
$\left(8,5^{\circ} \mathrm{C}\right)$. O clima, nesse sentido, é um importante diferencial para o setor, tanto para os custos de produção, por conta do menor gasto com a climatização dos galpões aviários e com a manutenção do status sanitário (ABPA, 2019).

A constante interação entre avicultores, técnicos pecuários, pesquisadores, bem como entre os segmentos de alimentação, tecnologia de alojamento, saúde animal e abate foi fundamental, ao longo das últimas décadas, para a evolução da área de genética e, consequentemente, para o crescimento da avicultura em diversos países do mundo. Esse exercício permanente possibilitou o desenvolvimento de linhagens híbridas, dotadas de melhorias em termos de conversão alimentar, ganho de peso e rendimento de carcaça, além de ter tido consequências diretas para a diminuição do risco sanitário do setor (JESUS JUNIOR, 2007).

Em suma, trata-se de uma atividade fundamental para a cadeia avícola, sobretudo porque influencia a capacidade do animal em se apropriar positivamente das características ambientais, sobretudo aquelas ligadas à nutrição, higiene, bem-estar e sustentabilidade. Toda essa dinâmica voltada à melhoria do desempenho do animal no campo está diretamente relacionada à maior produtividade e à qualidade da carne. Como já visto no eixo anterior, em meados do século $\mathrm{XX}$, o setor de material genético tinha como foco o ganho de peso das aves. Gradativamente, as empresas do setor passaram a diversificar sua forma de atuação e passaram a identificar outros motivadores, tais como: reprodução, eficiência da carcaça, qualidade da carne e robustez animal (MARTINELLI; ROHENKOHL; MURAKAMI; 2014).

Em linhas gerais, o material genético na atividade de avicultura de corte advém de aves procedentes de linhas puras ou dos cruzamentos que têm como objetivo a produção de carne. Os programas de melhoramento genético foram fundamentais para a evolução do desempenho das linhagens de corte. Todo o processo de seleção e multiplicação, dividido em cinco eixos, tem como foco gerar pintos de um dia que se transformarão em frangos destinados ao abate, processo que leva em média 4 anos (JESUS JUNIOR, 2007; PEIXOTO; LEDUR, 2019; EMBRAPA, 2019; COBB VANTRESS, 2019):

A pirâmide de produção apresenta três etapas complementares, situando em seu topo os Rebanhos Núcleo ou elite, responsáveis pelo melhoramento genético das linhas puras, via seleção intensiva das características economicamente importantes; na parte central os Rebanhos Multiplicadores, responsáveis pela produção de matrizes macho e fêmea, incorporando os benefícios da complementaridade entre as linhas puras; e na base da pirâmide 
os chamados Rebanhos Comerciais, que são os indivíduos destinados ao abate ou à produção de ovos. Dessa forma, o progresso genético é transferido para as gerações seguintes por meio de multiplicação, passando para as bisavós, avós, matrizes e finalmente, após cerca de 4 anos, chega-se ao produto final, os híbridos, denominados pintos de um dia, que são vendidos aos criadores comerciais de frangos de corte e de galinhas poedeiras. Nos rebanhos núcleo, é realizada a seleção genética, que é um processo altamente tecnológico, restrito a poucas empresas multinacionais. Essas granjas criam as linhas puras para produção de aves bisavós. As granjas bisavoseiras produzem aves avós. As granjas avoseiras produzem as matrizes. As granjas matrizeiras, por sua vez têm como produto final os híbridos obtidos do cruzamento entre matrizes, que são vendidos como pintos de um dia e tornar-se-ão os frangos de corte, onde machos e fêmeas são aproveitados. Dessa forma, frangos de corte e poedeiras são híbridos produzidos por meio de cruzamentos entre três ou quatro linhagens. (PEIXOTO; LEDUR, 2019).

Figura 17 - Fluxograma genético da produção de pintos de corte.

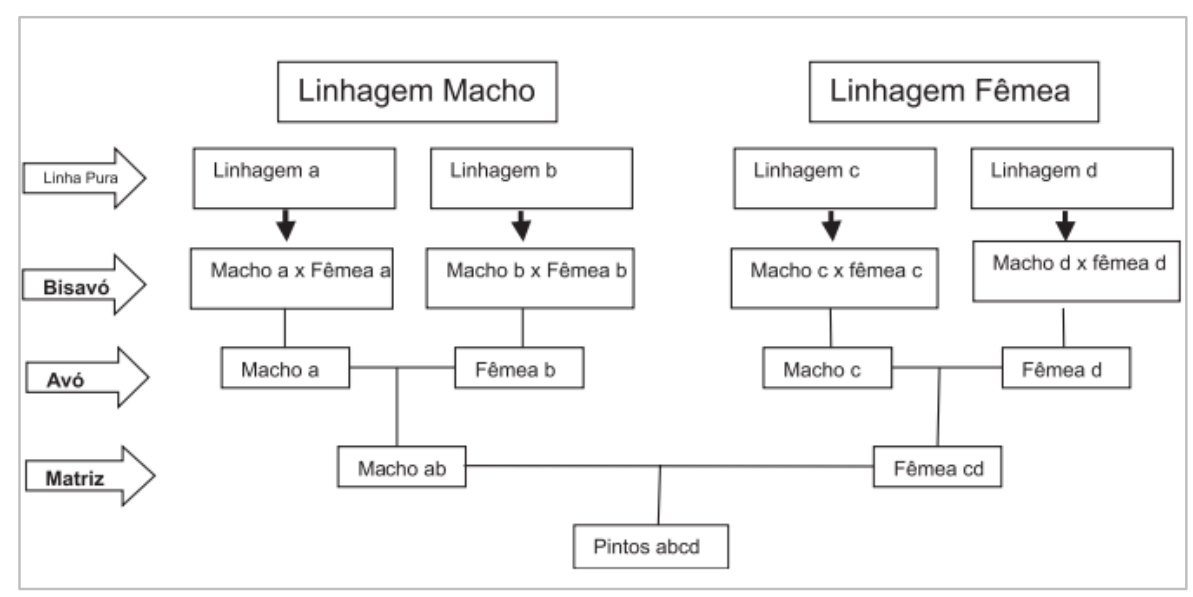

Fonte: EMBRAPA Suínos e Aves apud JESUS JUNIOR, 2007, p. 195.

Atualmente, três grandes empresas concentram grande parte da produção de material genético avícola (MGA) comercializado no mundo: COBB VANTRESS, AVIAGEN e HUBBARD. Elas são as principais fornecedoras de MGA para diversos mercados e investem em larga escala em P\&D I para o constante aperfeiçoamento da cadeia. Ademais, essas grandes empresas têm buscado diversificar a produção de avós e matrizes em diferentes países com o intuito de mitigar eventuais riscos decorrentes da concentração da produção em países e regiões com maiores probabilidades de apresentar focos de influenza aviária, como EUA, China, Europa. O Brasil, nesse sentido, por nunca ter apresentado foco da doença, tem aumentado sua produção e, consequentemente, incrementado a exportação de MGA para diversos países, fruto dos investimentos e do aumento da atividade econômica dessas grandes empresas no país nos 
últimos anos. Em 2018, por exemplo, a AVIAGEN investiu $\mathrm{R} \$ 100$ milhões no país com o intuito de se tornar a líder do mercado brasileiro de matrizes, por meio da ampliação de granjas e incubatório. A empresa tem buscado aperfeiçoar o lançamento de produtos no país ao longo dos anos, de acordo com a preferência das agroindústrias (BRF, Seara, Aurora, entre outras). A COBB VANTRESS, uma das líderes do setor, tem investimentos planejados da ordem de US\$ 22 milhões até 2022 (MENDES, 2018). Esse maciço volume de investimentos possibilitou que o Brasil passasse a ocupar destaque na produção e comercialização de MGA ao longo dos últimos anos. Em 2004, o país exportava 355 toneladas de pintos de um dia e 3.354 toneladas de ovos férteis. Em 2018, esses números saltaram para 1.075 e 15.268 toneladas respectivamente, incrementos da ordem 203\% para pintos de um dia e 355\% para ovos férteis, que tiveram como destino 56 países de seis regiões diferentes (ABPA, 2019).

Referente ao terceiro eixo dos inputs da atividade avícola — atividades suporte — podese destacar que, em conjunto com a evolução da genética, a correta utilização das práticas de manejo consiste num diferencial competitivo intrínseco à atividade avícola e diretamente relacionada ao nível de eficiência produtiva da cadeia (MARTINELLI; ROHENKOHL; MURAKAMI; 2014). Uma série de elementos devem ser considerados quando da construção do aviário, que vão desde a escolha do terreno, a qual deve maximizar as condições de ventilação natural, reduzir a incidência de radiação solar e facilitar o fluxo de pessoal, animais e insumos, até a distância entre o abatedouro e aviário, a mecanização para o fornecimento de água e ração às aves, a colocação de telas de malha fina nos galpões, bem como sua correta climatização, entre outros. Em suma, os materiais de construção, bem como os equipamentos, devem levar em consideração a sensibilidade das aves em relação à temperatura e às densidades propostas e devem ser voltados, sobretudo, à diminuição do estresse no aviário e ao aumento da comodidade das aves (JESUS JUNIOR, 2007; SEBRAE, 2008). No caso específico das tecnologias de ventilação em aviários, por exemplo, sua implementação e gradual evolução contribuíram substancialmente para melhorias nas taxas de conversão e crescimento do animal no campo (VALDES; HALLAHAN; HARVEY, 2015):

Os limites do crescimento de frangos estão relacionados com a adequada saúde e programas de biosseguridade animal; com o suprimento e consumo de água; com a ventilação, temperatura, umidade do ar e iluminação; com a densidade da criação; com o suprimento alimentar e a nutrição por fases, estações do ano e sexos; com genética e com o adequado manejo geral na produção dos frango (BELLAVER et al., 2003, p. 2) 
Ademais, a produção de aves, necessariamente, depende de iniciativas que visem evitar a entrada de doenças no rebanho (como a influenza aviária e a doença de Newcastle). Como já destacado, a prevenção de doenças é o ponto principal a ser considerado em todos os sistemas, fato que denota uma preocupação constante com as condições sanitárias desde o abate até o processamento da carne. Para tanto, busca-se restringir toda movimentação desnecessária em volta do aviário, bem como implementar compra de aves sadias, com linhagens reconhecidas pelo mercado e efetuar a vacinação dos lotes e o controle de infecções com o máximo de rigor. Constantes ações de cooperação, fiscalização, prevenção e monitoramento são o cerne de um sistema sanitário eficiente e de excelência (BELLAVER et al., 2003; JESUS JUNIOR, 2007).

Nesse sentido, um elo fundamental das atividades suporte à cadeia avícola é a indústria de saúde animal. Sua efetiva participação, por meio da interação junto a agroindústrias e fornecedores, com vistas à geração de soluções que visem trazer mais saúde aos plantéis, é componente fundamental para a consolidação de uma cadeia produtiva dinâmica e dotada dos mais altos padrões de sanidade. Como se pode ver até aqui, a atuação do setor de saúde animal foi fundamental para evolução da indústria de proteína animal ao longo do século XX, com a criação de medicamentos e substâncias essenciais a esse setor. A partir da década de 1990, ganha força o conceito one health, o qual tem como foco a integração entre a saúde humana, saúde animal e o ambiente, bem como eventuais medidas relativas à prevenção e ao combate à proliferação de zoonoses e doenças infecciosas. Como cerca de $60 \%$ das infecções humanas são zoonóticas e $75 \%$ das infecções humanas têm origem animal, a indústria passou a investir na condução de pesquisas que visem apresentar soluções efetivas para o problema da resistência antimicrobiana, anteriormente abordada por este trabalho. Esse é, certamente, um dos grandes desafios para a manutenção e crescimento desse importante setor, um dos pilares para a indústria avícola mundial (WHO, 2019; SINDAN; 2019; HEALTH FOR ANIMALS, 2020).

Por fim, um dos componentes fundamentais para a competitividade do setor de proteína animal é a nutrição. A evolução dos componentes da ração destinada à produção avícola foi fundamental para os ganhos de produtividade do setor, sobretudo em termos de conversão alimentar do plantéis. Em linhas gerais, o custo da ração equivale a cerca de $70 \%$ do custo total da produção do frango vivo e $60 \%$ do custo do frango abatido. A composição da ração está dividida em 67\% milho e 33\% farelo de soja (LAZZARI, 2004; WAKER; NÄÄS, 2018).

Além disso, a ração destinada à produção avícola conta com a adição de uma série de micronutrientes (minerais, aminoácidos e vitaminas) fundamentais para complementar os 
ingredientes básicos da ração animal (milho e farelo de soja). Por conta disso, o correto manuseio e implementação da nutrição animal consiste num diferencial competitivo às empresas do setor. O nível de qualidade dos ingredientes bem como as exigências nutricionais relativas ao rebanho são componentes fundamentais presentes nas especificações das rações. Importante ter presente, como visto anteriormente, que antimicrobianos podem ser aplicados levando-se em consideração os devidos conhecimentos tecnológicos e a legislação vigente (BELLAVER et al., 2003).

\subsubsection{Produção e distribuição}

Conforme já exposto, uma das razões para o incremento do consumo global de proteína animal avícola é a diversidade de produtos originada a partir da carne de frango. O sucesso para tal diversidade reside nos padrões de qualidade, boas práticas, inovação e excelência aplicados pelas grandes empresas agroindustriais no abate e processamento das aves. De maneira geral, cabe aos grandes frigoríficos a maior parte da coordenação da cadeia produtiva desde o campo até a fase de processamento que originará o produto final a ser disponibilizado ao público em geral (ARAÚJO et al., 2008).

A unidade de processamento ou planta produtiva é um componente fundamental para a cadeia avícola. Nela reside, em última instância, a interação entre cidade e o campo, entre o integrado e a integradora, entre os ambientes nacional e internacional. A unidade de processamento é responsável pela condução de todo trabalho de transformação efetiva da matéria-prima em produto final, com foco em gestão ambiental, da força de trabalho, automação, aplicação de iniciativas de P\&D e I, gerando emprego, renda e desenvolvimento regional, geralmente por estarem afastadas de grandes metrópoles:

Este segmento se distingue pelo predomínio de grandes empresas que apresentam tecnologias modernas de produção, alto grau de profissionalização e grande capacidade de comercialização. [...] As grandes indústrias utilizam linhas de abate automatizadas de grande escala, seguindo o modelo fordista de produção. Estas linhas permitem a produção de cortes de frango, com alto grau de padronização, oferecendo ao mercado um produto de maior valor agregado. A sofisticação da indústria brasileira levou ao estabelecimento de alguns paradigmas referentes às práticas e às instalações industriais, que orientam os sistemas produtivos atuais: aumento do percentual de frango em cortes no mix de produção; aperfeiçoamento contínuo da logística; diminuição da distância máxima dos aviários aos abatedouros; consumo de água e tratamento de efluentes; automatização da linha de cortes; fábrica própria de ração. (JESUS JUNIOR, 2007, p. 218). 
Uma das grandes preocupações dos frigoríficos atualmente consiste no processo de automação industrial. O setor tem buscado solucionar de maneira definitiva a falta de disponibilidade de mão de obra, sobretudo em países que ainda não implementaram por completo os processos de mecanização na maioria das suas plantas, como é o caso do Brasil, embora esse seja um processo gradualmente em curso (AVISITE, 2009). Outro ponto fundamental decorre da preocupação com a ecoeficiência das unidades de processamento, por conta, principalmente, da dinâmica de forte interação com o ambiente onde a planta produtiva se encontra. Em suma, há uma crescente preocupação com a utilização racional de recursos naturais, a gestão ambiental, o consumo de energia e tratamento de efluentes, resíduos, bemestar animal, entre outros. Ademais, destaca-se a interação que as grandes empresas têm com a comunidade onde estão inseridas, sobretudo por conta da necessidade de manutenção de uma relação profícua com os integrados da região e da população como um todo, uma vez que atuam como verdadeiros vetores de desenvolvimento regional e segurança alimentar (BRF, 2019; AURORA, 2019; SEARA, 2019; TYSON FOODS, 2019; TERRENA, 2019).

A cadeia de distribuição do setor, por sua vez, tem como destaque a necessidade permanente de atendimento ao cliente com qualidade, segurança e pontualidade. A logística a frio deve obedecer a parâmetros de temperatura que são dados de acordo com a classificação do produto (resfriado ou congelado). Atenção especial é dada a todo processo de transporte da fábrica até os centros de distribuição, entrepostos ou ao porto, no intuito de garantir a máxima qualidade do produto. Detalhes como a temperatura inicial do veículo antes do carregamento, abertura de portas, características do veículo refrigerado, rotas, entre outros, são verdadeiros pontos críticos da cadeia a frio e representam desafios às agroindústrias e à frota de veículos especializados nesse tipo de transporte (CARVALHO, 2013).

\subsubsection{Marketing, comercialização e pós-venda}

As dinâmicas de marketing e comercialização dos produtos do setor avícola estão diretamente relacionadas entre si. Estudos, análises mercadológicas, desenvolvimento de novos produtos, testes laboratoriais e sensoriais, entre outros trabalhos de base, são o cerne para a operacionalização das estruturas apresentadas na estrutura input-output da cadeia avícola. Em suma, o eixo de marketing apresenta duas grandes divisões de produtos: in natura e industrializados. Os produtos in natura geralmente são caracterizados pelos cortes resfriados e 
congelados de frango, enquanto os industrializados apresentam-se ao consumidor final de forma mais elaborada e com elevado nível de processamento quando comparado aos cortes in natura.

De acordo com representantes do setor, entrevistados para a presente tese de doutoramento, a agregação de valor contida nos produtos industrializados é apenas um dos diferenciais na comparação com os produtos in natura. $\mathrm{O}$ foco da empresa ao lançar um produto industrializado reside também em proporcionar maior evidência da marca, conveniência, atenção às necessidades do consumidor, além da maior rentabilidade. Adicionalmente, como evidenciado nos tópicos anteriores, os produtos orgânicos e suas variações, seja no formato in natura ou industrializado, têm ganhado cada vez mais espaço entre os consumidores com maior poder aquisitivo, por conta de seus apelos de diferenciação quando observados junto aos produtos tradicionais:

As características do mercado de aves vêm mudando desde os anos 60, quando a maioria da produção era composta de frango 'standard', sem grandes exigências de qualidade e vendida a preço baixo. As exigências de qualidade por parte dos consumidores sofrem alterações, ao longo do tempo, em função de mudanças nos hábitos alimentares, na qualidade real ou percebida dos produtos e nos valores culturais disseminados na sociedade; por outro lado, impulsionam o surgimento de diferenciais de qualidade nos produtos da avicultura. Passaram a ser comercializados produtos certificados, produtos orgânicos (frangos criados sem utilização de determinados produtos químicos) e produtos de origem regional controlada, que ampliaram uma oferta que atende às demandas desse novo público consumidor. (SEBRAE, 2008, p. 19).

No caso das exportações globais de produtos avícolas, entretanto, o foco tradicionalmente é direcionado a produtos in natura congelados que variam em termos de agregação de valor conforme o mercado. De acordo com o Coordenador do Insper Agro Global, Marcos Jank, os mercados apresentam distinções extremamente importantes em termos de consumo de proteína animal, e a empresa deve estar atenta e procurar atender da melhor forma o cliente final, seja ele um distribuidor local, uma rede de food service ou algum grande varejista. A figura 18, a seguir, destaca as principais diferenciações em termos mercadológicos entre quatro grandes grupos de países/regiões: (i) Least Developing Countries (LDCs), Índia e África; (ii) Ásia, China e Rússia; (iii) América Latina, Brasil, Oriente Médio e Japão; e (iv) Europa e EUA. 
Figura 18 - Principais particularidades mercadológicas e produtivas da cadeia avícola por grupos de países/regiões.

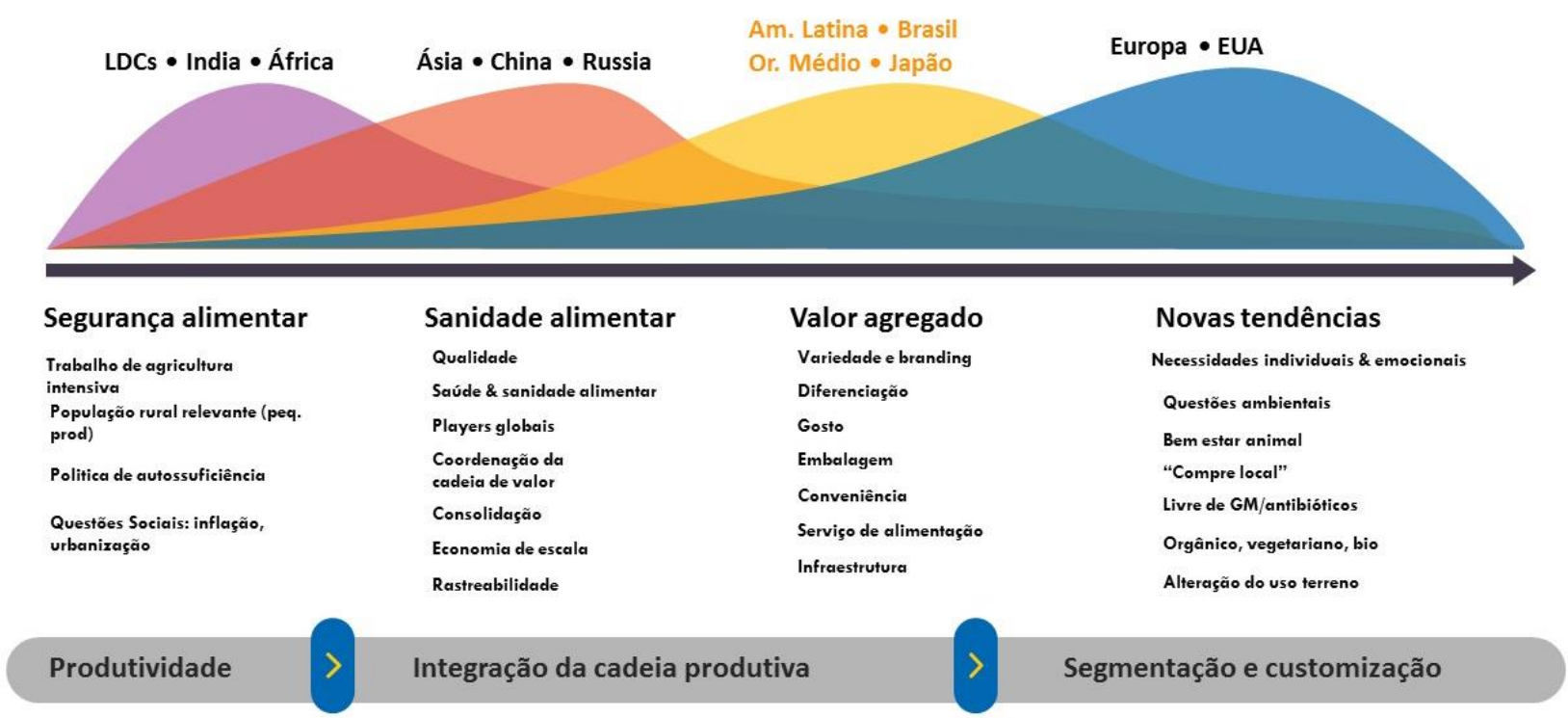

Fonte: JANK, 2019. Entrevista concedida ao autor.

Essa diferenciação inter-regional em termos de preferências mercadológicas e produtivas foi corroborada por outros especialistas entrevistados para este trabalho, os quais afirmaram a existência de dois grandes polos em termos de acesso a mercados, cuja diferenciação pode ser atrelada a alguns países e regiões, mas cujo fator preponderante é o poder aquisitivo e a renda per capita de um país e/ou mercado. Em suma, os entrevistados destacaram que um dos polos realmente leva em consideração, quando do momento da compra, as preocupações relativas a preço e segurança alimentar, geralmente ligadas a regiões como África, América Latina e Ásia; enquanto o outro polo, com maior poder aquisitivo, leva em conta fatores como sustentabilidade, bem-estar animal, métodos alternativos de produção (orgânicos, por exemplo), entre outros, geralmente relacionados aos EUA e ao continente europeu. Todavia, dependendo do poder aquisitivo de determinadas regiões pertencentes a países do primeiro polo, é possível encontrar nichos de mercado que vão ao encontro das preferências geralmente associadas a países desenvolvidos, como, por exemplo, algumas regiões metropolitanas do Brasil (São Paulo, Curitiba, Rio de Janeiro, etc.) e/ou cidades com elevado poder aquisitivo da China, como, por exemplo, Shanghai, e do Oriente Médio, em países como os Emirados Árabes Unidos, mais especificamente as cidades de Dubai e Rhyad, na Arábia Saudita. 
Figura 19 - Exemplos de produtos tradicionalmente importados por países e regiões selecionadas.

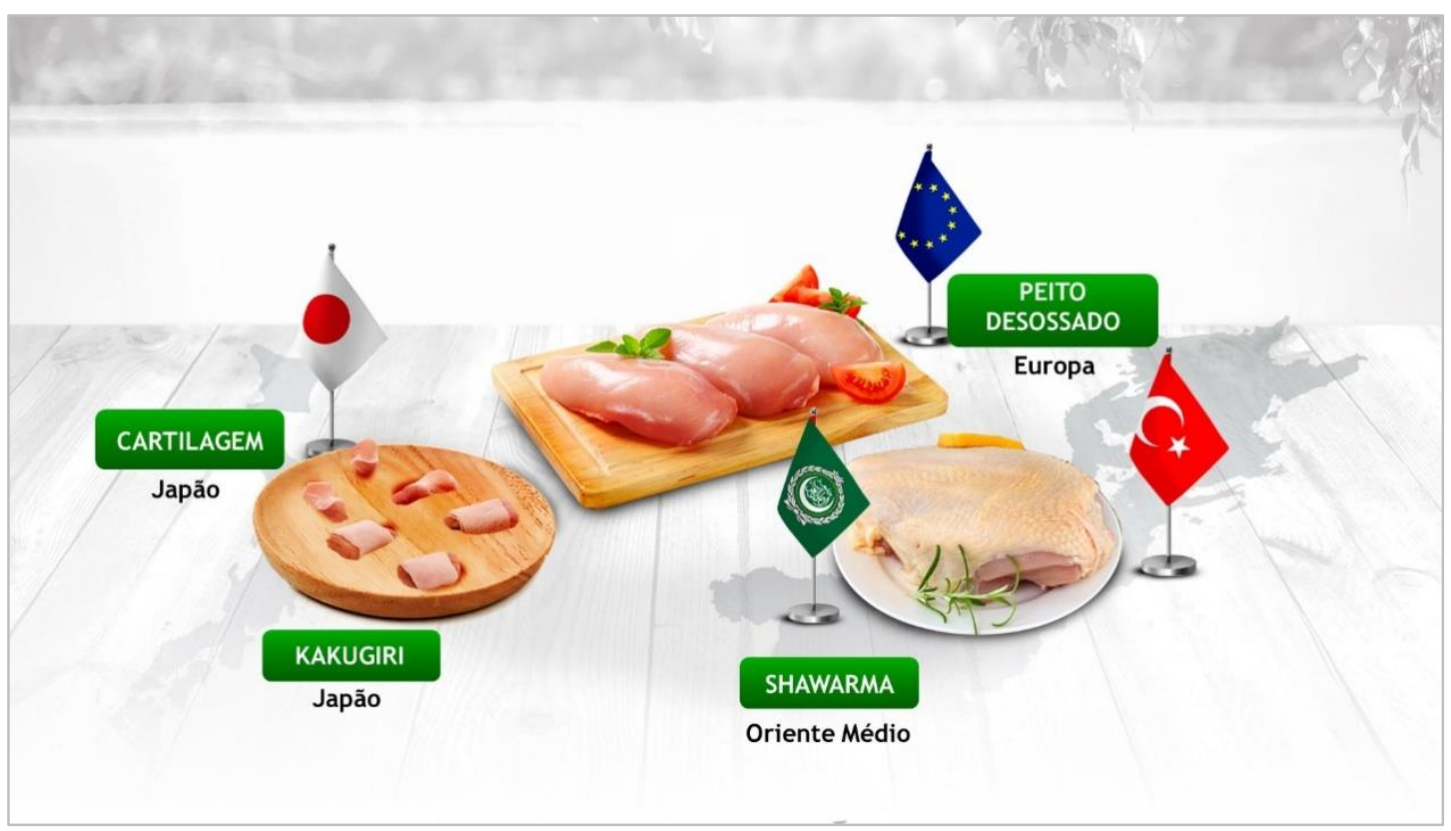

Fonte: ABPA, 2019.

Ao longo do tempo, os hábitos alimentares da população em nível global passaram por um processo de transformação durante as últimas décadas, principalmente, no que se refere às preferências pelas diferentes fontes de proteína. Essa dinâmica influenciou diretamente o comportamento das agroindústrias, sobretudo em relação ao desenvolvimento de novos produtos, mas também teve consequências para os canais de comercialização, como as redes de food service, varejistas e atacadistas que, necessariamente, são o último elo entre os frigoríficos e consumidor final. De acordo com o relatório Evolving Trends in Food and Nutrition, publicado pela Euromonitor International, em 2018, o consumo de alimentos atual apresenta três importantes características que deverão ser as principais tendências nos próximos anos, sobretudo para o conjunto populacional com poder aquisitivo mais elevado e que busca elementos de diferenciação na sua alimentação. São elas: (i) praticidade e conveniência, com embalagens menores, novas categorias, sobretudo com apelos mais nutritivos; (ii) consumo consciente (minduful eating/clean label) e novas crenças alimentares, que refletem a escolha de algumas faixas da população por alimentos menos processados e mais naturais, sem a presença de conservantes, aromas e adoçantes artificiais; (iii) dieta plant-based e busca por proteínas alternativas, com alimentos que, de alguma forma, remetem ao formato, aroma e textura da 
proteína animal tradicional, além da substituição de uma dieta baseada em produtos lácteos por opções derivadas de soja, amêndoas e coco (BAGUL; KOERTEN; REES, 2018).

Importante salientar, no entanto, que apesar das tendências em curso, diversos fatores como crescimento da classe média na Ásia, aumento da população urbana, incremento do mercado de food service, fast food e comidas read-to-eat, voltadas a uma população que busca se alimentar fora de suas residências, ainda farão com que o consumo de proteína animal seja elevado nos próximos anos, o que demandará um esforço e aperfeiçoamento constante de toda a cadeia produtiva, sobretudo dos canais de comercialização, desde os distribuidores locais até pequenos varejos, com o intuito de melhor atender aos anseios do consumidor (DA SILVA, 2013):

[...] the East and Southeast Asia region is expected to see per capita income grow by $60-100 \%$ by 2028 . These higher incomes will result in greater demand for meat in the region, with meat consumption rising by $5 \mathrm{~kg} /$ capita in China and $4 \mathrm{~kg} / \mathrm{capita}$ in Southeast Asia over the medium term. This expansion will be largely concentrated in greater poultry and pork consumption, the two meats most widely consumed in those regions. Beef consumption in China is also expected to rise in per capita terms by 0.5 $\mathrm{kg} /$ capita over the next decade, bringing average consumption to $4 \mathrm{~kg} / \mathrm{capita}$, slightly increasing the share of beef in total meat consumption. [...] Among high-income countries, per capita meat consumption will grow more slowly than in lower income economies. But given relatively high consumption, this translates into a larger absolute increase. Although per capita meat consumption in the United States is expected to grow by only $2 \%$, annual consumption is expected to rise by over $2 \mathrm{~kg} /$ capita, bringing the country's intake above $100 \mathrm{~kg} /$ capita in 2028, still the highest in the world. In total, United States meat consumption is projected to rise by $4 \mathrm{Mt}$, accounting for $10 \%$ of the global growth in food use. Substantive growth in meat consumption in many medium and high-income countries is expected to widen the gap in per capita meat consumption compared to many low income countries, especially in Sub-Saharan Africa (OECD-FAO, 2019).

Importante salientar que esse cenário desafiador de garantia do acesso à proteína e suas particularidades por uma população crescente, sobretudo nos grandes centros, tem gerado importantes dinâmicas quando da comercialização global da carne avícola. De acordo com representantes do setor, que gentilmente contribuíram para o presente trabalho por meio de entrevistas direcionadas, o papel do distribuidor local no abastecimento de países e regiões tem ganhado cada vez mais relevância. O distribuidor local consiste em um grande importador de carne de aves (Ex. Federal Foods e AL Islami-EAU; Al Munajem-Árabia Saudita; entre outros), que atua também no processamento da proteína a ser comercializada localmente, adequando o produto às preferências dos consumidores em uma determinada região. Alguns representantes 
de grandes empresas exportadoras brasileiras, entrevistados para o presente trabalho, atestam que muitas vezes é preferível trabalhar em conjunto com esses distribuidores no intuito de gerar um produto padronizado e que atenda às preferências locais de maneira geral, mas que ainda sofrerá importantes transformações em termos de processamento (sabor, cor, aroma, etc.) e adição de valor por parte desses distribuidores/processadores. Na visão dos profissionais entrevistados, seria inviável, em termos de custos e operacionalização da cadeia, produzir itens demasiadamente específicos para determinados mercados.

Por fim, cabe destacar todo o constante monitoramento que diversas empresas do setor passaram a ter no pós-venda da cadeia avícola. Esse monitoramento e constante relacionamento apresentam importantes iniciativas que visam aproximar de maneira permanente a agroindústria do consumidor final, por meio de canais diretos de comunicação, serviços de atendimento ao consumidor, $F A Q$ s, canais de receita online, entre outras iniciativas.

\subsubsection{ESCOPO GEOGRÁFICO}

Conforme salientado por Gereffi e Fernandez-Stark (2016), a análise do escopo geográfico de uma CGV compreende uma exposição ampla sobre a oferta e demanda dos produtos e setores que envolvem a cadeia. Em suma, busca-se, a partir da análise dos fluxos comerciais globais de carne de aves, compreender como ocorre a participação dos países em face dessa dinâmica. Antes, é importante contextualizar como operam alguns importantes stakeholders da cadeia.

Por se tratar de uma cadeia extremamente verticalizada em nível nacional, as principais empresas fornecedoras (sanidade animal, equipamentos e genética) buscam operar junto às agroindústrias, sobretudo por meio de empresas subsidiárias no país produtor e por importações de insumos específicos de caráter complementar. Os grandes centros de P\&D I de inputs são, geralmente, de empresas baseadas em países desenvolvidos, como Alemanha, França, Inglaterra, EUA, Holanda, entre outros. No caso de saúde animal, por exemplo, destacam-se Evonik (Alemanha), Elanco (EUA), Merck Animal Health (EUA), Farmabase (Brasil), Zoetis (EUA). Em relação à nutrição animal, as empresas com elevada participação no mercado avícola são: Cargill (EUA), BASF (Alemanha), Corteva (EUA), Adisseo (França-Bélgica), entre outros. As empresas-líderes de material genético obedecem ao mesmo padrão, sendo elas: Cobb-Vantress (EUA), Aviagen (EUA) e Hubbard (EUA) (SANTINI, 2006; IFIF, 2019; HEALTH FOR ANIMALS, 2019). 
Conforme exposto anteriormente, ao longo das últimas décadas um conjunto de inovações tecnológicas relativas ao setor de insumos, aliadas ao aperfeiçoamento da nutrição e saúde animal, bem como à ampliação da automatização e utilização de novas tecnologias de informação, comunicação e logística, possibilitaram um notável incremento da produção e exportação de produtos avícolas e de proteína animal em nível mundial.

Segundo dados do USDA, a produção mundial de carnes (suína, bovina e de aves) passou de 214 milhões de toneladas em 2005 para 270 milhões de toneladas em 2018, representando um aumento de $26,4 \%$. A produção de carne suína correspondeu a cerca de $42 \%$ da produção mundial no período analisado, seguida pela carne de aves e a carne bovina com $33 \%$ e $24 \%$ do volume respectivamente. As três proteínas apresentaram aumento no volume produzido nos 14 anos, conforme o Gráfico 3, com destaque para carne de aves, que cresceu 47,9\%, atingindo o patamar de 95,5 milhões de toneladas em 2018. As carnes suína e bovina cresceram apenas $20,6 \%$ e $11,4 \%$ respectivamente. O bom desempenho da carne de aves proporcionou aumento na participação de $30 \%$ para $35 \%$, enquanto a carne suína e a carne bovina reduziram de $44 \%$ para $42 \%$ e $26 \%$ para $23 \%$ do total produzido.

Gráfico 3 - Produção Mundial das carnes de aves, suína e bovina entre 2005 e 2018 (tons).

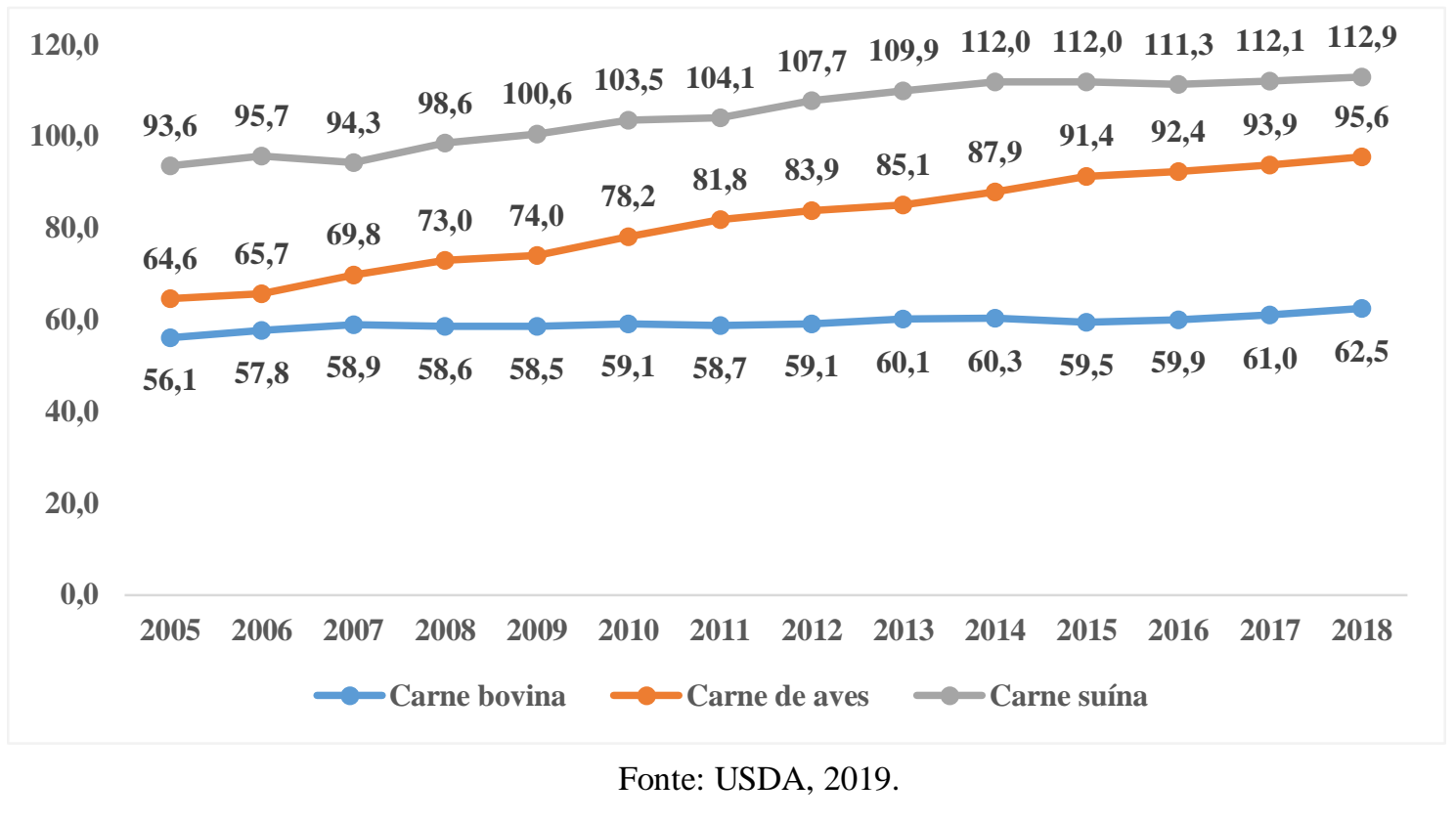

O expressivo crescimento da produção de carne de aves ocorreu em diversos países, não se limitando em apenas uma única região geográfica. A tabela 1, a seguir, mostra os 20 principais países produtores entre 2005 e 2018, que representaram cerca de $96 \%$ do total 
produzido no mundo. Em 2005, o ranking era composto por Estados Unidos, seguido pela China, Brasil e EU-28, com representatividade de 68\% do total produzido. Já em 2018, o ranking se altera para Estados Unidos, Brasil, EU-28 e China, reduzindo sua participação para 59\%. A alteração do ranking ocorreu no ano de 2016, quando a China apresentou quedas constantes no volume produzido, passando à terceira e quarta posição no ranking.

Essa queda da produção chinesa pode ser explicada pelos casos de influenza aviária de alta patogenicidade, que tiveram grandes impactos na produção de diversos países em 2014, 2015, 2016 e 2017. De acordo com a OIE, somente na China, foram registrados cerca 60 mil casos da doença em 2014, 48,6 mil casos em 2015, aumentando para 98,5 mil casos em 2016 e 248,9 mil casos em 2017. Nesses quatro anos, estima-se que 6,8 milhões de aves foram sacrificadas devido à doença (OIE, 2019). É importante destacar, da mesma forma, a expansão da produção em alguns países como Índia, Rússia, México, Tailândia, Turquia e Argentina. Esse grupo de países, que passa a inteirar o ranking dos dez maiores produtores, teve um crescimento de $115 \%$, equivalente a 10,9 milhões de toneladas. 
Tabela 1 - Maiores produtores de carne de aves entre 2005 e 2018 (mil toneladas). Fonte USDA, 2019.

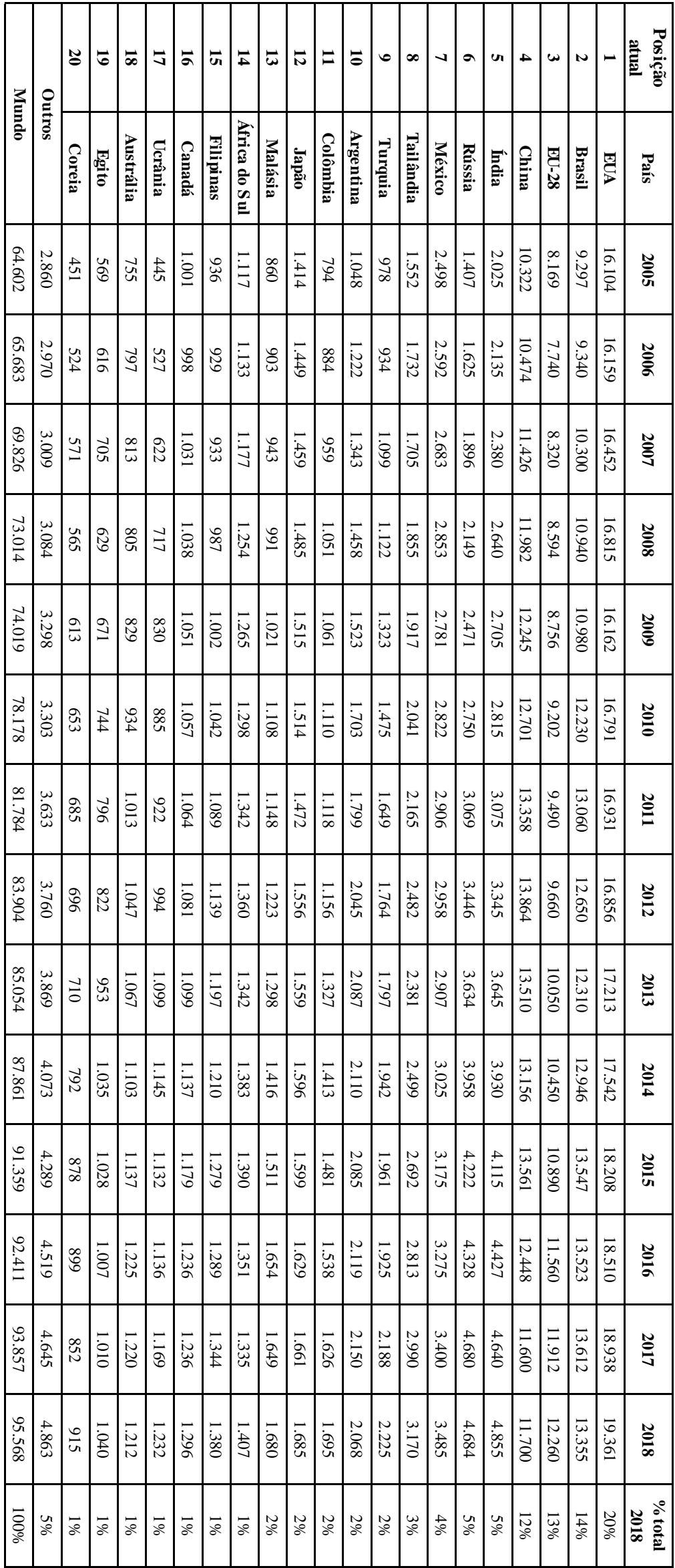


A ampliação da produção desses outros países do ranking apoiou a redução da participação dos quatro principais países produtores. Entre 2005 e 2008, eles representaram cerca de 67\%, passando a quase $65 \%$ entre 2009 e 2012, $61 \%$ entre 2013 e 2016, atingindo a menor participação em 2017 e 2018, 59,5\%. O Gráfico 4, a seguir, detalha evolução das participações dos países em geral.

Gráfico 4 - Evolução das participações em volume dos principais países produtores de carne de aves no mundo.

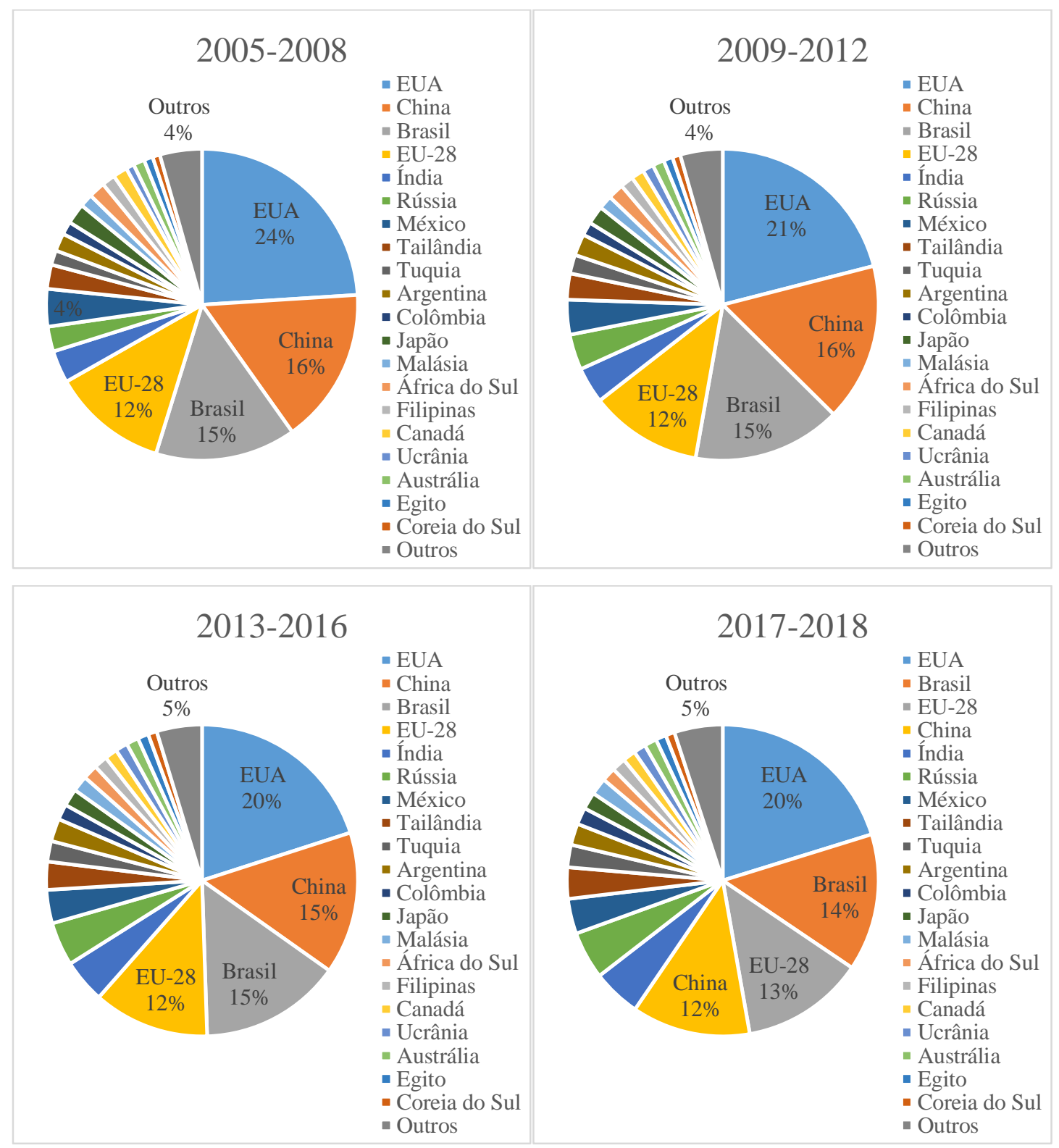

Fonte: USDA, 2019. 
Tabela 2 - Consumo per capita de carne de aves por região entre 2005 e 2018.

\begin{tabular}{|c|c|c|c|c|c|c|c|c|c|c|c|c|c|c|c|}
\hline Região & $\mathbf{2 0 0 5}$ & $\mathbf{2 0 0 6}$ & $\mathbf{2 0 0 7}$ & $\mathbf{2 0 0 8}$ & $\mathbf{2 0 0 9}$ & $\mathbf{2 0 1 0}$ & $\mathbf{2 0 1 1}$ & $\mathbf{2 0 1 2}$ & $\mathbf{2 0 1 3}$ & $\mathbf{2 0 1 4}$ & $\mathbf{2 0 1 5}$ & $\mathbf{2 0 1 6}$ & $\mathbf{2 0 1 7}$ & $\mathbf{2 0 1 8}$ & $\begin{array}{c}\text { Variação } \\
\mathbf{2 0 0 5 / 2 0 1 8}\end{array}$ \\
\hline América do Norte & 45,72 & 45,97 & 45,3 & 45,18 & 43,27 & 44,17 & 44,97 & 43,17 & 43,04 & 43,78 & 46,38 & 47 & 47,43 & 48,07 & $5 \%$ \\
\hline Oceania & 26,37 & 26,78 & 26,33 & 25,48 & 25,45 & 28,1 & 29,64 & 30,73 & 30,43 & 31,03 & 31,77 & 33,88 & 33,36 & 33,77 & $28 \%$ \\
\hline América Latina & 21,82 & 23,38 & 24,3 & 26,28 & 26,11 & 29,76 & 30,79 & 30,72 & 30,89 & 31,3 & 32,1 & 32,01 & 32,43 & 32,45 & $49 \%$ \\
\hline Europa & 17,95 & 17,88 & 19,1 & 20,93 & 19,95 & 20,17 & 20,41 & 21,57 & 21,84 & 22,52 & 23,44 & 24,3 & 24,55 & 24,97 & $39 \%$ \\
\hline Mundo & 10,87 & 11,13 & 11,64 & 12,19 & 12,16 & 12,78 & 13,16 & 13,32 & 13,45 & 13,59 & 13,85 & 14,1 & 14,1 & 14,17 & $30 \%$ \\
\hline Ásia & 6,57 & 6,78 & 7,3 & 7,62 & 7,94 & 8,27 & 8,63 & 8,83 & 9 & 9,03 & 9,07 & 9,39 & 9,28 & 9,33 & $42 \%$ \\
\hline África & 4,03 & 4,06 & 4,41 & 4,55 & 4,69 & 5,01 & 5,21 & 5,44 & 5,56 & 5,6 & 5,49 & 5,33 & 5,43 & 5,38 & $34 \%$ \\
\hline
\end{tabular}

Fonte: OECD-FAO.

De acordo com a OECD-FAO (2019), a carne de aves é a fonte mais barata e acessível de proteína animal para consumidor de baixa renda e vista como a opção de carne mais saudável por seu baixo teor de gordura saturada. Além disso, a carne de aves enfrenta poucas barreiras culturais relacionadas ao consumo, resultando em robusto consumo pelas áreas geográficas. A média mundial de consumo per capita por ano é estimada em 14,17 kg (2018).

Em comparativo da média por região, o consumo na Ásia e na África fica abaixo da média mundial, com 9,33 kg/hab. e 5,38 kg/hab. Já o consumo na Europa, América Latina, Oceania e América do Norte está acima da média mundial, sendo esta última a região com maior consumo per capita, 48,7 kg/hab. O elevado consumo identificado nas Américas e na Oceania pode ser visualizado na tabela 3, a seguir, na qual são apresentados os 20 países com maior consumo per capita no mundo. Os dados mostram que metade dos países estão localizados nas regiões de maior consumo.

A expansão do consumo mundial no período analisado foi viabilizada pela expansão da produção, em $48 \%$, e do comércio internacional, com exportações de $87 \%$ e importações de 79\%. As exportações mundiais passaram de 7 milhões de toneladas em 2005 para 13,2 milhões de toneladas em 2018, com participação $11 \%$ da produção mundial para 14\%. As importações passaram 6,5 milhões de toneladas para 11,8 milhões de toneladas. A tabela 4, a seguir, ilustra que, dentre os 20 principais países produtores, nem todos são considerados como autossuficientes para carne de frango, e somente nove exportam mais do que importam o produto. Países como China, Rússia, Japão, África do Sul, Filipinas e Coreia do Sul necessitam das importações para complementar a produção local. 
Tabela 3 - Consumo per capita de carne de aves entre 2005 e 201 - Países Selecionados. Kg. Fonte: OECD-FAO, 2019.

\begin{tabular}{|c|c|c|c|c|c|c|c|c|c|c|c|c|c|c|c|c|c|c|c|}
\hline & 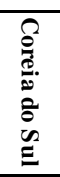 & 島 & & $\overline{2}$ & 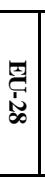 & 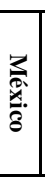 & & & & 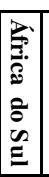 & & $\frac{2}{2}$ & & & 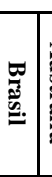 & & & व & 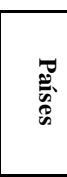 \\
\hline & 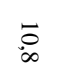 & $\stackrel{N}{\sim}$ & $\stackrel{\vec{N}}{u}$ & {$\left[\begin{array}{l}\vec{u} \\
\vec{t}\end{array} \mid\right.$} & $\begin{array}{c}\infty \\
\infty \\
0\end{array}$ & 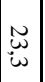 & $\underset{\text { ì }}{\vec{N}}$ & $\vec{a}$ & 岕 & $\simeq$ & $\mid \begin{array}{c}\omega \\
\sigma \\
\sigma\end{array}$ & 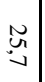 & $\simeq$ & w & 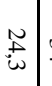 & D & 0 & $\underset{i}{ \pm}$ & 㐱 \\
\hline 5 & $\vec{\sigma}$ & $\vec{u}$ & $\vec{f}$ & $\mid \begin{array}{l}\vec{\partial} \\
\infty\end{array}$ & $\stackrel{\infty}{-}$ & 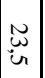 & $\underset{\infty}{\vec{\infty}}$ & $\vec{u}$ & $\underset{\omega}{\omega}$ & $\mid$ & & 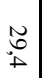 & 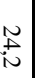 & U & $\stackrel{2}{\alpha}$ & 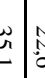 & $\begin{array}{c}0 \\
\text { S. }\end{array}$ & 离 & 气ू̆ \\
\hline$\underset{\sim}{\sim} \underset{\sim}{\sim}$ & $\overrightarrow{+}$ & $\underset{\omega}{\vec{\omega}}$ & $\underset{i}{\vec{i}}$ & $\mid \begin{array}{c}\vec{\infty} \\
\vec{t}\end{array}$ & $\stackrel{5}{-5}$ & 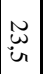 &. & $\begin{array}{l}0 \\
0 \\
\\
\end{array}$ & $\underset{u}{w}$ & 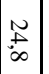 & $\mid \begin{array}{l}\omega \\
\vec{b}\end{array}$ & 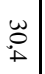 & ب̆ & 雚 & $\underset{v}{N}$ & \begin{tabular}{c}
0 \\
\multirow{L}{*}{}
\end{tabular} & $\begin{array}{c}\mathrm{t} \\
\mathrm{u}\end{array}$ & $\begin{array}{l}+ \\
\infty \\
\infty\end{array}$ & 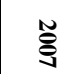 \\
\hline $\bar{u}$ & $\underset{+}{\overrightarrow{+}}$ & $\vec{\omega}$ & $\mid \begin{array}{l}0 \\
0 \\
+ \\
+\infty\end{array}$ & $\left|\begin{array}{|c|}\vec{\infty} \\
0 \\
0\end{array}\right|$ & $\mid \begin{array}{ll}0 \\
i \\
\text { in }\end{array}$ & 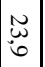 & $\begin{array}{c}0 \\
\widetilde{\sigma} \\
\sigma\end{array}$ & v & 岕 & $\stackrel{\sim}{-1}$ & $\underset{\sim}{~}$ & {$\left[\begin{array}{c}\infty \\
\infty \\
\infty \\
0\end{array}\right]$} & $\stackrel{N}{\sim}$ & ש. & $\frac{\omega}{\overrightarrow{+}}$ & 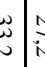 & 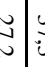 & 蒿 & $\tilde{\tilde{z}}$ \\
\hline$\underset{6}{f}$ & $\stackrel{N}{\sim}$ & $f$ & $\mid \begin{array}{l}0 \\
0 \\
0 \\
0\end{array}$ & $\mid \begin{array}{l}\overrightarrow{0} \\
\dot{w}\end{array}$ & $\mid \begin{array}{l}0 \\
\vdots \\
i n\end{array}$ & 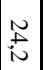 & 芯 & $\frac{N}{N}$ & ש్ర & $\mid$ & $\mid \begin{array}{c}\omega \\
\cdots \\
\sigma\end{array}$ & 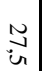 & 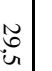 & 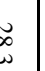 & $w$ & 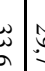 & 0 & $\begin{array}{l}f \\
\sigma \\
a\end{array}$ & 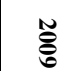 \\
\hline$\overline{\tilde{c}}$ & $\underset{\omega}{\vec{\omega}}$ & $\underset{\omega}{2}$ & $\frac{N}{i N}$ & $\left|\begin{array}{l}\vec{b} \\
\dot{\infty}\end{array}\right|$ & $\begin{array}{l}\overrightarrow{0} \\
\text { in }\end{array}$ & $\begin{array}{l}n \\
i \\
i n\end{array}$ & $\stackrel{n}{\sim}$ & $\frac{N}{\sim}$ & $\underset{\sim}{\stackrel{.}{v}}$ & {$\left[\begin{array}{c}\mathfrak{s} \\
: \\
i\end{array}\right]$} & $\stackrel{\omega}{\omega}$ & $\mathbb{S}$ & $\underset{\omega}{\omega}$ & $\begin{array}{l}\underbrace{}_{\infty} \\
\infty\end{array}$ & $\begin{array}{c}w \\
\infty \\
\infty \\
\infty \\
0\end{array}$ & 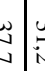 & $\underset{\omega}{\omega}$ & 点 & $\stackrel{\widetilde{O}}{0}$ \\
\hline $\bar{u}$ & $\underset{i}{\vec{f}}$ & $\overrightarrow{6}$ & $\mathbb{8}$ & $\stackrel{\underline{N}}{\omega}$ & $\left(\begin{array}{c}0 \\
\hdashline \\
\sim\end{array}\right.$ & 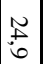 & $\stackrel{\sim}{\square}$ & N & $\begin{array}{l}\infty \\
\infty \\
\infty\end{array}$ & $\left|\begin{array}{c}\infty \\
\infty \\
\infty \\
\infty\end{array}\right|$ & $\left|\begin{array}{c}\vec{\omega} \\
\dot{\omega}\end{array}\right|$ & 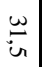 & 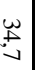 & : & 䓌 & : & 怨: & d. & $\cong$ \\
\hline $\bar{\alpha}$ & $\underset{\omega}{\stackrel{T}{\omega}}$ & $\underset{\sim}{\vec{N}}$ & 思 & $\underset{\infty}{\sim}$ & $\mid \begin{array}{c}0 \\
0 \\
0 \\
\end{array}$ & $\mid \begin{array}{c}\mathfrak{w}_{\infty} \\
\infty\end{array}$ & $\mathbb{N}$ & 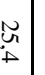 & $\underset{u}{u}$ & 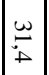 & 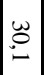 & $\stackrel{\omega}{v}$ & $\begin{array}{l}\omega \\
. \\
\alpha\end{array}$ & ú & 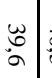 & $\begin{array}{c}t_{n} \\
\end{array}$ & 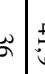 & 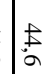 & $\stackrel{\widetilde{N}}{N}$ \\
\hline$\underset{\omega}{\infty}$ & $\underset{+}{F}$ & $\vec{a}$ & $\frac{N}{6}$ & 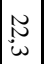 & 总 & $\approx$ & $\stackrel{\sim}{ \pm}$ & 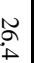 & $\stackrel{t}{*}$ & $\underset{\substack{w \\
\sim \\
\sim}}{w}$ & 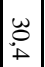 & 岕 & 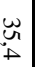 & نّ & . & $\vec{\omega}$ & 5 & $f_{i s}^{t}$ & $\stackrel{\widetilde{\omega}}{\widetilde{\omega}}$ \\
\hline$\underset{\infty}{\vec{\infty}}$ & $\underset{i}{\vec{i}}$ & $\vec{\sim}$ & 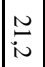 & $\underset{\substack{N \\
\text { N }}}{\mid}$ & $\stackrel{\frac{N}{N}}{\sim}$ & $\begin{array}{l}\alpha \\
\alpha \\
\alpha\end{array}$ & $\underset{\sim}{\approx}$ & $\begin{array}{c}\underset{\infty}{\infty} \\
-\end{array}$ & \pm & $\omega_{\omega}$ & 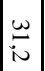 & $\underset{\sim}{w}$ & 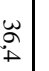 & 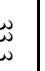 & $\underset{\sim}{\omega}$ & \pm & 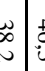 & 总 & $\stackrel{\mathscr{E}}{\underline{E}}$ \\
\hline $\begin{array}{l}n \\
\infty\end{array}$ & $\vec{\nabla}$ & $\underset{\substack{\infty \\
i}}{\vec{\infty}}$ & $\stackrel{N}{=}$ & $\underset{\substack{N \\
心}}{N}$ & 筑 & $\stackrel{\sim}{\simeq}$ & $\stackrel{\sim}{\sim}$ & ָ & $\underset{0}{\mathbb{N}}$ & $\omega$ & 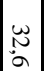 & 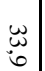 & $\begin{array}{l}w \\
\infty \\
0 \\
0\end{array}$ & W. & $\underset{v}{t}$ & E & 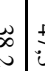 & ज़ & $\stackrel{\widetilde{v}}{\widetilde{U}}$ \\
\hline$\sigma$ & $\vec{u}$ & $\underset{\sim}{\sim}$ & $\mid \begin{array}{l}n \\
0 \\
i n\end{array}$ & 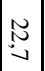 & $\underset{\substack{\sim \\
N}}{\mathbb{N}}$ & 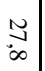 & 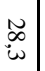 & 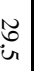 & $\stackrel{ \pm}{u}$ & $\omega$ & $\underbrace{w}_{\substack{\omega \\
\omega}}$ & $\mid$ & $\begin{array}{l}w \\
\infty \\
a \\
a\end{array}$ & u & $t$ & $\frac{t}{t}$ & 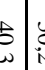 & 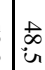 & $\stackrel{\widetilde{O}}{\widetilde{\sigma}}$ \\
\hline $\bar{\Xi}$ & $\underset{i}{\vec{N}}$ & $\underset{+}{\vec{b}}$ & $\cong$ & 岕 & 怘 & $\left.\mid \begin{array}{c}\underset{\infty}{\infty} \\
\sim \\
\sim\end{array}\right]$ & 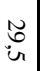 & $\frac{\omega}{N}$ & 岕 & 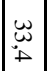 & $\mid \begin{array}{l}w \\
. \\
o \\
o\end{array}$ & $\omega$ & 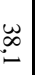 & $\begin{array}{l}w_{\infty} \\
+ \\
t\end{array}$ & 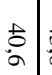 & $\begin{array}{ll}t \\
t \\
0.5\end{array}$ & $=\frac{1}{g}$ & t & $\stackrel{\cong}{\triangleq}$ \\
\hline$\underset{\sim}{N}$ & $\vec{\infty}$ & $\underset{\omega}{\vec{\omega}}$ & $\cong$ & $\sim$ & $\mid \begin{array}{l}\tilde{u} \\
\sigma\end{array}$ & $\left.\begin{array}{c}\tilde{\infty} \\
\infty \\
\infty\end{array}\right]$ & 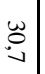 & $\frac{\omega}{\Delta}$ & $\underset{N}{\stackrel{\sim}{N}}$ & $\underset{\substack{w \\
\sim}}{\sim}$ & $\mid \begin{array}{c}\underset{w}{w} \\
\infty \\
\infty\end{array}$ & $\mid \begin{array}{l}\text { w. } \\
\text { s. } \\
\text { s. }\end{array}$ & $\begin{array}{c}\text { 岕 } \\
\text { in }\end{array}$ & 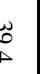 & $\begin{array}{l}\omega \\
\infty \\
\infty\end{array}$ & $E$ & $=1$ & $\stackrel{t}{\vec{v}}$ & $\stackrel{\widetilde{O}}{\infty}$ \\
\hline de & $\begin{array}{l}\text { aे } \\
\text { a }\end{array}$ & $\begin{array}{l}\text { Ua } \\
\text { वे }\end{array}$ & $\mid \begin{array}{l}\vec{a} \\
\vec{a} \\
a^{2}\end{array}$ & $\left|\begin{array}{c}1 \\
0 \\
\partial^{2}\end{array}\right|$ & $\begin{array}{l}\tilde{a} \\
\text { da }\end{array}$ & $\mid \begin{array}{c}0 \\
\frac{1}{d a}\end{array}$ & $\stackrel{8}{\circ}$ & & $\frac{1}{\partial}$ & $\frac{9}{2}$ & à & $\left|\begin{array}{c}\vec{t} \\
\partial^{2}\end{array}\right|$ & $\begin{array}{c}\infty \\
\mathbb{1} \\
d \\
d\end{array}$ & 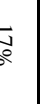 & $\frac{8}{\partial^{2}}$ & 苞 & & & 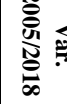 \\
\hline
\end{tabular}


Tabela 4 - Comparativo de indicadores - 20 principais produtores mundiais de carne de aves.

\begin{tabular}{|c|c|c|c|c|c|c|c|c|c|c|}
\hline \multirow{2}{*}{ País } & \multicolumn{2}{|c|}{$\begin{array}{c}\text { Produção } \\
\text { (mil tons) }\end{array}$} & \multicolumn{2}{c|}{$\begin{array}{c}\text { Consumo Per } \\
\text { capita } \\
\text { (kg/hab) }\end{array}$} & \multicolumn{2}{c|}{$\begin{array}{c}\text { Exportação } \\
\text { (mil tons) }\end{array}$} & \multicolumn{2}{c|}{$\begin{array}{c}\text { Importação } \\
\text { (mil tons) }\end{array}$} & \multicolumn{2}{c|}{$\begin{array}{c}\text { Exportação - } \\
\text { Importação }\end{array}$} \\
\cline { 2 - 14 } & $\mathbf{2 0 0 5}$ & $\mathbf{2 0 1 8}$ & $\mathbf{2 0 0 5}$ & $\mathbf{2 0 1 8}$ & $\mathbf{2 0 0 5}$ & $\mathbf{2 0 1 8}$ & $\mathbf{2 0 0 5}$ & $\mathbf{2 0 1 8}$ & $\mathbf{2 0 0 5}$ & $\mathbf{2 0 1 8}$ \\
\hline EUA & 16.104 & 19.361 & 47,3 & 49,7 & 2.082 & 3.430 & 50 & 112 & 2.032 & 3.318 \\
\hline Brasil & 9.297 & 13.355 & 24,3 & 39,8 & 2.846 & 4.018 & 1 & 3 & 2.845 & 4.014 \\
\hline EU-28 & 8.169 & 12.260 & 18,6 & 23,6 & 878 & 1.775 & 833 & 956 & 45 & 819 \\
\hline China & 10.322 & 11.700 & 8,9 & 11,6 & 332 & 447 & 371 & 502 & -39 & -55 \\
\hline Índia & 2.025 & 4.855 & 1,1 & 2,4 & 1 & 7 & 0 & 0 & 1 & 7 \\
\hline Rússia & 1.407 & 4.684 & 16,5 & 31,4 & 9 & 187 & 1.225 & 220 & -1.216 & -33 \\
\hline México & 2.498 & 3.485 & 23,3 & 28,8 & 1 & 6 & 385 & 823 & -384 & -816 \\
\hline Tailândia & 1.552 & 3.170 & 10,2 & 7,9 & 241 & 934 & 0 & 2 & 240 & 932 \\
\hline Turquia & 978 & 2.225 & 12,1 & 19,3 & 44 & 477 & 0 & 6 & 44 & 472 \\
\hline Argentina & 1.048 & 2.068 & 21 & 38,2 & 115 & 164 & 3 & 11 & 112 & 153 \\
\hline Colômbia & 794 & 1.695 & 16,2 & 30,7 & 0 & 2 & 2 & 86 & -2 & -84 \\
\hline Japão & 1.414 & 1.685 & 13,2 & 16,9 & 2 & 10 & 749 & 1.077 & -747 & -1.067 \\
\hline Malásia & 860 & 1.680 & 33,5 & 48,7 & 1 & 18 & 18 & 71 & -17 & -54 \\
\hline África do Sul & 1.117 & 1.407 & 21 & 33,7 & 4 & 52 & 189 & 539 & -185 & -488 \\
\hline Filipinas & 936 & 1.380 & 7,2 & 13 & 4 & 1 & 28 & 287 & -23 & -286 \\
\hline Canadáy & 1.001 & 1.296 & 31,6 & 33,8 & 106 & 128 & 123 & 170 & -16 & -42 \\
\hline Ucrânia & 445 & 1.232 & 12,5 & 21,1 & 9 & 331 & 143 & 124 & -134 & 207 \\
\hline Austrália & 755 & 1.212 & 34 & 44,1 & 19 & 38 & 0 & 10 & 19 & 28 \\
\hline Egito & 569 & 1.040 & 7,6 & 11,3 & 0 & 0 & 0 & 45 & 0 & -45 \\
\hline Coreia do Sul & 451 & 915 & 10,8 & 18 & 2 & 33 & 59 & 163 & -56 & -130 \\
\hline
\end{tabular}

Fonte: Trademap, 2019.

Os maiores exportadores mundiais de carne de frango são Brasil, seguido de Estados Unidos e UE-28. De 2005 a 2018, o volume exportado por eles teve aumento de 59\%, passando de 5,8 milhões para 9,2 milhões de toneladas. O Brasil foi o maior exportador no período analisado, entretanto, os Estados Unidos tiveram o maior incremento de volume, e a EU-28 apresentou o maior percentual de crescimento. A queda das exportações americanas em 2015 está relacionada aos casos de influenza aviária de alta patogenicidade, que se iniciaram em dezembro de 2014 e foram encerrados em junho de 2015 e geraram custo de 850 milhões de dólares. De acordo com o USDA, o maior desastre na avicultura americana causou a destruição de aproximadamente 50 milhões de aves, incluindo galinhas e perus, alavancando os preços dos produtos avícolas e reduzindo exportações. A doença também foi detectada na China em 2014 e na Turquia em 2015, gerando a destruição de 5,3 milhões e 2 milhões de aves. Apesar da presença da doença, outros países que também tiveram grande crescimento no período foram Tailândia, Turquia e Ucrânia, com aumentos de 694 mil toneladas (+288\%), 433 mil toneladas $(+974 \%)$ e 321 mil toneladas $(+3.482 \%)$ respectivamente (USDA, 2019). 
Tabela 5 - Principais exportadores mundiais de carne de frango (mil tons). Fonte: Trademap, 2019.

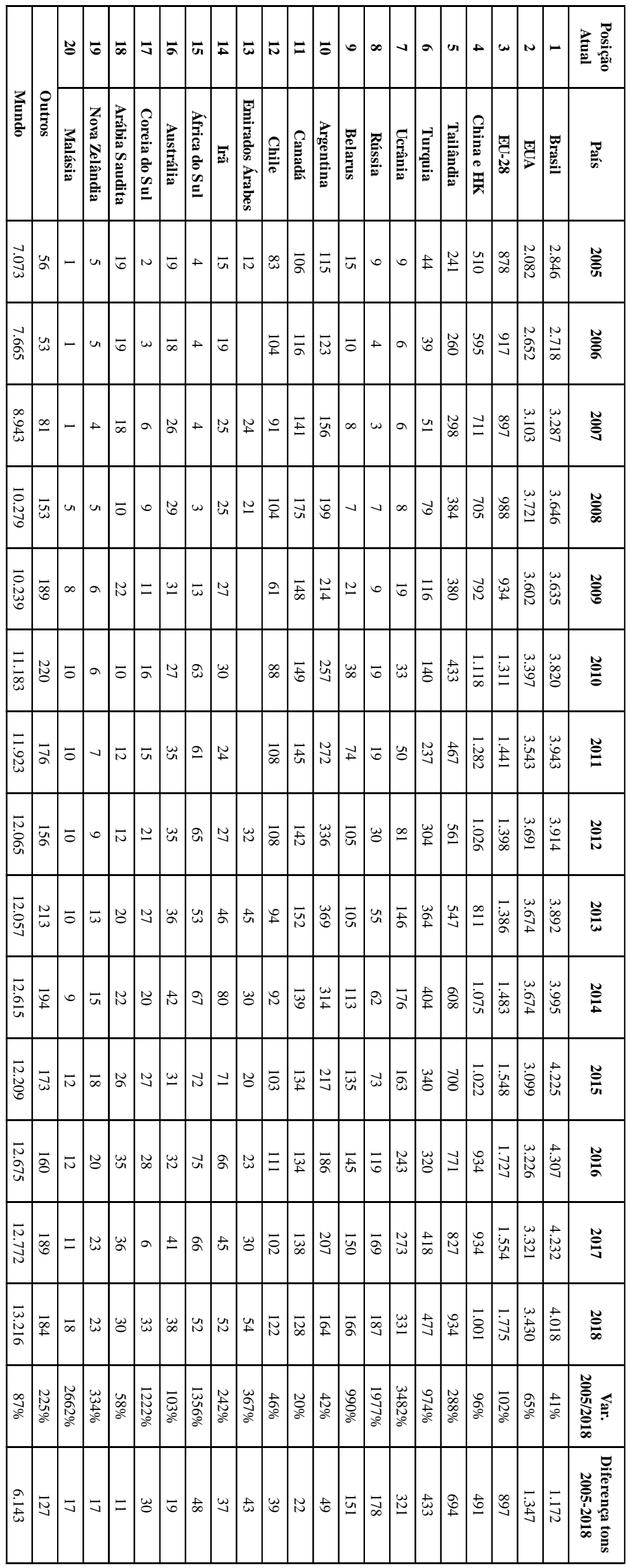


O ranking dos maiores importadores mundiais de carne de frango teve grande alteração ao longo do período. Em 2005, a Rússia era a maior importadora, seguida de China e Hong Kong, EU-28, Japão e Arábia Saudita, sendo as cinco primeiras posições responsáveis por 58\% do volume importado. A Rússia, que possuía um programa estatal para buscar a autossuficiência em carne de frango, reduziu drasticamente duas importações no período analisado, atingindo a décima segunda posição no ranking em 2018. Em contrapartida, a China, o Japão e México passam a ocupar a primeira, segunda e quarta posição no ranking, aumentando em 50\%, 44\% e $114 \%$ suas importações. O aumento dos volumes de vários países, incluindo outros pequenos mercados, levaram à redução da participação dos cinco maiores a 36\% ao longo do período analisado. 
Tabela 6 - Principais importadores mundiais de carne de frango (mil tons). Fonte: Trademap, 2019.

\begin{tabular}{|c|c|c|c|c|c|c|c|c|c|c|c|c|c|c|c|c|c|c|c|}
\hline & $\tilde{0}$ & $\overrightarrow{\boldsymbol{\omega}}$ & $\vec{\infty}=$ & & $\overrightarrow{\vec{v}} \overrightarrow{\mathrm{v}}$ & $\vec{A}$ & $\vec{\omega}$ & $\vec{N}$ & & & 0.0 & & 0 & or & $\rightarrow$ & $\omega$ & N. & 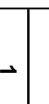 & 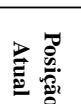 \\
\hline & 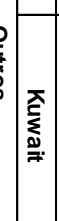 & 尊) & 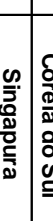 & 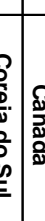 & 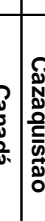 & 赵 & 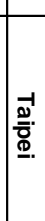 & 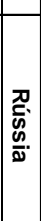 & $\stackrel{\varrho}{\frac{\varrho}{\Phi}}$ & & ئ & & 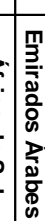 & 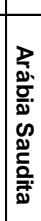 & 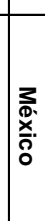 & 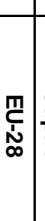 & & & $\vec{D}$ \\
\hline 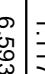 & & $\vec{A}$ & ठे. & & 岕 & $\mathbb{\infty}^{\infty}$ & जे & & $\vec{\omega} \mid$ & $\underset{\infty}{\infty}$ & 0 & & $\overrightarrow{\vec{N}}$ & & 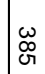 & $\begin{array}{c}\stackrel{\infty}{\omega} \\
\omega\end{array}$ & & $\begin{array}{l}\infty \\
0 \\
\infty \\
\infty \\
\end{array}$ & 彦 \\
\hline $\begin{array}{l}\mathbb{S} \\
\text { s }\end{array}$ & 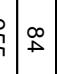 & $\tilde{0}$ & $\stackrel{\circ}{\circ}$ & & \begin{tabular}{l|l}
$\overrightarrow{⿱ ⺊ 口}$ \\
\end{tabular} & $O r$ & 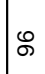 & $|\overrightarrow{\overrightarrow{\vec{\alpha}}}|$ & & w & 。 & & 30 & & 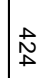 & 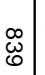 & & $\overrightarrow{\overrightarrow{\vec{\omega}}}$ & క్ \\
\hline & & $\tilde{+}$ & $\overrightarrow{\vec{A}}$ & & $\vec{\square}$ & ov & ભ & $\mid \begin{array}{l}\vec{N} \\
\text { N } \\
\text { N }\end{array}$ & $\overrightarrow{\widetilde{\Omega}}$ & & $\overrightarrow{\overrightarrow{0}}$ & & $\frac{N}{\mathrm{~V}}$ & & 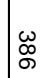 & $\mid \begin{array}{l}0 \\
\stackrel{0}{~}\end{array}$ & & 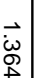 & 气ั \\
\hline$\dot{8}$ & & $\tilde{\sigma}$ & $\vec{\nabla}$ & & $\vec{\Delta} \mid \vec{\omega}$ & $N$ & 8 & $\overrightarrow{\overrightarrow{\vec{\partial}}}$ & $\vec{\sigma}$ & a & & & 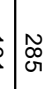 & & $\vec{\omega}$ & $\mid \begin{array}{l}\infty \\
\& \\
\&\end{array}$ & & 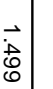 & $\tilde{\mathrm{E}}$ \\
\hline & & $\begin{array}{l}\omega \\
\infty\end{array}$ & $\overrightarrow{\vec{\Delta}}=$ & $\Delta=$ & $\vec{v}$ & oै & 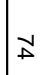 & 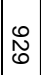 & $\mid \overrightarrow{\vec{v}}$ & & $\overrightarrow{\vec{y}}$ & สิ & 0 & & 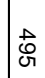 & $\mid$\begin{tabular}{|c|}
$\mid \overrightarrow{0}$ \\
$\vdots$ \\
0
\end{tabular} & & $\overrightarrow{\mathrm{r}}$ & 荛 \\
\hline og & $\begin{array}{lll}0 \\
0 \\
0\end{array}$ & $\stackrel{P}{v}=$ & $\overrightarrow{\vec{\omega}} \mid \vec{\partial}$ & & $\overrightarrow{\vec{A}}$ & $\vec{\circ}$ & $\vec{\Xi}$ & $\frac{\sigma}{\infty}$ & $|\vec{\infty}|$ & & : & & 0 & & Чુ & $\mid \begin{array}{l}\vdots \\
\vdots \\
\vdots\end{array}$ & & 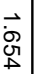 & $\stackrel{\widetilde{O}}{0}$ \\
\hline & \begin{tabular}{|l|l}
$\vec{N}$ \\
$\vec{N}$
\end{tabular} & जे & $\overrightarrow{\vec{v}} \mid \vec{a}$ & $\vec{\omega}$ & $\vec{~}$ & $\overrightarrow{\mathrm{v}}$ & $\vec{\infty}$ & $\vec{\omega}$ & $|\vec{\omega}|$ & $\overrightarrow{\vec{\infty}}$ & $\underset{\omega}{\mathcal{W}}$ & $\underset{\widetilde{\sigma}}{\omega}$ & 0 & & $\begin{array}{l}\mathscr{O} \\
\mathbb{O}\end{array}$ & $\mid \overrightarrow{\dot{\vec{\Xi}}}$ & $\begin{array}{l}\infty \\
\& \\
\infty\end{array}$ & $\overrightarrow{\vec{v}}$ & $\tilde{气}$ \\
\hline $\begin{array}{l}\tilde{n} \\
\tilde{u} \\
\tilde{c}\end{array}$ & $\begin{array}{lll}0 \\
\vdots \\
\vdots\end{array}$ & $N \vec{D}$ & $\vec{\omega} \mid \vec{\omega}$ & & $\vec{c} \vec{c}$ & $\overrightarrow{\mathrm{N}}$ & $\overrightarrow{\widetilde{\omega}}$ & $\vec{v}$ & $\vec{\S}$ & $\vec{N}$ & 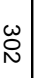 & & 䓌 & जे & $\frac{\sigma}{\infty}$ & $\left|\begin{array}{|c|}\mid \\
0 \\
0 \\
0\end{array}\right|$ & & $\overrightarrow{\vec{\omega}}$ & $\tilde{气}$ \\
\hline$F$ & & 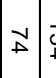 & \begin{tabular}{l|l}
$\vec{\omega}$ & $\vec{N}$
\end{tabular} & $\vec{v} \mid$ & $\stackrel{\vec{c}}{\mathrm{C}} \overrightarrow{\mathrm{J}}$ & $\overrightarrow{\ddot{\theta}}$ & $\vec{\exists}$ & $\stackrel{G}{\vec{I}}$ & $\mid$\begin{tabular}{|c|}
$\vec{\infty}$ \\
$\sim$ \\
$\sim$
\end{tabular} & $\overrightarrow{\mathrm{\Delta}}$ & 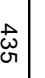 & & 空 & & 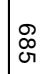 & $\mid$ & $\begin{array}{c}\infty \\
\text { 品 }\end{array}$ & $\begin{array}{l}\overrightarrow{\vec{\Delta}} \\
\text { a }\end{array}$ & $\stackrel{\widetilde{\omega}}{\widetilde{\omega}}$ \\
\hline$\dot{\sigma}$ & & $\stackrel{\infty}{v}$ & $\stackrel{\vec{\omega}}{\vec{\nexists}}$ & $\vec{E}$ & $\begin{array}{l}\overrightarrow{3} \\
\vec{u}\end{array}$ & & $\vec{\nexists}$ & $\$$ & 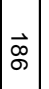 & $\vec{N}$ & \& & 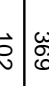 & $\left.\right|_{\infty} ^{+}$ & & 孞 & $\left.\mid \begin{array}{l}\infty \\
\oplus \\
\omega\end{array}\right]$ & 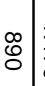 & $\overrightarrow{\mid \vec{\Delta}}$ & $\stackrel{\widetilde{O}}{\mathscr{E}}$ \\
\hline$\ddot{\otimes}$ & & $\vec{c}$ & $\overrightarrow{\vec{\Delta}} \mid \overrightarrow{\vec{\omega}}$ & $\overrightarrow{0}$ & $\omega \vec{\Phi}$ & & $\stackrel{\vec{\infty}}{\rightarrow}$ & $\stackrel{N}{ \pm}$ & $\mid$ & $\vec{\Phi}$ & $\frac{\omega}{\not}$ & is fo & 俞 & & $\stackrel{\sigma}{\sigma}$ & $\mid \vec{b}$ & 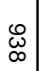 & 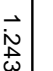 & 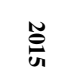 \\
\hline i & & $\vec{\omega}$ & $\overrightarrow{\stackrel{B}{N}} \mid \vec{\infty}$ & & t) & $\stackrel{\square}{\not}$ & $\overrightarrow{\vec{g}}$ & $\frac{N}{\overrightarrow{0}}$ & $\mid \begin{array}{c}\tilde{\omega} \\
\omega\end{array}$ & $\begin{array}{l}\sim \\
\vec{\omega}\end{array}$ & $\underset{\infty}{\infty}$ & ثي & רָ & & $\underset{\varnothing}{\varnothing}$ & $\mid \begin{array}{l}0 \\
0 \\
\infty\end{array}$ & & $\overrightarrow{\vec{E}}$ & 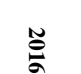 \\
\hline = & \begin{tabular}{|l|l|}
$\vec{\omega}$ \\
\end{tabular} & $\vec{\omega}$ & $\overrightarrow{⿱ \vec{N}} \mid \vec{\Omega}$ & $\vec{\omega}$ & $\vec{a}$ & $\overrightarrow{\mathrm{o}}$ & $\overrightarrow{\substack{\omega \\
\infty}}$ & $\begin{array}{l}N \\
N \\
+\end{array}$ & 怘 & 용 & 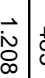 & 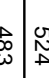 & 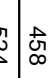 & & $\stackrel{\infty}{\circ}$ & \begin{tabular}{|l|}
0 \\
मे \\
\end{tabular} & 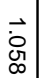 & $\overrightarrow{\dot{\omega}_{\tilde{\omega}}}$ & $\widetilde{\widetilde{\Xi}}$ \\
\hline 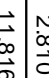 & $\overrightarrow{\mathrm{\omega}}$ & $\vec{G} \mid \vec{\partial}$ & 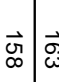 & 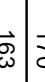 & $\vec{\Delta}]$ & స్ & $\frac{N}{v}$ & $\tilde{N}$ & $\underset{\stackrel{\infty}{\infty}}{\mid}$ & 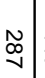 & 点 & $\begin{array}{l}\vec{b} \\
\text { by }\end{array}$ & 8 & 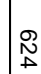 & $\underset{\omega}{\stackrel{\infty}{\infty}}$ & 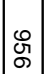 & & $\begin{array}{l}\overrightarrow{\hat{U}} \\
\stackrel{\emptyset}{\emptyset}\end{array}$ & $\stackrel{\varrho}{\infty}$ \\
\hline $\begin{array}{l}0 \\
0 \\
0\end{array}$ & & 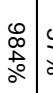 & 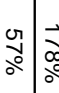 & 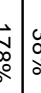 & \begin{tabular}{l|l}
0 \\
0 \\
0 \\
0 \\
0
\end{tabular} & $\begin{array}{l}\mathscr{D} \\
\text { d. } \\
\text { o. }\end{array}$ & \begin{tabular}{|l}
$\vec{\Phi}$ \\
o \\
o \\
0
\end{tabular} & 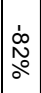 & $\left|\begin{array}{|c}\overrightarrow{0} \\
\text { on } \\
0\end{array}\right|$ & 怘 & & $\begin{array}{l}\overline{0} \\
0 \\
0\end{array}$ & $\frac{1}{\vec{t}}$ & $\mid \begin{array}{l}\omega \\
\text { o. } \\
\circ\end{array}$ & 崌 & \begin{tabular}{|c|}
$\overrightarrow{0}$ \\
응
\end{tabular} & $\begin{array}{c}\stackrel{\overrightarrow{0}}{\circ} \\
\frac{\mathrm{o}}{\circ}\end{array}$ & $\begin{array}{l}\stackrel{1}{\circ} \\
\circ\end{array}$ & 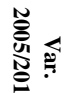 \\
\hline 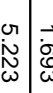 & & $\vec{\omega}$ & $\stackrel{\infty}{\infty} \vec{\AA}$ & $\vec{b}$ & $A \stackrel{\infty}{\wedge}$ & $\vec{\infty}$ & $\overrightarrow{\tilde{\omega}}$ & $\begin{array}{l}\overrightarrow{\dot{\delta}} \\
\text { ì }\end{array}$ & $\overline{\mathrm{\omega}}$ & | & $\stackrel{t}{v}$ & $\begin{array}{c}\Delta \\
B\end{array}$ & $\begin{array}{l}\text { o. } \\
\text { s. }\end{array}$ & & 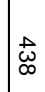 & $\overrightarrow{\tilde{\omega}}$ & 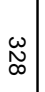 & & 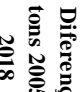 \\
\hline
\end{tabular}




\subsubsection{GOVERNANÇA}

A análise da governança de uma CGV permite a compreensão de como a cadeia é controlada e coordenada por determinados atores em detrimento de outros. A governança pode ser caracterizada como "authority and power relationships that determine how financial, material and human resources are allocated and flow within a chain" (GEFEFFI; FERNANDEZ STARK, 2016, p. 10). Conforme exposto no primeiro capítulo do presente trabalho, há cinco tipos de governança: (i) mercado; (ii) modular; (iii) relacional; (iv) cativa; e (v) hierárquica, as quais variam em torno de três eixos, quais sejam: (i) complexidade das transações; (ii) habilidade em codificar transações e (iii) competência dos fornecedores.

Ao se analisar a governança da CGV avícola, é importante ter presente as principais características do sistema de integração entre frigorífico e produtor, uma vez que se trata da forma mais tradicional de obtenção da principal da matéria-prima - frango de corte — por parte da agroindústria processadora. Ao se analisar as especificidades do modelo, pode-se caracterizar de maneira mais correta o tipo de governança pelo qual se caracteriza a CGV avícola.

De maneira geral, as empresas buscaram no modelo de integração uma maneira eficiente de internalizar eventuais custos de transação que gerariam incertezas à obtenção do frango de corte. Por meio de contratos e da formalização de direitos e obrigações, os grandes frigoríficos repassaram a responsabilidade de criação do frango vivo aos integrados, os quais tornaram-se parte fundamental da estratégia produtiva da empresa. Dessa forma, as integradoras passaram a coordenar as ações dos integrados, por meio de sua série de ações que vão desde a genética até o manejo. Em suma, a empresa integradora, geralmente, fornece ao produtor o pinto de um dia, ração e assistência técnica. O produtor, por sua vez, é responsável pelas instalações, os equipamentos e as despesas operacionais do aviário. A sinergia da operação certamente é a grande responsável pelo elevado nível de eficiência da produção, gerando escala e boa capacidade de distribuição por parte dos grandes frigoríficos (LAZZARI, 2004; ARAÚJO et al., 2008):

O controle de todo o processo produtivo passou a ser comandado por grandes empresas, desde a criação de matrizes, a incubação dos ovos, a produção da ração, até o abate e a comercialização, mantendo-se apenas a fase de engorda do frango sob atribuição de pequenos e médios produtores, ainda que submetidos à indústria por meio de contratos, formais ou não, e sob suas 
recomendações técnicas e organizacionais. (TAKAGI et al., 2002 apud LAZZARI, 2004, p. 260).

No caso do Brasil, essa virtuosa integração e coordenação vertical na indústria avícola foi preponderante para ganhos de eficiência, produtividade e diminuição dos custos de produção nas últimas décadas (VALDES; HALLAHAN; HARVEY, 2015). Importante salientar, como observam Araújo et al. (2008), que o integrado é parte fundamental do processo de obtenção de matéria-prima pela agroindústria, com elevado nível de controle na operação de campo, mas que está intrinsicamente ligada à macro-estratégia da integradora:

Neste cenário, a estrutura clássica de mercado apropriada é o Monopsônio existência de muitos vendedores e um único comprador. Nesta relação a oferta é otimizada, formada por centenas de aviários com tamanhos não muito diferenciados e, portanto, com capacidade de oferta semelhante, sendo a procura monolítica (único comprador). Dessa forma, o negócio do integrado não faz parte de um mercado de livre concorrência, dentro dos moldes tradicionais ou das variáveis que caracterizam o mercado capitalista como competitividade, negociação, informação, crescimento e perspectivas. Com relação ao integrado o preço do seu produto, o frango vivo, o sistema de integração não permite que seja formador, mas sim tomador de preço. Tal estrutura não permite a independência do elo aviário/integrado, o que o coloca como parte de um todo, indissociável do núcleo central, no caso, o frigorífico, exercendo a agroindústria, o total controle de preço e demanda. (ARAÚJO et al., 2008, p. 9).

Dessa forma, por apresentar elevado grau de assimetria de poder com alta capacidade de coordenação explícita, através de empresas-líderes que comandam a relação sobre pequenos produtores, a dinâmica entre integrado e agroindústria configura-se entre as opções cativa e hierárquica de governança. De acordo com Gereffi, Humphrey e Sturgeon (2005, p. 8), os três eixos que caracterizam os tipos de governança devem ser interpretados da seguinte forma:

a) Complexidade das transações: "The complexity of information and knowledge transfer required to sustain a particular transaction, particularly with respect to product and process specifications". Nesse quesito, a CGV avícola apresenta elevada complexidade de transações entre integrado e agroindústria, uma vez que a obtenção do frango de corte, principal insumo da cadeia, com a devida qualidade, sanidade e integridade deve obedecer a uma série de processos que começam desde o campo e vão até o momento do abate.

b) Habilidade em codificar transações: "the extent to which this information and knowledge can be codified and, therefore, transmitted efficiently and without 
transaction-specific investment between the parties to the transaction". Como foi possível observar, a interação entre integrado e agroindústria perpassa uma série de etapas coordenadas e padrões de atividade que demandam um maciço investimento de uma contraparte em relação à outra. A agroindústria fornece uma série de insumos, instruções, além de monitorar constantemente o desempenho do avicultor. Nesse sentido, a habilidade em codificar as transações do integrado, sem que haja esse tipo de interação e investimento é baixa, o que torna a agroindústria um ator fundamental também no processo que ocorre no campo.

c) Competência dos fornecedores: "the capabilities of actual and potential suppliers in relation to the requirements of the transaction". Tanto a governança hierárquica quanto a cativa pressupõem uma baixa competência dos fornecedores. Aqui, no entanto, deve-se compreender um pouco mais sobre a que se refere esse baixo nível de competência. O produtor avícola dispõe de elevada competência para a realização de suas funções, fator que denota a notória produtividade advinda do sistema de integração em diversas partes do mundo. Todavia, é importante salientar que, de acordo com o que foi exposto até aqui, o produtor é praticamente parte integrante da cadeia. Por meio de contratos e de mecanismos de monitoramento, há uma distinção clara das funções entre integrado e integradora, mas não há distinção da macroestratégia a ser executada entre ambos: eficiência, produtividade e qualidade do produto final. Nesse sentido, pode-se dizer que a agroindústria internalizou o processo de obtenção de sua principal matéria-prima, o frango de corte, por meio do controle sistemático da produção, utilizando o produtor como seu principal vetor. Esse é o cerne da relação entre ambos e sem essa relação, o elevado nível de competência do integrado, baseado no controle, inspeção, metas, pesquisa, desenvolvimento e inovação, estaria comprometido. Dessa forma, colocada de maneira isolada, sem a existência de uma parceria, a competência de um simples fornecedor, tendo em vista a macroestratégia produtiva, é baixa. Todavia, por meio do sistema integrado de produção, em que empresa líder assume elevados custos de ação coletiva, a competência dos fornecedores é elevada e comprovada cotidianamente.

Dessa forma, pode-se classificar a governança da CGV avícola como sendo hierárquica, em razão da elevada complexidade de obtenção do principal insumo — frango de corte — e da 
necessidade de internalização, mesmo que por meio do sistema de integração — de praticamente todos os processos produtivos por conta das empresas-líderes ou agroindústrias.

\subsubsection{UPGRADING}

Como já elucidado no primeiro capítulo do presente trabalho, o upgrading econômico é definido por Gereffi e Fernandez-Stark (2016, p. 12) como "countries or regions moving to higher value activities in GVCs in order to increase the benefits (e.g. security, profits, valueadded, capabilities) from participating in global production". Em geral, podem-se identificar quatro tipos de upgrading em uma CGV: (i) processo, em que uma empresa passa reorganizar parte de seu sistema produtivo, com a inserção de novas atividades; (ii) produto, no qual passase a fabricar produtos mais sofisticados; (iii) funcional, em que se busca realizar novas funções e migra-se para outro elo de uma CGV; e (iv) inter-setorial, no qual uma empresa passa a atuar em outra CGV (HUMPHREY; SCHMITZ, 2002; PINTO; FIANI; CORRÊA, 2017). A Figura 20, abaixo, exemplifica a atuação de diferentes países em uma mesma CGV, no caso, a de frutas e vegetais.

Figura 20 - Exemplos de países e estratégias de upgrading na CGV de frutas de vegetais.

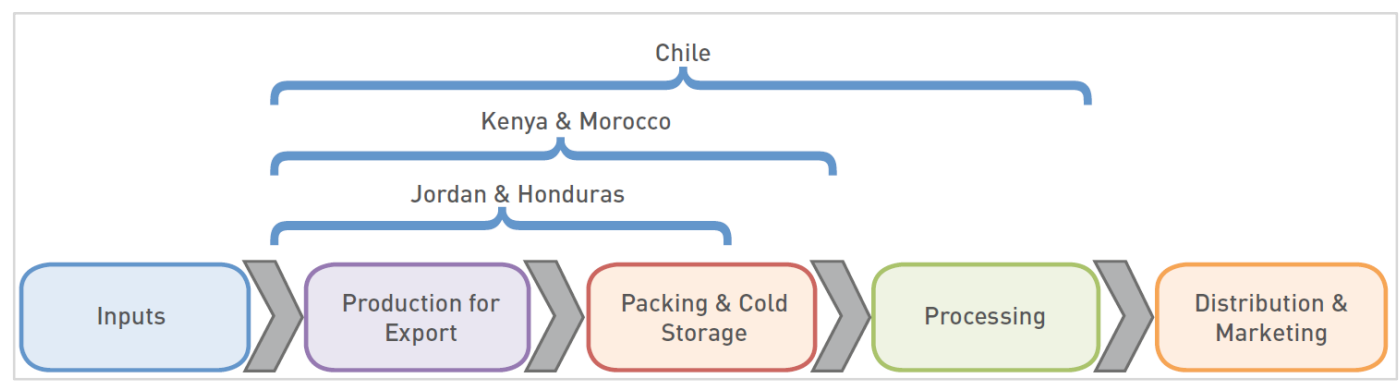

Fonte: GEREFFI; FERNANDEZ-STARK; 2016, p. 12.

Em linhas gerais, pode-se destacar, a exemplo do que foi analisado ao longo do presente trabalho, que grande parte das estratégias de upgrading da CGV avícola se relaciona a inovações em processos que vão dar origem a produtos mais sofisticados e que atendam melhor aos interesses dos stakeholders da cadeia, seja no elo de inputs, produção e/ou marketing/comercialização. De acordo com Bassi (2013), o tipo de tecnologia utilizada em empresas-líderes (agroindústria) é de caráter incremental e tem origem, sobretudo, na interação 
entre elas e fornecedores. O Brasil, por sua vez, destaca-se pelo fato de ter trabalhado extensamente na adaptação de tecnologias advindas do exterior, com vistas à melhoria da performance da cadeia como um todo.

Dessa forma, conforme amplamente explicitado no eixo de $\mathrm{P} \& \mathrm{D}$, quando da apresentação da estrutura input-output da CGV avícola, as empresas-líderes da agroindústria têm buscado, gradualmente, incrementar suas estruturas de $\mathrm{P} \& \mathrm{D}$, com vistas a gerar efeitos tanto na montante da cadeia, por meio da melhor interação e solicitações específicas aos fornecedores das áreas de material genético, nutrição e saúde animal, geralmente empresas advindas de países desenvolvidos; como na jusante da cadeia, com vistas a diversificar seus produtos e atender às demandas dos consumidores.

\subsubsection{CONTEXTO INSTITUCIONAL E ANÁLISE DOS STAKEHOLDERS}

A análise do contexto institucional e dos stakeholders da CGV avícola deve ser observada a partir de duas principais esferas normativo-regulatórias, quais sejam, o ambiente multilateral/global e o nível nacional. Ambas dispõem de atores de caráter estatal e privado que, atuando de unilateral ou conjuntamente, são fontes de regras, normas, convenções, procedimentos operacionais, certificações, informações, requisitos e exigências essenciais à gestão cotidiana da produção avícola em geral.

No nível multilateral/global, destacam-se: as organizações internacionais responsáveis pela regulamentação de insumos, como vacina, rações e medicamentos; a negociação de regras específicas ao comércio internacional, que, necessariamente, impactam sobre os produtos da cadeia avícola; e outras regulamentações voltadas para procedimentos de abate, industrialização e manipulação. Dentre as principais, destacam-se as já citadas OIE, OMC e o CODEX ALIMENTARIUS.

A OE, formada por 182 membros e sediada em Paris, tem como principal objetivo coordenar atividades relativas à produção de informações sobre doenças específicas, cooperação técnica e atividades científicas, as quais são delegadas pela Assembleia Geral de Delegados. O trabalho técnico está disposto em seis eixos principais que guiam as ações da entidade e tem uma relação direta com a saúde animal em nível global: (i) garantir transparência na situação global de doenças animais; (ii) coletar, analisar e disseminar informações científicas no campo da veterinária; (iii) encorajar a solidariedade e a cooperação internacional no controle 
de doenças amimais; (iv) garantir a segurança global por meio da publicação de padrões sanitários para o comércio internacional de animais e produtos animais; (v) auxiliar na implementação dos recursos e do arcabouço legal dos serviços veterinários nacionais; e (vi) trabalhar em prol da garantia da qualidade dos alimentos originário de animais e promover o bem-estar animal com base em no conhecimento científico (science-based approach). Alguns exemplo de trabalhos importantes que a organização têm em relação à cadeia avícola podem ser vistos por meio da publicação dos princípios de bem-estar animal em sistemas de produção de frangos, pertencente ao Terrestrial Animal Health Code, além da publicação atualizada do status global de doenças graves à cadeia avícola, como influenza aviária e doença de Newclastle (OIE, 2019).

Figura 21 - Plano estratégico OIE 2016-2020, objetivos e eixos de ação.

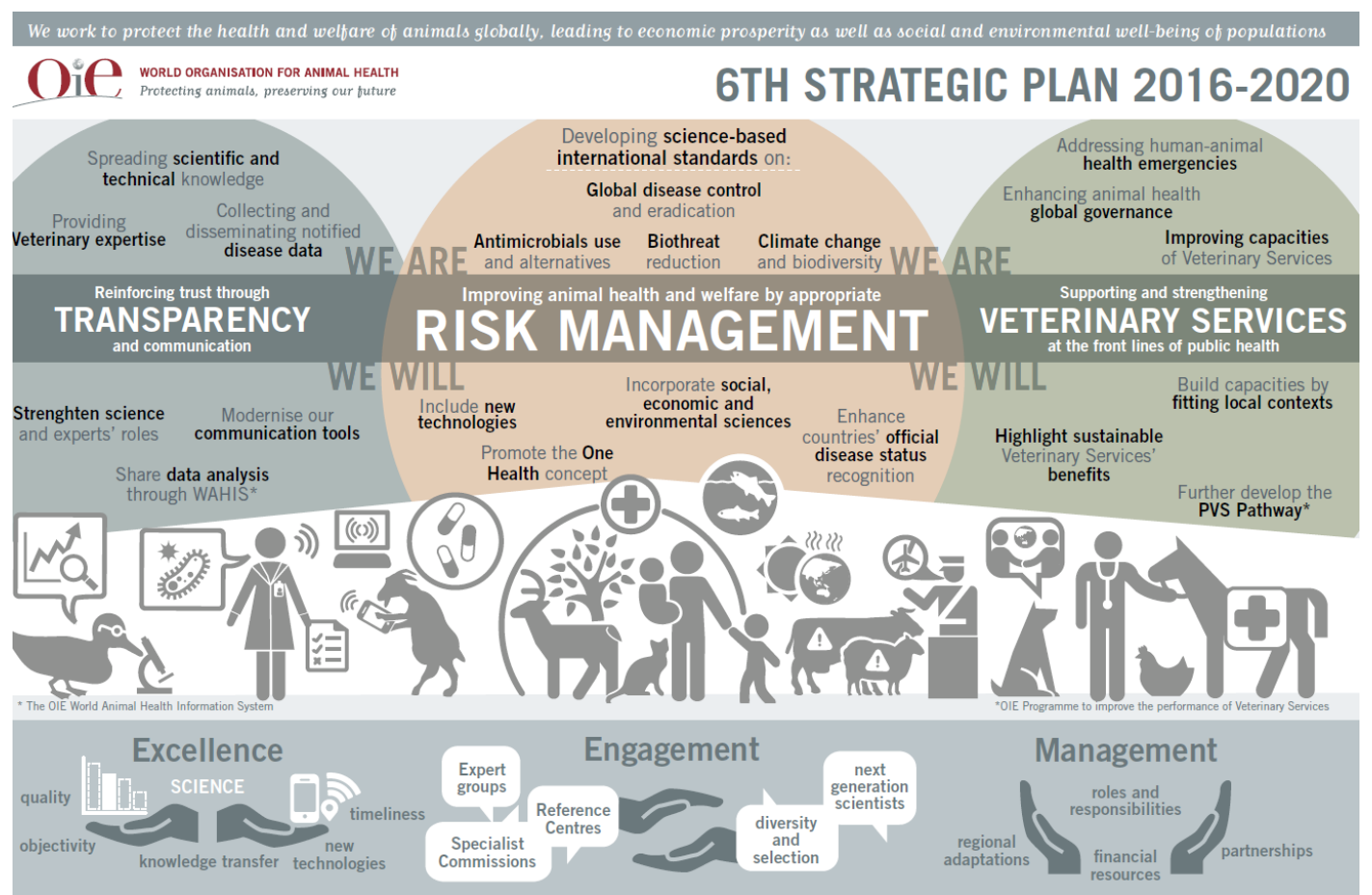

Fonte: OIE, 2019.

O Organização Mundial do Comércio, sediada em Genebra e atualmente com 165 membros, tem como principal objetivo assegurar, por meio dos acordos que fazem parte de seu arcabouço jurídico, a previsibilidade do sistema multilateral de comércio. Por meio de negociações e da eventual assinatura de novos acordos, a entidade também busca gradualmente avançar na agenda de liberalização comercial em nível global. 
Em suma, diversos temas que encontram respaldo em diferentes acordos podem estar relacionados ao setor avícola, como investimentos, subsídios, defesa comercial, barreiras técnicas, agricultura, entre outros. Todavia, é no acordo de Medidas Sanitárias e Fitossanitárias (SPS, em inglês) e, em parte no Acordo sobre Barreiras Técnicas ao Comércio (TBT, em inglês) que o setor mais encontra medidas que o afetam diretamente, tais como diretrizes relativas a processos e métodos produtivos, procedimentos de análise, inspeção e certificação, procedimentos de amostragem, métodos de avaliação de risco, requisitos para embalagem e rotulagem relacionadas com a segurança dos alimentos, entre outros (MAPA, 2017; OMC, 2019).

Importante destacar que a Organização, por meio do Órgão de Solução de Controvérsias (OSC), já recebeu diversas alegações de práticas ilegais de comércio relacionadas à carne avícola, sendo que 11 delas se tornaram contenciosas. Os casos quase sempre envolveram os grandes produtores de carne de frango e estão geralmente relacionados a temas como alterações em cotas tarifárias, proibição do uso de substâncias por uma das partes, medidas antidumping, banimentos por falta de garantia de segurança do produto, entre outros. O quadro 4, a seguir, detalha os contenciosos da OMC envolvendo carne de aves. 
Quadro 4 - Contenciosos na OMC relacionados ao comércio de carne avícola.

\begin{tabular}{|c|c|c|c|}
\hline $\begin{array}{l}\text { Número } \\
\text { do caso }\end{array}$ & Nome do caso & Requerente & Respondente \\
\hline DS 492 & $\begin{array}{l}\text { European Union - Measures Affecting Tariff } \\
\text { Concessions on Certain Poultry Meat Products }\end{array}$ & China & União Europeia \\
\hline DS 484 & $\begin{array}{c}\text { Indonesia - Measures Concerning the Importation } \\
\text { of Chicken Meat and Chicken Products }\end{array}$ & Brasil & Indonésia \\
\hline DS 392 & $\begin{array}{l}\text { United States - Certain Measures Affecting Imports of } \\
\text { Poultry from China }\end{array}$ & China & Estados Unidos \\
\hline DS 389 & $\begin{array}{c}\text { European Communities - Certain Measures Affecting } \\
\text { Poultry Meat and Poultry Meat Products from the } \\
\text { United States }\end{array}$ & Estados Unidos & União Europeia \\
\hline DS 286 & $\begin{array}{c}\text { European Communities - Customs Classification of } \\
\text { Frozen Boneless Chicken Cuts }\end{array}$ & Tailândia & União Europeia \\
\hline DS 269 & $\begin{array}{c}\text { European Communities - Customs Classification of } \\
\text { Frozen Boneless Chicken Cuts }\end{array}$ & Brasil & União Europeia \\
\hline DS 241 & $\begin{array}{c}\text { Argentina - Definitive Anti-Dumping Duties on } \\
\text { Poultry from Brazil }\end{array}$ & Brasil & Argentina \\
\hline DS 102 & Philippines - Measures Affecting Pork and Poultry & Estados Unidos & Filipinas \\
\hline DS 100 & $\begin{array}{c}\text { United States - Measures Affecting Imports of } \\
\text { Poultry Products }\end{array}$ & União Europeia & Estados Unidos \\
\hline DS 74 & Philippines - Measures Affecting Pork and Poultry & Estados Unidos & Filipinas \\
\hline DS 69 & $\begin{array}{l}\text { European Communities - Measures Affecting } \\
\quad \text { Importation of Certain Poultry Products }\end{array}$ & Brasil & União Europeia \\
\hline
\end{tabular}

Fonte: OMC, 2019.

O CODEX ALIMENTARIUS consiste em uma iniciativa conjunta entre a FAO e a OMS, estabelecida em 1963, com o intuito de implementar normas internacionais relativas à área de alimentos por meio das deliberações de seus diversos comitês. São inúmeros padrões, diretrizes e convenções sobre boas práticas, avaliação de Segurança, entre outros temas que visam à proteção da saúde dos consumidores e garantia de práticas leais de comércio entre os países. Apesar de terem um caráter de aplicação voluntária, os 189 membros do CODEX ALIMENTARIUS geralmente utilizam essas normas como referência para suas respectivas legislações nacionais. Na área avícola, um dos comitês mais importantes é o Comitê Codex de Resíduos de Pesticidas, que tem como um de seus objetivos o estabelecimento de limites máximos de resíduo (LMRs) para pesticidas em alimentos de origem animal (ANVISA, 2019; CODEX, 2019). 
No âmbito privado, uma organização de caráter global com grande relevância para o setor avícola é o International Poultry Council (IPC), criada formalmente em 2005 por um grupo de empresas e associações líderes do setor. Atualmente, a organização conta com 23 países membros, distribuídos em mais de 52 associados. O IPC representa cerca de $95 \%$ do comércio global e 90\% da produção mundial de carne de aves. Em suma, a entidade de representação busca o aperfeiçoamento contínuo da cadeia avícola mundial, por meio de estudos, análises, diretrizes, encontros, seminários, entre outras iniciativas. Recentemente, destaca-se a assinatura, em setembro de 2019, entre o IPC e a FAO, do Compromisso (Commitment) do setor em implementar iniciativas sustentáveis que possam contribuir para efetivamente cinco objetivos de desenvolvimento sustentável (ODS) da ONU, os quais deverão ser cumpridos pelos países até 2030. São eles: (i) fome zero; (ii) bem-estar e saúde; (iii) educação de qualidade; (iv) indústria, inovação e infraestrutura; e (v) ações relacionadas ao clima. A figura 22, a seguir, detalha os compromissos assumidos pelo setor junto à $\mathrm{FAO} / \mathrm{ONU}$ (IPC, 2019):

Figura 22 - Compromissos do setor avícola global relacionados aos (ODS) da ONU.

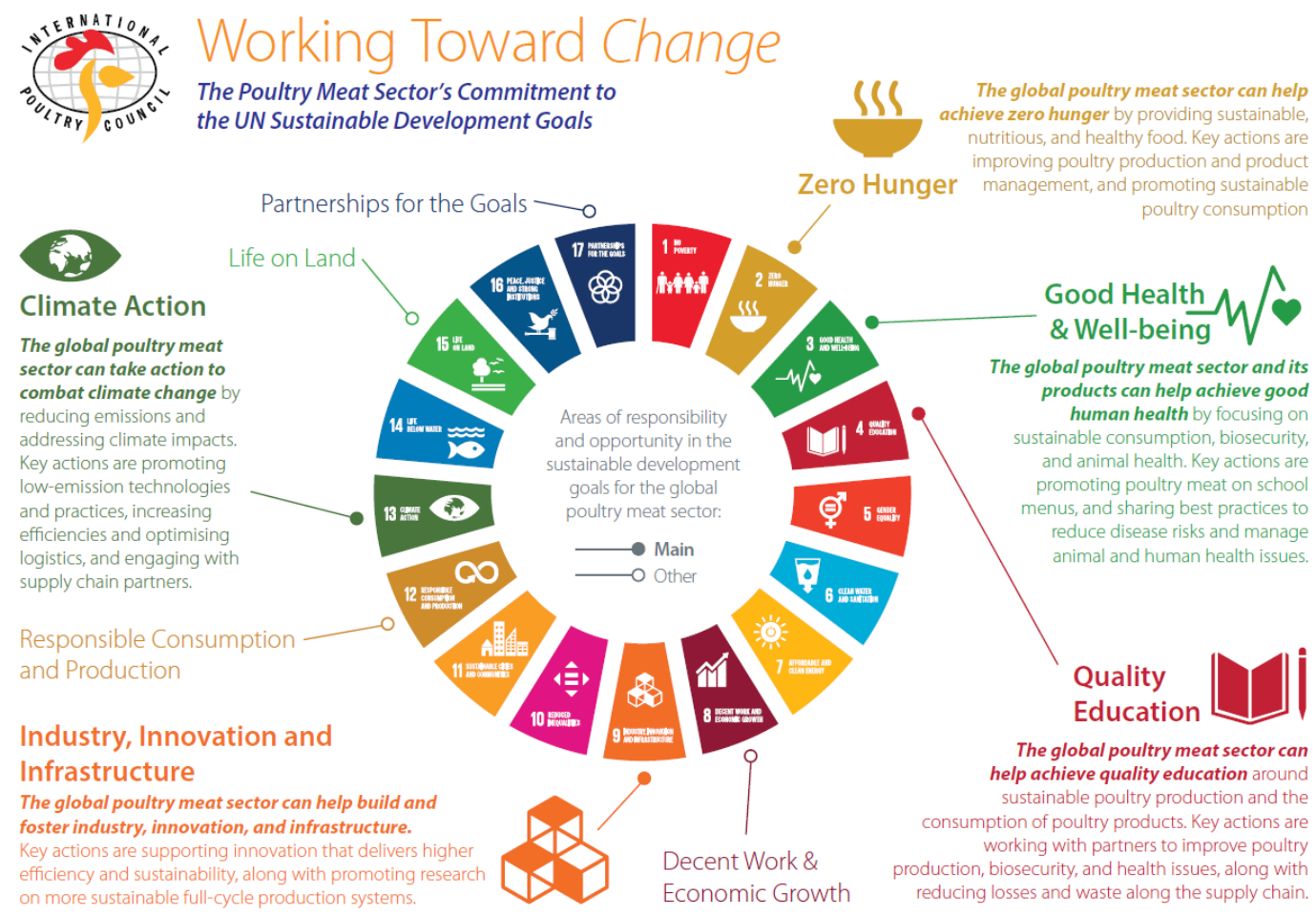

Fonte: IPC, 2019 
Também no nível privado e atuando em escala global estão as grandes certificadoras e entidades voltadas ao estabelecimento de padrões privados que influenciam diretamente a atuação das agroindústrias, sobretudo no que se refere aos métodos alternativos de produção, como orgânicos, slow growth, antibiotic-free, etc. Em geral, essas certificadoras passaram a lançar mão de padrões voluntários de sustentabilidade (Voluntary Sustainability Standars VSS $)^{7}$ que buscam assegurar o cumprimento de medidas de cunho ambiental, social, ético e reputacional. Estima-se que, atualmente, haja mais cerca de 54 VSSs em vigor para ovos e carne de aves, os quais adotam critérios relativos a ações de bem-estar animal, uso de água e energia, recursos genéticos, status sanitário, resistência antimicrobiana, uso de antibióticos, emissão de GEEs (LIMA, 2019). Alguns exemplos de certificadoras são: Certified Humaine, WQS, Global Animal Partnership, IBD, entre outros.

No nível nacional, há diversas fontes de regulação em nível governamental, como Ministérios da Agricultura, responsáveis pela condução de programas de incentivo setorial, bem como pela elaboração de regras relativas à produção e comercialização de produtos de origem animal, entre outros. As agências reguladoras, por sua vez, têm o papel de fiscalizar a aplicação de normas essenciais à segurança dos alimentos tendo em vista o consumidor final:

[...] the Government actor has a higher capacity to access, directly or indirectly, to other actors in the network. In this sense, the government's role is to encourage the chicken meat production not only as a policy of income and employment generation but mainly as a food-security policy. (WAKER; NÄ̈̈S; 2018, p. 522).

Ademais, destaca-se o papel das associações setoriais em ações que envolvem campanhas, representação institucional, realização de estudos e análises das mais diversas naturezas (comercial, produtiva, econômica, etc.), entre outras atividades voltadas para um diálogo mais efetivo e a construção de relevantes estratégias setoriais em conjunto com governos nacionais/regionais. Como exemplos, podem ser citadas: Associação Brasileira de Proteína Animal (ABPA); USA Poultry \& Egg Export Council (USAPEEC); British Poultry Council (BPC); Association of Poultry Processors and Poultry Trade in the EU Countries (a.v.e.c.); China Chamber of Commerce of Foodstuffs and Native Produce (CFNA); Candian

\footnotetext{
${ }^{7}$ De acordo com o United Nations Forum on Sustainability Standards (UNFSS): “[...] Voluntary Sustainability Standards (VSS) are rules that producers, traders, manufacturers, retailers or service providers may be asked to follow so that the things they make, grow or do don't hurt people and the environment. These standards help keep workers healthy and safe, protect communities and land, and uphold human rights, as well as moderating the environmental impacts of production and consumption". Disponível em: https://unfss.org/. Acesso em: $10 / 01 / 2020$.
} 
Poultry \& Egg Processors Council (CPEPC); entre outras. Por fim, há a necessidade de salientar o trabalho feito pela academia e institutos de pesquisa por meio da busca permanente por inovações em processos e produtos ao longo da cadeia. A interação entre esses institutos, empresas e, em certa medida, governos, é parte fundamental de uma dinâmica que tem beneficiado toda a CGV avícola ao longo das últimas décadas (BASSI, 2013).

\subsubsection{CONSIDERAÇÕES FINAIS}

Como se pode perceber, a CGV avícola é composta por uma série de atividades de alto nível de complexidade coordenada por inúmeros stakeholders que atuam do campo à mesa do cliente final. O incremento do consumo de carne de aves nas últimas décadas ocorreu graças à coordenação de alto nível entre empresas de genética, nutrição, saúde animal e as agroindústrias, fato que viabilizou constantes e crescentes ações de $\mathrm{P} \& \mathrm{D}$, com influência direta no aumento da produtividade do setor, sobretudo por meio de iniciativas relativas a bem-estar, manejo, mobilidade, densidade, rastreabilidade e sanidade.

A análise da estrutura input-output da CGV avícola ilustra essa complexa interação entre os mais diversos stakeholders da cadeia. Composta por sete elos, a estrutura tem como cerne tanto as atividades de P\&D I nas áreas já citadas, como o desenvolvimento de novos produtos, os quais visam à praticidade, conveniência e qualidade tão caras ao consumidor final. As observações dispostas do eixo de upgrading corroboram esse panorama de busca constante por inovações incrementais e com vistas à melhoria constante dos índices de produtividade das empresas-líderes.

A análise do escopo geográfico do setor, por meio de uma exposição minuciosa dos fluxos comerciais de carne de aves em nível global, permitiu a compreensão dos movimentos dos principais países que competem no setor, bem como dos eventuais desafios enfrentados por eles ao longo dos últimos anos, sobretudo em termos de sanidade e eficiência produtiva.

A governança da CGV avícola, caracterizada no presente trabalho como hierárquica, denota a importância das agroindústrias em todo o processo produtivo, influenciando praticamente todas as atividades da montante à jusante da cadeia. Por meio da coordenação e controle efetivo das atividades, sobretudo aquelas ligadas aos integrados, as agroindústrias são, em grande parte, o principal vetor de competitividade do setor. 
Por fim, a análise do contexto institucional e dos stakeholders da CGV avícola expôs como a construção de um extenso conjunto de normas, regras e convenções, produzidas por organizações internacionais e governos nacionais, influenciam diretamente as atividades produtivas e comerciais da cadeia como um todo. Da mesma forma, foi possível observar como a participação de associações empresariais e a atuação de certificadoras privadas têm impactado diretamente a atuação das grandes empresas do setor tanto local quanto internacionalmente. 


\section{A Inserção do Brasil na Cadeia Global de Valor Avícola}

A presente seção tem como objetivo analisar a inserção do Brasil na CGV avícola, por meio da análise da evolução da atividade no país ao longo das últimas décadas e do mapeamento dos principais elementos que fizeram do país um ator fundamental no abastecimento mundial desse tipo de proteína. Essa análise ampla da inserção do Brasil abre espaço para que, em seguida, ao longo do capítulo 4, apresentem-se de forma estruturada os fatores que, efetivamente, têm impacto direto no desempenho do setor avícola brasileiro.

\subsection{A Avicultura no Brasil: histórico e evolução}

Um dos grandes diferenciais de competitividade do setor no Brasil refere-se ao modelo de governança da CGV avícola, caraterizada pelo sistema de integração entre agroindústria e produtor rural. A introdução do modelo de integração entre as décadas de 1960 e 1970 no Brasil, mais especificamente no sudoeste do estado de Santa Catarina, proporcionou uma verdadeira revolução na atividade avícola brasileira. Esse sistema de integração expandiu-se, paulatinamente, aos estados do Rio Grande do Sul, São Paulo, Minas Gerais e Paraná, com aperfeiçoamentos e adaptações tecnológicas, viabilizando sucessivos ganhos em termos de produtividade. Cerca de $90 \%$ da produção do frango de corte no Brasil é realizada por meio do chamado sistema integrado. Nos últimos anos, todavia, esse modelo de produção focado na integração do pequeno produtor-agroindústria tem contrastado com diferentes formas de produção e organização, mais amplas e com elevada escala, influenciadas pela expansão da fronteira agrícola na região Centro-Oeste (LAZZARI, 2004; JESUS JUNIOR; 2007; WAKER; NÄ̈̈S; 2018).

Ao longo da década de 1980, com o aperfeiçoamento desse modelo de governança e da evolução de outros fatores inerentes ao negócio, a avicultura brasileira passou a contar com uma estrutura diferenciada e passou por uma significativa transformação vis-à-vis as décadas anteriores. Esse período foi caracterizado por ganhos notórios de produtividade, acesso a novos mercados e a consolidação da organização industrial em larga escala, com melhorias tecnológicas e maior sinergia entre os elos da cadeia. Esse novo cenário passou a orientar parte da produção brasileira ao mercado externo, e o surgimento de grandes grupos agroindustriais 
no país, com modernos frigoríficos e ampla capacidade de abate e processamento, foi fundamental para tanto. (BASSI, 2013; COSTA et al., 2015; MOTA VEIGA; RIOS, 2016).

Em suma, tanto as inovações tecnológicas à montante da cadeia (insumos, genética, nutrição, manejo) quanto aquelas à jusante (logística, distribuição, comercialização), aliadas ao incremento gradual das pesquisas científicas e um ambiente de constante inovação, promoveram sucessivas transformações no setor avícola brasileiro. Ações de melhoria e controle do sistema produtivo, diminuição dos custos de energia, diminuição da mortalidade e da idade de abate, aumento do peso médio, e incremento do mix de produtos, foram alguns dos ganhos adquiridos ao longo das últimas décadas no país (ESPINDOLA, 2012; OLIVEIRA et al., 2012; MARTINELLI; ROHENKOHL; MURAKAMI; 2014; VALDES; HALLAHAN; HARVEY, 2015).

\begin{abstract}
[...] Até 1960, a avicultura brasileira tinha pouca expressão econômica e era realizada de forma bastante artesanal. A partir dessa década surgiu, principalmente em São Paulo, uma avicultura moderna, apoiada em um modelo de produção com grandes produtores independentes e autônomos em relação à indústria e com uso de mão-de-obra assalariada. No entanto, somente a partir da década de 1970, a avicultura brasileira deu um grande salto. Entre outros motivos para tal desenvolvimento podemos citar a adoção do modelo de integração no sudoeste catarinense e a introdução de um pacote tecnológico que aumentou a produtividade do setor como um todo. A introdução de tecnologia na avicultura nacional colocou a atividade em posição privilegiada em relação à produção de outras carnes, como também permitiu ao país alcançar altos níveis de produtividade, comparados aos principais países do mundo. A avicultura nacional deixou, portanto, de ser uma atividade de subsistência sem uso de tecnologia, para se tornar um verdadeiro complexo agroindustrial sob uma coesa articulação entre os segmentos da cadeia produtiva. (COSTA et al., 2015, p. 7).
\end{abstract}

O investimento em diversos eixos da cadeia produtiva possibilitou a expansão da produção e do abate de aves que, atualmente, ocorrem em diversos estados brasileiros, com destaque para os três estados da região Sul, que representam $65 \%$ do abate de aves inspecionado pelos fiscais federais (MAPA, 2019). A figura 23, a seguir, mostra a localização dos abatedouros no Brasil, concentrados no Sul e Sudeste, fora do bioma amazônico. Em 2005, o estado com maior quantidade de cabeças abatidas era Santa Catarina, com participação de 21,7\%, seguido do Paraná e Rio Grande do Sul, com participação de 21\% e 18,6\%, respectivamente. Já em 2006, o estado do Paraná tem um salto na quantidade de aves abatidas $(+32 \%)$ e ultrapassa o estado de Santa Catarina, tornando-se o primeiro do ranking, com 25,9\% de participação. Nos doze anos seguintes, o posicionamento dos estados permanece o mesmo, 
com alteração apenas da quantidade de aves abatidas e da participação dos estados no abate do Brasil. Em 2018, o Paraná aumenta a participação para 34,9\%, enquanto Santa Catarina e Rio Grande do Sul reduzem participação para 15,2\% e 14,4\%. As quantidades de abate aumentam $140 \%, 1 \%$ e $12 \%$, respectivamente entre 2005 e 2018 . A figura 23, a seguir, mostra a localização geográfica dos abatedouros avícolas industriais do Brasil.

Figura 23 - Localização dos abatedouros avícolas no Brasil

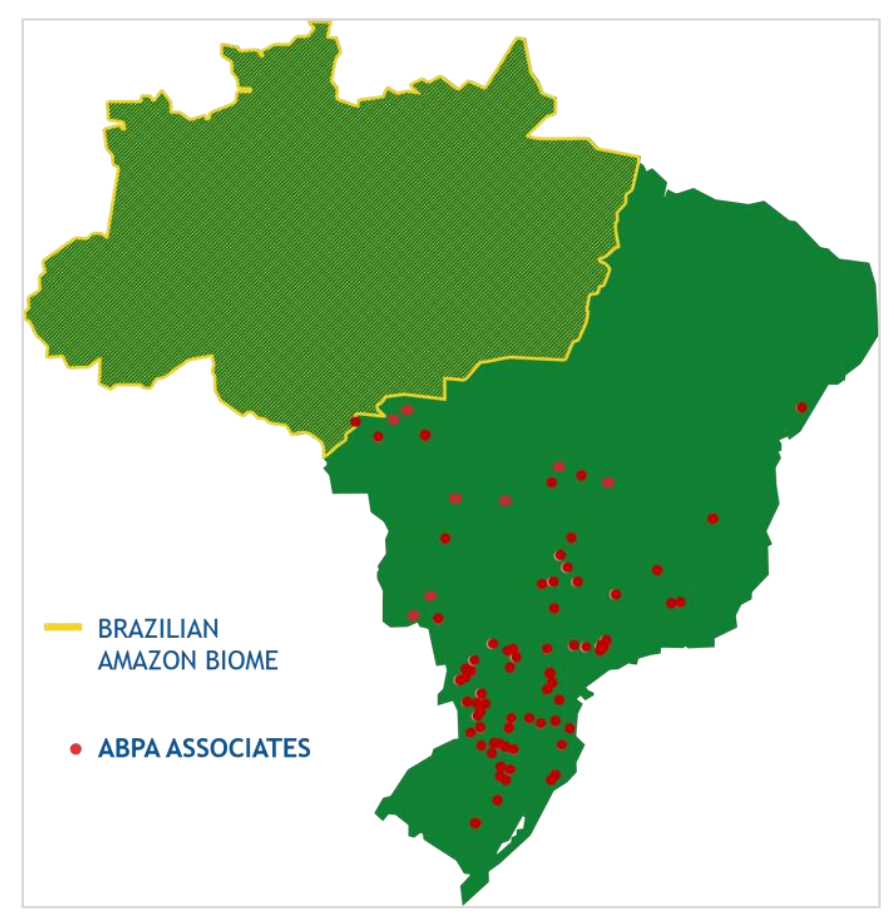

Fonte: ABPA. 
Tabela 7: Quantidade de aves abatidas por estado em milhões de cabeças.

\begin{tabular}{|c|c|c|c|c|c|c|c|c|c|c|c|c|c|c|}
\hline Estado & $\mathbf{2 0 0 5}$ & $\mathbf{2 0 0 6}$ & $\mathbf{2 0 0 7}$ & $\mathbf{2 0 0 8}$ & $\mathbf{2 0 0 9}$ & $\mathbf{2 0 1 0}$ & $\mathbf{2 0 1 1}$ & $\mathbf{2 0 1 2}$ & $\mathbf{2 0 1 3}$ & $\mathbf{2 0 1 4}$ & $\mathbf{2 0 1 5}$ & $\mathbf{2 0 1 6}$ & $\mathbf{2 0 1 7}$ & $\mathbf{2 0 1 8}$ \\
\hline Brasil & 3.530 & 3.785 & 4.129 & 4.550 & 4.497 & 4.796 & 5.153 & 5.105 & 5.146 & 5.202 & 5.455 & 5.518 & 5.377 & 5.098 \\
\hline PR & 741 & 980 & 1.106 & 1.219 & 1.245 & 1.326 & 1.461 & 1.538 & 1.611 & 1.665 & 1.751 & 1.867 & 1.834 & 1.780 \\
\hline SC & 767 & 733 & 789 & 842 & 843 & 895 & 935 & 890 & 856 & 885 & 881 & 874 & 866 & 776 \\
\hline RS & 658 & 640 & 705 & 780 & 737 & 756 & 780 & 716 & 739 & 735 & 755 & 768 & 733 & 734 \\
\hline SP & 630 & 651 & 683 & 731 & 649 & 672 & 741 & 647 & 558 & 544 & 545 & 509 & 494 & 466 \\
\hline MG & 223 & 264 & 276 & 322 & 341 & 348 & 355 & 380 & 388 & 369 & 394 & 430 & 383 & 368 \\
\hline GO & 172 & 184 & 206 & 252 & 243 & 287 & 314 & 331 & 349 & 352 & 388 & 365 & 379 & 307 \\
\hline MT & 72 & 87 & 103 & 122 & 148 & 181 & 201 & 238 & 245 & 226 & 242 & 229 & 213 & 217 \\
\hline MS & 123 & 110 & 124 & 129 & 128 & 146 & 146 & 141 & 153 & 158 & 171 & 167 & 171 & 164 \\
\hline PE & 18 & 17 & 14 & 16 & 18 & 19 & 19 & 16 & 20 & 41 & 62 & 52 & 58 & 58 \\
\hline PA & & 3 & & & 3 & 23 & 29 & 34 & 35 & 28 & 42 & 42 & 46 & 46 \\
\hline DF & 62 & 51 & 54 & 60 & 71 & 61 & 80 & 82 & 84 & 75 & 89 & 76 & 61 & 45 \\
\hline BA & 45 & 38 & 37 & 39 & 35 & 30 & 32 & 32 & 44 & 38 & 39 & 40 & 41 & 45 \\
\hline ES & 7 & 10 & 10 & 7 & 11 & 23 & 26 & 21 & 23 & 27 & 30 & 33 & 35 & 35 \\
\hline PB & & & & & 1 & 13 & 19 & 19 & 20 & 22 & 22 & 21 & 20 & 21 \\
\hline RO & 7 & 6 & 8 & 8 & 9 & 7 & 6 & 8 & 9 & 11 & 12 & 10 & 14 & 16 \\
\hline TO & 5 & 5 & 6 & 15 & 14 & 8 & 10 & 11 & 12 & 19 & 27 & 28 & 21 & 13 \\
\hline PI & 0 & & & & & & & 0 & 0 & 7 & 5 & 6 & 7 & 8 \\
\hline RJ & 1 & 6 & 8 & 5 & & & & & & & & & & \\
\hline SE & & 1 & 2 & 2 & 1 & 0 & & & & & & & & \\
\hline
\end{tabular}

Fonte: MAPA. Relatório de Abates sob Inspeção Federal. Dados quantitativos de abate sob a responsabilidade dos SIPAs/DFAs.

O crescimento do setor avícola no Brasil também pode ser visto por meio de sua evolução em termos de representatividade econômica. A cadeia produtiva gera cerca de 3,5 milhões de empregos, diretos e indiretos, sendo mais de 300 mil somente nas agroindústrias. $\mathrm{O}$ o Valor Bruto da Produção (VBP) gerado passou de R \$ 36,9 bilhões em 2005 para R \$ 57,2 bilhões em 2018. Esse montante posicionou a carne de frango como segundo produto da pecuária com maior VBP, atrás apenas da carne bovina, e com representatividade de $28,4 \%$ do VBP da Pecuária e 9,3\% do VBP da Agropecuária brasileira (MAPA, 2019; ABPA, 2019). O gráfico 5 mostra que a carne de frango teve aumento de $55 \%$ no VBP, mesmo com uma estabilização na participação do total da pecuária brasileira. 
Gráfico 5 - Comparativo do Valor Bruto da Produção (VBP) na pecuária brasileira em 2005 e 2018 em bilhões de reais.

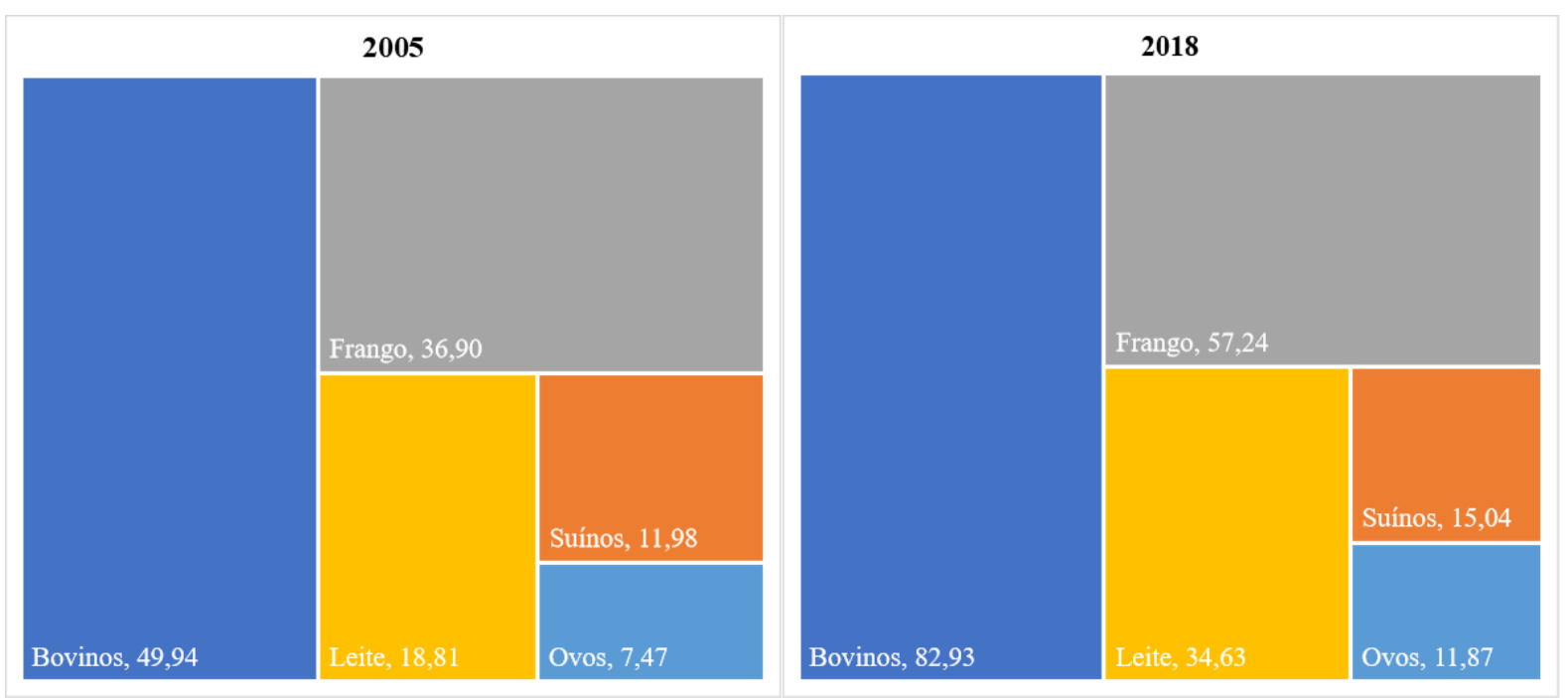

Fonte: MAPA, 2019. Valor Bruto da Produção Agropecuária (VBP).

A expansão da produção brasileira de carne de frango também ocorreu em volume, 43,6\% entre 2005 e 2018, passando de 8,95 milhões de toneladas para 12,85 milhões de toneladas produzidas em 2018. Para melhor compreensão desse crescimento ao longo do período, deve-se analisá-lo em 4 momentos diferentes: de 2005 a 2008, quando a produção cresceu 5,1\% ao ano, refletindo um momento de expansão orientada à exportação; de 2009 a 2012, quando a taxa de crescimento variou entre 3,6\% ao ano, em uma fase de menor aumento nas exportações, mas com incremento de fusões e aquisições de empresas do setor; de 2013 a 2016, com taxas de crescimento ainda menores, 1,2\% ao ano, e melhoria nas exportações e um cenário externo extremamente incerto, sobretudo em termos de sanidade animal, com o aumento do número de doenças mundo afora; e, por fim, entre 2017 e 2018, quando a produção teve decréscimo de $0,7 \%$, com retração também nas exportações, ocasionadas pela dinâmica de mercado e por conta de restrições parciais aos produtos brasileiros no plano internacional, como consequência das operações Carne Fraca e Trapaça da Polícia Federal. 
Gráfico 6 - Evolução da produção e exportação brasileiras de carne de frango em milhões de toneladas

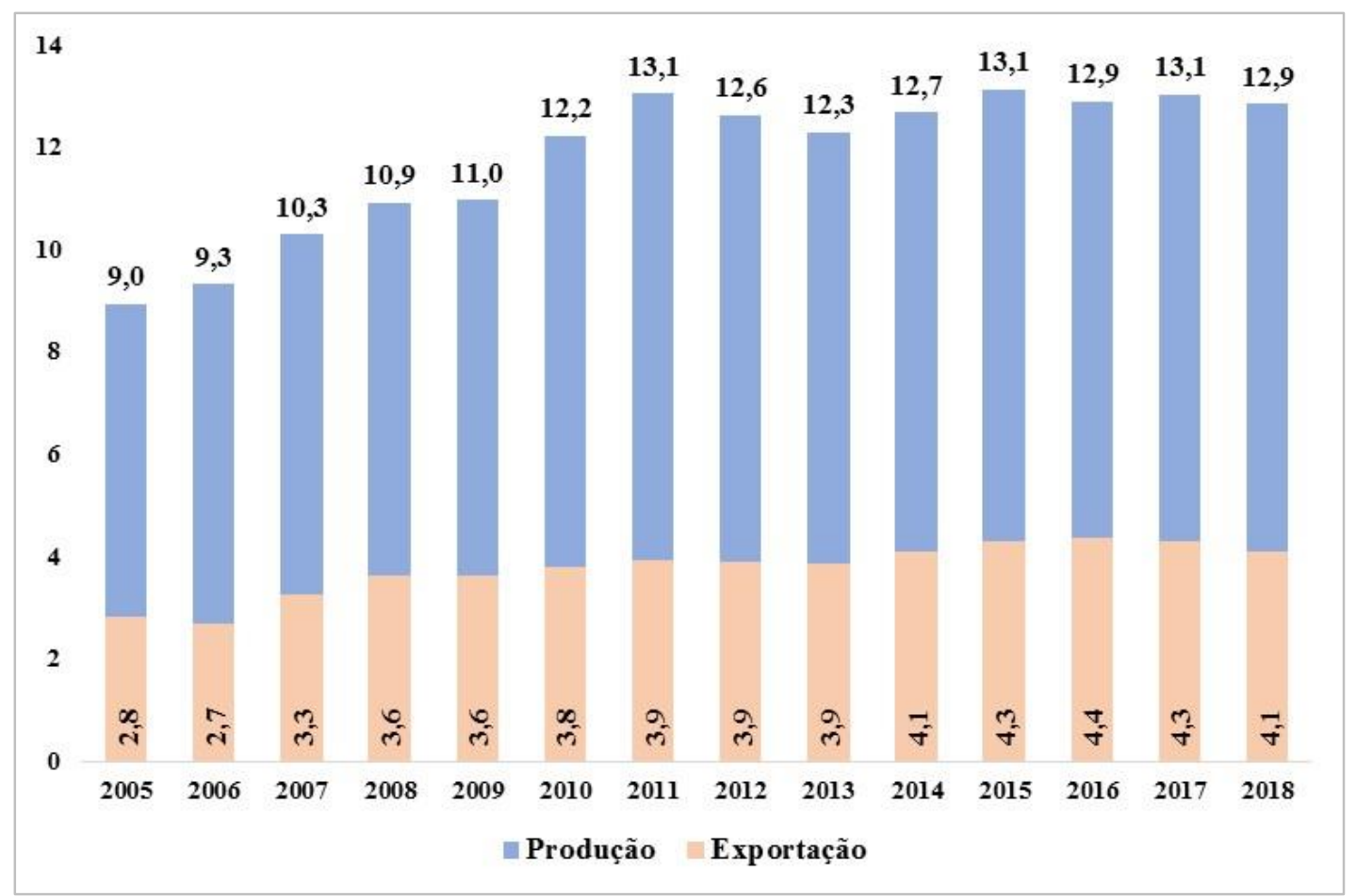

Fonte: Elaborado a partir dos dados da ABPA e SECEX.

Em 2005, o Brasil já havia atingido a posição de maior exportador mundial de carne de frango e, embora o cenário fosse favorável à expansão da produção, os surtos de influenza aviária nos principais concorrentes do Brasil no mercado internacional auxiliaram também o incremento das exportações. No entanto, em 2006, esse cenário sofreu uma inversão com a retração do consumo em importantes mercados consumidores da Europa e da Ásia, devido às preocupações sanitárias decorrentes do agravamento dos casos de influenza aviária (ABEF, 2005; ABEF, 2006; WAKER; NASS, 2018).

Estima-se que, entre 2005 e 2008, tenham sido reportados 2,5 milhões de casos, com destruição de 29,5 milhões de aves. Essa quantidade de animais supera a produção anual de países como Singapura e Omã. Nesse contexto, as preocupações do Brasil como fornecedor do alimento levaram ao lançamento do Plano Nacional de Prevenção à influenza aviária e doença de Newcastle, elevando o patamar da sanidade brasileira e permitindo a preservação dos mercados (UBA 2006; WAHIS, 2019). 
Broiler chain has been structured encompassing producers, suppliers and partners. In the 2000s, the United States had the hegemony in the production and export of broiler meat. However, the country was seriously affected by avian influenza, which also affected Canada and Indonesia in 2004. At that time, Brazilian producers presented a wellstructured and competitive business, reaching the world's leadership in exports of this meat. (OLIVEIRA, 2012, p. 2).

Em 2007 e 2008, as notícias de aumento de produção de etanol a partir de milho nos Estados Unidos beneficiaram os produtores brasileiros dos grãos, melhorando o cenário externo para exportação. A produção brasileira de carne de frango ficou pressionada pelo aumento do custo de produção decorrente da redução dos estoques de milho, em especial após o anúncio do recorde histórico da exportação desse importante insumo para a ração animal, responsável por cerca de 70\% da composição da ração (ESTADÃO, 2007; ABPA, 2019).

Ainda nesses anos, algumas grandes mudanças aconteceriam no setor, com o início de expressivos movimentos de fusões e aquisições. Em 2007, a Tyson Foods, grande produtora de proteína animal americana, inicia as operações no Brasil com a compra da empresa Macedo Agroindustrial e a Avícola Itaiópolis. Em 2008, o Grupo Marfrig passa a operar no setor avícola, adquirindo as empresas DaGranja, Penabranca, Penasul e Agrofrango. Em 2009, adquiriu os ativos da Seara, que pertenciam à Cargill, tornando-se o segundo maior exportador de carne de aves no Brasil (O GLOBO, 2008; SCOT Consultoria, 2008; Agência Estado, 2008; MARFRIG GROUP, 2009).

Também em 2009, foi anunciado o maior acordo de fusão da história do Conselho Administrativo de Defesa Econômica (CADE) até aquele ano, entre as empresas Sadia e Perdigão. O parecer só foi divulgado em 2011 e contava com importantes ressalvas relativas à venda de algumas marcas e de pontos referentes à estrutura produtiva da nova empresa. A criação da BRF consolidou a posição da empresa como maior produtora de carne de frango no Brasil e uma das maiores empresas do ramo no mundo (BRF, 2019; G1, 2011). Em 2012, a Cooperativa Central Aurora Alimentos, importante produtora de carne de aves e suínos do Brasil, assume as operações da Bondio Alimentos (AURORA, 2012).

Após as grandes modificações no mercado avícola, a JBS inicia, em 2012, as operações no setor de aves, com o aluguel das instalações da Frangosul, empresa controlada pela francesa 
Doux. Em 2013, a JBS fecha acordo com a Marfrig e compra a empresa Seara, além de outras duas empresas: Tramonto e Agrovêneto. No ano de 2014, a JBS adquire outras cinco empresas: o Grupo Céu Azul, a Avebom, as operações da Tyson no Brasil, a Belafoods e a Big Frango (EXAME, 2012; O GLOBO, 2014; JBS, 2019).

Atualmente, as maiores empresas produtoras de carne de frango são BRF S.A., com 30,5\% de participação no abate do Brasil, seguida da Seara Alimentos, com 23,5\%, e da Cooperativa Central Aurora Alimentos, com 4,5\%, como mostra a tabela 8, a seguir, com dados obtidos a partir dos relatórios de sustentabilidade dessas empresas.

Tabela 8 - Participação das maiores empresas produtoras de carne de aves em 2018.

\begin{tabular}{|c|c|c|}
\hline Empresa & Abate em 2018 & $\begin{array}{c}\text { Participação no } \\
\text { abate SIGSIF }\end{array}$ \\
\hline BRF & 1,554 bilhão de aves & $\mathbf{3 0 , 5 0 \%}$ \\
\hline Seara & 1,20 bilhão de aves & $23,50 \%$ \\
\hline Aurora & $\begin{array}{c}229,5 \text { milhões de } \\
\text { aves }\end{array}$ & $4,50 \%$ \\
\hline
\end{tabular}

Fonte: Relatórios de Sustentabilidade 2019 - BRF, JBS e Aurora.

A tendência de aquisições no setor ocorreu em anos em que o custo de produção pressionou muito a rentabilidade das empresas produtoras de carne de frango. Entre 2013 e 2018, o custo industrial, em R \$, teve elevação de $45 \%$ e o custo do frango na plataforma cresceu 25\%, adicionados aos 66\% de elevação entre 2006 a 2013. O componente mais impactante do custo industrial foi o salário, com crescimento de 48\% em reais entre 2013 e 2018, decorrente dos encargos, que representaram 80,8\% do valor dos salários. Em dólares, os impactos foram menores em $-14 \%$ em custos industriais e $-25 \%$ em custos na plataforma, considerando os anos de 2013 a 2018, devido à desvalorização cambial (Agroicone, 2019). A figura 24, a seguir, ilustra a evolução desses custos. 
Figura 24 - Evolução dos custos de produção de carne de frango no Brasil.

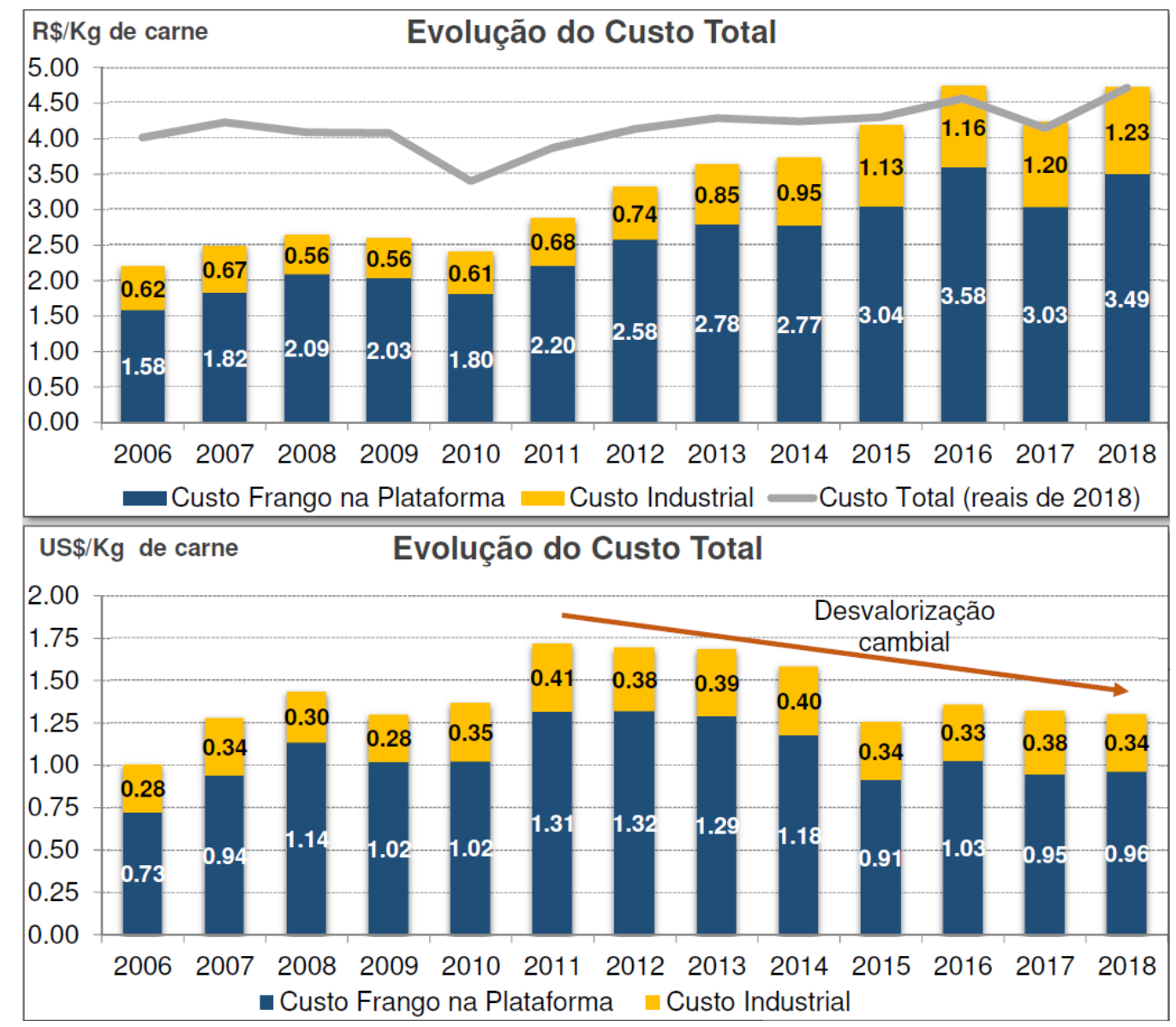

Fonte: Agroicone; ABPA, 2019; Embrapa, 2019.

Ainda que a competitividade externa tenha melhorado o cenário para as indústrias, o mercado doméstico sempre foi o principal destino da produção brasileira. Entre 2005 e 2018, o consumo interno correspondeu a $67 \%$ e $68 \%$ do total produzido. Nesse período, o consumo passou de 6,1 milhões de toneladas para 8,7 milhões de toneladas. Assim como a produção, o consumo interno apresentou redução na taxa de crescimento, passando de 4,6\% entre 2005 a 2008, para 4,4\% entre 2009 a 2012, de 0,3\% entre 2013 e 2016, para 0,1\% entre 2017 e 2018.

O consumo per capita de proteína animal no Brasil era, até 2009, predominantemente de carne bovina, com cerca de 38,8kg por habitante. A alteração de cenário ocorreu em 2010, quando o consumo per capita de carne de frango ultrapassou a carne bovina com a quantidade de $44,0 \mathrm{~kg}$ por habitante contra 39,8kg de carne bovina. Até 2018, a carne de frango permaneceu como a proteína mais consumida pelos brasileiros, com $41,9 \mathrm{~kg}$, seguido pela carne bovina com $30,7 \mathrm{~kg}$, pela carne suína com 14,7 kg e ovos com 11,5 kg. (ABPA, 2019). O gráfico 7, a seguir, 
detalha e evolução do consumo per capita de proteína animal no Brasil ao longo das últimas décadas.

Gráfico 7 - Evolução do consumo per capita de proteína animal no Brasil em $\mathrm{kg} /$ habitante.

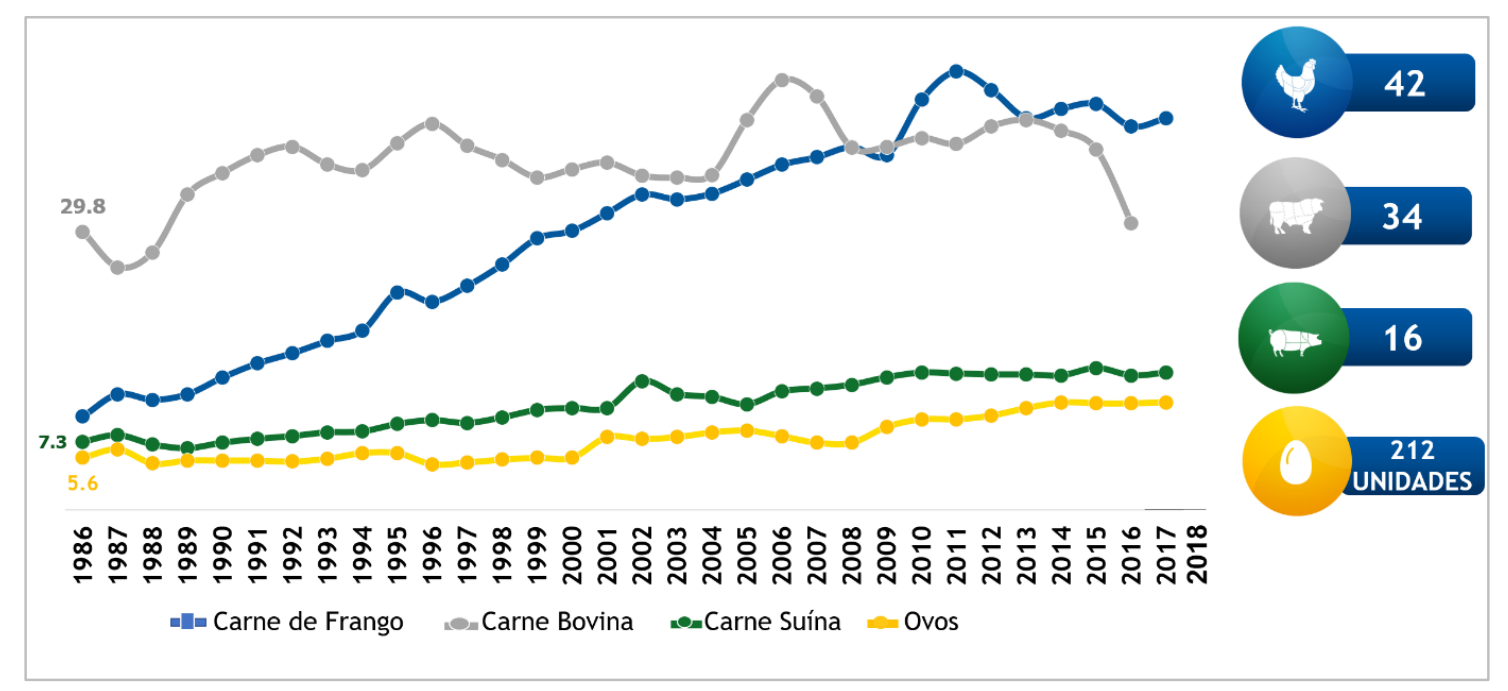

Fonte: ABPA, 2019.

O comércio internacional tem grande importância para o setor avícola, visto que as exportações correspondem a 32\% do volume produzido no Brasil (2018) e permitem o acesso a cerca de 150 mercados por ano, incluindo os 10 maiores importadores mundiais já mencionados no presente trabalho. O produto também tem destaque na pauta exportadora brasileira, ocupando a $6^{a}$ posição entre os principais produtos exportados e com participação de 6,5\% em receita nas exportações do agronegócio (2018). Em comparativo estadual, as exportações de carne de frango no Paraná e Santa Catarina representaram 12,2\% e 22,9\% do total exportado pelos estados. Em 2018, 22 estados brasileiros exportaram carne de frango, sendo os três estados sul com maior representatividade, com $82 \%$ do volume total (ABPA, 2019; MDIC, 2020). 
Gráfico 8 - Evolução da exportação brasileira de carne de frango entre 2005 e 2018.
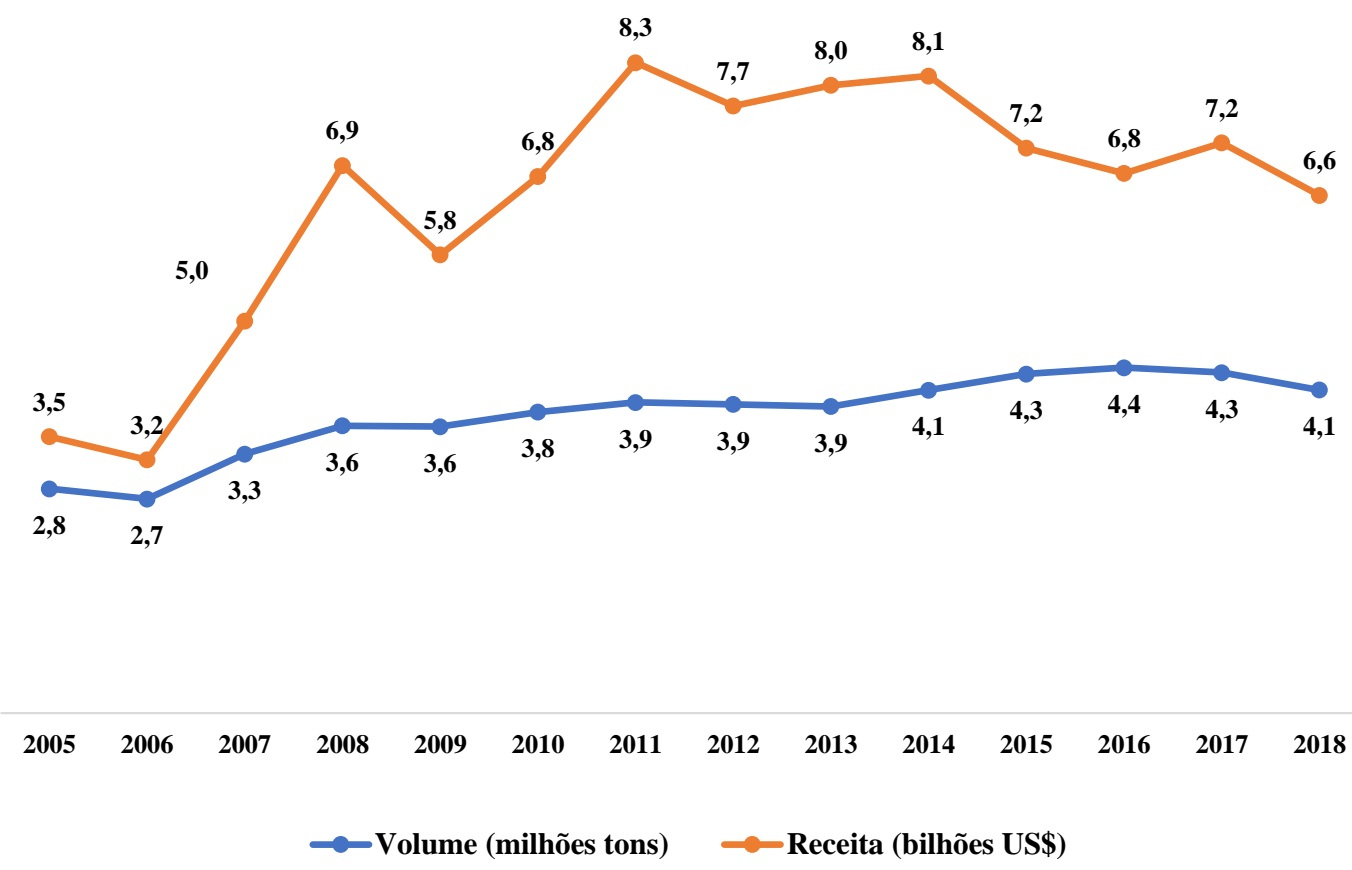

Fonte: Comexstat, 2019.

Tabela 9 - Evolução da exportação brasileira de carne de frango por estado (mil tons).

\begin{tabular}{|c|c|c|c|c|c|c|c|c|c|c|c|c|c|c|c|c|}
\hline Estados & 2005 & 2006 & 2007 & 2008 & 2009 & 2010 & 2011 & 2012 & 2013 & 2014 & 2015 & 2016 & 2017 & 2018 & \begin{tabular}{|c|} 
Share \\
em 2005
\end{tabular} & \begin{tabular}{|c|} 
Share \\
em 2018
\end{tabular} \\
\hline PR & 791 & 754 & 882 & 978 & 954 & 1.000 & 1.043 & 1.124 & 1.141 & 1.286 & 1.481 & 1.544 & 1.574 & 1.554 & $28 \%$ & $39 \%$ \\
\hline SC & 792 & 757 & 933 & 974 & 986 & 1.020 & 1.065 & 1.023 & 937 & 977 & 984 & 1.001 & 971 & 1.262 & $28 \%$ & $31 \%$ \\
\hline RS & 676 & 609 & 683 & 775 & 769 & 799 & 743 & 726 & 710 & 733 & 746 & 741 & 744 & 427 & $24 \%$ & $11 \%$ \\
\hline SP & 241 & 195 & 268 & 323 & 273 & 266 & 294 & 276 & 246 & 253 & 262 & 272 & 256 & 241 & $8 \%$ & $6 \%$ \\
\hline GO & 89 & 98 & 148 & 161 & 170 & 198 & 196 & 205 & 217 & 178 & 203 & 182 & 184 & 150 & $3 \%$ & $4 \%$ \\
\hline MS & 66 & 95 & 118 & 124 & 127 & 131 & 137 & 125 & 149 & 170 & 170 & 168 & 181 & 128 & $2 \%$ & $3 \%$ \\
\hline MG & 93 & 103 & 117 & 121 & 140 & 165 & 189 & 181 & 185 & 189 & 197 & 213 & 171 & 116 & $3 \%$ & $3 \%$ \\
\hline MT & 61 & 60 & 87 & 107 & 129 & 172 & 216 & 174 & 214 & 115 & 99 & 123 & 90 & 77 & $2 \%$ & $2 \%$ \\
\hline DF & 33 & 41 & 45 & 69 & 63 & 57 & 46 & 74 & 73 & 82 & 71 & 51 & 49 & 44 & $1 \%$ & $1 \%$ \\
\hline ES & \begin{tabular}{|l|}
0,00 \\
\end{tabular} & - & 0,1 & - & - & 0,1 & 6,8 & 0,5 & 0,4 & 1,1 & 1,6 & 2,3 & 2,7 & 11 & $0 \%$ & $0 \%$ \\
\hline PE & 0,3 & 0,5 & 1,3 & 2,0 & 1,5 & 1,7 & 1,5 & 1,6 & 1,6 & 1,2 & 0,6 & 1,5 & 2,0 & 1,8 & $0 \%$ & $0 \%$ \\
\hline BA & 0,2 & 2,7 & 1,8 & 4,4 & 14,7 & 6,5 & 0,1 & 0,2 & 12,4 & 5,1 & 5,9 & 3,3 & 1,9 & 1,4 & $0 \%$ & $0 \%$ \\
\hline TO & - & 0,02 & - & - & - & 0,03 & - & - & - & 0,1 & 0,9 & 5,2 & 3,8 & 1,3 & - & $0 \%$ \\
\hline PB & \begin{tabular}{|l|}
0,05 \\
\end{tabular} & - & 0,03 & 0,03 & - & - & - & - & - & 0,4 & 0,1 & 0,4 & 1,0 & 1,2 & $0 \%$ & $0 \%$ \\
\hline PA & - & - & - & - & - & - & 0,01 & 0,1 & 0,02 & 0,02 & 0,02 & 0,03 & 0,00 & 0,4 & - & $0 \%$ \\
\hline $\mathbf{R R}$ & - & 0,03 & - & - & - & - & - & - & - & - & - & 0,0 & 0,1 & 0,1 & - & $0 \%$ \\
\hline RJ & 0,1 & 0,1 & 0,1 & 0,1 & 0,2 & 0,01 & 0,01 & 0,00 & 0,00 & 0,00 & 0,1 & 0,2 & 0,03 & 0,01 & $0 \%$ & $0 \%$ \\
\hline MA & - & - & - & - & - & - & - & - & - & - & - & - & - & \begin{tabular}{|l|}
0,01 \\
\end{tabular} & - & $0 \%$ \\
\hline $\mathbf{A M}$ & - & - & - & - & - & - & - & - & - & - & - & 0,0 & - & 0,005 & - & $0 \%$ \\
\hline $\mathbf{C E}$ & - & 0,03 & 0,04 & - & - & - & - & - & - & - & - & - & 0,1 & 0,001 & - & $0 \%$ \\
\hline $\mathbf{A L}$ & - & - & - & - & - & - & - & - & - & - & - & - & - & 0,001 & - & $0 \%$ \\
\hline RO & - & 0,02 & - & - & - & 0,3 & 2,3 & 1,8 & 1,0 & 0,9 & 0,3 & - & - & - & - & - \\
\hline Não Declarada & 3,3 & 0,1 & 0,1 & 0,0 & 0,4 & 0,0 & 0,0 & 0,0 & 0,2 & 0,0 & 0,0 & 0,1 & 0,6 & 0,4 & $0 \%$ & $0 \%$ \\
\hline Total & 2.846 & 2.714 & 3.285 & 3.638 & 3.628 & 3.816 & 3.939 & 3.912 & \begin{tabular}{|l}
3.887 \\
\end{tabular} & 3.991 & 4.223 & 4.307 & 4.232 & 4.018 & $100 \%$ & $100 \%$ \\
\hline
\end{tabular}

Fonte: Comexstat, 2019. 
De maneira mais específica, os produtos exportados podem ser divididos em cinco categorias: frango inteiro, cortes de frango, preparações à base de carne de frango, carne de frango salgada e embutidos à base de carne de frango (ABPA, 2019). Os principais produtos comercializados pelo Brasil são os cortes, com 2,7 milhões de toneladas e participação de $66 \%$ em 2018, seguido do frango inteiro, com 1,1 milhão de toneladas e participação de $27 \%$ em 2018. A tabela 10, a seguir, demonstra a evolução das exportações entre 2005 e 2018.

Tabela 10 - Exportação brasileira de carne de frango por tipo de produto (mil tons).

\begin{tabular}{|c|c|c|c|c|c|c|c|c|c|c|c|c|c|c|c|c|}
\hline Produto & $\mathbf{2 0 0 5}$ & $\mathbf{2 0 0 6}$ & $\mathbf{2 0 0 7}$ & $\mathbf{2 0 0 8}$ & $\mathbf{2 0 0 9}$ & $\mathbf{2 0 1 0}$ & $\mathbf{2 0 1 1}$ & $\mathbf{2 0 1 2}$ & $\mathbf{2 0 1 3}$ & $\mathbf{2 0 1 4}$ & $\mathbf{2 0 1 5}$ & $\mathbf{2 0 1 6}$ & $\mathbf{2 0 1 7}$ & $\mathbf{2 0 1 8}$ & $\begin{array}{c}\text { Share } \\
\text { em 2005 }\end{array}$ & $\begin{array}{c}\text { Share } \\
\text { em 2018 }\end{array}$ \\
\hline Cortes & 1.713 & 1.633 & 1.839 & 1.928 & 1.866 & 1.972 & 2.066 & 2.142 & 2.066 & 2.218 & 2.484 & 2.588 & 2.698 & 2.714 & $58 \%$ & $66 \%$ \\
\hline Inteiro & 1.047 & 948 & 1.166 & 1.332 & 1.394 & 1.486 & 1.501 & 1.413 & 1.481 & 1.427 & 1.403 & 1.371 & 1.246 & 1.109 & $35 \%$ & $27 \%$ \\
\hline Preparações & 87 & 128 & 155 & 169 & 172 & 169 & 179 & 180 & 161 & 158 & 157 & 166 & 145 & 100 & $3 \%$ & $2 \%$ \\
\hline Enchidos & 103 & 74 & 105 & 117 & 94 & 99 & 98 & 89 & 98 & 116 & 87 & 84 & 95 & 97 & $3 \%$ & $2 \%$ \\
\hline Salgado & 0 & 5 & 124 & 209 & 197 & 190 & 193 & 177 & 178 & 189 & 179 & 182 & 143 & 95 & $0 \%$ & $2 \%$ \\
\hline
\end{tabular}

Fonte: Comexstat, 2019. Elaboração do autor.

No comparativo de preço das exportações brasileiras, os produtos com melhor rentabilidade são as preparações e o frango salgado. Esses produtos apresentaram preços $70 \%$ e $205 \%$ maiores do que o preço dos cortes em 2005. Mesmo com o aumento de preços ao longo do período, em 2018 o contraste de preços entre esses produtos e os cortes de frango exportados pelo Brasil ainda foi considerável (71\% maiores para preparações e $64 \%$ para o frango salgado) A tabela 11, a seguir, apresenta as variações e diferenças de valores por produto, enquanto a Figura 25 ilustra exemplos dos produtos exportados pelo Brasil.

Tabela 11 - Preço de exportação dos produtos de carne de frango (US\$/ton).

\begin{tabular}{|c|c|c|c|c|c|c|c|c|c|c|c|c|c|c|c|}
\hline Produto & $\mathbf{2 0 0 5}$ & $\mathbf{2 0 0 6}$ & $\mathbf{2 0 0 7}$ & $\mathbf{2 0 0 8}$ & $\mathbf{2 0 0 9}$ & $\mathbf{2 0 1 0}$ & $\mathbf{2 0 1 1}$ & $\mathbf{2 0 1 2}$ & $\mathbf{2 0 1 3}$ & $\mathbf{2 0 1 4}$ & $\mathbf{2 0 1 5}$ & $\mathbf{2 0 1 6}$ & $\mathbf{2 0 1 7}$ & $\mathbf{2 0 1 8}$ & $\begin{array}{c}\text { Variação } \\
\mathbf{0 5} / \mathbf{1 8}\end{array}$ \\
\hline Preparações & 2.211 & 2.217 & 2.589 & 3.148 & 2.843 & 2.755 & 3.114 & 2.655 & 2.811 & 3.013 & 2.539 & 2.492 & 2.638 & 2.753 & $25 \%$ \\
\hline Salgado & 3.967 & 2.135 & 2.862 & 2.852 & 2.578 & 2.911 & 3.274 & 2.781 & 2.862 & 2.991 & 2.456 & 2.203 & 2.278 & 2.640 & $-33 \%$ \\
\hline Cortes & 1.300 & 1.211 & 1.509 & 1.872 & 1.548 & 1.792 & 2.155 & 1.994 & 2.031 & 2.010 & 1.593 & 1.528 & 1.712 & 1.605 & $23 \%$ \\
\hline Inteiro & 1.041 & 988 & 1.234 & 1.651 & 1.377 & 1.515 & 1.736 & 1.735 & 1.889 & 1.700 & 1.618 & 1.453 & 1.451 & 1.369 & $31 \%$ \\
\hline Enchidos & 869 & 954 & 990 & 1.293 & 1.496 & 1.514 & 1.621 & 1.613 & 1.510 & 1.458 & 1.227 & 1.141 & 1.123 & 1.038 & $19 \%$ \\
\hline
\end{tabular}


Figura 25 - Exemplos de produtos exportados pelo Brasil.

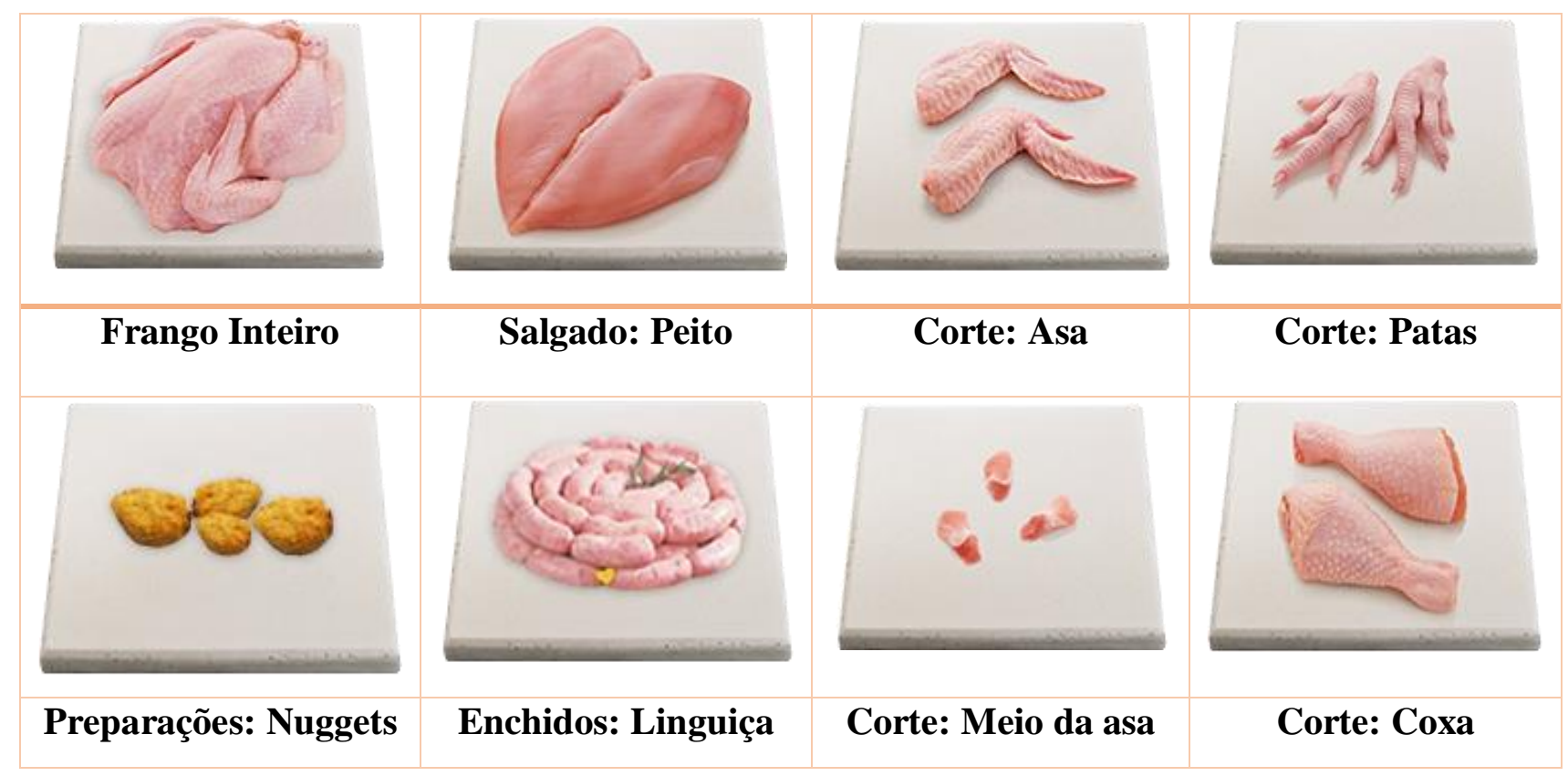

Fonte: ABPA, 2019

A flexibilidade das empresas brasileiras em termos de diversificação de produtos foi um fator de extrema relevância que permitiu ao país acessar mais de 150 mercados por ano, viabilizando as vendas de todas as partes da ave. Exemplos dessa diversificação são: o frango inteiro pequeno ou griller, exportado ao Oriente Médio; o peito de frango salgado, exportado à União Europeia; cartilagens e patas de frango vendidos aos países asiáticos, sobretudo China, Japão e Coreia do Sul; preparações vendidas a países da América Latina, entre outros. Além de ampliar a quantidade de clientes e de produtos comercializados, as exportações também possibilitaram às empresas brasileiras uma melhoria considerável na rentabilidade, sobretudo por conta das oportunidades geradas pelas oscilações de câmbio, conferindo ao Brasil a proeminente posição de principal exportador dessa proteína desde 2004:

Em síntese, enfatiza-se que posição de destaque assumida pelo Brasil como maior mercado exportador brasileiro de carne de frango deve-se a diversos fatores. Dentre os quais estão: a) as mudanças nos fluxos de comércio motivadas por ocorrências sanitárias como a 'vaca louca', no Canadá e nos Estados Unidos e, em 2003; b) o surgimento da "gripe aviária" em países asiáticos como a Tailândia, Vietnã, China, e em países de outros continentes, como Estados Unidos e Canadá; c) o avanço tecnológico e melhorias no processo e na cadeia produtiva e d) a conjuntura internacional favorável com crescimento da demanda mundial, especialmente no Oriente Médio e na Ásia Oriental. (VOILA; TRICHES; 2015, p. 144). 
Entre 2005 e 2008, o cenário externo foi favorável às exportações brasileiras pelos recorrentes surtos de influenza aviária em diversos países produtores e exportadores, como já salientado. A destruição dos quase 29,5 milhões de aves em 53 países apoiou o crescimento das exportações em 6,4\% ao ano no período, mesmo com a valorização do real frente ao dólar, de 6,8\% ao ano. Os casos de influenza ainda continuaram em 2011, com 257 mil casos reportados à OIE e 4 milhões de aves destruídas, afetando grandes importadores como o Japão. Entre 2012 e 2014, os casos reportados subiram para 4,6 milhões e 34,9 milhões de aves destruídas.

O país mais afetado com essa crise sanitária, entre 2012 e 2013, foi o México, grande comprador de carne de frango americana, com prejuízo estimado em US\$ 700 milhões. Em 2014, os casos se espalharam por diversos países asiáticos, como China, Coreia do Sul, Japão, Vietnã e alguns países da Europa. Entre 2015 e 2017, as crises ganharam escala e a quantidade de aves destruídas subiu para 27,7 milhões, 37,6 milhões e 23,8 milhões. Em 2015, a crise atingiu o maior produtor mundial e principal concorrente do Brasil, os Estados Unidos. Foram reportados 15,8 milhões de aves destruídas somente no país norte-americano, com custo de mais de US\$ 1 bilhão e várias restrições de mercados (ABPA, 2019).

Esse cenário beneficiou o Brasil, que, por seus elevados níveis de biosseguridade, nunca registrou casos de influenza aviária e, ademais, é declarado como livre da doença de Newcastle desde 2003 pela OIE. Ainda que as exportações brasileiras atingissem mais de 120 mercados em 2005, é importante salientar que as vendas ocorriam de maneira extremamente concentrada. Os dez principais destinos representavam, naquela época, $80 \%$ dos volumes embarcados e os cinco principais somavam 58\%. Já em 2018, após diversos eventos, os dez principais destinos contabilizam $70 \%$ dos volumes, enquanto os cinco principais reduziram para 49\%. Os gráficos 9 e 10, a seguir, mostram a ampliação dos mercados e diferença dos maiores mercados entre os anos e o crescimento da participação dos mercados menores. 
Gráfico 9 - Comparativo da exportação brasileira de carne de frango por país de destino em 2005 e 2018.

2005

Volume (mil tons)
439

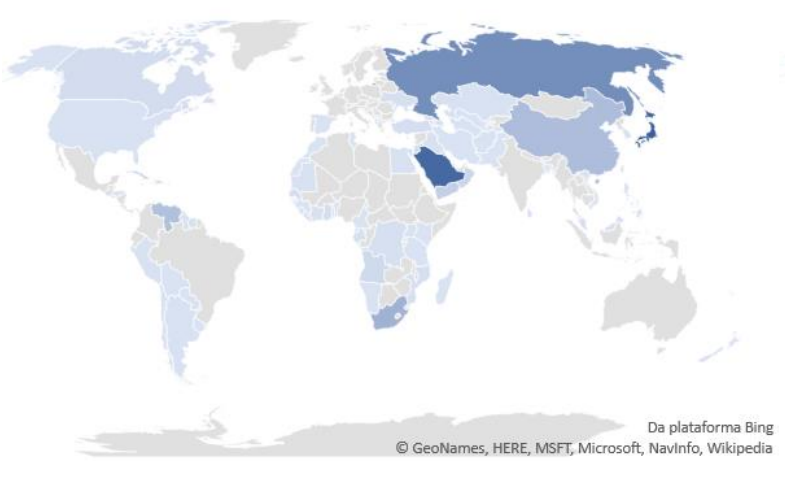

2018

Volume (mil tons)

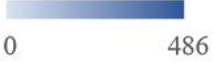

Fonte: Comexstat. Elaboração do autor.

Gráfico 10 - Comparativo da exportação brasileira de carne de frango para os 10 principais destinos em 2005 e em 2018.

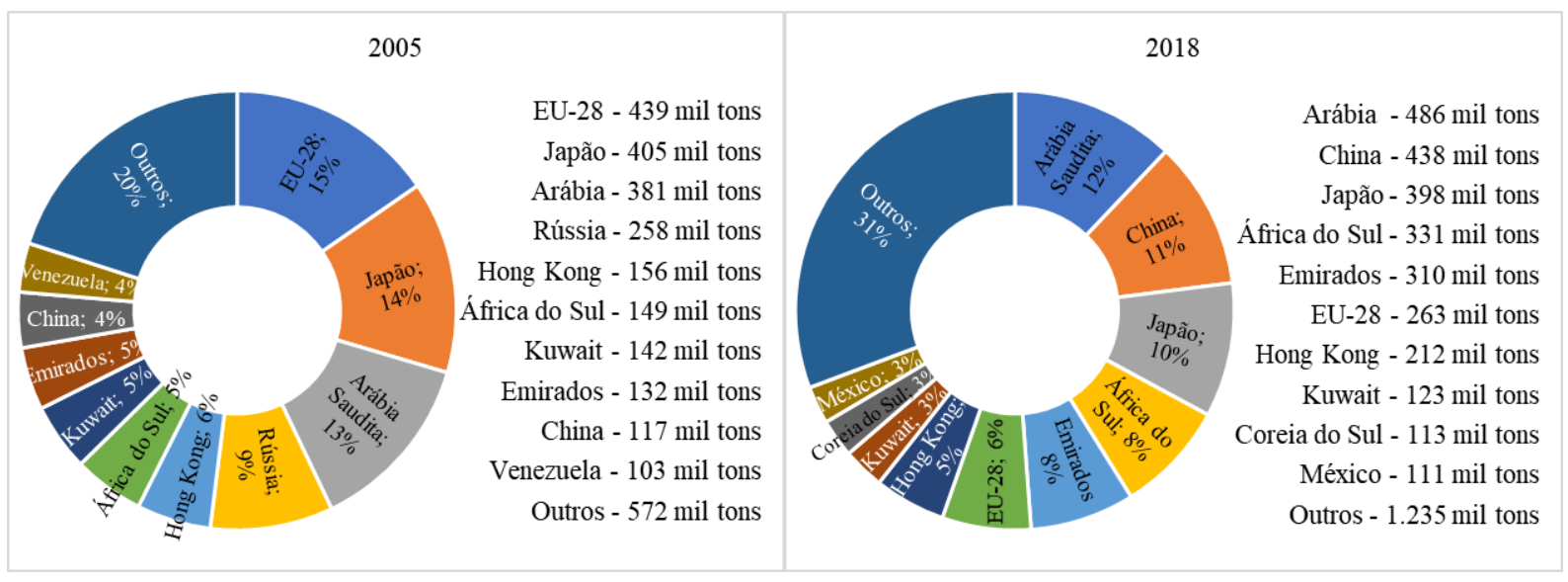

Fonte: Comexstat. Elaboração do autor.

Entre as principais alterações do ranking de principais compradores do Brasil, entre 2005 e 2018, podemos citar a saída da Rússia e da Venezuela entre os maiores importadores e a inclusão da Coreia do Sul e do México. Esse último, inclusive, estabeleceu uma cota de importação para produtos avícolas com tarifas reduzidas em meio à crise de influenza aviária de 2013, a qual beneficiou sobremaneira o Brasil. Outras alterações de destaque referem-se à situação da União Europeia, que passou de maior importador em 2005 para a sexta posição em 2018, enquanto a Arábia Saudita subiu da terceira para a primeira posição ao longo desse período. Outros mercados que tiveram aumento considerável foram China, Emirados e África 
do Sul, que passaram da nona posição para a segunda, da oitava para a quinta posição e da sexta para a quarta posição respectivamente. Os mercados em queda foram Japão, Hong Kong e Kuwait, com queda nas posições e redução da participação.

Com impacto direto sobre a competitividade setorial, o custo de produção nos principais produtores mundiais sofreu redução entre 2013 e 2018. A mesma tendência também ocorreu no Brasil, que continuou com o menor custo de produção total da carne de frango, passando de US\$1,73kg em 2013 para US\$1,3/kg em 2018. O custo industrial na Tailândia é o menor entre os seis países analisados, com US\$ 0,15/kg e US\$ 0,14/kg, devido baixo custo da mão de obra. Os Estados Unidos ganharam maior competividade em 2018 frente à Tailândia, considerando que o custo total era bem próximo em 2013. Os países da União Europeia continuam com os maiores custos, mesmo com redução de US\$ 0,4/kg (AGROICONE, 2019). O gráfico 11, a seguir, mostra as comparações entre custo total de produção nos principais produtores e exportadores mundiais.

Gráfico 11 - Evolução do custo total de carne de frango em 2013 e 2018.

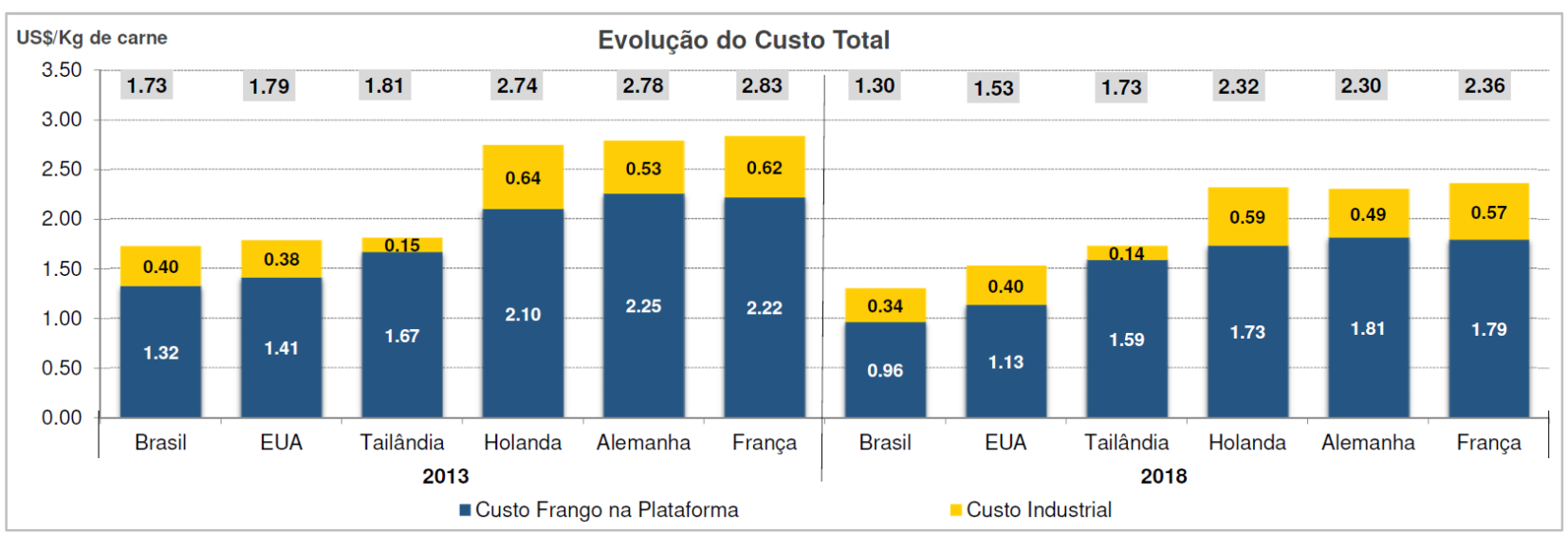

Fonte: Agroicone, 2019.

O principal ponto de atenção em termos de competitividade do produto brasileiro está no mercado doméstico, uma vez que o custo do frango vivo corresponde a $74 \%$ do custo total da carne e é sensível às variações no preço do milho e farelo, os quais dependem de forças de mercado, além da influência referente ao custo do tabelamento de frete. No custo industrial, a energia foi o item que teve o maior aumento percentual, resultado da crise energética vivenciada pelo Brasil em 2015, além da mão de obra, que ainda continua sendo uma séria questão para a competitividade brasileira. Os custos logísticos representam uma pequena parcela no custo do 
produto brasileiro colocado no mercado de destino, entre $2 \%$ e $6 \%$. No comparativo, em termos de valores, os Estados Unidos levam vantagem frente a todos seus principais competidores nos custos logísticos relativos às exportações para o continente asiático.

Gráfico 12 - Comparativo do custo logístico entre os principais exportadores mundiais de carne de frango.

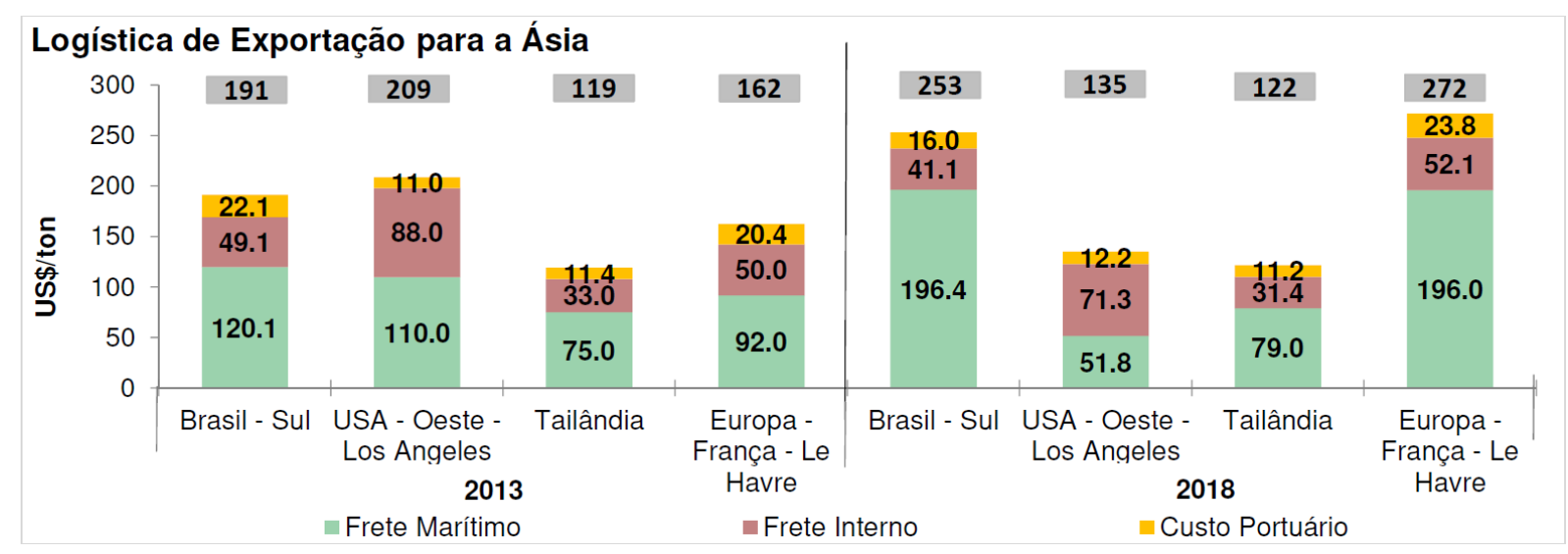

Fonte: Agroicone, 2019.

Brazil's broiler industry future competitive position will depend not only on macroeconomic factors including volatility of the exchange rate and domestic and foreign income growth, but more importantly on the level of efficiency of individual broiler operations. Various factors including labor and feed availability, access to technical assistance, and access to credit significantly influence the level of efficiency of individual broiler operations. Policy and institutional arrangements that address these factors will lead to improved overall efficiency of an industry that remains as a benchmark due to the technical efficiency and technological advances attained in selected regions of the country. (VALDES; HALLAHAN; HAR VEY, 2015, p. 273).

Outro fator que impactou severamente a atuação das empresas brasileiras no exterior, recentemente, refere-se às consequências advindas da Operação Carne Fraca, deflagrada em março de 2017, pela Polícia Federal (PF) e com forte repercussão internacional. A Operação divulgou um suposto esquema de corrupção com envolvimento de auditores fiscais agropecuários do Ministério da Agricultura, Pecuária e Abastecimento (MAPA) e empresas do setor alimentício. Ainda que as autoridades brasileiras e as empresas investigadas enviassem explicações técnicas para amenizar o problema, diversos mercados aplicaram restrições à entrada da carne brasileira em seus territórios apenas uma semana após a divulgação da 
operação. Naquela época, foram contabilizados cerca de 20 países com suspensão total, 15 com suspensão parcial e 5 com pedidos de reforço no controle sanitário, incluindo parceiros importantes como China, Chile, Hong Kong, União Europeia e Arábia Saudita. Os mercados com suspensão total representavam apenas 3,6\% dos compradores de carne de frango, no entanto, os países com suspensão parcial representavam 72,6\%. Em menos de um mês, vários países já haviam anunciado a reabertura de mercado, porém, os reflexos continuaram em 2018, com queda de 5\% em volume ou 220 mil toneladas e 9\% em receita US\$ 665 milhões. Na Arábia Saudita, a redução de comércio foi de 103 mil toneladas, queda de $18 \%$ no comparativo de 2017 e 2018, já com queda de 156 mil toneladas ou 21\% no comparativo de 2016 e 2017 (ABPA, 2018).

Diante desse cenário, o setor tem investido gradualmente no reforço da imagem do produto brasileiro, salientando a biosseguridade na produção, transparência nos processos produtivos e qualidade e rastreabilidade do alimento (ABPA, 2019). Esse movimento de melhoria de imagem da carne brasileira, aliado à elevada capacidade de atendimentos das empresas do país, com altos ganhos em eficiência comprovados ao longo dos anos, é fundamental para a consolidação e crescimento das exportações brasileiras de carne de aves nos próximos anos. Em consonância com as projeções já indicadas no presente trabalho, a ABPA estima que até 2050 seriam necessários $70 \%$ a mais de produtos alimentícios para atender à demanda de 9,7 bilhões de habitantes.

Grande parte desse aumento populacional ocorrerá na Ásia, onde o consumo per capita de proteína animal ainda é baixo. A China, por exemplo, tem indicador per capita de 46,1 kg de carnes por habitante, sendo somente $11,9 \mathrm{~kg}$ de carne de frango - o que denota uma possibilidade real de incremento de consumo de carne avícola, sobretudo se comparada ao Brasil, onde se consome, per capita, $94 \mathrm{~kg}$ de carnes por ano, sendo 37,6 kg de carne de frango. Ademais, ainda há uma parcela da população que não tem acesso a alimentos suficientes e de qualidade, e a falta de recursos naturais para a produção, grãos, terra e água, aliada ao aumento da expectativa de vida em diversos países, amplia a discussão da alocação da produção de alimentos a um nível global, na qual o comércio internacional pode necessariamente melhorar o acesso a esses produtos. Por fim, destacam-se o uso de práticas avançadas de produção, a crescente utilização de tecnologia e de investimentos em P\&D, a ampliação de acordos comerciais e a padronização de regulamentos em nível internacional como desafios futuros para o que o Brasil possa incrementar sua atuação como relevante provedor de proteína animal, 
sobretudo avícola, para diversos países em um mundo em constante transformação (ABPA, 2020).

Como se pode perceber, uma série de fatores coordenados possibilitaram que o Brasil passasse a operar globalmente na cadeia avícola, acessando mais de 150 mercados e provendo carne de qualidade a populações que, necessariamente, dependem do produto brasileiro para compensar seu deficit de proteína. O modelo de governança da cadeia, baseado no sistema de integração foi potencializado no país e possibilitou a criação de uma rede de atores que, atuando de maneira coordenada, foram os responsáveis pela dinamização do setor e dos elevados ganhos de produtividade. Da mesma forma, o acesso a diferentes mercados possibilitou o acúmulo de conhecimento por parte das empresas brasileiras, aperfeiçoando seu processo de internacionalização e incentivou o desenvolvimento de um portfólio diversificado e que atendesse às diferentes preferências em nível global e regional. 


\section{Capítulo 4 A Inserção do Brasil na CGV Avícola}

O presente capítulo visa mapear os fatores que influenciam diretamente as atividades das empresas brasileiras do setor quando da atuação em grandes mercados internacionais. De acordo com o material obtido, foi possível estabelecer quais fatores atuam como propulsores e quais podem vir a restringir o aperfeiçoamento do Brasil na atividade avícola em nível global. Conforme o desenho de pesquisa apresentado, foram realizadas 15 entrevistas em profundidade com profissionais de grandes empresas do setor avícola, alocados no Brasil e no exterior (agroindústria, saúde animal, certificação, entre outras), com representantes governamentais (Ministério da Agricultura, Pecuária e Abastecimento), além de especialistas e consultores com ampla experiência na área de proteína animal, com o intuito de aprofundar e qualificar a inserção do Brasil na CGV da avicultura. As entrevistas classificam-se como padronizada ou estruturada, uma vez que a aplicação de um roteiro previamente estabelecido permitiu a comparação das respostas com base nos mesmos questionamentos (MARCONI; LAKATOS, 2010).

\subsection{A produção e comercialização da proteína avícola em nível global}

Ao serem questionados sobre fatores que influenciam diretamente a produção e comercialização de produtos avícolas, especialistas entrevistados para o presente trabalho enfatizam a dinâmica de consumo global, mas, sobretudo, em algumas regiões, como um dos principais impulsionadores do setor. Em suma, diversos países em desenvolvimento, por conta principalmente do aumento de sua renda per capita, passaram a incrementar o consumo de carne de aves nas últimas décadas, proteína que dispõe de um preço geralmente inferior às carnes suína e bovina. Trata-se, assim, de uma proteína com preço atrativo e de fácil acesso, dois componentes que influenciam diretamente a cadeia de proteína animal em geral. Além disso, como salientado por grande parte dos entrevistados, o apelo à saudabilidade que a carne frango dispõe vis-à-vis outras proteínas, bem como a ausência de barreiras religiosas a ela relacionadas, algo extremamente importante para a população muçulmana, grande consumidora desse tipo de proteína. Importante notar que países extremamente dependentes de importações de alimentos, como os situados no Oriente Médio, por exemplo, necessitam lançar mão de medidas que visem, em última instância, equalizar a oferta e a demanda de proteína animal. Dessa forma, a alimentação é vista como um fator de manutenção de equilíbrio institucional interno, e graves problemas de abastecimento e acesso a alimentos podem gerar protestos e 
insatisfações da população em geral. A região asiática, contudo, foi vista por praticamente todos os entrevistados como o grande vetor de crescimento da demanda por proteína avícola nos últimos anos e no futuro, conforme indicado pelos entrevistados:

"A carne de frango é uma carne relativamente barata quando comparada à carne bovina, e que traz um teor de proteína elevado, o que a torna uma fonte importante de proteína acessível e que tem contribuído para suprir a demanda mundial relacionadas a esse tipo de alimento" (Profissional do setor).

"O aumento de renda global fez as pessoas consumirem mais proteína. No caso da proteína de frango, ela é uma das que são de mais fácil produção e de um ciclo mais curto. Então, mais fácil de você produzir localmente e também de transportar. Existe, dessa forma, a facilidade de o Brasil e Estados Unidos serem grandes exportadores deste perfil de exportação. Globalmente, isso ajudou muito. Além disso, você tem o driver dos os países islâmicos, muçulmanos, que começaram a crescer em termos de renda, aumentando o consumo de proteína animal" (Ricardo Santin, Presidente da Associação Brasileira de Proteína Animal - ABPA e Vice-Presidente do International Poultry Council - IPC)

"Creio que que há três fatores que explicam bem o crescimento da proteína avícola. Pelo lado da oferta foram os ganhos de produtividade que o frango teve, superiores aos que aconteceram em suínos e bovinos, e que fizeram do frango uma carne, digamos, com preços relativos mais baixos do que as outras duas carnes. $\mathrm{O}$ ganho de produtividade do frango se refletiu numa redução do seu custo relativo e o tornou uma carne mais popular. Além disso, o mundo conseguiu desenvolver cadeias integradas com sanidade, com qualidade, com integração vertical e todo o restante que conhecemos. Obviamente, isso explica o sucesso dessa proteína e particularmente dos países que conseguem produzir a custo baixo. Esse é um fator importantíssimo que impulsiona o frango numa velocidade maior do que outras proteínas. Além disso, há dois fatores ligados à demanda. Um deles é o crescimento da renda per capita, principalmente nos países em desenvolvimento. As pessoas mais pobres tiveram aumentos de renda e esses aumentos de renda se refletem na procura por mais proteína. Então, proteína, digamos, é um dos setores privilegiados ao lado de frutas e legumes também, que é outro setor que cresce quando a renda cresce. Pela renda mais elevada, as proteínas substituem outros produtos e eles passam a ser privilegiados no consumo dos mais pobres. Há ainda um terceiro fator, que tem a ver com mudanças de hábitos alimentares, algo que os economistas chamam de efeito graduação. Existe um limite que, na medida em que a renda per capita muda, também muda o hábito alimentar. Aumenta o volume quantitativo da proteína, como de renda, mas também muda a composição da dieta na direção, por exemplo, de proteínas animais substituindo cereais, por exemplo; ainda que exista nos países ricos uma pressão, hoje, de carne vegetal e etc., mas essa pressão é muito menor do que é o efeito graduação nos países mais pobres" (Marcos Jank, professor do Insper e consultor especialista em questões globais do agronegócio).

“Até novembro [2019], a China tinha importado do Brasil 520 mil toneladas. É absurdo isso se você pensar que a China abriu o mercado há 10 anos. Eu 
lembro quando eu participei das primeiras negociações para abrir o mercado da China. Hoje o país é o principal player, tanto em carne de frango como em carne suína. Certamente, esse movimento chinês é o principal driver de crescimento do setor, mas outros países do sudeste asiático, que antes não tinham grande participação, começam também a importar carne de frango" (Profissional do Setor).

Eventos sanitários, como os casos de influenza aviária de alta patogenicidade, ocorridos nos anos 2000 em diversos países produtores e consumidores de carne de aves, bem como o caso recente da peste suína africana, com um elevado número de surtos ocorridos na China em 2019, o qual dizimou grande parte dos plantéis de suínos no país, foram vistos como extremamente importantes para a dinâmica produtiva e comercial da proteína avícola. Em suma, esses eventos são encarados como elementos disruptivos da cadeia, sobretudo por conta da velocidade com que acontecem e de suas consequências abruptas ao negócio, pois causam desvios de comércio, choques de demanda e incremento nos preços. Por fim, é importante ilustrar que, na opinião de alguns especialistas, a cadeia avícola estaria chegando no seu limite em termos de redução de custos de produção ligados ao incremento da conversão alimentar, como se pode ver pelo depoimento abaixo de um especialista do setor:

\footnotetext{
"A base de todo esse processo de desenvolvimento da oferta da ave, da carne avícola, está, primeiro, na capacidade de produção em escala que essa proteína tem a um baixo custo. De maneira geral, há possiblidade de aumentar o volume de oferta do produto, mantendo o custo de produção baixo. Porém, estamos chegando nos limites. Nos limites estruturais do próprio animal. A parte sanitária do animal está perfeitamente controlada, exceto quando vemos esses problemas que estão ocorrendo em algumas regiões, decorrentes, muitas vezes, da falta de medidas mais rígidas em relação aos riscos existentes especialmente esses países que têm muitas aves silvestres. Porém, acho que estamos chegando no limite máximo da redução do custo de produção em termos de melhoria genética e melhoria da parte nutricional - conversão alimentar" (Profissional do setor).
}

\subsection{Fatores que influenciam diretamente a inserção do Brasil na CGV avícola}

Os entrevistados, em geral, concordam que não há um fator isolado que tenha impulsionado a atuação do Brasil na cadeia avícola ao longo das últimas décadas. Trata-se, na verdade, como explorado ao longo da seção anterior, de uma série de fatores que, ao atuarem de maneira coordenada, influenciaram sobremaneira o desenvolvimento de uma cadeia produtiva extremamente competitiva no país. Ou seja, fatores que abrangem desde uma espécie de competitividade natural da qual o país dispõe, geralmente relacionada a recursos naturais (água, solo, clima, área, etc), até aos elevados investimentos em P\&D I nas últimas décadas, 
em áreas como genética, nutrição e manejo, além da existência de complexo sistema de biosseguridade. Todas essas variáveis operam dentro de uma dinâmica que impacta diretamente a capacidade de produção em larga escala do país, bem como a qualidade do produto final tanto no mercado interno quanto externo.

Uma variável fundamental dessa dinâmica é a qualidade percebida pelo consumidor oriunda da carne de frango brasileira. Apesar dos recentes acontecimentos que efetivamente questionaram a qualidade da proteína avícola brasileira, como no caso das alterações de padrões de análise de produtos com salmonela pela Comissão Europeia e das mudanças implementadas pelas autoridades sanitárias sauditas relativas ao processo de abate halal, ambas ocorridas a partir de 2018 e que culminaram com restrições à entrada do produto brasileiro nesses territórios. A qualidade percebida pelos clientes locais em relação à carne brasileira era extremamente positiva, e até mesmo superior, quando comparada a produtos originados de outros países, conforme depoimento de um entrevistado:

\begin{abstract}
"Existe também renome, existe tradição, que é parte de tudo que se conquistou na construção desse nome das empresas brasileiras, e no trabalho para construir uma imagem de que o frango brasileiro tem, realmente, qualidade. Veja o caso da Arábia Saudita. Quando algumas pessoas atacaram as marcas da BRF no Twitter na Arábia Saudita, dizendo que era um produto que não é Halal - isso aconteceu muitas vezes ao longo do tempo, não só com a BRF, com outras empresas brasileiras, mas a BRF, por ser líder, geralmente, é atacada - a própria população respondeu no Twitter. A construção dessa imagem envolve o fator preço, o fator qualidade, a capacidade de atendimento em larga escala e ela envolve parcerias com clientes globais" (Profissional do Setor).
\end{abstract}

Da mesma forma, "a qualidade do produto é mencionada, sim, pelos importadores em geral. Inclusive na Europa, os importadores relatavam que o produto que eles estavam tendo que comprar, que eram da Polônia ou mesmo da Tailândia, tinha um nível de contaminação muito maior - e isso nos controles feitos pelo próprio importador. Tinha uma questão de salmonela muito mais complicada do que no produto brasileiro. Então a qualidade do produto, na verdade, era um fator que os levaram a querer importar do Brasil" (Profissional do Setor).

Essa qualidade é vista, sobretudo, pela capacidade de atendimento a demandas específicas dos distribuidores locais e outros clientes específicos. Em linhas gerais, a responsividade local é um fator que efetivamente fez com que as exportações brasileiras se tornassem, ao longo do tempo, cativas em alguns importantes mercados, como Oriente Médio, Ásia e Europa. As empresas do país, notadamente, passaram a desenvolver produtos com 
padrões que atendiam às especificações desses clientes estrangeiros, algo que somado à escala produtiva e preço, contribuiu para que o Brasil se tornasse um global player do setor:

"A gente tem uma capacidade de atender especificações do país importador muito refinada. Para o Oriente Médio se produz um determinado tamanho de ave; no caso da União Europeia, o peito; no caso da China, o pé. Nossa condição de atendimento ao que o mercado pede é bastante boa" (Profissional do setor).

"O Brasil, às vezes, é preferido por causa de sua qualidade. Um exemplo é o Japão, que tem um padrão de qualidade crítico em termos de serviço. No Japão, as empresas brasileiras agregam valor mesmo mandando [produto] para processar; [envia] um produto cortado em altura, largura e espessura específicas. Na África do Sul, eles sabem que o frango brasileiro tem pouca adição de água, e isso dá mais margem para eles adicionarem os molhos e os temperos utilizados localmente. Então, pode-se dizer que a qualidade também é um diferencial e fez o Brasil se transformar em um player global ao longo do tempo" (Ricardo Santin, Presidente da Associação Brasileira de Proteína Animal e Vice-Presidente do International Poultry Council - IPC).

É importante salientar, todavia, que outros países, como a Tailândia, têm ganhado espaço em termos de qualidade percebida junto aos clientes locais, sobretudo quando do atendimento a mercados mais específicos, como o Japão. Esse tipo de constatação fica clara por vários entrevistados que atestam falhas, por parte de empresas brasileiras, no atendimento a mercados que dispõem de exigências mais específicas. Ademais, os especialistas destacam a necessidade constante de as empresas trabalharem em prol do atendimento às demandas dos clientes locais, como forma de garantir o acesso ao mercado, agregar valor e garantir um produto mais rentável à companhia:

"Acho que, nos últimos 10 anos, o frango brasileiro perdeu espaço para, por exemplo, a Tailândia - em termos de qualidade de produto ou de atendimento a demandas específicas. Antigamente, a gente conseguia fazer uma calibragem mais adequada dos produtos para mandar, por exemplo, para o Japão. Hoje, já não é mais a realidade tanto assim, pois há muita reclamação de adequação de calibragem dos nossos produtos. [...] Isso porque o nosso volume cresceu demais [...] Eu acho que a qualidade do produto é o fator que nos diferenciou, que nos fez primeiro lugar de exportação, mas creio que nós, nos últimos anos, deixamos de dar tanta atenção a isso" (Profissional do setor).

Segue ainda: "creio que o fator qualidade ainda existe, principalmente se combinado com escala; quer dizer, você não vai encontrar fornecedor com escala e qualidade que o Brasil tem. Mas o problema da qualidade é que ela é extremamente heterogênea. Por exemplo, eu convivia muito com esses importadores lá na Ásia e eles reclamavam muito de qualidades de uma determinada planta em relação a outra planta. Existe todo um pequeno mercado de aquisição de produtos que não são de qualidade similar. Há 
plantas excelentes e há plantas com produtos menos padronizados, às vezes com o mesmo preço. Não é uma unanimidade. Mas podemos dizer que, na média, o Brasil, até pela experiência que tem ao exportar para 140 países dispõe de qualidade. Ele não chegaria nesse lugar sem qualidade. Mas existe uma heterogeneidade. [...] Ao trabalhar na ponta, sempre há conversas de desenvolvimento de parcerias de certos produtos, de certas especificidades. Por exemplo, o Japão tem as suas exigências. Singapura também tinha. Mas você não sai muito da commodity, essa que é verdade. Quer dizer, você tem uma capacidade de atender ao seu cliente porque o Brasil é um grande exportador, então se o cliente quer uma determinada especificação você vai fazer; isso vale tanto para uma especificação técnica, quanto para uma especificação religiosa. Mas eu diria que são, na verdade, características de processo, e não de produto. Ou seja, não há um produto mais valorizado por conta desse item da parceria; há, na verdade, uma determinada exigência em relação ao processo, como um determinado tipo de abate, um certo tipo de corte, etc. Mas não vejo muito essa diferenciação acontecendo pelo lado do Brasil. Creio que outros players têm condição de fazer isso até melhor do que a gente. A Tailândia, por exemplo, é um país que tem uma capacidade de fazer calibragem e especificações de produto de forma muito mais precisa do que o Brasil" (Marcos Jank, professor e consultor especialista em questões globais do agronegócio).

Em linhas gerais, vários entrevistados destacaram dois fatores conjuntos que impulsionam a competividade das empresas brasileiras, quais sejam a capacidade de atendimento em larga escala, aliada ao fator preço. A expressiva desvalorização do Real nos últimos anos impulsionou sobremaneira a competividade das empresas brasileiras em termos de preço, enquanto os investimentos produtivos, ao longo das últimas décadas, fizeram do Brasil um grande produtor global de alimentos, sobretudo no campo da proteína animal avícola.

Em relação ao desenvolvimento de parcerias, os especialistas entrevistados destacam sua relevância, mas argumentam que se trata de um movimento muito restrito às empresaslíderes, como BRF e JBS, que atendem a clientes globais como Mcdonalds, KFC, YUM, entre outros. Trata-se de um nicho relevante, de alto valor agregado e que exige elevados investimentos na linha de produção para que se alcance os padrões de tamanho, calibragem, espessura, entre outros, exigidos por essas grandes redes.

Importante salientar, da mesma forma, que, de acordo com alguns entrevistados, há questões mercadológicas que impactam diretamente na competitividade do Brasil, sobretudo em relação à composição dos custos de determinados produtos e, consequentemente, de seu preço, como se pode ver em relação a alguns itens produzidos nos EUA:

"Capacidade de atendimento em larga escala é, sem dúvida, um diferencial. Sendo o segundo maior produtor de frango, a gente realmente tem uma 
capacidade de atender mercados que demandam muito, por exemplo" (Profissional do setor).

"Um fator muito importante, pelo que eu vejo, é o fator estabilidade e capacidade de atender às demandas. Os importadores confiam no produto, sabem que vai ter produto disponível e com preço acessível. O Brasil tem um histórico excelente de sanidade e estabilidade, importantes fatores para este tipo de negócio" (Representante do Ministério da Agricultura, Pecuária e Abastecimento).

"As empresas brasileiras fornecem para o McDonalds no mundo inteiro, fornece pra Yum no mundo inteiro e isso é capacidade de manter padronização e uniformização dos produtos e que faz com que esses clientes nos vejam como bons fornecedores" (Profissional do setor).

"O fator preço, com certeza, é o impulsionador principal da participação do Brasil no mercado mundial e de sua inserção nas cadeias globais de produção" (Profissional do setor).

"Nós estamos na base mesmo, na base produtiva. Grãos disponíveis, um local apropriado, terra boa para plantio, que dê a safra e que tenha volume interessante. Isso tudo se refere à construção do preço. Quando se fala em preço, há alguma coisa nessa formação de preço que impacta diretamente, e o custo é uma delas. Outra questão importante é a mão de obra. O desenvolvimento dessa mão de obra, sua preparação. Porque existe mão de obra que se identifica com aquilo que faz, e a mão de obra que temos é qualificada, ela é boa" (Profissional do setor).

"Ninguém nunca vai conseguir competir com o leg quarter americano, que é a coxa e sobrecoxa americana. Porque trata-se de uma questão de precificação da carcaça da ave nos Estados Unido. O mercado americano consome muito peito, paga um valor extremamente alto pelo peito, e isso paga, praticamente, o frango que eles produziram. Então, eles pegam a perna, que tem um consumo muito menor, e eles praticamente desovam a perna no mundo. Então, o quarter leg americano tem um preço que, na verdade, é um preço fictício. É impossível competir com ele" (Profissional do Setor).

Diversos entrevistados destacam: a competividade que o país detém em relação ao campo e às práticas agrícolas que fizeram do país um grande produtor de proteína animal.

Uma extensa produção de milho e soja, que representam, como citado anteriormente, cerca de $70 \%$ do custo do frango vivo, a utilização em larga escala do sistema de integração entre produtor e agroindústria, que praticamente abarca toda a produção brasileira de carne de frango, o clima favorável, a extensão de terra, os profissionais técnicos qualificados, e aspectos de sanidade, entre outros, fazem com que as empresas do país operem a um nível extremamente competitivo em termos de custo de produção. Importante notar, todavia, que alguns entrevistados já identificam dinâmicas, principalmente relativas à produção e comercialização 
de insumos, que podem vir a influenciar negativamente algumas variáveis em termos de competitividade setorial. O custo e a disponibilidade dos grãos, por exemplo, é um importante ponto a ser considerado:

"O fato de ter tido uma marca pioneira que desbravou o mercado de exportação e que se posicionou, trouxe muita gente atrás. [...] o fato de ser uma cadeia integrada nos valida muito. No caso da pecuária de corte, é difícil conseguir um produto igual a cada lote de produção - e na avicultura a gente não tem esse problema. Creio que a integração seja um dos grandes fatores que nos permite ser um player global. O país consegue atender a uma demanda regular e, ao mesmo tempo, com uma qualidade semelhante a cada partida" (Profissional do setor).

"Eu acho que há outras coisas que fazem o Brasil ser um player importante. Há, na verdade, duas coisas que são fundamentais e pouca gente menciona: uma delas é o sistema de integração, que está vinculado aqui ao fator custo em larga escala, ou seja, esse sistema de integração como um elo entre o campo e a indústria, e como um sistema que funciona de forma a garantir a sanidade, a qualidade e a padronização da carne de frango. [...] Mas eu acho que é fundamental o know-how que se gerou nesses quarenta, cinquenta anos de exportação. Há profissionais, aqui no Brasil, que conhecem muito o mercado de carnes. Não só da área comercial, aquele gerente comercial, o diretor comercial de uma determinada empresa que domina a dinâmica de mercado, mas também na área técnica, temos os melhores profissionais. Em termos técnicos, o Brasil é referência mundial" (Profissional do setor).

"Eu acho que, de maneira geral, o preço é um dado bastante conhecido, o um custo mais baixo, ainda que ele esteja deixando de ser o custo mais baixo. Isso porque de uns anos para cá um dos elementos que faziam o custo baixo, que era o milho, o milho barato, hoje já não existe. O Brasil está se tornando um player global de milho, como é de soja, então o fator custo que sempre foi uma vantagem - o fato do frango e do suíno estarem perto do milho e da soja no Brasil. Mas hoje esse milho é retirado, colocado num trem e enviado direto para os nossos clientes para fora. Existe uma perda de eficiência ao longo do tempo no fator custo" (Marcos Jank, professor e consultor especialista em questões globais do agronegócio).

"Nós temos que trabalhar em todos os polos de mercado. Creio que se o Brasil se afastar dessa capacidade de diversificar, de obedecer ao cliente, entender suas necessidades, o Brasil vai ser somente um produtor de aves, ele não vai ter mais a diferença maior, aquela mais importante. Hoje o Brasil se distingue por quê? Porque ele oferece um produto com uma diferenciação, especialmente, no sabor, na apresentação, na qualidade. É um produto feito com um clima muito mais adequado do que o clima que é feito em alguns outros países; tem uma tecnologia aplicada. Sobre isso, é importante dizer o seguinte: nós importamos muita tecnologia de produção de outros países, mas nós criamos a nossa. Eu acho que a avicultura venceu por causa disso: ela exportou ideias, ela não copiou. Adaptação. Até mesmo do nosso manejo de criação. Há décadas, havia cartilhas de grandes empresas americanas com instruções e indicações de como agir em vários procedimentos. Os técnicos 
aqui faziam do jeito que era melhor! O produtor achava 'não, eu vou fazer aqui porque aqui eu conheço o meu clima, conheço a minha região, toda a condição, o meu galpão, então a ave precisa disso, precisa daquilo'. Houve aquele 'algo mais' que é dado pela pessoa. Não é uma cópia. Ao simplesmente copiar, você acaba às vezes tendo problemas que depois não se torna possível achar a causa do problema" (Rui Vargas, Médico Veterinário, especialista em produção e inspeção sanitária da área de proteína animal).

Outro ponto fundamental relativo à competitividade e inserção do país no mercado global avícola refere-se, de acordo com os entrevistados, ao tema sanidade. Em suma, praticamente todos os entrevistados atestaram a segurança do sistema de sanidade do Brasil. Esse status diferenciado é fundamental para a manutenção de mercados importantes, cujos governos, recorrentemente, vêm ao Brasil para realizar missões técnicas e de avaliação do sistema de saúde animal do país:

"Essa competitividade acabou fazendo do Brasil um grande player global. O país tem água, tem sol, tem clima favorável e tem área para produzir de uma maneira sustentável. Outro ponto é a sanidade. O Brasil se tornou um grande exportador mundial a partir do episódio da influenza aviária, onde todos os grandes concorrentes tiveram influenza aviária e o Brasil não teve. Abriu-se uma janela de oportunidade de crescimento, e ele soube agarrar" (Profissional do setor).

"Clima, oferta de grãos para alimentação em um nível bastante adequado, o fato de se ter trazido para dentro do país uma tecnologia bem avançada, avaliando com muito cuidado aquilo que era de interesse trazer e aquilo que não era. Agora, em termos de qualidade, eu acho que o Brasil é o país que melhor trabalha. É o que melhor trabalha em termos de sanidade, em termos de saúde pública, em termos de segurança, em termos de controle, em termos de cuidado. Eu acho que hoje o Brasil é o que mais trabalha, e muitos países, especialmente os Estados Unidos, que é um dos maiores produtores, já observou esse tipo de cuidado que o Brasil tem nessa área e está procurando seguir o caminho que o Brasil seguiu" (Rui Vargas, Médico Veterinário, especialista em produção e inspeção sanitária da área de proteína animal).

Um outro ponto levantado por alguns entrevistados foi a abordagem, sobretudo em nível institucional, utilizada pelo setor para a entrada em novos mercados ou expansão/consolidação nos mercados já compradores. Trata-se de uma abordagem que visa explorar a complementaridade em termos de abastecimento de um determinado mercado, um tipo de discurso que lança mão de uma narrativa cujos pilares estão em afirmar que não haverá prejuízos para o produtor local caso haja necessidade de importar do Brasil. A ABPA, nesse sentido, é a grande promotora desse tipo de abordagem, por meio da participação em diversos fóruns, eventos, feiras e missões internacionais: 
"O que é interessante no Brasil é que há uma característica de inserção com complementaridade; a maneira de inserção no mercado. Eu noto isso por parte da ABPA. Percebe-se uma preocupação em não desestabilizar ou desorganizar a produção interna. O Brasil, então, consegue ocupar uma lacuna que a produção interna não consegue cumprir. Veja o peito de frango na União Europeia, o pé na China, etc. Com isso, as empresas conseguem realmente dar a saída na ave inteira. Porque o frango, na verdade, realmente é vendido, em alguns casos, como no Oriente Médio, inteiro. Mas, na maior parte das vezes, ele é vendido como corte. E os cortes têm penetração num mercado ou no outro. Além disso, há o mercado interno, que consome uma parte que normalmente é difícil exportar, como coxa, fígado, coração. Então, a maneira com a qual o setor tem se colocado é bastante compreensiva, pois pega realmente todo o leque de produto e consegue se encaixar em diferentes mercados" (Profissional do Ministério da Agricultura, Pecuária e Abastecimento - MAPA).

A despeito da evolução do Brasil como importante produtor e exportador de proteína animal avícola ao longo das últimas décadas, uma série de fatores restringem ou, pelo menos, influenciam negativamente a expansão ou manutenção dos mercados nos quais as empresas brasileiras operam. Assim como no caso das variáveis que impulsionam a atuação do Brasil, esses fatores, segundo os especialistas consultados, atuam de maneira coordenada e com intensidades e localizações diferentes, gerando, ainda mais, imprevisibilidade no presente e futuro das transações comerciais do Brasil com o mundo.

Um fator destacado por vários entrevistados se refere às alterações na própria dinâmica de mercado da cadeia avícola. Em linhas gerais, percebe-se atualmente que a operação relativa a vários produtos ocorre com margens de lucro menores e um espaço para margem de manobra extremamente restrito. Há um consenso de que a entrada em importantes mercados deve ser feita de maneira extremamente estratégica, observando as lacunas existentes e as tendências das demandas futuras. Planejamento no acesso e na manutenção de um determinado mercado são fatores essenciais, sobretudo por conta do recrudescimento do protecionismo em nível global e das diversas formas de proteção ao produtor local implementadas pelos governos de países que precisam complementar sua produção interna por meio de importações. Como se pode observar no Quadro 5, a seguir, cerca de 50\% das exportações brasileiras nos últimos três anos acessou mercados com algum tipo de restrição:

"A indústria brasileira precisa entender que os tempos mudaram e já não estamos mais naquele momento de crescimento vertiginoso da exportação brasileira de carne de aves, em que vários mercados tinham demanda e as empresas chegavam com um produto acessível de qualidade e conseguiam expandir volume de forma maneira muito rápida. Hoje em dia, você tem os países muito preocupados com segurança alimentar, produzir o seu próprio 
alimento e não ficar dependente de importação nem de variações externas. Há uma tendência protecionista muito forte, que afeta, praticamente, o mundo inteiro. As empresas têm que ser mais inteligentes na maneira de acessar os mercados. Ou seja, o impulsionar, não necessariamente, é um aumento exponencial de volume, entretanto pode ser em alguns locais" (Profissional do setor).

"Por que que a gente discute o uso de antimicrobianos na produção animal? Pela preocupação do risco que isso pode trazer em termos de resistência aos antimicrobianos e, principalmente, que essa resistência aos antimicrobianos atravesse a cadeia e chegue aos humanos, causando complicações. Então, primeiro que a gente precisa compartimentar o nosso ponto de vista e, principalmente, precisa falar de risco. Qual que é o risco de que esses eventos aconteçam, separados e em conjunto, um após o outro, e como gerenciar isso depois. $\mathrm{O}$ assunto já vem sendo estudado há muitos anos. Há estudos sobre bactérias resistentes de 1943, 1940. E aí, nesse momento, a preocupação era a eficácia do medicamento. Funciona ou não funciona? Vai parar de funcionar ou não vai parar de funcionar? À medida que ele foi avançando, isso foi tomando outros âmbitos, até que você chega ali nos anos 2000 e a Dinamarca proibindo, fazendo os primeiros movimentos de banimento de moléculas para a suinocultura especialmente. E, desde então, isso tomou uma proporção enorme de vários países, numa pressão da sociedade — parte da sociedade civil. O que se debate hoje é o uso responsável, o uso racional. E o que que é o uso racional? É o medicamento correto, na dose correta, no animal correto. O que vem acontecendo é, muitas vezes, uma mistura de todos os tipos de antimicrobianos, uma confusão entre antibióticos e antimicrobianos. É impressionante o quanto que a gente tem de falta de informação [...] Eu participei da última reunião da força-tarefa do CODEX agora, em dezembro, na Coreia, e é muito preocupante quando você vê Europa, Rússia e outros países querendo promover uma restrição quase que absoluta de uso de tecnologia, inserindo isso num guia do CODEX, de vigilância. Então, você percebe que esse tema passou a ser tomado como uma medida protecionista por vários países e as questões políticas vêm antes de questões científicas [...] Em termos de tendência, haverá alguma restrição ainda pela frente; a pressão para restrição é muito grande, mas a pressão que a gente vai fazer no Brasil é para que as decisões sejam baseadas em ciência e não como acontece na UE e outros países, em que são usados estudos isolados e inconclusivos como base da medida [princípio da precaução]" (Profissional do setor, especialista em resistência antimicrobiana"). 
Quadro 5 - Status dos 40 principais destinos (2019) - Exportação brasileira de carne de frango (tons).

\begin{tabular}{|c|c|c|c|c|c|c|c|}
\hline \multicolumn{8}{|c|}{ Situação dos 40 principais destinos (2019) - Exportação brasileira de carne de frango (Tons) } \\
\hline $\begin{array}{l}\text { Posição } \\
\text { em } 2019\end{array}$ & País & 2017 & 2018 & 2019 & $\begin{array}{l}\text { Situação do } \\
\text { mercado }\end{array}$ & Habilitação & Comentários adicionais \\
\hline 1 & CHINA & 391.441 & 438.071 & 513.306 & Aberto com restrição & Específica & $\begin{array}{l}\text { Processo de investigação antidumping sobre as exportações de } \\
\text { carne de frango brasileiro encerrado em } 2019 \text { por meio da } \\
\text { celebração de compromisso de preço. }\end{array}$ \\
\hline 2 & ARABIA SAUDITA & 589.873 & 486.437 & 428.744 & Aberto com restrição & Específica & $\begin{array}{l}\text { Discussão em curso sobre procedimentos de insensibilização; } \\
\text { certificação HALAL privada e uso de embalagens } \\
\text { Oxibiodegradáveis }\end{array}$ \\
\hline 4 & EMIRADOS ARABES & 300.403 & 309.702 & 315.523 & Aberto & Geral & \\
\hline 5 & AFRICA DO SUL & 345.516 & 331.052 & 245.525 & Aberto & Geral & $\begin{array}{l}\text { Definição sobre aumento tarifário relativo às importações de carne } \\
\text { de frango deve ocorrer até março de } 2020 \text {. A alíquota pode chegar à } \\
\text { faixa de } 80 \%\end{array}$ \\
\hline 6 & UNIÃO EUROPÉIA & 323.680 & 263.423 & 229.307 & Aberto com restrição & Específica & Cota de importação e habilitação específica \\
\hline 10 & MEXICO & 94.690 & 111.268 & 95.866 & Aberto com restrição & Específica & Cota de importação e habilitação específica \\
\hline 11 & IRAQUE & 120.851 & 104.130 & 95.748 & Aberto & Geral & $\begin{array}{l}\text { Aumento recente da alíquota do imposto de importação sobre carne } \\
\text { de frango para } 50 \% \text {. }\end{array}$ \\
\hline 12 & IEMEN & 68.011 & 85.530 & 95.409 & Aberto & Geral & Certificação HALAL \\
\hline 13 & CINGAPURA & 82.007 & 96.616 & 88.477 & Aberto com restrição & Específica & \\
\hline 14 & OMA & 79.600 & 74.589 & 76.014 & Aberto & Geral & Certificação HALAL \\
\hline 15 & CATAR & 77.852 & 63.324 & 66.183 & Aberto & Geral & Certificação HALAL \\
\hline 16 & RUSSIA & 83.131 & 64.668 & 57.941 & Aberto com restrição & Específica & Habilitação específica \\
\hline 22 & LIBIA & 33.052 & 43.545 & 35.239 & Aberto & Geral & \\
\hline 23 & CUBA & 61.726 & 73.310 & 29.962 & Aberto com restrição & Específica & Habilitação específica \\
\hline 24 & BAREIN & 22.138 & 24.541 & 28.453 & Aberto & Geral & \\
\hline 25 & VIETNA & 14.939 & 18.293 & 23.838 & Aberto com restrição & Específica & Habilitação específica \\
\hline 26 & PERU & 16.751 & 21.582 & 19.904 & Aberto com restrição & Específica & Habilitação específica \\
\hline 27 & AFEGANISTAO & 5.958 & 8.246 & 16.670 & Aberto & Geral & \\
\hline 28 & GEORGIA & 4.885 & 10.359 & 15.976 & Aberto & Geral & \\
\hline 29 & ALBANIA & 11.163 & 13.730 & 15.936 & Aberto com restrição & Específica & \\
\hline 30 & SUICA & 15.733 & 13.025 & 14.366 & Aberto com restrição & Específica & \\
\hline 31 & CANADA & 15.052 & 11.381 & 13.986 & Aberto com restrição & Específica & \\
\hline 32 & NAMIBIA & 8.256 & 9.857 & 12.459 & Aberto & Geral & \\
\hline 33 & TURQUIA & 13.256 & 11.467 & 12.330 & Aberto & Geral & \\
\hline 34 & GANA & 12.311 & 16.162 & 11.390 & Aberto & Geral & \\
\hline 35 & MALASIA & 16.272 & 10.768 & 10.862 & Aberto com restrição & Específica & \\
\hline 36 & LIBERIA & 3.061 & 4.556 & 8.242 & Aberto & Geral & \\
\hline
\end{tabular}


Em linhas gerais, todos os especialistas consultados citaram, em maior ou menor escala, os fatores intrínsecos à economia brasileira, aqui chamados de fatores internos, como um dos principais entraves à maior inserção do Brasil na CGV avícola nos últimos anos. Foram citados problemas relativos à logística, infraestrutura, custo de energia, burocracia, estrutura regulatória, entre outros, como sendo os principais pontos de melhoria para uma atuação mais efetiva, dinâmica e competitiva do Brasil no plano internacional em matéria de proteína animal:

\begin{abstract}
"A tendência é que os países consigam avançar em tecnologia e reduzam seus custos de produção. Assim, o gap entre o custo de produção brasileiro e os demais países se torna mais curto de acordo a evolução deles. Sua cultura, sua produção de grãos, etc. Não acho que eles cheguem na competitividade do Brasil, mas, esse gap, a tendência é diminuir. Por isso é que o Brasil tem que trabalhar a questão de logística e do custo Brasil. Ele realmente tem que ser reduzido. Não há a menor dúvida disso. Além disso, acho que temos que olhar com cuidado também para os mercados que demandam o topo da pirâmide de Maslow. Esses mercados que demandam questões mais refinadas, eles não podem ser ignorados, até porque é lá que você vai vender produtos de valor agregado e é justamente no produto de valor agregado que as empresas de agricultura ganham dinheiro" (Profissional do Setor).
\end{abstract}

"Obviamente que se a gente conseguisse ter uma infraestrutura de logística, de estrutura interna do país, com uma logística melhor, sem sombra de dúvida isso nos traria muita competitividade porque os nossos custos de transporte hoje são muito altos. Então, sem sombra de dúvida, isso faria muita diferença. Uma reestruturação tributária, por exemplo" (Profissional do Setor).

"A facilitação de negócio, a segurança jurídica, isso é algo que pode deixar o Brasil muito melhor, mais competitivo, mais aberto para investimentos estrangeiros e novas parcerias. Então, esse tipo de reforma [tributária] vai facilitar esse movimento financeiro. Primeiro deve-se investir em logística, do frango e dos insumos, e, em segundo plano, a reforma tributária" (Profissional do setor).

"Primeiro, o ambiente interno: obviamente a gente tem questões de logística que certamente aumentariam a eficiência da produção com a redução do chamado 'custo brasileiro em logística e infraestrutura' - a questão de energia, a questão da burocracia, etc. Vejo uma preocupação muito grande em torno disso, esse peso que é o processo burocrático para uma empresa. Sabemos, por exemplo, que a área de certificação sanitária em uma empresa grande tem cerca de 50 pessoas. Isso reflete uma estrutura que foi crescendo e se moldando a partir dos desafios que teve, e aí há uma série de imperfeições que precisam ser corrigidas tão intrinsecamente que não vai ser tão rápido como se gostaria" (Representante do Ministério da Agricultura, Pecuária e Abastecimento - MAPA). 
Um ponto que merece destaque dos fatores internos refere-se à estrutura regulatória brasileira, sobretudo no que se refere ao processo de habilitação das plantas frigoríficas a serem exportadas. Trata-se de um procedimento que conta com o respaldo normativo das melhores práticas e diretrizes internacionais e que devem ser obedecidas no plano nacional. Todavia, ter uma cadeia regulatória em nível nacional que efetivamente promova fluidez na troca de informações, agilidade na prestação de serviços (elaboração de relatórios, resposta a questionários, etc.) e uma comunicação extremamente dinâmica entre os órgãos nacionais e as embaixadas no plano internacional são fatore-chave para uma atuação mais sólida do Brasil no exterior:

"Claramente, a sanidade é muito mais importante do que sustentabilidade. [...] Quando você analisa o mundo da proteína animal, temas como sanidade e mão de obra se tornam muito importantes. Por exemplo, a sanidade, no fim, é o nosso calcanhar de Aquiles por causa do sistema de habilitação de plantas. Então, digamos, talvez fator mais importante ligado ao modelo de negócios, é a capacidade de habilitar novas plantas, que depende de uma melhoria da estrutura regulatória brasileira. Eu acho que o fator intrínseco mais importante ligado ao modelo de negócio é a capacidade baixa que o país tem de conseguir habilitar plantas, não só plantas individuais, mas também de forma coletiva. Eu acho que isso realmente é um calcanhar de Aquiles hoje, que nos fecha muitos mercados. Mesmo, assim, esse mega entusiasmo que está havendo com a China hoje, a gente sabe que isso dura pouco, certo? A gente sabe que eles, daqui a pouco, fecham de novo. Então, eu acho que esse é o problema maior: eu diria que é uma combinação de barreira sanitária, com barreira técnica e com barreira burocrática. Eu acho que a gente tem todas as três. Ou você é bloqueado porque está usando ractopamina, ou você é bloqueado por um problema sanitário típico. Ou você é bloqueado por burocratas, por sistemas poucos transparentes, sistemas que você não tem previsibilidade. Qual é o problema da maior parte das habilitações de plantas? É que você não sabe quando elas vão acontecer, simplesmente. Nenhum país se compromete a te dar um prazo, um número de plantas, você fica o tempo todo naquela eterna negociação e tentando fazer trade-offs, tentando fazer trocas. Acho que é um sistema é muito perverso. O sistema de venda de carne, de proteína animal, é muito mais difícil do que é o sistema de soja, de milho, de algodão, de celulose, onde se o país está aberto, qualquer um pode exportar. A carne, você não pode dizer que o país está aberto, porque quem está aberto são plantas individuais. Você tem algumas plantas que entram e outras que não entram, então, na prática, você tem uma enorme restrição à exportação. Eu acho que isso é muito mais importante do que a sustentabilidade [...] A cadeia regulatória tem que funcionar melhor. Então tudo aquilo que envolve questionários para habilitação de plantas, mesmo essa questão ligada ao processo regulatório. No Brasil, isso é super ineficiente. Estamos muito atrás de que eu vi na Austrália, na Nova Zelândia, na Europa, nos Estados Unidos. A estrutura regulatória brasileira está completamente ultrapassada para garantir o desempenho brasileiro. A cadeia regulatória da proteína animal é fundamental para você conseguir capturar valor na cadeia. Infelizmente, o Brasil tem um sistema que foi desenhado muito mais para atender à burocracia 
interna do que o cliente externo" (Marcos Jank, professor e consultor especialista em questões globais do agronegócio).

Ao serem questionados sobre os fatores externos com influência direta na atuação do Brasil na CGV avícola, os especialistas se dividem quanto à verdadeira importância da celebração de acordos comerciais como vetores de acesso a novos mercados por parte do Brasil. Na mesma linha, as ações de promoção comercial, sobretudo em nível institucional, tiveram seu valor reconhecido, mas não são, necessariamente, um fator a ser priorizado em termos de acesso a mercados. De maneira oposta, três pontos foram percebidos como essenciais à melhoria da atuação do Brasil no plano internacional: (i) aumento da representação institucional do setor no plano internacional, a exemplo do que foi realizado recentemente pela ABPA, por meio da abertura de escritórios comerciais em Shanghai, Bruxelas e Dubai; (ii) aumento da capacitação de profissionais das empresas do setor em termos de inteligência comercial, no intuito de aperfeiçoarem o entendimento acerca de padrões e especificidades de consumo de diferentes mercados; e (iii) implementação de ações comunicação em larga escala, com o intuito de melhorar a imagem do Brasil no exterior na área da agricultura.

Antes de apresentarmos as transcrições das entrevistas referentes aos tópicos ora abordados, é importante ter presente que a celebração de acordos comerciais visa, justamente, conferir previsibilidade às relações comerciais em nível bilateral. Dessa forma, ao assinarmos acordos com diretrizes claras em termos de barreiras técnicas e medidas sanitárias e fitossanitárias, por exemplo, poderíamos reforçar os interesses do Brasil no campo da proteína animal. Esse comentário faz-se necessário, pois é justamente na proliferação de regras e normas públicas e privadas que se encontra um dos grandes pontos de atenção para esse setor atualmente. Ao celebrarmos regras bilaterais nessas matérias com importantes compradores de produtos agrícolas brasileiros, por exemplo, estaríamos, em tese, eliminando uma série de eventuais medidas distorcivas ao comércio bilateral. $\mathrm{Ou}$, na pior das hipóteses, abrindo uma esfera de negociação mais rápida com a contraparte.

Além disso, como se pode ver no Quadro 5, que apresenta o status de abertura de mercado dos principais destinos das exportações brasileiras de carne de frango em 2019, há importantes problemas referentes a aumentos repentinos de tarifa de importação sobre o produto advindo do Brasil. Na verdade, quando esses países elevam suas tarifas de importação para carne de frango, raramente isso é feito de maneira a atingir o Brasil, pois tal medida violaria as regras multilaterais de comércio. Porém, mesmo que a elevação tarifária seja feita erga omnes, 
o Brasil sempre perde uma vez que é o principal exportador de proteína avícola do mundo. Ademais, em estudo que simula a celebração de acordos comerciais entre o Brasil e vários países, por meio da aplicação do modelo Global Trade Analysis Projetc (GTAP), Gurgel et al. (2012) nos mostram que, segundo o modelo, o setor avícola brasileiro aumentaria o saldo de suas transações comerciais no caso da celebração de um acordo comercial com Japão, México, África do Sul, União Europeia, Estados Unidos e América do Sul (MORAES; GURGEL; GTAP, 2012; GURGEL et al., 2012; PALTSEV, 2015).

Outro fator importante que deve ser observado é que, realmente, a estrutura de representação institucional do Brasil junto aos principais polos importadores ainda é inferior quando comparada a associações representativas dos setores agrícolas de outros grandes países produtores como Estados Unidos, Canadá, Austrália, nações europeias, entre outros. De acordo com Jank (2018), a US Meat Export Federation dispõe de 11 escritórios no exterior, enquanto a Meat and Livestock Australia dispõe de sete escritórios. A ABPA, conforme já exposto, iniciou seu processo de internacionalização, com três escritórios inaugurados em 2019, porém espera-se que esse número se amplie nos próximos anos (JANK, 2018). A seguir, estão as principais contribuições dos entrevistados quanto à influência dos fatores externos sobre a participação do Brasil na CGV avícola:

\footnotetext{
"Quanto a fatores ligados ao ambiente externo, gosto desse ponto e acho que ele tem muito a ver com o momento que vivemos, mas particularmente eu não acredito que acordos comerciais, questões bilaterais, discussões bilaterais vão trazer algum benefício que seja um game changer para o setor e para as empresas. Eu acredito muito mais na inteligência comercial das empresas, no conhecimento de novos mercados, no aprender a como se relacionar com esses mercados. Isso é extremamente importante, porque, por exemplo, um ano em que a China tem uma questão sanitária [crise recente de peste suína africana que dizimou praticamente metade da produção de suínos do país], o mercado melhora. Em seguida, daqui a dois, três anos, ela controla, e o mercado piora. Com isso, você dependa talvez de uma outra doença aparecer. Essas questões que não estão diretamente ligadas ao poder de controle das empresas têm uma influência muito impactante no negócio. Quando começou a guerra comercial entre Estados Unidos e China, por exemplo, em questão seis meses você já começou a ver uma série de restrições em mercados, algo que não acontecia com frequência. Isso foi muito nítido. Esse tipo de fator externo, ele tem um impacto muito maior. O impacto é muito abrupto, muito forte. E como você sobrevive a esses impactos, na minha opinião? Sendo inteligente como empresa, fazendo as alianças corretas, colocando portfólio de produto correto, tendo marcas fortes. Esse tipo de coisa ajuda você a desenvolver mercado mesmo num ambiente adverso" (Profissional do setor).
}

"Se a gente conseguir ter melhor acesso a um país ou a tarifas preferenciais em países que são chave - e não só aqueles que são chave hoje, mas aqueles 
que podem vir a ser chave. Isso é fundamental. A importância da promoção comercial também em continuar com os mecanismos de apoio por meio da APEX. Eu acho que são fundamentais. Melhorar a imagem do Brasil. Além disso, capacitar as empresas para que elas possam compreender que estar numa cadeia global de valor é muito importante, e não simplesmente vender um produto que, em tese, poderia ter mais agregação de valor e apresentar mais rentabilidade à companhia. Que elas possam entender que existem cadeias de valor e que eles podem se inserir em determinadas etapas dessa cadeia" (Profissional do setor).

"Não acho que promoção comercial seja a solução, não acho que acordo comercial vá realmente abrir mercado para frango. $\mathrm{O}$ que eu acho que precisa ser feito é um trabalho mais no nível bilateral. $\mathrm{O}$ adido agrícola brasileiro na China, na Indonésia, no Japão, na União Europeia. O diplomata que está na linha de frente deve ser habilitado a lidar com as demandas e com as questões burocráticas regulatórios do dia a dia" (Profissional do setor).

“Algo que falta é a representação institucional do Brasil lá fora. E não é representação de governo, é a do setor privado. O setor privado tem que estar no estar lá na discussão quando for discutido qualquer coisa. Acompanhamento de imprensa referente ao Brasil, ao setor. O Brasil passa por um momento de muita contestação. Então, se não montarmos uma estrutura parecida com a da Austrália, a dos Estados Unidos, em que o setor e as indústrias têm representantes e representantes experientes, que consigam com um alto nível participar dessas discussões, passaremos a vida tomando pancada" (Profissional do setor).

"Acho que a gente tem boas histórias para contar e, se a gente não consegue contar boas histórias do agronegócio porque não gostamos de nos comunicar, todo o mundo se comunica por nós, certo? E comunica da maneira errada. Há boas histórias para contar do ponto de vista da sustentabilidade na avicultura, sem necessariamente colocar as outras proteínas. É possível encontrar mensagens-chave que podem tornar a visão do consumidor, não só do Brasil, mas também do exterior, de que este é negócio sustentável - principalmente do ponto de vista socioeconômico. É extremamente sustentável porque é a maneira de você fixar o produtor no campo e fazer com que ele tenha a possibilidade de se manter e de sobreviver e de ganhar dinheiro ali, de formar filho e tudo mais, participando da integração, do modelo de integração, que tem alguns problemas, mas no geral é algo bem-sucedido. Acho que se a gente investir cada vez mais na conscientização, biosseguridade e prevenção é melhor para setor como um todo, porque uma doença acaba não só com o plantel, mas com a imagem do setor" (Profissional do setor).

"O Brasil vai precisar entender e entrar no jogo, na disputa das questões de retórica e de narrativa. Hoje isso vale muito. Hoje o que se conta do Brasil é uma narrativa que o Brasil é o vilão do mundo na área da agricultura. [Isso acontece] muito por viés protecionista, principalmente da Europa, de produtores que querem se beneficiar de subsídios" (Profissional do setor).

Por fim, uma última variável explorada pelos entrevistados foi a questão do bem-estar animal, presente, sobretudo nas certificações privadas já exploradas ao longo do texto. Para os 
especialistas, trata-se de um tema importante, embora, como já visto, ainda pouco presente como fator decisivo para a compra da maior parte dos consumidores em nível global. Pode-se perceber que a ampla exposição sobre o tema, ao longo do segundo capítulo, encontra respaldo junto à opinião dos especialistas, que atestam que o Brasil implementa em larga escala as diretrizes de bem-estar animal internacionalmente recomendadas. Trata-se, principalmente, de um dos vetores de ganhos de produtividade que as empresas do país tiveram ao longo dos últimos anos. A questão principal fica por conta dos padrões privados que passaram a criar diferenciações com o intuito de gerar produtos que atendam cada vez mais a tais requisitos. A governança público-privada em torno desse tema é central para alguns nichos de mercado que atestam sua relevância, como União Europeia e Estados Unidos. O Brasil, por ser o maior exportador de carne avícola do mundo, deve ficar atento a essa evolução:

"Há um fator que é extremamente importante, um dos grandes drivers de mudança, que é bem-estar animal. Porque é um fator que está altamente ligado à aceitação do produto junto aos consumidores e as empresas; e se os países não estiverem atentos às demandas de bem-estar animal, sejam elas totalmente baseadas em ciência ou não, a gente mesmo assim vai precisar se preocupar porque é a percepção do consumidor" (Profissional do setor).

"Nossa situação, em termos de bem-estar animal, quando comparada com a União Europeia deve levar em conta que lá existem regulamentos, de forma que há uma legislação exige o cumprimento dos procedimentos. Se está sendo feito ou não, isso é outra história. Mas na Europa você pode falar que a sua produção tem que obedecer àquilo. Aqui no Brasil, a nossa legislação sobre o bem-estar animal ela ainda é um pouco incipiente, de forma que nós não temos como. Muito embora, se você fosse comparar na realidade, você poderia dizer que aqui no Brasil as condições do bem-estar animal sejam melhores do que na Europa, e pode efetivamente ser; eu não duvido que seja. Na realidade isso poderia ser dito, mas quando você analisar o que tem que ser cumprido em cada um dos dois lados, aí ficamos na desvantagem, porque nós não evoluímos muito nessa legislação. Então, o que aparenta para o exterior é que isso não é observado, que isso não tem tanta relevância" (Especialista global em bemestar animal).

"Há 15 anos atrás, frango era frango. Hoje, o que as empresas estão buscando? É um diferencial. As empresas querem ter diferenciais hoje para um público específico, que, às vezes, nem entende tanto o que que é, pois se trata de algo muito mais conceitual. Eles buscam isso hoje: diferenciais de frango que é tudo frango. Agora, há de se adequar a regulação pensando nesse tema. Não é que ele não existia há 15 anos atrás, porque o tema bem-estar, em termos de critérios básicos, já vem sendo praticado. Até porque, sem isso, a nossa produtividade não teria chegado onde chegou. Veja bem, a gente trabalha com uma necessidade específica. Se eu colocar pressão demais em densidade, que é algo que impacta em bem-estar animal, eu vou ter maior perda no abatedouro: o animal vai se arranhar mais, e eu vou ter mais ter mais perda no abatedouro. Então, não adianta eu imprimir uma pressão produtiva tão grande 
que eu cause um stress no animal, pois eu vou ter perda, ele vai comer menos, ele vai ganhar menos peso. Se você não provê uma dieta adequada, se faltar ou desbalancear determinados ingredientes, determinadas fases, eu comprometo conversão alimentar, e aí eu coloco em xeque um negócio que briga por centavos. Seu não houver uma nutrição adequada, um tamanho de calha, o comedouro em número suficiente, baixa o ganho de peso ou, então, o lote se torna heterogêneo, e repassa o problema para o abatedouro. Por isso, é importante entender que para o Brasil chegar no nível em que chegou hoje, tudo isso já vem sendo trabalhado. É que, quando gente fala de bem-estar, a gente fala desse básico, mas você não imprime nenhum sofrimento desnecessário. Dentro do tema bem-estar, entretanto, há outros níveis: enriquecimento do ambiente, diminuição da densidade, não só pensando em produtividade, mas, em realmente a ave conseguir expressar um comportamento muito próximo do que ela teria na natureza, etc. Então, existem níveis inclusive de bem-estar. $\mathrm{E}$ isso que hoje se discute [nas certificações privadas]. É que o básico a gente já tem, qualquer empresa hoje de médio porte, no Brasil, já tem isso. [...]A União Europeia é muito forte com esse tema. Sempre é de cliente. O plus [em termos de bem estar-animal] sempre é de cliente. Veja as grandes redes de fast food, que compram frango, falando: amanhã ou depois fotografam uma granja, um abatedouro e não quero compactuar com o sofrimento, não quero a minha marca atrelada a isso" (Profissional do setor, especialista global em bem-estar animal).

"O bem-estar animal é um tema de enorme relevância. Diria que até mais que sustentabilidade no caso de proteínas animais. Eu colocaria até por ordem. Se eu fosse colocar por ordem, eu colocaria primeiro os aspectos regulatórios ligados à habilitação de plantas. Em segundo, bem-estar animal. E terceiro, a sustentabilidade. Eu acho que é um tema super importante, mas ele é muito mais importante na Europa do que na Ásia. Se o foco [da empresa] for Europa, então os temas de bem-estar animal e todos os temas ligados à resistência antimicrobiana, do uso de antibióticos como promotores de crescimento ou como profiláticos; o tema de bem-estar animal e todos os temas relacionados com as novas demandas lá dos europeus. Por exemplo, essa questão de freerange que eles querem implementar, uma crítica ao uso de dark houses. Acho que tudo isso entra. Orgânicos, certificações. Tudo isso tem muito mais importância para o cliente europeu do que para o seu cliente asiático" (Marcos Jank, professor e consultor especialista em questões globais do agronegócio).

\subsection{O Brasil na cadeia global de valor avícola}

Da mesma forma que diversos fatores e dinâmicas até aqui estudados foram alvo de análise dos especialistas entrevistados para o presente trabalho, o perfil de atuação do Brasil na cadeia global da avicultura foi foco de um dos questionamentos de maneira bem objetiva. Nesse sentido, todos tiveram que analisar o posicionamento do Brasil na CGV avícola tendo por base três alternativas diferentes, quais sejam: (i) o Brasil como sendo um global player fornecedor de produtos in natura e/ou matéria-prima a ser processada em terceiros mercados; (ii) global player fornecedor de produtos in natura e/ou matéria-prima a ser processada, mas com viés de 
adição de valor e futuro desenvolvimento de marca em terceiros mercados; ou, finalmente, (iii) um global player com foco em produtos de alto valor adicionado e marca premium.

Em geral, a grande maioria dos especialistas classificam o Brasil como um global player fornecedor de produtos in natura e/ou matéria-prima a ser processada, mas com viés de adição de valor e futuro desenvolvimento de marca em terceiros mercados. Apesar de haver variações nas observações e análises dos entrevistados, fica claro que o Brasil, a despeito de ser maior exportador mundial de carne avícola, permanece num elo intermediário da cadeia de valor do setor, ocupando a oportunidade existente entre o custo de produção e o preço de importação, praticado pelo importador local nos vários países para quais o país exporta. É notório nas observações feitas pelos especialistas que o preenchimento dessa lacuna entre custo de produção e o preço de importação seria, de fato, o tipo de vantagem comparativa que o setor conseguiu construir ao longo de anos de atuação. Isso, pois o país consegue produzir com o volume e com o custo mais baixo que os seus concorrentes, com um portfólio de produtos mais amplo do que a grande maioria deles - como no caso dos Estados Unidos, por exemplo, que por terem um grande mercado consumidor interno exportam produtos menos diversificados. Essa dinâmica permitiu que o Brasil desenvolvesse um portfólio mais amplo, enquanto a produção em larga escala, advinda de ganhos sucessivos de produtividade, e o alto rendimento do abate permitiram que o país passasse a atender a uma gama cada vez maior de países.

É importante citar, no entanto, que há variações e particularidades que merecem destaque quando da análise mais desagregada do setor. Isso, pois grandes empresas como Seara e, sobretudo, BRF, passaram, ao longo dos anos, a operar globalmente, caminhando rumo a uma maior agregação de valor da marca. Esse, todavia, é um processo em curso e é latente no discurso dos entrevistados. No entanto, o consenso, entre eles, sobre o único caso efetivamente em que uma marca brasileira de carne de aves alcançou um patamar superior de qualidade percebida junto ao consumidor é o caso da marca Sadia no Oriente Médio, onde a empresa começou a operar ainda na década de 1960. Grande parte do setor ainda opera agregando valor no produto, com base nas orientações e padrões observados por importadores e distribuidores locais. A adição de valor adicionado à marca, apesar de ser um trabalho em curso, ainda é uma realidade distante das empresas brasileiras, já que exige uma grande quantidade de aporte capital, investimento, monitoramento e atuação in loco que o setor, atualmente, parece não estar disposto a implementar como eixo central de sua atuação: 
"Eu acho que o Brasil se posiciona das três maneiras de acordo com cada mercado. O mesmo Brasil e a mesma empresa brasileira, por exemplo, dependendo do seu grau de internacionalização vai estar presente das três maneiras em diferentes mercados. Há países, por exemplo, que não permitem a importação de frango a ser consumido direto pela população e afunilam, através de barreiras comerciais, a importação apenas pra matéria-prima. Malásia, que só importa matéria-prima, a própria África do Sul, que, cada vez mais, restringe a importação de produtos que podem ser direcionados direto ao consumidor final e potencializa a importação de produtos que vão para processamento. É o caso do CMS (da carne mecanicamente separada), é o caso do peito de frango. [...] A questão da marca também depende muito do mercado. Há mercados em que as empresas têm mais condição de distribuir os seus produtos próprios, que a população já mais alerta à marca, e há países em que o produto ainda é muito comoditizado. Mesmo nesses países onde o produto é comoditizado, você tem espaço para construir marca? Tem, mas numa escala de força ainda menor, né. Quando se fala de produto in natura, a gente está falando de duas famílias: whole poultry ou poultry parts. A grande maioria das empresas já vende o frango inteiro, embalado, desde a fábrica com o logo dela, a não ser que você esteja falando de um private label, o que é uma proporção muito pequena da produção das brasileiras. A diferença não está em embalar com a sua marca, está em como você trabalha ela no destino. Se você tem distribuição própria, que talvez seja a grande diferença da BRF no Oriente Médio, que é a capacidade que ela tem de trabalhar suas marcas a partir do momento que ela teve maior presença local, você consegue trabalhar imagem do produto, garantir que o produto chegue com a máxima qualidade possível até o consumidor final. Se você não tem esse tipo presença, você depende muito do seu importador/distribuidor, que é quem vai trabalhar a marca para você na prática. Então, se você acha, por exemplo, um país X, se você encontra um importador/distribuidor qualificado, profissional, ele consegue trabalhar a sua marca de maneira que, em cinco anos, as pessoas estão cobrando essa marca nos supermercados. Se você acha alguém amador, que, simplesmente, compra e vende, alguém sem muita aptidão para entender como trabalhar marca, como posicionar, como precificar, como comunicar, a tendência é que o seu produto seja comoditizado. Então, se você tem controle ou presença na distribuição, você tem maior chance de trabalhar sua marca. Do ponto dois para o três, já muda um pouco, porque, quando você fala num perfil de portfólio com produtos de maior valor agregado, alguns mercados te permitem inserir esses produtos, outros não. Oriente Médio, alguns países da Ásia, Américas também. Há espaço para colocar produto processado, produtos de valor agregado com uma embalagem mais prática, etc. Isso passa a ser competência das empresas. Agora, em outros mercados, você não tenha talvez capacidade financeira nem hábito da população. Muitas vezes vai mais além: muitas vezes você não tem capacidade de armazenagem de frio" (Profissional do setor).

"A gente é fornecedor de matéria-prima a ser processada como viés de retorno de valor de alguns recortes específicos, tipo Oriente Médio, mas na grande maioria dos lugares a gente é um fornecedor de matéria-prima. Então, com exceção dos países árabes, que têm a questão da Sadia, da marca, em todos os outros a gente nós somos uma parte da cadeia" (Profissional do setor)

"Isso [o discurso de global player] para mim esconde verdade. Você tem 15 países que são $68 \%$. Então, você tem 30 países importantes. No curto prazo, 
são esses 30 países que vão influenciar, a longuíssimo prazo, o crescimento virá desses outros 100, vamos dizer. Para escolher entre essas três opções, realmente é a segunda. O Brasil não está focado em produto de alto valor adicionado, premium. Isso hoje para mim seria a posição da Tailândia, que foca $70 \%$ da exportação em industrializados de muito valor adicionado, muito valor agregado, com calibragem. Tailândia envia metade para o Japão e metade para Europa. A Europa é commodity e tem muito pouco de valor agregado. Então, é o mercado japonês que tem foco no valor agregado da Tailândia. Então, eu com essas três opções, eu, provavelmente, escolheria a segunda: matéria-prima a ser processada, mas com o desenvolvimento de marca em poucos lugares, como Oriente Médio" (Especialista no setor).

"Na grande maioria, nós estamos nas duas primeiras alternativas. Existem algumas empresas diferenciadas. Vamos falar do caso da Sadia, do caso da Seara, que estão trabalhando marca e produto com valor agregado. Mas ainda há uma parcela dos exportadores, e vários deles são iniciantes, que estão na primeira alternativa, vender matéria-prima para ser processada. Mas há uma busca de melhorar esse perfil. E mesmo no caso de vender matéria-prima para processamento, o Brasil já consegue, em alguns casos, um diferencial de preço com relação aos Estados Unidos. No mercado africano, por exemplo, uma coxa de frango americana vende por 100 dólares a menos, 50 dólares a menos que o Brasil. Outros produtores menores, por exemplo, já têm marca, mesmo que seja para processamento, e consegue ter um diferencial. Um diferencial na qualidade do produto, não na marca efetiva, como a Sadia no Oriente Médio" (Profissional do setor).

"Sem dúvida alguma, o Brasil já passou a primeira etapa ali que você mencionou, eu acho que nós estamos naquela segunda, somos um global player na parte de matéria-prima a ser processada, mas a gente já tem esse viés de adição de valor, como você mencionou. Até por que as próprias empresas brasileiras, os grandes grupos, também tão presentes lá fora. Então eles já estão até usando a própria matéria-prima onde ele tem uma marca já reconhecida lá fora em algumas regiões, ou utilizando-se de marcas já desenvolvidas lá fora, produzindo produto mais elaborado e agregando valor. Dentro da cadeia, isso para acontecer também passa por uma série de coisas. Como eu disse, seja aquisição de empresas lá fora, seja o próprio desenvolvimento aqui no Brasil. Na parte de produtos realmente mais elaborados, calibrados, embalados em embalagens menores, processados de alguma forma. Estamos caminhando para isso, apesar de ainda o grosso ser a matéria-prima. É um caminho a ser percorrido, mas acho que o setor todo está trabalhando com muito carinho nesse sentido" (Profissional do setor).

"Acho que o Brasil é o número 1. Um global player fornecedor de produtos in natura e matéria-prima a ser processada. $\mathrm{O}$ grosso do relacionamento do Brasil com o mundo se dá através de importadores - e algumas empresas têm representações comerciais em outros países —, mas é basicamente para trabalhar com importadores locais. Então, o que existe de adição de valor no exterior; quer dizer, eu acho que é, talvez, a única experiência mais sólida, é a da BRF, que, de fato, fez um trabalho no Oriente Médio e, mais recentemente na Ásia, e agora ela desfez. A gente ganha da Tailândia, dos Estados Unidos, no custo baixo dos produtos in natura, né, mas a gente não consegue, por exemplo, competir com a Tailândia nos produtos cozidos. A mão de obra 
tailandesa, a disponibilidade de mão de obra, os custos industriais de produção dos produtos cozidos, mesmo que comoditizados, são mais baixos na Tailândia do que são no Brasil. Então eu acho que o Brasil fica realmente só no item 1 mesmo, com exceção de alguma pequena presença de marcas e valor adicionado de algumas empresas. A Seara também tem um pouco de marca fora, mas assim: é a marca da caixa, não é a marca do produto. A caixa de frango sai com a marca, mas você não vai ver essa marca lá no varejo, lá no final. O que vai existir no final é um produto que foi processado, reprocessado localmente e que virou uma outra coisa, com uma outra marca e com um outro canal pra distribuir. No produto industrial processado, como são os produtos cozidos que a Tailândia faz, o Brasil não consegue entrar nesse segmento, não consegue ter essa agilidade e o custo que a Tailândia consegue. A Tailândia consegue, por exemplo, trabalhar just in time, certo? Quer dizer, o cliente europeu e o cliente japonês, eles colocam pessoas na planta na Tailândia e essas empresas que operam lá, elas operam sem estoque. Basicamente, elas vendem antecipadamente volumes de produção futura, já saem as caixas no formato exato que o cliente quer, principalmente clientes de food service ou para quick service restaurants, ou até mesmo para varejo, para supermercados; mas já sai com a marca do cliente sem ter que formar estoque. E não é muito valor adicionado, é simplesmente o valor adicionado de um processamento industrial em que você vai fazer empanados, você vai fazer produtos cozidos, você vai fazer produtos marinados. E isso daí hoje, talvez o único lugar que o Brasil faça (ainda) alguma coisa é no Oriente Médio com a planta da BRF que, inclusive vai ser expandida na Arábia Saudita" (Profissional do setor).

Quando questionados sobre o nível de competividade de outros países vis-à-vis o Brasil, os entrevistados apresentam importantes reflexões para que o país mantenha a liderança e protagonismo na cadeia global de valor avícola. No entanto, é consenso que qualquer nação que busque competir em nível de igualdade com o Brasil terá um árduo trabalho pela frente. Isso ocorre, sobretudo, pela conjunção de fatores, amplamente debatidos ao longo do presente trabalho, que fizeram o país se destacar ao longo das últimas décadas, tais como abundância em recursos naturais e grãos, investimento em genética, nutrição e ambiência, elevada produtividade e ampla capilaridade de atuação no plano internacional. É importante ter presente, todavia, que países como Ucrânia, Polônia, Tailândia, entre outros do sudeste asiático e, no longo prazo, no continente africano, podem apresentar diferentes desafios à atuação brasileira no mercado internacional avícola, sobretudo porque tais países congregam algumas das características que fizeram do país um grande player do setor, como se pode observar pelas transcrições a seguir:

"Esse movimento tem que ser analisado em escalas de tempo e por regiões. No curto prazo, não há nenhum país que vá competir com o Brasil globalmente, porque talvez ele não tenha escala de produção com custo. Você teria os Estados Unidos, mas o mercado doméstico nos Estados Unidos é tão aquecido que ele não tem tanta aptidão pra disputar com o Brasil, mercado a mercado, no mundo. O mercado interno deles já consome demais. Há a 
Ucrânia competindo com o Brasil no Oriente Médio; Há a França competindo com o Brasil no Oriente Médio e na África; Há Tailândia produzindo algum volume no Sudeste Asiático. Polônia, na União Europeia, sem dúvida alguma. Agora, de maneira global, não vejo ninguém competindo com o Brasil tão cedo, não consigo ver, no futuro, alguém, de fato, competindo com o Brasil como país. Agora, o grande holofote para esse tema está na África, porque o Sudeste Asiático, por mais que o Sudeste Asiático priorize a produção e a incremente, o crescimento da população é absurdo. Eles vão continuar sendo demandantes. A África concentra, se não me engano, $40 \%$ da terra agricultável do mundo, não usa quase nada disso, porque não tem tecnologia, porque não tem capital, porque não tem investimento. Então, hoje a dificuldade para se produzir na África é muito grande. Talvez, daqui a 10, 15 anos, 20 anos não seja tanto" (Profissional do setor).

"Com exceção de Tailândia e Estados Unidos, que já são competitivos, que já competem conosco no mercado externo, acho que temos que pensar na Ucrânia, que cresceu a produção absurdamente e acessa mercados importantes que o Brasil já teve e China, que tem investido muito e, em algum momento, vai sobrar alguma coisa. Pode ser que a China também impulsione a sua produção de cozidos e tenha a maior acesso a outros mercados porque realmente, para eles, há o fator influenza, que é bastante crítico, para acessar mercados com in natura. Mas ainda há o problema de acesso à água, do custo de ração, mas a China é grande potência em qualquer coisa que eles se prontificarem a fazer e agora eles têm um mecanismo de incentivo à produção de carne de aves, assim como de carne de suíno, que talvez daqui a uns anos, a gente talvez veja a China tentando competir não nos mesmos níveis [do Brasil], mas pode ser um player no futuro" (Profissional do setor).

“A Ucrânia é um país que pode ser tão competitivo quanto, mas ela vai enfrentar desafios que o Brasil já enfrentou e conseguiu superar. A Argentina, com certeza, se melhorar a economia e pode ser, porque tem as mesmas condições de competividade aqui do Brasil, principalmente quando nos grãos. E os Estados Unidos já é competitivo como o Brasil. A Tailândia pode melhorar um pouco seus processos, já que ela passa por um processo grande de automatização de suas empresas e isso vai facilitar mais ainda, porém a Tailândia eternamente vai ter problema de grãos" (Profissional do setor).

"Basicamente são os grandes players agrícolas. Eu colocaria, em primeiro lugar, os Estados Unidos, por que Estados Unidos sempre serão um grande competidor do Brasil (não só em grãos, mas em carnes); eu acho que a Tailândia é um país que fez um desenvolvimento extraordinário na Ásia, em carne de aves, fazendo coisas que o Brasil não faz. Eu acho que o leste europeu é a nossa maior ameaça, fora Estados Unidos e Tailândia, que já são players. Eu acho que quem nos ameaça de fato, a médio, longo prazo, é o leste europeu; porque o leste europeu, desde a Polônia, a Ucrânia, sul da Rússia, têm um potencial muito grande de fazer grãos. E eles estão muito pertos da Europa e estão também perto do Oriente Médio e da Ásia. Eles estão, vamos dizer, geograficamente mais bem localizados do que a gente. Se tiver uma boa logística, eu acho que eles são uma grande ameaça para a gente. Eu acho que, por exemplo, a África, não será ameaça nessa área, pois eles estão muito ainda de conseguir ter cadeias integradas. Talvez Argentina possa ser um player no futuro, porque ela faz soja e milho, mas ela nunca conseguiu ir além do boi. 
Ela sempre foi muito forte em soja, milho e boi, mas nunca conseguiu fazer suínos e aves. Até porque eles sempre quiseram, vamos dizer, focar mais na industrialização da soja e de milho, do que na ave, né. Como eles fazem hoje, óleo por exemplo, eles fazem local; eles fazem muito biodiesel, mas nunca foram para frango" (Marcos Jank, professor e consultor especialista em questões globais do agronegócio).

Por fim, quando questionados sobre o futuro do setor, em termos, principalmente mercadológicos, o consenso entre os entrevistados foi notório, indicando a região da Ásia, sobretudo o Sudeste Asiático, como o grande impulsionador do consumo de carne de frango no mundo. A Índia também foi citada como um dos grandes centros potenciais de consumo da proteína avícola, assim como, mas num prazo mais distante, a África Subsaariana. Tal percepção é justificada por conta de todos esses países e regiões terem em comum populações relativamente jovens, em crescimento e uma classe média também em expansão, o que varia entre os países. Esses fatores, em conjunto, favorecem o aumento relativo da renda per capita da população e, consequentemente, o maior consumo de uma proteína com preço acessível, como a carne de frango:

\begin{abstract}
"Sem dúvida, os olhos dos produtores de carne, de uma maneira geral, do mundo todo, estão no Sudeste Asiático. O grande crescimento, incremento na demanda virá de lá. Tanto por consumo per capita como por crescimento populacional. Por esses dois fatores, a grande demanda por alimento está lá. Então, sem dúvida alguma, o acesso ao mercado, a prioridade dele, tem que ser Sudeste Asiático. Depois do Sudeste Asiático, há o Oriente Médio, pois a população cresce num ritmo mais acelerado que a média mundial e, por questões climáticas, não consegue produzir toda a sua demanda. É muito caro produzir no Oriente Médio, porque você tem que importar grão para alimentar ave. Então, sem dúvida alguma, continua sendo um mercado demandante por produtos e, num prazo mais longo. Em seguida, há a África Subsaariana, que já é um mercado interessante, de certa forma, mas os desafios ainda são enormes. Quando esses desafios começarem a ser superados, veremos uma população que cresce também num ritmo muito forte e que vai passar a ser de classe média. Isso significa que quanto maior for a renda per capita maior vai ser a proporção de proteína animal que eles colocam na mesa" (Profissional do Setor).
\end{abstract}

"Oriente Médio, a gente nunca pode deixar de olhar para o Oriente Médio. Japão, pensando em marca. Quem sabe um dia a gente consiga ter um posicionamento de marca no Japão. Não há como não para pensar em Índia. $\mathrm{E}$ os outros mercados que estão fechados hoje, além da Indonésia, que é um imbróglio, Índia e Nigéria são grandes mercados" (Profissional do Setor).

"O primeiro deles é a China, que já está aberto, mas tem que priorizar, porque a China é o drive do grande consumo. Indonésia, onde tem grande população e baixo consumo. A Îndia é um mercado que tem que ser priorizado, porque a China está passando por um processo de urbanização e aumento de consumo 
da sua classe média que, na Índia, está apenas começando. Depois há outros, como Paquistão, Nigéria, Bangladesh, ainda tem os grandes contingentes populacionais de população mais carente. E a África como um todo, porque ela é um continente que vai crescer em termos de população, apesar de ter pouco poder de compra atual" (Profissional do Setor).

"Com certeza Sudeste Asiático, China e Oriente Médio. Já temos acesso nessas regiões, mas ali no Sudeste Asiático falta alguma coisa. Ocupamos também o mercado japonês né. A Europa tem que ser mantida. É importante ter acesso à União Europeia e participar desse mercado, porque ele acaba sendo um impulsionador de melhorias na nossa produção. $\mathrm{O}$ acesso a mercados mais sofisticados é importante não necessariamente pelo mercado em si, mas pelo efeito que ele tem na melhoria, no impulsionamento das melhorias" (Representante do Ministério da Agricultura, Abastecimento e Pecuária).

"Eu acho que a priorização de todo agronegócio é uma só: é o que eu chamo do hemisfério oriental, ou emergente. Se você considerar desde África até Filipinas, ou a Indonésia. Inclusive o norte da África, do Oriente Médio, o sul da Ásia, o leste e o sudeste da Ásia, são o nosso único foco em frango, em tudo" (Marcos Jank, professor e consultor especialista em questões globais do agronegócio). 


\section{Conclusão}

O presente trabalho teve como objetivo analisar a inserção do Brasil na cadeia global de valor da avicultura, por meio do mapeamento dos principais fatores que explicam a estratégia de atuação das empresas do setor em nível global. Para tanto, utilizou-se uma metodologia conjunta marcada, notadamente, por dois eixos: a aplicação do modelo teórico de CGV, com foco nos trabalhos recentes de Gereffi e Fernandez-Stark (GEREFFI, 2012; GEREFFI; FERNANDEZ-STARK, 2016) e uma avaliação detalhada dos principais fatores relevantes para a inserção do Brasil na CGV em tela, obtidos a partir da realização de entrevista fechadas em profundidade por meio de questionário estruturado com 15 especialistas no setor que atuam no Brasil e internacionalmente (MARCONI; LAKATOS, 2010; DUARTE, 2010). A pesquisa parte da hipótese de que o Brasil, maior exportador de produtos avícolas nos últimos anos, está inserido na CGV do setor como um global player fornecedor de produtos in natura e/ou matéria-prima a ser processada, mas com viés de adição de valor e futuro desenvolvimento de marca em terceiros mercados.

Para poder comprovar os resultados apresentados ao longo do texto, a estruturação do trabalho contou, num primeiro momento, com a descrição detalhada da evolução do conceito de CGV, partindo de estudos de autores da década de 1970, voltados à teoria do Sistema-Mundo com foco, principalmente, em uma perspectiva ampla e circunstanciada historicamente das commodity chains, até a análise mais elaborada de Gary Gereffi (2012) e outros autores que buscavam construir um framework analítico - global commodity chains - com elementos oriundos da sociologia organizacional e estudos comparativos sobre desenvolvimento econômico. Como observado ao longo deste trabalho, tais esforços culminaram com o modelo teórico das global value chains, no ínicio dos anos 2000, que passou a conjugar, de maneira interligada, elementos econômicos, sociais, políticos e jurídicos quando da configuração de uma atividade produtiva em nível global (HOPKINS; WALLERSTEIN, 1986; GEREFFI; KORZENIEWICZ, 1994; GEREFFI; HUMPHFREY; STURGEON, 2005).

Após tal análise, o trabalho buscou analisar os principais aspectos da atividade avícola em nível global, à luz do modelo teórico ora exposto, destacando seus principais eixos e elos produtivos, a dispersão geográfica de seus principais insumos e produtos finais, sua governança, as estratégias de upgrading em curso e, por fim, os principais stakeholders e o contexto institucional do setor (GEREFFI; FERNANDEZ-STARK, 2016). A última parte do trabalho 
teve como foco a análise das entrevistas e dos fatores com influência direta sobre a atuação do Brasil na CGV avícola. Tais fatores estão expostos, resumidamente, no Quadro 6, a seguir:

Quadro 0=6 - Resumo dos impactos e do nível de influência das variáveis analisadas sobre a atuação do Brasil na cadeia global de valor da avicultura.

\begin{tabular}{|c|c|c|}
\hline Variável/Fator & Influência / Impacto & Observações \\
\hline Consumo Global & Impulsionador & $\begin{array}{l}\text { A previsão do aumento da renda per capita em diversos países em } \\
\text { desenvolvimento, com população jovem e classe média em } \\
\text { crescimento, favorecerá o acesso a uma proteína animal com } \\
\text { preço atrativo e elevada disponibilidade. De acordo com os } \\
\text { especialistas consultados, a concentração desse movimento estaria } \\
\text { na China e no restante do Sudeste Asiático em um primeiro } \\
\text { momento. A Índia seria, no médio prazo, um vetor de crescimento } \\
\text { do consumo global de proteína animal e, no longo prazo, os países } \\
\text { da África Subsaariana também aumentariam o consumo per capita } \\
\text { de proteína. }\end{array}$ \\
\hline $\begin{array}{c}\text { Eventos Sanitários } \\
\text { (Enfermidades Globais) }\end{array}$ & Impulsionador & $\begin{array}{l}\text { Pelo elevado nível de sanidade e controle de doenças na área } \\
\text { animal, o Brasil, historicamente, sempre foi beneficiado, em } \\
\text { termos comerciais, com a ocorrência de surtos de enfermidades } \\
\text { em nível global, a exemplo do que aconteceu com os casos de } \\
\text { Influênza Aviária de Alta Patogenicidade em grandes países } \\
\text { produtores de aves (EUA, China e União Europeia) desde meados } \\
\text { dos anos 2000. Todos os entrevistados atestaram a segurança do } \\
\text { sistema de sanidade do Brasil, fator fundamental para a } \\
\text { manutenção do acesso a mercados importantes. }\end{array}$ \\
\hline Qualidade percebida & Impulsionador & $\begin{array}{l}\text { A percepção do consumidor intermediário (parceiros e } \\
\text { distribuidores locais) em relação à proteína avícola brasileira é } \\
\text { extremamente positiva, segundo os especialistas consultados. A } \\
\text { despeito de problemas de ordem rotineira, eles alertam que é } \\
\text { preciso buscar a manutenção desse status diferenciado, tendo em } \\
\text { vista que outros países têm buscado aperfeiçoar seus produtos } \\
\text { visando ganhar participação nos mercados em que o Brasil opera. }\end{array}$ \\
\hline Responsividade Local & Impulsionador & $\begin{array}{l}\text { Essa variável se assemelha à anterior, tendo em vista todo o } \\
\text { processo de aperfeiçoamento produtivo e capacidade de } \\
\text { atendimento a demandas específicas dos distribuidores locais e } \\
\text { outros clientes específicos por parte das empresas brasieliras. }\end{array}$ \\
\hline $\begin{array}{l}\text { Capacidade de } \\
\text { atendimento em larga } \\
\text { escala e fator preço }\end{array}$ & Impulsionador & $\begin{array}{l}\text { Os ganhos em termos de produtividade nas últimas décadas } \\
\text { possibilitou às empresas operar com elevada escala e } \\
\text { capilaridade global. Aliado a isso, a expressiva desvalorização } \\
\text { do Real nos últimos anos impulsionou sobremaneira a } \\
\text { competividade das empresas brasileiras }\end{array}$ \\
\hline
\end{tabular}

Fonte: Elaboração do autor com base nas entrevistas concedidas. 
Quadro 6 - Resumo dos impactos e do nível de influência das variáveis analisadas sobre a atuação do Brasil na cadeia global de valor da avicultura (continuação).

\begin{tabular}{|c|c|c|}
\hline Variável/Fator & Influência / Impacto & Observações \\
\hline $\begin{array}{c}\text { Fator Campo } \\
\text { (recursos naturais, } \\
\text { genética, nutrição, } \\
\text { manejo, sutentabilidade } \\
\text { e ambiência) }\end{array}$ & Impulsionador & $\begin{array}{l}\text { Uma extensa produção de milho e soja; a utilização em larga } \\
\text { escala do sistema de integração entre produtor e agroindústria; } \\
\text { clima favorável; extensão de terra; profissionais técnicos } \\
\text { qualificados; aspectos de sanidade, entre outros fatores, fazem } \\
\text { com que as empresas do país operem a um nível extremamente } \\
\text { competitivo em termos de custo de produção. }\end{array}$ \\
\hline $\begin{array}{c}\text { Viés de } \\
\text { complementaridade }\end{array}$ & Impulsionador & $\begin{array}{c}\text { A abordagem, sobretudo em nível institucional, utilizada pelo } \\
\text { setor para a entrada em novos mercados ou } \\
\text { expansão/consolidação nos mercados já compradores, baseada na } \\
\text { complementaridade produtiva do mercado destino, é vista como } \\
\text { extremamente positiva pelos especialistas do setor e pode ser } \\
\text { considerada um fator que ajuda a impulsionar a presença global do } \\
\text { Brasil. }\end{array}$ \\
\hline $\begin{array}{c}\text { Desenvolvimento de } \\
\text { parcerias }\end{array}$ & Ponto de atenção & $\begin{array}{l}\text { Especialistas consultados destacam a relevância das percerias } \\
\text { globais entre agroindustrias e redes globais de fast food ou até } \\
\text { mesmo parceiros globais, porém argumentam que se trata de um } \\
\text { movimento muito restrito às empresas líderes do setor, que } \\
\text { atendem a clientes específicos, como Macdonald's, KFC, YUM, } \\
\text { entre outros. Trata-se de um nicho relevante, de alto valor } \\
\text { agregado e que exige elevados investimentos na linha de produção } \\
\text { para que se alcance os padrões de tamanho, calibragem, } \\
\text { espessura, entre outros, exigidos por essas grandes redes. }\end{array}$ \\
\hline $\begin{array}{c}\text { Protecionismo em nível } \\
\text { global }\end{array}$ & Ponto de atenção & $\begin{array}{l}\text { Há um consenso de que a entrada em importantes mercados deve } \\
\text { ser feita de maneira estratégica, observando as lacunas existentes } \\
\text { e as tendências das demandas futuras. Planejamento no acesso e na } \\
\text { manutenção de um determinado mercado são fatores essenciais, } \\
\text { sobretudo por conta do recrudescimento do protecionismo em } \\
\text { nível global e das diversas formas de proteção ao produtor local } \\
\text { implementadas pelos governos de países que precisam } \\
\text { complementar sua produção interna por meio de importações }\end{array}$ \\
\hline Cadeia Regulatória & Ponto de atenção & $\begin{array}{c}\text { A implementação de uma cadeia regulatória em nível nacional que } \\
\text { efetivamente promova fluidez na troca de informações, agilidade } \\
\text { na prestação de serviços (elaboração de relatórios, resposta a } \\
\text { questionários, etc) e uma comunicação extremamente dinâmica } \\
\text { entre os órgãos nacionais e as embaixadas no plano internacional } \\
\text { são fatore-chave para uma atuação mais sólida do Brasil no } \\
\text { exterior. }\end{array}$ \\
\hline
\end{tabular}

Fonte: Elaboração do autor com base nas entrevistas concedidas. 
Quadro 6 - Resumo dos impactos e do nível de influência das variáveis analisadas sobre a atuação do Brasil na cadeia global de valor da Avicultura (Continuação)

\begin{tabular}{|c|c|c|}
\hline Variável/Fator & Influência / Impacto & Observações \\
\hline $\begin{array}{l}\text { Acordos Comerciais e } \\
\text { Ações de Promoção } \\
\text { Comercial }\end{array}$ & Ponto de atenção & $\begin{array}{l}\text { Os especialistas se dividem quanto à verdadeira importância da } \\
\text { celebração de acordos comerciais como vetores de acesso a } \\
\text { novos mercados por parte do Brasil. Na mesma linha, as ações de } \\
\text { promoção comercial, sobretudo em nível institucional, tiveram seu } \\
\text { valor reconhecido, mas não são, necessariamente, um fator a ser } \\
\text { priorizado em termos de acesso a mercados. Eles são vistos como } \\
\text { elementos complementares à fatores, segundo eles, mais } \\
\text { importantes para o setor, como (i) melhoria da infraestrutura } \\
\text { interna e do custo brasil; (ii) aperfeiçoamento da cadeia } \\
\text { regulatória interna e (iii) negociações bilaterais mais restritas ao } \\
\text { setor, que envolvam problemas relativos a habilitações e outras } \\
\text { questões de acesso a mercados. }\end{array}$ \\
\hline $\begin{array}{c}\text { Ameaça de } \\
\text { competidores externos }\end{array}$ & Ponto de atenção & $\begin{array}{l}\text { Quando questionados sobre o nível de competividade de outros } \\
\text { países vis-à-vis o Brasil, os entrevistados apresentam importantes } \\
\text { reflexões para que o país mantenha a liderança e protagonismo na } \\
\text { cadeia global de valor avícola. No entanto, é consenso que } \\
\text { qualquer nação que busque competir em nível de igualdade com o } \\
\text { Brasil terá um árduo trabalho pela frente. Isso ocorre, sobretudo, } \\
\text { pela conjunção de fatores, amplamente debatidos ao longo do } \\
\text { presente trabalho, que fizeram do país se destacar ao longo das } \\
\text { últimas décadas, tais como abundância em recursos naturais e } \\
\text { grãos, investimento em genética, nutrição e ambiência, elevada } \\
\text { produtividade e ampla capilaridade de atuação no plano } \\
\text { internacional. É importante ter presente, todavia, que países como } \\
\text { Ucrânia, Polônia, Tailândia, entre outros do sudeste asiático e, no } \\
\text { longo prazo, no continente africano, podem apresentar diferentes } \\
\text { desafios à atuação brasileira no mercado internacional avícola, } \\
\text { sobretudo porque tais países congregam algumas das } \\
\text { características que fizeram do país um grande player do setor }\end{array}$ \\
\hline $\begin{array}{c}\text { Certificações privadas, } \\
\text { sobretudo com foco em } \\
\text { Bem Estar Animal }\end{array}$ & Ponto de atenção & $\begin{array}{l}\text { Para os especialistas, trata-se de um tema importante, embora, } \\
\text { ainda pouco presente como fator decisivo para a compra da maior } \\
\text { parte dos consumidores em nível global. Os especialistas atestam } \\
\text { que o Brasil implementa em larga escala as diretrizes de Bem- } \\
\text { Estar Animal internacionalmente recomendadas. Trata-se, } \\
\text { principalmente, de um dos vetores de ganhos de produtividade que } \\
\text { as empresas do país tiveram ao longo dos últimos anos. A questão } \\
\text { principal fica por conta dos padrões privados que passaram a } \\
\text { criar diferenciações com o intuito de gerar produtos que atendam } \\
\text { cada vez mais a tais requisitos. A governança publico-privada em } \\
\text { torno desse tema é central para alguns nichos de mercado que } \\
\text { atestam sua relevância, como União Europeia e Estados Unidos. O } \\
\text { Brasil, por ser o maior exportador de carne avícola do mundo, } \\
\text { deve ficar atento a essa evolução. }\end{array}$ \\
\hline
\end{tabular}

Fonte: Elaboração do autor com base nas entrevistas concedidas 
Quadro 6 - Resumo dos impactos e do nível de influência das variáveis analisadas sobre a atuação do Brasil na cadeia global de valor da avicultura (Continuação)

\begin{tabular}{|c|c|c|}
\hline Variável/Fator & Influência / Impacto & Observações \\
\hline Fatores Internos & Restrição & $\begin{array}{l}\text { Todos os especialistas consultados citaram, em maior ou menor } \\
\text { escala, os fatores intrínsecos à economia brasileira, aqui chamado } \\
\text { de fatores internos, como um dos principais entraves à maior } \\
\text { inserção do Brasil na CGV avícola nos últimos anos. Foram } \\
\text { citados problemas relativos à logística, infraestrutura, custo de } \\
\text { energia, burocracia, estrutura regulatória, entre outros. }\end{array}$ \\
\hline $\begin{array}{c}\text { Representação } \\
\text { Institucional no plano } \\
\text { internacional; } \\
\text { Capacitação em } \\
\text { Inteligência Comercial e } \\
\text { Ações de melhoria de } \\
\text { imagem em nível } \\
\text { internacional }\end{array}$ & Restrição & $\begin{array}{l}\text { Três pontos foram percebidos como essenciais à melhoria da } \\
\text { atuação do Brasil no plano internacional: (i) aumento da } \\
\text { representação institucional do setor no plano internacional, a } \\
\text { exemplo do que foi realizado recentemente pela ABPA, por meio } \\
\text { da abertura de escritórios comerciais em Shangai, Bruxelas e } \\
\text { Dubai; (ii) aumento da capacitação de profissionais das empresas } \\
\text { do setor em termos de inteligência comercial, no intuito de } \\
\text { aperfeiçoarem o entendimento acerca de padrões e } \\
\text { especificidades de consumo de diferentes mercados; (iii) } \\
\text { implementação de ações comunicação em larga escala, com o } \\
\text { intuito de melhorar a imagem do Brasil no exterior na área da } \\
\text { agricultura. }\end{array}$ \\
\hline
\end{tabular}

Fonte: Elaboração do autor com base nas entrevistas concedidas.

De acordo com a análise, foi possível levantar pontos que corroboram a hipótese sugerida, e apontar a especificidade brasileira, uma vez que há um consenso quanto à atuação do Brasil como fornecedor global de produtos in natura e/ou matéria-prima a ser processada, com viés de adição de valor e futuro desenvolvimento de marca em terceiros mercados. Por meio da análise combinada das metodologias aplicadas, é possível perceber que o país dispõe de um nível de inserção gradual e intermediária, em termos de agregação de valor de marca, mas com alto valor adicionado em termos de produto, na referida cadeia em nível global.

Tal constatação decorre, num primeiro momento, do fato de que, dentre os quinze fatores elencados pelos entrevistados como passíveis de influência da atuação do Brasil na CGV avícola, quatro são fundamentais: (i) a presença de importantes elementos internos, chamados aqui de fator-campo, que criaram as bases para os ganhos de produtividade avícola ao longo do período analisado; (ii) a coordenação das ações entre diversos 
stakeholders da cadeia direta e indiretamente relacionados ao setor; (iii) o elevado nível de sanidade e o controle de doenças na cadeia avícola; e (iv) as estratégias produtiva e comercial implementadas pelas empresas-líderes do setor que operam em nível global.

Conforme explicitado anteriormente, ao longo sobretudo do capítulo três, as empresas brasileiras operam a partir de inúmeras vantagens comparativas relativamente a outros competidores alocados em outros países. Em suma, pode-se perceber que o Brasil tem como trunfo a construção, ao longo de décadas, de uma cadeia produtiva coordenada e que opera com os mais elevados padrões de qualidade em nível mundial. Tal fato decorreu de uma extensa e constante estratégia de aperfeiçoamento produtivo e capilaridade comercial, que perpassa todos os elementos dispostos no modelo teórico das CGV.

Em termos de pesquisa e desenvolvimento, por exemplo, pode-se perceber, ao longo do tempo, a criação e adaptação de importantes tecnologias por parte de produtores brasileiros de frango de corte (integrados) e, da mesma forma, das agroindústrias, principalmente no que se refere a inovações incrementais em processos e máquinas e equipamentos, as quais passaram a dispor de caraterísticas intrínsecas ao modo de produção brasileiro. Apesar da existência de inúmeras multinacionais nessa e em outras importantes áreas como genética, nutrição e saúde animal, o trabalho em conjunto com técnicos e agroindústrias brasileiras possibilitou o desenvolvimento de tecnologias e produtos específicos, responsáveis pela dinamização da produção avícola nacional ao longo do tempo.

No que tange aos inputs necessários à participação efetiva na cadeia, o Brasil dispõe de diversos fatores naturais relevantes para sua produção agrícola, assim como elevada disponibilidade de grãos e a presença fundamental de empresas multinacionais em importantes indústrias-suporte, como as citadas acima, que operam diretamente em conjunto com os grandes frigoríficos e, assim, auxiliam na manutenção dos altos índices de produtividade observados pelo país nas últimas décadas.

Esses elementos fizeram com que o Brasil pudesse aproveitar eventuais lacunas de mercado provocadas por enfermidades globais, com elevado número de surtos, e passasse a ocupar uma posição de destaque no setor nas últimas décadas, como maior exportador e segundo maior produtor de carne de aves, exportando para mais de 150 países nesse período.

Os resultados do presente trabalho destacam que os quatro fatores previamente explicitados estão diretamente relacionados a dois importantes eixos de análise do modelo de 
CGV, os quais têm impacto direto sobre o incremento da produtividade avícola e expansão comercial do Brasil nas últimas décadas: a governança e o upgrading. Os eixos de análise traduzem a contribuição original da presente tese de doutoramento ao debate teórico em torno do conceito da CGV, e da aplicação empírica do modelo em tela, especificando o caso da cadeia avícola.

Quanto ao primeiro eixo, destaca-se como cerne do modelo de governança da cadeia avícola o sistema de integração, que compreende $95 \%$ de toda produção avícola nacional. Conforme exposto ao longo do presente trabalho, esse sistema corresponde à espinha dorsal da produção avícola no país, já que congrega todo um sistema de ações diretas entre integrados (produtores) e integradoras (agroindústrias). A coordenação e monitoramento dessas empresas, vis-à-vis os integrados, são eixos fundamentais para o incremento da eficiência produtiva, dos ganhos de escala e da qualidade do produto. É fundamental destacar que essa coordenação junto aos produtores e a empresas de outros setores fazem com que os fatores locais sejam os elementos centrais da competitividade brasileira. Os ganhos em termos de eficiência produtiva em uma cadeia extremamente verticalizada são, dessa forma, potencializados pela atuação central das grandes agroindústrias exportadoras. Essa constatação é importante, uma vez que refuta a ideia, explorada ao longo do texto, de que uma inserção qualificada em CGV decorreria de uma estratégia de especialização produtiva atrelada, em grande parte, a um panorama de fragmentação global da produção e intensiva trocas comerciais de insumos. O Brasil, dessa forma, consegue ter um elevado nível de presença global, atendendo a diferentes mercados, com escala, preço e qualidade, tendo como base para tanto uma indústria extremamente verticalizada.

Em relação ao segundo eixo, este trabalho procura ampliar a agenda de pesquisa das CGV, indicando que o Brasil dispõe de um tipo de estratégia de inserção interacional na qual as empresas procuram lançar mão do que aqui chamamos de upgrading estratégico-seletivo (HUMPHREY; SCHMITZ，2002; UNCTAD，2013; GEREFFI; FERNANDEZ-STARK, 2016). Esse tipo de upgrading decorre do fato de a cadeia avícola brasileira ter como vetor principal de agregação de valor aos seus produtos a constante interação com parceiros locais em diferentes países. Essa interação é base para a estratégia de inserção seletiva do país na CGV avícola, na qual as empresas multinacionais procuram ocupar um elo intermediário da cadeia de valor do setor, o qual se situa entre o custo de produção e o preço de importação praticado pelo importador local nos vários países que consomem a carne brasileira. O grande 
vetor da inserção do Brasil é justamente a responsividade local da empresa exportadora não ao cliente final, mas sim ao seu parceiro local, que deverá processar o produto brasileiro e distribuílo junto ao mercado. Em suma, é possível compreender que o país consegue, sim, produzir com o volume e com o custo mais baixo que os seus concorrentes, e com um portfólio de produtos geralmente mais amplo do que a grande maioria deles, mas não tem a pretensão de avançar em níveis de maior agregação de valor, como o lançamento de marcas, produtos específicos para o varejo e ações de distribuição local. Esse tipo de upgrading estratégico-seletivo mostra como o país é capaz de operar em escala global, porém tendo parceiros locais como elementos-chave para sua atuação, uma vez que esses serão os responsáveis pela maior parte do processamento da carne brasileira e de sua distribuição junto ao varejo local.

Dessa forma, essa estratégia deliberada de inserção seletiva e gradual, liderada pelas grandes indústrias exportadoras, comprova que o Brasil é, realmente, um global player na condição de fornecedor de produtos in natura e/ou matéria-prima a ser processada, com viés de adição de valor e futuro desenvolvimento de marca em terceiros mercados. Todavia, fica claro que essa adição de valor ocorre junto às particularidades e solicitações de um parceiro local, que deposita no Brasil a confiança necessária para ter um produto com disponibilidade, flexibilidade e, sobretudo, qualidade. A adição de valor à marca junto ao varejo, em nível internacional, ainda é uma realidade distante das empresas brasileiras, já que exige uma grande quantidade de aporte de capital, investimentos, monitoramento constante e atuação in loco, algo que o setor, atualmente, parece não estar disposto a implementar como eixo central de sua atuação.

A análise desses fatores denota, efetivamente, que o Brasil participa ativamente na CGV avícola global como um grande player exportador de matéria-prima e cortes a serem processados em terceiros mercados, dotados de qualidade, escala e qualidade percebida, sobretudo pelos intermediários da cadeia, como processadores e distribuidores locais. Todavia, as empresas do país ainda operam com um viés restrito de adição de valor à marca, exceto no caso da atuação da empresa BRF e da sua atuação no Oriente Médio por meio da marca Sadia. Essa constatação é relevante, pois não corrobora a ideia de que uma inserção qualificada na CGV deva ter como prerrogativa a constante adição de valor ao longo da cadeia até o consumidor final. Por meio dos resultados obtidos, percebe-se que essa agregação pode acontecer de maneira modulada, gradual e extremamente seletiva, e isso não é nenhum demérito à atuação das empresas do setor. Pelo contrário, trata-se de uma estratégia de atuação 
internacional que busca ampliar sua presença, consolidar posições junto a mercados específicos, sem, contudo, colocar em risco a qualidade do seu produto e da eficiência quanto à distribuição in loco. Ir além desse ponto, no intuito de promover a expansão de seu portfólio ou uma nova estratégia de inserção internacional - upgrading de produto e até mesmo de função buscando atender ao varejo diretamente ou adotar estratégias de distribuição local, são ações vistas pelos especialistas consultados como parte de uma estratégia extremamente custosa e difícil de ser gerenciada no curto prazo.

Além das variáveis que impulsionam a atuação do Brasil junto ao setor em nível global, foi possível identificar inúmeros pontos de atenção para a atuação global do setor produtivo brasileiro de proteína avícola. São eles: (i) o desenvolvimento de parcerias; (ii) o protecionismo em nível global; (iii) a cadeia regulatória nacional; (iv) a celebração de acordos comerciais e ações de promoção comercial; e, por fim, (v) competidores externos e (vi) certificações privadas, sobretudo com foco em bem-estar animal. Além disso, dois tipos de fatores são considerados como aqueles cujas dinâmicas efetivamente restringem a maior participação atual do Brasil na CGV avícola global: fatores internos, como logística, infraestrutura, custo-Brasil, entre outros, e fatores externos, divididos em outros três itens - necessidade de uma maior ampliação da representação institucional do setor no plano internacional, aumento da capacitação de mão de obra pública e privada em termos de inteligência comercial e atuação global, e ações de melhoria de imagem em nível internacional.

Em que pese as análises até aqui empreendidas, o presente trabalho lança luz a temas que merecem a devida atenção em trabalhos futuros referentes ao tópico em tela. Sob o ponto de vista teórico, os estudos de cadeias globais de valor provam ser ferramentas profícuas por conta da análise integrada e específica de fatores que influenciam diretamente uma determinada atividade econômica. É imprescindível avançar, sobretudo, no estudo dos diferentes tipos de governança e estratégias de upgrading implementadas em nível setorial. Assim como visto no presente trabalho, a análise minuciosa e integrada desses dois fatores permite compreender as principais relações e dinâmicas produtivas e comerciais da cadeia em questão.

Quanto ao avanço dos estudos no setor avícola, a partir do ponto de vista brasileiro, fazse mister analisar detalhadamente alguns importantes fatores que impactam diretamente o setor, sobretudo aqueles relacionados ao ambiente econômico-jurídico internacional, notadamente as certificações privadas e as diferentes dinâmicas processuais de abertura de mercados. O primeiro se justifica pela crescente proliferação de certificações internacionais que buscam, 
cada vez mais, a implementação de critérios produtivos específicos com vistas a atender determinadas demandas do consumidor. Uma melhor compreensão da dinâmica operacional, bem como da gênese relativa a esses padrões, bem como da sua relação com os regulamentos públicos, faz-se necessária de forma a mitigar qualquer efeito adverso que ela possa vir ter sobre a produção em si, assim como sobre a decisão do consumidor no ato da compra de um determinado produto oriundo de proteína animal.

Quanto ao segundo, fica clara a necessidade de o Brasil adotar trâmites e processos mais ágeis quanto à sua estrutura regulatória no que tange à abertura e manutenção de novos mercados, à troca de informações em nível nacional, aos processos de solicitação de abertura de mercados, à velocidade de respostas rápidas a questionamentos internacionais com efeitos diretos sobre os fluxos comerciais agrícolas do país e até mesmo a uma melhor articulação quanto a ações que visem preservar a imagem do agronegócio brasileiro. Esses fatores, necessariamente, necessitam de aperfeiçoamento e coordenação institucional, tanto no nível privado quanto na esfera pública. Nesse sentido, estudos comparativos tendo em vista grandes países exportadores de proteína animal avícola e de outros produtos do agronegócio podem ser importantes para eventuais alterações procedimentais e estruturais na estrutura regulatória brasileira, com o intuito de permitir que o Brasil explore ao máximo sua vocação como um dos mais importantes produtores e exportadores mundiais de produtos agrícolas.

Finalmente, é possível afirmar, a partir do trabalho empreendido na presente tese de doutoramento, que, tanto o modelo teórico aqui aplicado quanto as contribuições dos dados empíricos e entrevistas estruturadas a partir das variáveis aqui propostas adicionaram valor ao status do debate atual quanto à inserção do Brasil em cadeias globais de valor agrícolas, ampliando assim as possibilidades futuras em diversas frentes de estudo, sejam teóricas (testes teóricos, lapidação e refinamento do modelo teórico-conceitual, entre outros), sejam empíricas (análise de outros setores, estudos comparativos com outros países produtores globais, entre outros). 


\title{
ANEXO I - Questionário aplicado aos especialistas para fins de subsídio técnico à presente pesquisa
}

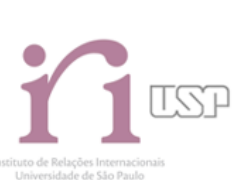 \\ Questionário para fins de subsídio técnico à pesquisa de doutorado "A inserção do Brasil na Cadeia Global de Valor \\ da Avicultura", realizada pelo discente José Luiz Pimenta Junior ( ${ }^{\circ}$ USP 6280619), sob a orientação do Prof. Dr. João \\ Candia Veiga.
}

\section{Perguntas:}

1) Em sua opinião, quais são os principais impulsionadores do setor de proteína animal avícola em nível global?

2) Como o Brasil está posicionado hoje na cadeia global de valor da avicultura?

- Global Player fornecedor de produtos in natura e/ou matéria-prima a ser processada em terceiros mercados?

- Global player fornecedor de produtos in natura e/ou matéria-prima a ser processada, mas com viés de adição de valor e futuro desenvolvimento de marca em terceiros mercados?

- Global player com foco em produtos de alto valor adicionado e marca premium?

3) Quais fatores fazem do Brasil hoje um Global Player no Setor?

- Fator Preço

- Qualidade do Produto

- Capacidade de atendimento em larga escala

- Desenvolvimento de parcerias e produtos junto a clientes globais

- Outros? Citar

4) O que pode impulsionar ainda mais o desempenho do Brasil?

- Fatores ligados ao ambiente interno (Logística, infraestrutura, energia, diminuição da burocracia, etc.).

- Fatores intrínsecos ao modelo de negócio (Sustentabilidade, mão de obra, sanidade, automação, bem estar animal, etc.).

- Fatores ligados ao ambiente externo (Acordos comerciais, promoção comercial, ampliação do conhecimento de atuais e/ou novos mercados, parcerias, etc.).

5) Quais países podem ser tão ou mais competitivos que o Brasil no futuro? Por quê?

6) Quais são os mercados que os exportadores brasileiros devem priorizar em termos de acesso nos próximos 10 anos? - (manutenção dos já existentes ou novos).

7) Quais tipos de upgradings, produtivos o Brasil deve buscar pra aumentar sua competitividade global no setor?

- Produto (Novos produtos, portfólio)

- Processo (Investimento em P\&D e inovação)

- Funcional (Aquisição de outras competências dentro da cadeia) 


\section{REFERÊNCIAS}

ABCS - ASSOCIAÇÃO BRASILEIRA DOS CRIADORES DE SUÍNOS; MAPA. MINISTÉRIO DA AGRICULTURA, PECUÁRIA E ABASTECIMENTO; EMBRAPA. Manual brasileiro de boas práticas agropecuárias na produção de suínos. Brasília, DF, 2011. Disponível em: http://www.majop.com.br/27012012124348manual_brasileiro.pdf. Acesso em: 02/01/2020.

ABEF - ASSOCIAÇÃO BRASILEIRA DOS PRODUTORES E EXPORTADORES DE FRANGOS. Relatório anual 2005. ABEF, 2005. Disponível em: Acesso em: 20/01/2020.

ABEF - ASSOCIAÇÃO BRASILEIRA DOS PRODUTORES E EXPORTADORES DE FRANGOS. Relatório anual 2006. ABEF, 2006. Disponível em: Acesso em 20/01/2020.

ABPA - ASSOCIAÇÃO BRASILEIRA DE PROTEINA ANIMAL. Protocolo de Bem-Estar Animal para Frangos de Corte. São Paulo, 2016. Disponível em: http://abpabr.com.br/storage/files/protocolo_de_bem-estar_para_frangos_de_corte_2016.pdf. Acesso em: 04/01/2020.

ABPA - ASSOCIAÇÃO BRASILEIRA DE PROTEINA ANIMAL. Relatório Anual 2019. Disponível em: http://abpa-br.org/. Acesso em: 12/01/2020.

AE - AGÊNCIA ESTADO. Frigorífico Marfrig compra ativos do OSI por US\$ 680 mi. 2008. Disponível em: https://economia.estadao.com.br/noticias/geral,frigorifico-marfrigcompra-ativos-do-osi-por-us-680-mi,194901 Acesso em: 21/01/2020.

ANVISA. AGÊNCIA NACIONAL DE VIGILÂNCIA SANITÁRIA. Limites máximos de resíduos de medicamentos veterinários em alimentos de origem animal. Brasília, 2018. Disponível em:

http://portal.anvisa.gov.br/documents/219201/219401/Med+Vet_Documento+base+discussa o+18.10/69d161b5-785c-4907-862c-2294b48a79c5. Acesso em: 06/01/2020.

AGROICONE; ABPA - ASSOCIAÇÃO BRASILEIRA DE PROTEINA ANIMAL. Estudo da Competitividade Internacional da Cadeia de Aves no Brasil. 2019. Disponível em: Acesso em: 20/01/2020

ARAÚJO, G.; BUENO, M.; BUENO, V.; SPROESSER, R.; SOUZA, I. Cadeia Produtiva da Avicultura de Corte: avaliação da apropriação de valor bruno nas transações econômicas dos agentes envolvidos. Revista Gestão \& Regionalidade, v. 24, n. 72, 2008. Disponível em: https://seer.uscs.edu.br/index.php/revista_gestao/article/view/95. Acesso em: 12/10/2019.

AURORA ALIMENTOS. Coopercentral Aurora Alimentos assume operação da Bondio Alimentos. 2012. Disponível em: https://www.auroraalimentos.com.br/comunicacao/noticia/209/coopercentral-auroraalimentos-assume-operacao-da-bondio-alimentos. Acesso em: 22/01/2020. 
AZEVEDO, G. S.; SOUZA, J. P. L. de; CARDOSO, J. A.; ARAÚJO, P. H. Haddad; NETA, E. R. dos S.; NOVAS, M. Pe. V. Produção de Aves em Sistema Orgânico. PUBVET Publicações em Medicina Veterinária e Zootecnia. Maringá, PR, Brasil. v. 10, n. 04, 2016. p. 271-355. Disponível em: http://www.pubvet.com.br/artigo/2641/produccedilatildeo-de-avesem-sistema-orgacircniconbsp. Acesso em: 04/01/2020.

BADIN, M. R. S. A regulação de "novos temas" em acordos preferenciais de comércio celebrados por União Europeia, Estados Unidos, China e Índia: pontos relevantes para o Brasil. IPEA, 2012. Disponível em:

http://www.ipea.gov.br/portal/index.php?option=com_content\&view=article\&id=16367. Acesso em: 10/04/2014.

BAGUL, K.; KOERTEN, J.; REES, T. Evolving trends in food and nutrition. Euromonitor International, 2018. Disponível em: https:/go.euromonitor.com/ANUGA19.html. Acesso em $15 / 01 / 2020$.

BAIR, J. Global Capitalism and Commodity Chains: Looking Back, Going

Forward. Competition \& Change, New York: Sage Publications, v. 9, n. 2, 2016. p. 153.

Disponível em: Acesso em: 12/06/2019.

BAIR, J. Global Commodity Chains: genealogy and review. In: BAIR, Jennifer (Ed.)

Frontiers of Coomodity Chain Research. Palo Alto: Stanford University Press. p. 1-34. 2009.

BALDWIN, R. Global supply chains: why they emerged, why they matter, and where they are going. CEPR Discussion Papers 9103, C.E.P.R. Discussion Papers. 2012. Disponível em: Acesso em: 12/06/2019.

BASSI, N.; SILVA, C.; SANTOYO, A. Inovação, pesquisa e desenvolvimento na agroindústria avícola brasileira. Estudos Sociedade e Agricultura, a. 21, vol. 2, p. 392-417. Disponível em: https://revistaesa.com/ojs/index.php/esa/article/view/374. Acesso em: $11 / 10 / 2019$.

BELLAVER, C.; COSTA, C. F.; FIGUEIREDO, E. A. P.; JAENISCH, F. R. F.; FAVERO, J. Á.; PALHARES, J. C. P.; FIORENTIM, L; BRUM, P. A. R; ABREU, P. G; AVILA, V. S. Boas práticas de produção de frango. Circular Técnica: Embrapa, vol. 38, 2003. Disponível em: http://www.cnpsa.embrapa.br/sgc/sgc_publicacoes/cit38.pdf. Acesso em: 21/10/2019.

BELLINI, S. Application of biosecurity in different production systems at individual, country and regional levels. OIE Regional Commission, 2018. Disponível em:

https://www.oie.int/fileadmin/Home/eng/Publications_\%26_Documentation/docs/pdf/TT/201 8_EUR1_Bellini_A.pdf. Acesso em: 20/12/2019.

BENNETT, D. Gestão de operações internacionais: conceitos fundamentais. In: FLEURY, A.; FLEURY, M. T. L. (Orgs.) Internacionalização e os países emergentes. São Paulo: Editora Atlas, 2007. 
BITTENCOURT, S. Sanidade animal \& qualidade de alimentos. Palestra proferida no âmbito do Programa de Acesso a Mercados do Agronegócio (PAM-AGRO) - Agência Brasileira de Promoção de Exportações e Investimentos - APEX, Brasil. São Paulo, 2017.

BOECKEL, T. V. Global trends in antimicrobial use in food animals. Apresentação. 2018. Disponível em: https://www.swissre.com/dam/jcr:b8c6410f-755b-4d13-836df611c3510a3d/amr_thomas_boeckel.pdf Acesso em 05/01/2020.

BOECKEL, T. V.; BOWER, C.; GILBERT, M.; GRENFELL, B. T.; LEVIN, S. A; ROBINSON, T. P.; AUDE, T.; LAXMINARAYAN, R. Global trends in antimicrobial use in food animals. Proceedings of the National Academy of Sciences of the United States of America. Research Article. Maio, 2015. Disponível em: https://www.pnas.org/content/112/18/5649. Acesso em: 08/01/2020.

BOECKEL, T. V.; GLENNON, E. E.; CHEN, D.; GILBERT, M.; ROBINSON, T. P.; GRENFELL, B. T; LEVIN, S. A.; BONHOEFFER, S.; LAXMINARAYAN, R. Reducing antimicrobial use in food animals. Science Magazine, v. 357, issue 6358, setembro, 2017. Disponível em: https://science.sciencemag.org/content/sci/357/6358/1350.full.pdf. Acesso em: 05/01/2020.

BUCKLEY, P. J. Is the international business research agenda running out steam? Journal of Internatinal Busines Studies, v. 33, n. 2, p. 365-373, 2002. Disponível em: Acesso em: 09/10/2014.

BUSSE, M. Competition Intensity, Potential Competition and Transaction Cost Economics. 2002.

CARNEIRO, F. Fragmentação internacional da produção e cadeias globais de valor. In: OLIVEIRA, I. T. M.; CARNEIRO, F. L.; FILHO, E. B. da S. (orgs.). Cadeias globais de valor, políticas públicas e desenvolvimento. Brasília: Ipea, 2017.

CARNEIRO, J.; DIB, L. A. Avaliação comparativa do escopo descritivo e explanatório dos principais modelos de internacionalização de empresas. INTERNEXT - Revista Eletrônica de Negócios Internacionais da ESPM, São Paulo, v. 2, n. 1, pp. 1-25, jan./jun, 2007. Disponível em: http://internext.espm.br/index.php/internext/article/view/16/15. Acesso em: 09/10/2014.

CARVALHO, C. C. Otimização dinâmica da indústria da logística de distribuição de produtos alimentícios refrigerados e congelados. Tese de doutorado. Pós-Graduação da Faculdade de Engenharia Civil, Arquitetura e Urbanismo. Universidade Estadual de Campinas. 2013. Disponível em:

http://repositorio.unicamp.br/jspui/bitstream/REPOSIP/257986/1/Carvalho_CarolinaCorreade _D.pdf. Acesso em: 10/01/2020.

CAVUSGIL, S. T.; KNIGHT, G.; RIESENBERGER, J. R. Negócios internacionais: estratégia, gestão e novas realidades. São Paulo: Pearson Prentice Hall, 2010.

CEBALLOS, M. \& SANT'ANNA, A. Evolução da ciência do bem-estar animal: Uma breve revisão sobre aspectos conceituais e metodológicos. Revista Acadêmica: Ciência Animal, v. 
16, p. 1-24, ago., 2018. Disponível em:

https://periodicos.pucpr.br/index.php/cienciaanimal/article/view/23740. Acesso em:

08/01/2020.

CHADADD, F. Economia e organização da agricultura brasileira. $1^{\mathrm{a}}$ ed. Rio de Janeiro: Elsevier, 2017.

CODEX ALIMENTARIUS. Limites máximos de resíduos. 2019. Disponível em: http://www.fao.org/fao-who-codexalimentarius/codex-texts/maximum-residue-limits/es/. Acesso em: 05/01/2020.

COELHO, D. B.; OLIVEIRA JUNIOR; M. M. Internacionalização de empresas na agenda governamental contemporânea de desenvolvimento: reflexões críticas e analíticas para os negócios internacionais. Cad. EBAPE.BR, v. 14, Edição Especial, Artigo 7, Rio de Janeiro, jul. 2016. Disponível em: Acesso em: 05/01/2020.

COELHO, D. Empresas e governo no contexto da economia global: o papel do governo brasileiro na internacionalização das empresas brasileiras de bens de capital mecânicos. Tese de doutorado. Universidade de São Paulo, 2016. Disponível em:

http://www.teses.usp.br/teses/disponiveis/12/12139/tde-03072014-174858/pt-br.php. Acesso em: 19/03/2019.

COSTA LEITE, P. R. de S. da; MENDES, F. R.; FERREIRA, L. L.; LACERDA, M. J. R.; ANDRADE, M. A. Utilização de Antimicrobianos na avicultura. Revista Eletrônica Nutritime, v. 10, n. 02, p. 2352 - 2389, mar./abr., 2013. Disponível em: https://www.nutritime.com.br/arquivos_internos/artigos/artigo_197.pdf. Acesso em: 08/01/2020.

COSTA, A.C. e GUERRA, C. REVISTA VEJA. CADE aprova fusão de Sadia e Perdigão, mas impõe restrições. 2011. Disponível em: https://veja.abril.com.br/economia/cade-aprovafusao-de-sadia-e-perdigao-mas-impoe-restricoes. Acesso em: 21/01/2020.

COSTA, L. S.; GARCIA, L. A. F.; BRENE, P. R. A. Panorama do setor de Frango de Corte no Brasil e a Participação da Industria Avícola Paranaense no Complexo dado seu Alto Grau de Competitividade. Anais do IV SINGEP, São Paulo-SP, Brasil, 2015. Disponível em: https://singep.org.br/4singep/resultado/209.pdf. Acesso em 13/10/2019.

COTTO, A. The consumer of tomorrow: what should we be aware of. Palestra proferida no âmbito do Programa de Acesso a Mercados do Agronegócio (PAM-AGRO). Agência Brasileira de Promoção de Exportações e Investimentos - APEX Brasil. São Paulo, 2017. Disponível em: http://www.mbtt.hu/content/download/7629/59935/file/Antonio_Coto.pdf Acesso em: 02/01/2020.

DA SILVA, M. V. Consumption. Poultry Development Review. Food and Agriculture Organisation of the United Nations (FAO). Rome, 2013. Disponível em: http://www.fao.org/3/i3531e/i3531e00.htm. Acesso em: 12/01/2020.

DICKEN, P. Mudança global: mapeando as novas fronteiras da economia mundial. Ed. Bookman. $5^{\mathrm{a} e d .}$ 
DUARTE, J. Entrevista em Profundidade. In: DUARTE J.; BARROS. Métodos e técnicas de pesquisa em comunicação. 2. ed. São Paulo: Atlas.

DUNNING, J. H. Toward an ecletic theory of international production: some empirical tests. Journal of International Business Studies, v. 11, n. 1, p. 9-31, 1980. Disponível em: Acesso em: 20/01/2020.

DUNNING, J. The ecletic paradigm of international production: a restatement and some possible extensions. Journal of international Business Studies, v. 19, p. 1-31, 1988.

ESPINDOLA, C. Trajetórias do progresso técnico na cadeia produtiva de carne de frango do Brasil. Geosul, Florianópolis, v. 27, n. 53, p. 89-113, jan./jun. 2012. Disponível em: https://periodicos.ufsc.br/index.php/geosul/article/download/21775230.2012v27n53p89/24472. Acesso em:12/10/2019.

ESTADÃO - O ESTADO DE S. PAULO. Exportação de milho é recorde. 2007. Disponível em: https://economia.estadao.com.br/noticias/geral,exportacao-de-milho-e-recorde, 26573. Acesso em: 20/01/2020.

FAO - FOOD AND AGRICULTURE ORGANIZATION OF THE UNITED NATIONS (FAO). Livestock Solutions for Climate Change. 2017. Disponível em: http://www.fao.org/3/a-i8098e.pdf. Acesso em 08/01/2020.

FARREL, D. The role of poultry in human nutrition. In: FAO. FOOD AND AGRICULTURE ORGANIZATION OF THE UNITED NATIONS. Poultry Development Review. 2013. Disponível em http://www.fao.org/3/i3531e/i3531e.pdf. Acesso em: 10/10/2019.

FAWC - FARM ANIMAL WELFARE COUNCIL. Farm animal welfare in Great Britain: past, present and future. Londres: Farm Animal Welfare Council, 2009. Disponível em: https://assets.publishing.service.gov.uk/government/uploads/system/uploads/attachment_data/ file/319292/Farm_Animal_Welfare_in_Great_Britain_-_Past_Present_and_Future.pdf Acesso em: 02/01/2020.

FGI - FUNG GLOBAL INSTITUTE; NTU. NANYANG TECHNOLOGICAL UNIVERSITY; WTO. WORLD TRADE ORGANIZATION. Global value chains in a changing world. World Trade Organization Publications, 2013. Disponível em: http://www.wto.org/english/res_e/booksp_e/aid4tradeglobalvalue13_e.pdf. Acesso em $12 / 12 / 2014$.

FIESP - FEDERAÇÃO DAS INDÚSTRIAS DO ESTADO DE SÃO PAULO. Análise quantitativa das negociações internacionais. São Paulo, 2012. Disponível em: http://www.fiesp.com.br/indices-pesquisas-e-publicacoes/analise-quantitativa-denegociacoes-internacionais. Acesso em 07/04/2018.

FIGUEIREDO, E.; SCHIMIDT, G.; AVILA; V.; JAENISCH, F.; PAIVA, D. Recomendações técnicas para a produção, abate, processamento e comercialização de frangos de corte coloniais. Embrapa Suínos e Aves. 2007. Disponível em:

http://www.cnpsa.embrapa.br/SP/frangos/preparo.htm Acesso em 03/01/2020. 
FLEURY, A; FLEURY, M.T. L. Multinacionais brasileiras: competências para internacionalização. São Paulo: FGV Editora, 2012.

FRIEDEN, J. A. Capitalismo global: história econômica e política do século XX. Rio de Janeiro: Editora Zahar, 2008.

GAZETA DO POVO. 2014. Disponível em:

https://www.gazetadopovo.com.br/economia/jbs-compra-a-paranaense-big-frango-por-r-430milhoes-eghtu769tmz666u5t2ksh0swe/ Acesso em: 22/01/2020.

GEREFFI, G. Global Production Systems and Third World Development. In: STALLINGS, B. (ed.). Global change, regional response: the new international context of development. New York: Cambridge; Melbourne: Cambridge University Press, p. 100-142, 1995. Disponível em: Acesso em: 11/10/2014.

GEREFFI, G; HUMPHREY, J.; KAPLINSKY, R.; STURGEON, T., Introduction: globalisation, value chain and development. In: GAREFFI, G.; KAPLINSKY, R. (eds.). Value of Value Chains. IDS Bulletin, v. 32, issue 3, jul. 2001. Disponível em: Acesso em: 15/07/2019.

GEREFFI, G. The organization of buyer-driven global commodity chains: how U. S. retailers shape overseas production networks. In: GEREFFI, G.; KORZENIEWICZ, M. (eds.). Commodity chains and global capitalism, London: Praeger, 1994.

GEREFFI, G. Global value chains, development and emerging economies. Inclusive and Sustainable Industrial Development Paper Series - WP 18. United Nations Industrial Development Organization, 2015. Disponível em: https://www.unido.org/api/opentext/documents/download/9924327/unido-file-9924327. Acesso em: 07/10/2016.

GEREFFI, G.; FERNANDEZ-STARK, K. Global value chain analysis: a primer. Center on Globalization, Governance \& Competitiveness (CGGC). Duke University. Durham, EUA, 2012. Disponível em: http://www.cggc.duke.edu/pdfs/2011-05-

31_GVC_analysis_a_primer.pdf. Acesso em: 11/10/2014.

GEREFFI, G.; FERNANDEZ-STARK, K. Global value chain analysis: a primer, $2^{\text {nd }}$ Edition. Center on Globalization, Governance \& Competitiveness (CGGC). Duke University. Durham, EUA, jul., 2016. Disponível em: https://dukespace.lib.duke.edu/dspace/handle/10161/12488. Acesso em: 07/01/2020.

GEREFFI, G.; HUMPHFREY, J.; STURGEON, T. The governance of global value chains. Review of International Political Economy, v. 12, n. 1, p. 78-104, 2005. Disponível em: http://www.rrojasdatabank.info/sturgeon2005.pdf. Acesso em: 11/10/2014.

GEREFFI, G.; KORZENIEWICZ, R.; KORZENIEWICZ, M. Introduction: global value chains. In: GEREFFI, G.; KORZENIEWICZ, M. (eds.). Commodity chains and global capitalism. London: Praeger, 1994. 
GILPIN, R. A economia política das relações internacionais. Trad. Sérgio Bath. Brasília: Universidade de Brasília, 2002.

GLOBO - G1. Fusão de Sadia e Perdigão é aprovada e cria gigante do setor de alimentos. Brasília, 2011. Disponível em: http://g1.globo.com/economia/noticia/2011/07/fusao-de-sadiae-perdigao-e-aprovada-e-cria-gigante-do-setor-de-alimentos.html. Acesso em: 07/12/2014.

GOY, L. REVISTA EXAME. CADE aprova arrendamento de ativos da Frangosul pelo JBS. 2012. Disponível em https://exame.abril.com.br/negocios/cade-aprova-arrendamento-deativos-da-frangosul-pelo-jbs-2/. Acesso em: 22/01/2020.

GROSSMAN, G.; ROSSI-HANSBERG, E. Trading tasks: a simple theory of offshoring. NBER Working Paper No. 12721, Cambridge, MA, USA, dez. 2006. JEL No. F11, F16 Disponível em: https://www.nber.org/papers/w12721. Acesso em: 22/01/2020.

GUEDES. A. L. Negócios Internacionais e gestão internacional: evolução do campo teórico. In: OLIVEIRA JUNIOR, M. M. (Org.). Multinacionais brasileiras: internacionalização, inovação e estratégia global. Porto Alegre, 2010.

GURGEL, A. et al. Análise quantitativa das negociações internacionais. São Paulo: Federação das Indústrias do Estado de São Paulo, 2012.

GURGEL, A.; NASSAR, A.; HARFUCH, L. ; PIMENTA JUNIOR, J. L. ; PELLIZZON, C. ; MEIRA, F. A.; SUZUKI, J. P.; GONZALEZ, M. M.; FREIRE, W. L. Análise quantitativa das negociações internacionais. São Paulo: Federação das Indústrias do Estado de São Paulo, 2012. Disponível em: https://www.fiesp.com.br/indices-pesquisas-e-

publicacoes/analise-quantitativa-de-negociacoes-internacionais/. Acesso em: 30/01/2020.

HARPER, J. Consumer attitudes to sustainable chicken, Apresentação realizada no Salão Internacional da Avicultura e Suinocultura. São Paulo, 2019.

HOPKINS, T. K.; WALLERSTEIN, I. Commodity Chains in the World-Economy Prior to 1800. Review (Fernand Braudel Center), v. 10, n. 1. Anniversary issue: the work of the Fernand Braudel Center (Summer, 1986), p. 157-170. Disponível em: Acesso em: 14/03/2019.

HUMPHREY, J; SCHMITZ, H. How does Insertion in global value chains affect upgrading upgrading in industrial clusters? Regional Studies. 36, p. 1017-1027, 2002. Disponível em: Acesso em: 14/03/2019.

ISAAC, F. L. SCOT CONSULTORIA. Marfrig compra DaGranja e Pena Branca e entra no mercado de aves. 10 mar. 2008. Disponível em:

https://www.scotconsultoria.com.br/noticias/todas-noticias/3282/marfrig-compra-dagranja-epena-branca-e-entra-no-mercado-de-aves.htm. Acesso em: 21/01/2020.

JANK, M.; ZERBINI, A.; CLEAVER, I. Competitividade internacional do agronegócio brasileiro. Visão Estratégica e Políticas Públicas. In: RODRIGUES, R. (org.). Agro é paz: análises e propostas para o Brasil alimentar o mundo. Piracicaba: ESALQ, 2018. 
JBS. Perfil Corporativo. 2019. Disponível em: https://ri.jbs.com.br/a-jbs/perfil-corporativo. Acesso em: 23/01/2020.

JESUS JUNIOR, C. de, et al. A cadeia da carne de frango: tensões, desafios e oportunidades. BNDES Setorial, n. 26, p. 191-232, set. 2007. Disponível em:

https://www.bndes.gov.br/SiteBNDES/bndes/bndes_pt/Galerias/Convivencia/Publicacoes/Co nsulta_Expressa/Setor/Agroindustria/200709_9.html. Acesso em: 13/10/2019.

JOHANSON, J.; VAHLNE, J-E. The Uppsala internationalization process model revisited: from liability of foreigness to liability of outsidership. Journal of International Business Studies, 40(9) p. 1411-1431, 2009. Disponível em: Acesso em: 10/12/2018.

JULIBONI, M. REVISTA EXAME. As principais aquisições da JBS nos últimos anos. 2013. Disponível em: https://exame.abril.com.br/negocios/as-principais-aquisicoes-do-jbsnos-ultimos-anos/. Acesso em: 22/02/2020.

KEOHANE, R. O. After hegemony: cooperation and discord in the world political economy. Princeton: Princeton University Press, 1984.

KHATOUNIAN, C. A. A reconstrução ecológica da agricultura. Botucatu: Livraria e Editora Agroecológica, 2001. Disponível em:

http://www.reformaagrariaemdados.org.br/sites/default/files/A\%20reconstru\%C3\%A7\%C3\% A3o\%20ecol\%C3\%B3gica\%20da\%20agricultura.pdf. Acesso em: 05/01/2020.

KORZENIEWICZ, R.; MARTIN, W. The global distribution of commodity chains. In: GEREFFI, G.; KORZENIEWICZ, M. (eds.). Commodity chains and global capitalism. London: Praeger, 1994.

LANZ, R.; MIROUDOT, S.; NORDAS, H. K. Trade in tasks. OECD Trade Policy Working Papers, No. 117, OECD Publishing. Disponível em: http://dx.doi.org/10.1787/5kg6v2hkvmmw-en. Acesso em: 27/12/2016.

LAZZARI, R. M. Avicultura de corte no Brasil: uma comparação entre as regiões sul e centro-oeste. Índic. Econ. FEE, v. 31, n. 4, p. 259-290, fev. 2004. Disponível em: https://revistas.fee.tche.br/index.php/indicadores/article/view/234. Acesso em 10/10/2019.

LEDUR, M.; PEIXOTO, J. Árvore do conhecimento frango de corte: material genético. Agência Embrapa de Informação Tecnológica. 2019. Disponível em: https://www.agencia.cnptia.embrapa.br/gestor/frango_de_corte/arvore/CONT000fc66uyih02 wx5eo0a2ndxyampko73.html. Acesso em: 15/01/2020.

LIMA, R. The role of international trade in promoting sustainable development. Agroicone IPC Second Semester Conference, 2019. São Paulo, Brasil.

LUSK, J. L. Consumer beliefs, knowledge, and willingness-to-pay for sustainabilityrelated poultry production practices broiler survey report. 2018. Disponível em: https://www.nationalchickencouncil.org/wpcontent/uploads/2018/04/Report_broiler_Final.pdf. Acesso em 05/01/2020. 
MAPA - MINISTÉRIO DA AGRICULTURA, PECUÁRIA E ABASTECIMENTO.

Interesses e desafios na OMC. Apresentação, 2017.

MAPA - MINISTÉRIO DA AGRICULTURA, PECUÁRIA E ABASTECIMENTO. Valor bruto da produção agropecuária (VBP). Disponível em:

http://www.agricultura.gov.br/assuntos/politica-agricola/valor-bruto-da-producao-

agropecuaria-vbp. Acesso em: 20/01/2020.

MAPA - MINISTÉRIO DA AGRICULTURA, PECUÁRIA E ABASTECIMENTO.

Relatório de abates por ano e UF. Quantidade de Abate Estadual por Ano/Espécie.

Disponível em:

http://sigsif.agricultura.gov.br/sigsif_cons/\%21ap_abate_estaduais_cons?p_select=SIM.

Acesso em: 29/03/2018.

MARCONI, M.; LAKATOS, E. Fundamentos da metodologia científica. $7^{\text {a }}$. ed. São Paulo: Atlas, 2010.

MARFRIG GROUP. Relatório Anual 2009. MARFRIG, 2009. Disponível em: http://ri.marfrig.com.br/rao/2009/port/index.htm. Acesso em: 20/01/2020.

MARTINELLI, O.; ROHENKOHL, J.; MURAKAMI, T. Technology and innovation on input sectors of brazilian meat production. Journal of Economics and Development

Studies, v. 2, n. 4, 2014. Disponível em:

https://www.researchgate.net/publication/276373305_Technology_and_Innovation_on_Input _Sectors_of_Brazilian_Meat_Production. Acesso em: 20/10/2019.

MELLOR, D. Comprehensive assessment of harms caused by experimental, teaching and testing procedures on live animals. Alternatives to laboratory animals, 2004. ATLA. 32 Suppl. 1B. 453-7. Disponível em

MELLOR, D. Animal emotions, behaviour and the promotion of positive welfare states. Massey University, Nova Zelândia, 2012. Apresentação disponível em: https://www.ed.ac.uk/files/imports/fileManager/MellorDJM\%20\%2Bve\%20AW\%20States.pdf. Acesso em: 07/01/2020.

MENDES, L. H. Disputa acirrada entre Aviagen e Cobb. Valor Econômico. São Paulo, 12 jul. 2018. Disponível em: https://valor.globo.com/agronegocios/noticia/2018/07/12/disputaacirrada-entre-aviagen-e-cobb.ghtml. Acesso em 20/01/2020.

MORAES, M., GURGEL, A., PALTSEV, S. Is the Brazilian pre-salt oil competitive? Economic and environmental long run impacts from the incentives to the pre-salt. 18th Annual Conference on Global Economic Analysis, Melbourne, Australia. Purdue University, West Lafayette, In: Global Trade Analysis Project (GTAP). 2015.

https://www.gtap.agecon.purdue.edu/resources/res_display.asp?RecordID=4623. Acesso em: $10 / 03 / 2018$

MOREIRA, C. O GLOBO. Tyson usará Brasil para ter acesso ao mercado europeu em aves. 2008. Disponível em: https://oglobo.globo.com/economia/tyson-usara-brasil-para-ter-acessoao-mercado-europeu-em-aves-3830895. Acesso em 20/01/2020. 
MOTTA VEIGA, P.; RIOS, S. Cadeias de valor baseadas em recursos naturais: o caso do Brasil. Texto para Discussão No. 2173, Instituto de Pesquisa Econômica Aplicada (IPEA), Brasília, 2016. Disponível em:

http://repositorio.ipea.gov.br/bitstream/11058/8767/1/Cadeias\%20de\%20valor\%20baseadas.p df. Acesso em: 15/10/2019.

MOTTA VEIGA, P.; RIOS, S. Cadeias globais de valor e implicações para a formulação de políticas. In: OLIVEIRA, I.; CARNEIRO, F.; FILHO, E. (Orgs.). Cadeias globais de valor, políticas públicas e desenvolvimento. Brasília: Ipea, 2017.

NÄÄS, I. de A. Princípios de bem-estar animal e sua aplicação na cadeia avícola. Revista $\mathbf{O}$ Biológico, São Paulo, v. 70, n. 2, p. 105-106, jul./dez., 2008. Disponível em: https://www.researchgate.net/publication/312167929_PALESTRA_PRINCIPIOS_DE_BEMESTAR_ANIMAL_E_SUA_APLICACAO_NA_CADEIA_AVICOLA. Acesso em: 02/01/2020.

NONNENBERG, M. J. B. Participação em cadeias globais de valor e desenvolvimento econômico. Boletim de Economia e Política Internacional - BEPI, n. 17, mai./ago, 2014. Disponível em:

http://repositorio.ipea.gov.br/bitstream/11058/3449/1/BEPI_n17_Participa\%C3\%A7\%C3\%A 3o.pdf. Acesso em: 01/11/2017.

NUNES, F. Frigoríficos entram em ciclo irreversível de automação. Revista do Avisite, $n$. 96, set. 2015. Disponível em: http://www.run-time.com.br/noticia/frigorificos-entram-emciclo-irreversivel-de-automacao.html. Acesso em: 15/01/2020.

NYE, J.; KEOHANE, R. O. Power and interdependence in the information age. Foreign Affairs, set./out. 1998; 77, 5. Disponível em: Acesso em: 15/04/2020.

OECD - ORGANISATION FOR ECONOMIC CO-OPERATION AND DEVELOPMENT; WTO - WORLD TRADE ORGANIZATION; UNCTAD - UNITED NATIONS CONFERENCE ON TRADE AND DEVELOPMENT. Implications of global value chains for trade, investment, development and jobs. Prepared for the G-20 Leaders Summit Saint Petersburg (Russian Federation), set. 2013. Disponível em: http://www.oecd.org/sti/ind/G20Global-Value-Chains-2013.pdf. Acesso em: 12/10/2014.

OECD - ORGANISATION FOR ECONOMIC CO-OPERATION AND DEVELOPMENT. Interconnected economies: benefiting from global value chains. OECD Publishing, 2013. Disponível em: http://www.keepeek.com/Digital-Asset-Management/oecd/science-andtechnology/interconnected-economies_9789264189560-en\#page1. Acesso em 10/10/2014.

OECD - ORGANISATION FOR ECONOMIC CO-OPERATION AND DEVELOPMENT. Enhancing the role of SMEs in global value chains. OECD Publishing, Paris, 2008. Disponível em: https://www.oecd-ilibrary.org/industry-and-services/enhancing-the-role-ofsmes-in-global-value-chains_9789264051034-en. Acesso em: 20/01/2020.

OECD - ORGANISATION FOR ECONOMIC CO-OPERATION AND DEVELOPMENT. Innovation in Southeast Asia. OECD Reviews of Innovation Policy, OECD Publishing, 
Paris, 2013. Disponível em: https://www.oecd-ilibrary.org/science-andtechnology/innovation-in-southeast-asia-2012_9789264128712-en Acesso em: 20/01/2020.

OECD - ORGANISATION FOR ECONOMIC CO-OPERATION AND DEVELOPMENT; FAO - FOOD AND AGRICULTURE ORGANIZATION OF THE UNITED NATIONS; OECD-FAO agricultural outlook 2019-2028. Roma, 2019. Disponível em: https://www.oecd-ilibrary.org/agriculture-and-food/oecd-fao-agricultural-outlook-20192028_agr_outlook-2019-en. Acesso em 03/01/2020.

OIE - WORLD ORGANIZATION FOR ANIMAL HEALTH. OIE situation report for highly pathogenic avian influenza. 2018b. Disponível em https://www.oie.int/fileadmin/Home/eng/Animal_Health_in_the_World/docs/pdf/OIE_AI_sit uation_report/OIE_SituationReport_AI_August2018.pdf. Acesso em 24/12/2019.

OIE - WORLD ORGANIZATION FOR ANIMAL HEALTH. PVS evaluation follow-up report. Brasil, 2017. Disponível em:

https://www.oie.int/fileadmin/Home/eng/Support_to_OIE_Members/pdf/PVS_FU_Report_Br asil_Eng.pdf. Acesso em: 20/12/2019.

OIE - WORLD ORGANIZATION FOR ANIMAL HEALTH. Terrestrial animal health code. 2018a. Disponível em:

https://www.oie.int/fileadmin/Home/eng/Health_standards/tahc/2018/en_glossaire.htm. Acesso em: 20/12/2019.

OLIVEIRA, D. R. M. dos S.; NÄSS, I. de A.; MOLLO NETO, M.; CANUTO, S. A.; WALKER, R.; VENDRAMETTO, O. Issues of sustainability on the Brazilian broiler meat production chain. In: International Conference Advances In Production Management Systems, Rhodes, 2012. Competitive Manufacturing for Innovative Products and Services: proceedings... Greece: International Federation for Information Processing, 2012.

ONDEI, V. DINHEIRO RURAL. A JBS começa a colher os frutos. 11 dez. 2014. Disponível em: https://www.dinheirorural.com.br/secao/melhores-da-dinheiro-rural/jbscomeca-colher-os-frutos Acesso em: 21/01/2020.

PEREIRA, D. M.; LINZMEIER, L. G.; BAZAN, C. T.; ENDO, R. M.; LINO, R. S.; MENINO, B. B.; PUGLIESE, P.; SHAFRANSKI, E.; SILVA, L. C. Uso de Antibióticos em Aves de Produção. Revista Científica Eletrônica De Medicina Veterinária, a.7, n. 12, jan. 2009. Periódico Semestral. Disponível em: http://faef.revista.inf.br/imagens_arquivos/arquivos_destaque/976s3vLOvIY3TKW_2013-624-16-28-21.pdf. Acesso em: 08/01/2020.

PIMENTA JUNIOR, J. L. O Brasil e o regime internacional de investimentos. In: AMARAL JUNIOR, A. do; CELLI JUNIOR, U. (Org.). A OMC: desafios e perspectivas. $1^{\text {a }}$ ed. São Paulo: Aduaneiras, 2014. 
PINHEIRO, J. G. Biosseguridade. Working Paper. Ribeirão Preto, 2014. Disponível em: https://www.ourofinosaudeanimal.com/ourofinoemcampo/categoria/artigos/biosseguridade/. Acesso em: 20/12/2019.

PINTO, E.; FIANI, R.; CORRÊA, L. Dimensões da abordagem da cadeia global de valor: upgrading upgrading, governança, políticas governamentais e propriedade intelectual. In: OLIVEIRA, I.; CARNEIRO, F.; FILHO, E. (Orgs.). Cadeias globais de valor, políticas públicas e desenvolvimento. Brasília: Ipea, 2017.

PORTER, M. E. The competitive advantage of nations. Harvard Business Review, 68, n. 2, mar./abr., 1990. p. 73-93. Disponível em: Acesso em: 10/12/2019.

PORTER, M.E. Competitive advantage: creating and sustaining superior performance. New York: Free Press, 1985.

REVISTA DO AVISITE - Perspectivas para 2010. Mundo Agro Editora, n. 32, dez., 2009. Disponível em: https://www.avisite.com.br/revista/pdfs/revista_edicao32.pdf. Acesso em: 12/01/2020.

ROCHA, A; ALMEIDA. Estratégias de entrada e de operações em mercados internacionais. In: TANURE, B; DUARTE, R.G. (Orgs.). Gestão internacional. São Paulo: Editora Saraiva, 2006.

SANTINI, G. A. Dinâmica tecnológica da cadeia e frango de corte no Brasil: análise dos segmentos de insumo e processamento. 2006, 235f. Tese (Doutorado em Eng. Produção). Universidade Federal de São Carlos (USFCAR), São Carlos, 2006. Disponível em: https://repositorio.ufscar.br/handle/ufscar/3474?show=full. Acesso em: 10/01/2020.

SANTOS FILHO, J. I. dos; MIELE, M.; MARTINS, F. M.; TALAMINI, D. J. D. Os 35 anos que mudaram a avicultura brasileira. In: SOUZA, J. C. P. V. B.; TALAMINI, D. J. D.; SCHEUERMANN, G. N.; SCHMIDT, G. S. (Eds.). Sonho, desafio e tecnologia: 35 anos de contribuições da Embrapa Suínos e Aves. Concórdia: Embrapa Suínos e Aves, 2011. p. 59-87.

SCHMIDT, N. S.; SILVA, C. L. da. Pesquisa e desenvolvimento na cadeia produtiva de frangos de corte no Brasil. Rev. Econ. Sociol. Rural, Brasília, v. 56, n. 3, p. 467482, set. 2018 . Disponível em:

http://www.scielo.br/scielo.php?script=sci_arttext\&pid=S010320032018000300467\&lng=pt\&nrm=iso. Acessos em: 20/01/2020.

SCHOENBERGER, E. Competition, time, and space in industrial change. In: GEREFFI, G.; M. (eds.). Commodity chains and global capitalism. London: Praeger, 1994.

SCRIVANO, R. O GLOBO. JBS compra negócio de aves da americana Tyson Foods por 575 milhões. 2014. Disponível em: https://oglobo.globo.com/economia/negocios/jbs-compranegocio-de-aves-da-americana-tyson-foods-por-us-575-milhoes-13403504. Acesso em: 20/01/2020. 
SEBRAE - SERVIÇO DE APOIO ÀS MICRO E PEQUENAS EMPRESAS. Cadeia produtiva da avicultura: cenários econômicos e estudos setoriais. Recife, 2008. Disponível em: http://189.39.124.147:8030/downloads/avicultura.pdf. Acesso em: 09/10/2019.

SHERRARD, J. Global Poultry Outlook. Sustainability, now an important driver of change. Rabobank. Apresentação realizada no Salão Internacional da Avicultura e Suinocultura. São Paulo, 2019a.

SHERRARD, J. Global outlook for poultry and meat markets: focusing on chicken marketing. Rabobank, 2019. Apresentação disponível em: https://www.wattglobalmedia.com/wp-content/uploads/2019/07/190712-

ChickenMarketingSummit-Poultry-market-outlook-Sherrard-v3.pdf. Acesso em: 02/01/2020.

SILVA; M. V. da. Comsumption. In: FAO - FOOD AND AGRICULTURE ORGANIZATION OF THE UNITED NATIONS. Poultry Development Review. 2013. Disponível em http://www.fao.org/3/i3531e/i3531e.pdf. Acesso em 10/10/2019.

SINDAN - SINDICATO NACIONAL DA INDÚSTRIA DE PRODUTOS PARA SAÚDE ANIMAL. Anuário da Indústria de Produtos para Saúde Animal. SINDAN, 2018. Disponível em: Acesso em: 13/01/2020

SOUZA, A. P. de O. Atualizações em bem-estar na avicultura: problemas e soluções. Universidade Federal do Paraná. LABEA - Laboratório de Bem-Estar Animal, 2017. Apresentação disponível em: http://www.agricultura.gov.br/assuntos/sustentabilidade/bemestar-animal/eventos/arquivos/AnaPaulaSouza12.07.pdf. Acesso em: 04/01/2020.

STEPHENSON, S. Global value chains: the new reality of international trade. E15 Initiative. Geneva: International Centre for Trade and Sustainable Development (ICTSD) and World Economic Forum, 2013. Disponível em: www.e15initiative.org/. Acesso em: 15/01/2020.

STEVADEORDAL, A.; BLYDE, J.; SUOMINEM, K. As cadeias globais de valor são realmente globais? Políticas para acelerar o acesso dos países às redes de produção internacionais. Revista Brasileira de Comércio Exterior, Fundação Centro de Estudos do Comércio Exterior, Rio de Janeiro, ano 27, n. 115, abr./jun., 2013.

STURGEON, T. J. How do we define value chains and production networks? In: GAREFFI, G.; KAPLINSKY, R. (eds.). IDS Bulletin, v. 32, issue 3, jul., 2001. Disponível em: Acesso em: 02/02/2020.

STURGEON, T.; GEREFFI, G.; GUINN, A.; ZYLBERBERG, E.. O Brasil nas cadeias globais de valor: implicações para a política industrial e de comércio. Revista Brasileira de Comércio Exterior, 115, 2003, p. 26-41. Disponível em: Acesso em: 04/09/2015.

STURGEON, T.; GEREFFI, G.; GUINN, A.; ZYLBERBERG, E. A indústria brasileira e as cadeias globais de valor: uma análise com base nas indústrias aeronáutica, de eletrônicos e de dispositivos médicos. Confederação Nacional da Indústria. Tradução Luiz Marcos Bianchi de Vasconcelos. Rio de Janeiro: Elsevier; Brasília: CNI, 2014. 
TAKAGI, M. et al. Reestruturação da indústria de carnes avícola e suinícola e impactos regionais. O caso da Perdigão em Rio Verde - Goiás. Congresso Brasileiro de Economia e Sociologia Rural, 40. 2002. Passo Fundo. Anais. Brasília, SOBER, 2002.

TEIXEIRA, S. Frangos convencional, capira, caipira-orgânico e caipira biodinâmico: diferenças na criação. Working Paper, 2019. Disponível em: https://www.cpt.com.br/cursosavicultura/artigos/frango-convencional-caipira-caipira-organico-e-caipira-biodinamicodiferencas-de-criacao Acesso em: 02/01/2020.

THORSTENSEN, V.; JANK, M. S. O Brasil e os grandes temas do comércio internacional. São Paulo: Lex Editora, Aduaneiras, 2005.

THORSTENSEN, V. O multissistema da regulação do comércio global: proposta de novo referencial teórico e nova metodologia de análise. Revista Tempo do Mundo, IPEA, 2011. Disponível em: http://www.controversia.com.br/uploaded/pdf/12964_120404-rtmv3portugues01.pdf. Acesso em 10/04/2014.

UBA - UNIÃO BRASILEIRA DE AVICULTURA. Relatório Anual 2006. UBA, 2006. Disponível em: Acesso em: 12/04/2014.

UNCTAD - UNITED NATIONS CONFERENCE ON TRADE AND DEVELOPMENT. Bilateral Investment Treaties 1959-1999. United Nations, New York and Geneva, 2000. Disponível em: Acesso em: 02/09/2014.

UNCTAD - UNITED NATIONS CONFERENCE ON TRADE AND DEVELOPMENT. Global value chains and development: investment and value added trade in the global economy: a preliminary analysis. Geneva, United Nations, United Nations Publication, 2013a. Disponível em: Acesso em: 02/09/2014.

UNCTAD - UNITED NATIONS CONFERENCE ON TRADE AND DEVELOPMENT. World Investment Report 2013. Global value chains: investment and trade for development. United Nations Publication, 2013. Disponível em: http://unctad.org/en/publicationslibrary/wir2013_en.pdf. Acesso em: 02/09/2014.

UNIDO - UNITED NATIONS INDUSTRIAL DEVELOPMENT ORGANIZATION. Mapping global value chains: intermediate goods trade and structural change in the world economy. 2011. Disponível em: http://www.unido.org//fileadmin/user_media/Publications/Research_and_statistics/Branch_pu blications/Research_and_Policy/Files/Working_Papers/2010/WP\%2005\%20Mapping\%20Glo cal\%20Value\%20Chains.pdf. Acesso em: 15/12/2014.

UNITED NATIONS: World population prospects 2019. United Nations Department of Economic and Social Affairs. 2019. Disponível em: https://population.un.org/wpp/Publications/Files/WPP2019_DataBooklet.pdf. Acesso em: 05/01/2020.

VALDES, C., HALLAHAN, C.; HARVEY, D. Brazil's broiler industry: increasing efficiency and trade. International Food and Agribusiness Management Review, v. 18, p. 263- 275, 
2015. Disponível em: https://www.ifama.org/resources/Documents/v18ia/Valdes-HallahanHarvey.pdf. Acesso em: 20/10/2019.

VAN DEN BOSSCHE, P.; ZDOUC, W. The law and policy of the world trade organization: text, cases and materials. Cambridge: Cambridge University Press, 2013.

VERISSIMO, A. Sanidade animal e qualidade nos alimentos. Palestra proferida no âmbito do Programa de Acesso a Mercados do Agronegócio (PAM-AGRO) - Agência Brasileira de Promoção de Exportações e Investimentos - APEX, São Paulo, Brasil, 2017. Disponível em: http://www.mbtt.hu/content/download/7629/59935/file/Antonio_Coto.pdf. Acesso em: 02/01/2020.

VOILÀ, M.; TRICHES, D. A cadeia de carne de frango: uma análise dos mercados brasileiro e mundial de 2002 a 2010. Teoria e Evidência Econômica, ano 21, v. 44, 2015, p. 126-148. Disponível em: http://seer.upf.br/index.php/rtee/article/download/5357/3477. Acesso em: 09/10/2019.

WAHIS - WORLD ANIMAL HEALTH INFORMATION DATABASE (WAHIS Interface); OIE - World Organisation for Animal Health, 2019. Disponível em:

https://www.oie.int/wahis_2/public/wahid.php/Countryinformation/Diseasetimeseries. Acesso em: $20 / 01 / 2020$.

WAKER, R; NÄÄS, I. Structural Attributes Dynamics of the Brazilian Broiler Production Chain. Braz. J. Poult. Sci., Campinas, v. 20, n. 3, p. 517-526, set., 2018. Disponível em: http://www.scielo.br/scielo.php?script=sci_arttext\&pid=S1516-

635X2018000300517\&lng=pt\&nrm=iso. Acesso em: 09/10/2019.

WALLERSTEIN, I.; HOPKINS, T. K. Commodity chains in the capitalist world-economy prior to 1800. In: GEREFFI, G.; KORZENIEWICZ, M. (eds.). Commodity chains and global capitalism. London: Praeger, 1994.

WOOD, A. Value chains: an economist's perspective. In: GAREFFI, G.; KAPLINSKY, R. (eds.). Value of value chains. IDS Bulletin, v. 32, issue 3, jul., 2001. Disponível em: Acesso em: 15/04/2019.

WEF - WORLD ECONOMIC FORUM. The shifting geography of global value chains: implications for developing countries and trade policy. World Economic Forum, 2012. Disponível em:

http://www3.weforum.org/docs/WEF_GAC_GlobalTradeSystem_Report_2012.pdf. Acesso em $12 / 10 / 2014$

WHO - WORLD HEALTH ORGANIZATION. WHO guidelines on use of medically important antimicrobials in food-producing animals. Genebra, Suiça: World Health Organization, 2017. Licence: CC BY-NC-SA 3.0 IGO. Disponível em: https://apps.who.int/iris/bitstream/handle/10665/258970/9789241550130eng.pdf;jsessionid=D23F8CDDE2C3E75444F836DD9E11116A?sequence=1. Acesso em: 05/01/2020. 
WTO - WORLD TRADE ORGANIZATION. World Trade Statistical Review 2018. WTO, 2018. Disponível em:

https://www.wto.org/english/res_e/statis_e/wts2018_e/wts18_toc_e.htm. Acesso em: 18/10/2014.

WTO - WORLD TRADE ORGANIZATION. World trade report 2011: the WTO and preferential trade agreements from co-existence to coherence. Disponível em:

http://www.wto.org/english/res_e/booksp_e/anrep_e/world_trade_report11_e.pdf. Acesso em: $18 / 10 / 2014$.

WTO - WORLD TRADE ORGANIZATION. World trade report 2013: factors shaping the future of world trade. WTO, 2013. Disponível em:

http://www.wto.org/english/res_e/booksp_e/world_trade_report13_e.pdf. Acesso em: $18 / 10 / 2014$.

WTO - WORLD TRADE ORGANIZATION. World trade profiles 2017. WTO, 2017.

Disponível em: https://www.wto.org/english/res_e/booksp_e/trade_profiles17_e.pdf. Acesso em: 01/04/2018.

WTO - WORLD TRADE ORGANIZATION. WTO highlights: trade in global value chains statistics 2013. Disponível em:

http://www.wto.org/english/res_e/statis_e/its2013_e/its13_highlights4_e.pdf. Acesso em $12 / 10 / 2017$.

\section{<Sítios da Web consultados>}

International Centre for Trade and Sustainable Development: http://www.ictsd.org/ WTO:

http//www.wto.org

UNCTAD: http://unctad.org/en/Pages/Home.aspx

OECD: http://www.oecd.org/

Ministério do Desenvolvimento Indústria e Comércio Exterior (MDIC):

http://www.mdic.gov.br/sitio/

MAPA: Ministério da Agricultura, Pecuária e Abastecimento -http://www.agricultura.gov.br/

ABPA: Associação Brasileira de Proteína Animal - http://abpa-br.com.br/

USDA: US Department of Agriculture - https://www.usda.gov/

GTAP: Global Trade Analysis Project - https://www.gtap.agecon.purdue.edu/

FAO: Food and Agriculture Organization of the United Nations (FAO) -

http://www.fao.org/home/en/

CEPEA-USP: Centro de Estudos Avançados em Economia Aplicada - Universidade de São

Paulo - https://www.cepea.esalq.usp.br/br/consultas-ao-banco-de-dados-do-site.aspx

WHO: World Health Organization - https://www.who.int/

AVIAGEN: http://pt.aviagen.com/

COBB VANTRESS: https://www.cobb-vantress.com/

BRF: https://www.brf-global.com/

SEARA: https://www.seara.com.br/

HEALTH FOR ANIMALS: https://healthforanimals.org/general/one-health.html

SINDAN: Sindicato Nacional das Indústrias de Produtos para Saúde Animal:

http://www.sindan.org.br/

TYSON FOODS: https://www.tysonfoods.com/

TERRENA: https://www.terrena.fr/en/ 